\begin{tabular}{|c|c|c|}
\hline $\begin{array}{c}\text { UnB } \\
\text { Universidade de Brasilia }\end{array}$ & $\begin{array}{c}\text { UFPB } \\
\text { Universidade Federal da Paraiba }\end{array}$ & $\begin{array}{c}\text { Universidade Federal do Rio Grande do } \\
\text { Norte }\end{array}$ \\
\hline \multicolumn{2}{|c|}{ Programa Multiinstitucional e Inter-Regional de Pós-graduação em Ciências Contábeis } \\
\hline
\end{tabular}

JOSÉ LÚCIO TOZETTI FERNANDES

MALDIÇÃO DOS RECURSOS NATURAIS E PRODUTIVIDADE DO GASTO PÚBLICO NOS MUNICÍPIOS BRASILEIROS

BRASÍLIA/DF 
Professor Doutor Ivan Marques de Toledo Camargo

Reitor da Universidade de Brasília

Professora Doutora Sônia Nair Báo

Vice-Reitora da Universidade de Brasília

Professor Doutor Jaime Martins de Santana

Decano de Pesquisa e Pós-graduação

Professor Doutor Roberto de Goes Ellery Júnior

Diretor da Faculdade de Economia, Administração e Contabilidade

Professor Doutor José Antônio de França

Chefe do Departamento de Ciências Contábeis e Atuariais

Professor Doutor Rodrigo de Souza Gonçalves

Coordenador-geral do Programa Multi-institucional e Inter-regional de Pós Graduação em Ciências Contábeis da UnB, UFPB e UFRN 
JOSÉ LÚCIO TOZETTI FERNANDES

MALDIÇÃO DOS RECURSOS NATURAIS E PRODUTIVIDADE DO GASTO PÚBLICO NOS MUNICÍPIOS BRASILEIROS

Tese apresentada ao Programa Multiinstitucional e Inter-regional de PósGraduação em Ciências Contábeis da UnB, UFPB e UFRN como requisito à obtenção do título de Doutor em Ciências Contábeis.

Orientador: Professor Doutor César Augusto Tibúrcio Silva.

BRASÍLIA/DF 
Fernandes, José Lúcio Tozetti.

Maldição dos recursos naturais e produtividade do gasto público nos municípios brasileiros/ José Lúcio Tozetti Fernandes; orientador Dr. César Augusto Tibúrcio Silva. -- Brasília, 2016.

$140 \mathrm{p}$.

Tese (Doutorado em Ciências Contábeis) - Universidade de Brasília. Programa Multi-institucional e Inter-Regional de PósGraduação em Ciências Contábeis UnB/UFPB/UFRN, 2016.

1. Maldição dos recursos naturais. 2. Gasto público. 3. Municípios. I. Silva, César Augusto Tibúrcio. II. Título. 


\title{
MALDIÇÃO DOS RECURSOS NATURAIS E PRODUTIVIDADE DO GASTO PÚBLICO NOS MUNICÍPIOS BRASILEIROS
}

\author{
Tese apresentada ao Programa Multi- \\ institucional e Inter-regional de Pós- \\ Graduação em Ciências Contábeis da \\ UnB/UFPB/UFRN como requisito à obtenção \\ do título de Doutor em Ciências Contábeis.
}

\section{Prof. Dr. César Augusto Tibúrcio Silva \\ Universidade de Brasília \\ Orientador}

Prof. Dr. Luís Eduardo Afonso

Universidade de São Paulo

Membro Externo

Prof. Dr. Fernando Antonio Slaibe Postali

Universidade São Paulo

Membro Externo

Profa. Dra. Diana Vaz de Lima

Universidade de Brasília

Membro Interno

Profa. Dra. Andréa de Oliveira Gonçalves

Universidade de Brasília

Membro Interno

Brasília-DF, 22 de março de 2016 
À minha esposa, Andressa, e aos meus pais, Elizabeth e Waldir 


\section{AGRADECIMENTOS}

Agradeço, inicialmente, a Deus, por atender às minhas orações e estar sempre ao meu lado, pelas bênçãos e pela oportunidade de realizar mais este projeto em minha vida.

À minha esposa, Andressa, por fazer parte de mais uma conquista comigo, pela compreensão, carinho e apoio oferecidos durante todo o processo de elaboração deste trabalho, sempre me incentivando a seguir em frente.

Aos meus pais, Elizabeth e Waldir, pelo exemplo de vida, pela torcida, pelas orações, pelo amor sempre demonstrado e por acreditarem em mim.

Ao meu irmão e companheiro Diogo e sua linda família, à minha cunhada Patrícia e ao meu afilhado Eduardo, por estarem sempre presentes e torcendo por mim.

Ao professor Doutor César Augusto Tibúrcio Silva, grande mestre que sempre me orientou e incentivou, em toda a minha vida acadêmica: graduação, iniciação científica, mestrado e doutorado. Em cada uma dessas etapas, o senhor sempre se mostrou especialmente confiante, paciente, disposto a ensinar e a encorajar. Obrigado professor!

Aos professores Ivan Gartner, Anderson Mol, José Matias-Pereira, Paulo Lustosa, Otávio Medeiros, Jorge Katsumi, Edilson Paulo e Paulo Cavalcante pelos incalculáveis conhecimentos transmitidos no decorrer do curso.

Aos colegas e amigos da quinta turma de doutorado, Adriana Steppan, Daniel Falcão, Gilmara Mendes, Josicarla Santiago, Leonardo Seixas, Lidiane Dias, Luiz dos Anjos, Mateus Santos e Márcia Tavares. Pessoas adoráveis, que tive o enorme prazer de conhecer e com quem tive o privilégio de estudar, discutir e conviver nesses quatro anos. Que a nossa amizade perdure!

Aos professores que participaram das qualificações e banca final de avaliação deste trabalho, Luís Afonso, Fernando Postali, Andréa Gonçalves, Diana Lima e Bruno Ramos pelas valiosas contribuições.

Aos chefes, secretários (as) e professores do Departamento de Ciências Contábeis e Atuariais da UnB, pelo incentivo, amparo e suporte.

Aos coordenadores e secretárias do Programa, pelo auxílio e solicitude.

À Ludmila Mello, Danielle Montenegro e Fernanda Fernandes pela amizade, apoio, discussões e grande ajuda.

Aos meus sogros, Ieda e Francisco, pelo carinho e incentivo.

À minha prima Fernanda, pelo carinho e apoio com a revisão do Abstract.

À Inês do DPO-UnB, pela ajuda com os dados da pesquisa. 
À Josefina Albuquerque, pela cuidadosa revisão do texto.

Por fim, agradeço a todos que contribuíram direta e indiretamente, ao longo do curso, na consecução deste trabalho. 
"Confia ao Senhor tuas obras, e terão bom êxito os teus projetos."

Provérbios 16,3 


\section{RESUMO}

A exploração dos recursos naturais pode representar uma vantagem econômica para determinada região. Contudo, a literatura tem indicado que países que dependem desse tipo de exploração tendem a ter menor crescimento econômico - circunstância que se convencionou chamar de maldição dos recursos naturais. Fatores ligados aos interesses e à gestão dos rendimentos provenientes dessa exploração explicam o efeito negativo sobre o crescimento. Descoberto o recurso natural, o Estado exerce seu direito constitucional sobre ela e repassa para os municípios brasileiros a compensação financeira pela prerrogativa de exploração desses recursos em seus territórios, ficando a cargo dos municípios a forma como os rendimentos devem ser aplicados. Esta pesquisa analisa a relação entre a abundância em recursos naturais e o gasto público com o crescimento econômico dos municípios brasileiros no período de 2003-2012. Para tanto, o estudo conta com uma amostra de 4.573 municípios e 22.865 observações, além de subamostras com apenas municípios que receberam receitas pela exploração de recursos hídricos, minerais e petrolíferos em todos esses anos. Os modelos empíricos têm como base os modelos de regressão com variável interação, para se demonstrar como o gasto público condicionado à abundância em recursos naturais se relacionou com o crescimento dos municípios. Todos os modelos foram estimados por Least Square Dummy Variable com efeitos específicos de tempo. Os resultados da pesquisa apontam para uma relação negativa entre a abundância em recursos naturais e o crescimento econômico dos municípios, principalmente quando se analisa a profusão em recursos minerais e de petróleo. Quanto à produtividade do gasto público - de forma geral, para todos os municípios -, o gasto corrente e seus componentes e, principalmente, o gasto em educação foram os que mais contribuíram para o crescimento econômico. Os resultados mostram, ainda, indícios de que o efeito da exploração dos recursos naturais no crescimento foi sensível à produtividade do gasto público dos municípios. Observa-se que tal produtividade não foi muito diferente entre municípios abundantes/não abundantes e mais/menos abundantes em recursos naturais. Portanto, verificam-se, no período do estudo, evidências da maldição dos recursos naturais nos municípios brasileiros e constata-se que parte desse indício pode ser explicada pela pouca contribuição dos rendimentos advindos dos recursos naturais para a produtividade do gasto público.

Palavras-chave: Maldição dos Recursos Naturais. Gasto Público. Crescimento Econômico. Municípios. 


\begin{abstract}
The exploration of natural resources may represent an economic advantage for locations where they occur. However, the literature has shown that in countries that depend on the exploitation of natural resources, the economic growth tends to be lower - a circumstance that came to be named as natural resource curse. Factors linked to the interests and the management of income from this type of exploitation would explain this negative effect on growth. After the State encounters a location abundant in natural resources, it exerts its constitutional right over these resources and then provides monetary compensation to the municipalities, to be spent at their own discretion, in exchange for the right to exploit the natural resources in their territory. This research analyzes how the abundance of natural resources and government spending is related to the economic growth of municipalities in the 2003-2012 period. To this end, the study has a sample of 4.573 municipalities and 22.865 observations, in addition to sub-samples with only municipalities that received income from the exploitation of water, minerals and oil resources every year. The empirical models are based on regression models with variable interaction, to show how the public spending conditioning the abundance in natural resources is related to the growth of cities. All models were estimated by Least Square Dummy Variable with time specific effects. The survey results point to a negative relation between natural resource abundance and economic growth of the cities, especially when considering the abundance in mineral and oil resources. As for the productivity of the public expenditure - in general, and for all municipalities -, the current spending and its components and, especially, the spending on education were the main contributors to economic growth. The results also show evidence that the effect of natural resources on growth was sensitive to the productivity of the public spending of municipalities. It can be verified that the productivity of public expenditure did not change significantly between abundant/not abundant and more/less abundant municipalities in natural resources. Therefore, there is evidence to support the existence of the resource curse in Brazilian municipalities during the period of study, part of which can be explained by the low contribution of natural resource revenues for the productivity of public spending.
\end{abstract}

Keywords: Resource Curse. Government Spending. Economic Growth. Municipalities. 


\section{LISTA DE ILUSTRAÇÕES}

\section{QUADROS}

Quadro 2.1 - Pesquisas empíricas sobre a MRN ........................................................ 38

Quadro 2.2 - Pesquisas empíricas sobre a produtividade do gasto público ...................... 48

Quadro 2.3 - Arrecadação e distribuição dos recursos provenientes da exploração hídrica. 51

Quadro 2.4 - Arrecadação e distribuição dos recursos provenientes da exploração mineral 52

Quadro 2.5 - Arrecadação e distribuição dos recursos provenientes da exploração do petróleo. 54

Quadro 3.1 - Amostra e subamostras da pesquisa ......................................................... 56

Quadro 3.2 - Resumo dos modelos empíricos...........................................................6 60

Quadro 3.3 - Variáveis de recursos naturais .................................................................. 64

Quadro 3.4 - Variáveis de gastos públicos ................................................................66

Quadro 3.5 - Anos estimados de estudo para cada nível de escolaridade ........................ 68

\section{FIGURA}

Figura 4.1 - Modelo analítico 72 


\section{LISTA DE TABELAS}

Tabela 1.1 - Compensações financeiras de recursos naturais distribuídas aos municípios 2003-2012.

Tabela 4.1 - Estatísticas descritivas 73

Tabela 4.2 - Abundância em recursos naturais e crescimento econômico

Tabela 4.3 - Nível de abundância em recursos naturais e crescimento econômico 79

Tabela 4.4 - Gastos públicos e crescimento econômico 80

Tabela 4.5 - Gastos por função e crescimento econômico 82

Tabela 4.6 - Abundância em recursos naturais, gastos por categoria e crescimento econômico

Tabela 4.7 - Nível de abundância em recursos naturais, gastos por categoria e crescimento econômico

Tabela 4.8 - Abundância em recursos naturais, gastos por natureza e crescimento econômico

Tabela 4.9 - Nível de abundância em recursos naturais, gastos por natureza e crescimento econômico

Tabela 4.10 - Abundância em recursos naturais, gastos por função e crescimento econômico

Tabela 4.11 - Nível de abundância em recursos naturais, gastos por função e crescimento econômico 


\section{LISTA DE ABREVIATURAS E SIGLAS}

ANEEL Agência Nacional de Energia Elétrica

ANP Agência Nacional do Petróleo

CFEM Compensação Financeira pela Exploração de Recursos Minerais

CFHI Compensação Financeira pela Exploração de Recursos Hídricos para a geração de energia elétrica

DNPM Departamento Nacional de Produção Mineral

FINBRA Finanças do Brasil

FNDCT Fundo Nacional de Desenvolvimento Científico e Tecnológico

IBGE Instituto Brasileiro de Geográfica e Estatística

IFDM Índice Firjan de Desenvolvimento Municipal

IPCA Índice Nacional de Preços ao Consumidor Amplo

IPEA Instituto de Pesquisa Econômica Aplicada

IPTU Imposto de Propriedade Territorial Urbana

LSDV $\quad$ Last Squares Dummy Variable

MCT Ministério da Ciência, Tecnologia e Inovação

MEC Ministério da Educação

MMA Ministério do Meio Ambiente

MME Ministério de Minas e Energia

MRN Maldição dos Recursos Naturais

MTE Ministério do Trabalho e Emprego

PIB Produto Interno Bruto

RAIS Relação Anual de Informações Sociais

STN Secretaria do Tesouro Nacional

TAR Tarifa atualizada de referência 


\section{SUMÁRIO}

1 INTRODUÇÃO................................................................................................ 15

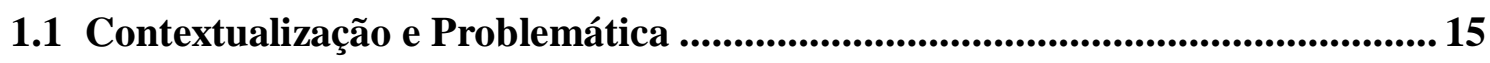

1.2 Objetivos da Pesquisa ........................................................................ 20

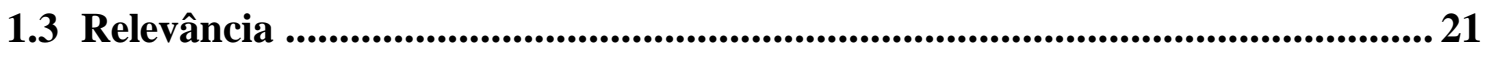

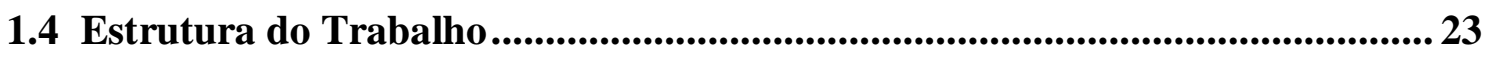

2 ARCABOUÇO TEÓRICO E LEGAL/INSTITUCIONAL .................................... 24

2.1 Arcabouço Teórico sobre a Maldição dos Recursos Naturais ............................. 24

2.2 Pesquisas empíricas sobre a Maldição dos Recursos Naturais.......................... 29

2.3 Arcabouço Teórico sobre a Produtividade do Gasto Público............................... 41

2.4 Pesquisas empíricas sobre gastos públicos e crescimento ...............................43

2.5 Arcabouço Legal e Institucional dos Recursos Naturais no Brasil ................... 50

2.5.1 Recursos hídricos para fins energéticos ........................................................51

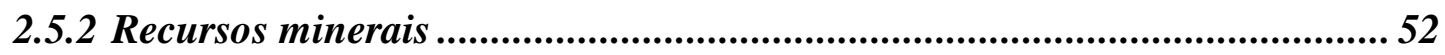

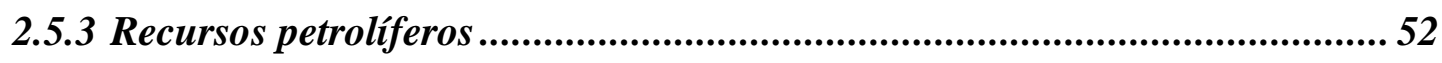

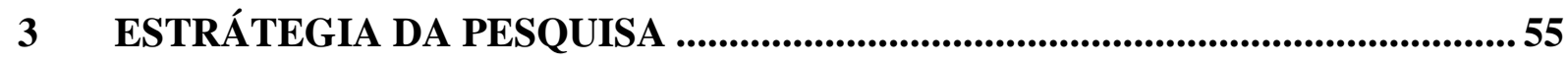

3.1 Seleção e Composição da Amostra ..........................................................55

3.2 Modelos Empíricos..............................................................................56

3.3 Estimação dos modelos ....................................................................................... 61

3.4 Dados e Variáveis ........................................................................................62 62

3.4.1 Variável Crescimento Econômico ................................................................. 62

3.4.2 Variáveis de Recursos Naturais...........................................................63

3.4.3 Variáveis de Gastos Públicos ...................................................................65

3.4.4 Variável Dummy para o Nível de Abundância ............................................. 67

3.4.5 Variáveis de Controle .................................................................................... 67

3.5 Procedimentos e Testes de Qualidade dos Ajustes.......................................... 69

3.6 Delimitação/Escopo da pesquisa ............................................................. 70 
4 ANÁLISE DOS RESULTADOS ..................................................................... 72

4.1 Estatísticas Descritivas......................................................................... 72

4.2 Comentários aos Testes de Qualidade dos Ajustes e Estimação dos Modelos.75

4.3 Recursos Naturais e o Crescimento Econômico dos Municípios ........................ 76

4.4 Produtividade do Gasto Público dos Municípios .............................................. 79

4.5 Recursos Naturais e a Produtividade do Gasto Público dos Municípios ......... 83

4.5.1 Recursos Naturais e Gastos pela Categoria Econômica............................... 83

4.5.2 Recursos Naturais e Gastos pela Natureza da Despesa ............................... 88

4.5.3 Recursos Naturais e Gastos por Função .................................................. 92

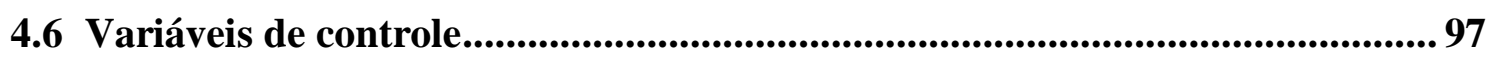

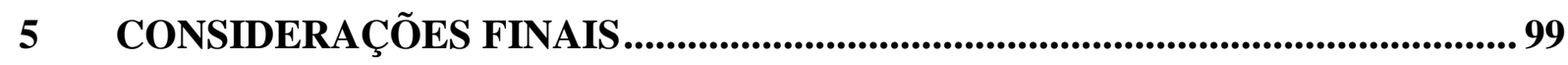

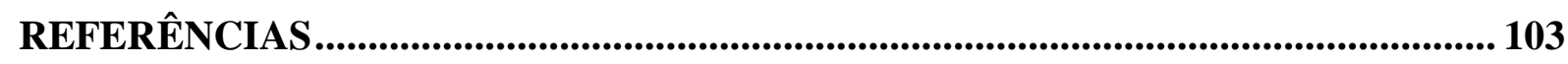

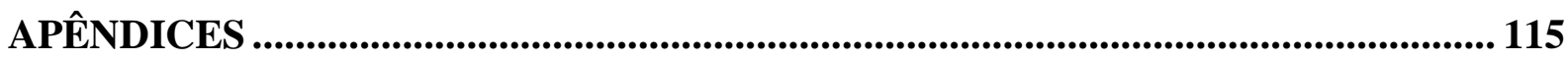




\section{INTRODUÇÃO}

A história do Brasil é marcada pela constante e intensa exploração dos seus recursos naturais, assim foi desde o início da sua colonização, com a extração do pau-brasil e a utilização das terras férteis para o cultivo da cana-de-açúcar, com o extrativismo mineral na região central e norte do País e com o ciclo da borracha no Norte, nos Séculos XVII e XVIII. Mais recentemente, apontam-se como exemplos marcantes a utilização das terras para o agronegócio - que confere ao País posição de destaque no mercado internacional -, a exploração do potencial elétrico das bacias aquíferas e a busca por petróleo, com destaque para as reservas em águas marítimas profundas. Entretanto, apesar de contar economicamente com a essa prática habitual, isso pode não importar concomitantemente em vantagem que possa contribuir para um maior crescimento econômico.

\subsection{Contextualização e Problemática}

Uma corrente de estudos tem focado em como a exploração de recursos naturais contribui para o crescimento econômico. A constatação geral é de uma relação inversa entre abundância de recursos e crescimento, ou seja, países ricos em recursos naturais experimentam crescimento econômico menor do que países não tão beneficiados com tais recursos. Esse fenômeno é conhecido como Maldição dos Recursos Naturais (a partir de agora MRN). Sachs e Warner (2001) afirmam que o pensamento popular é de que muitos países ricos em recursos naturais suportariam seu desenvolvimento com a ajuda destes recursos, entretanto as evidências da MRN surpreendem, pois contrariam os livros de história ou a discussão comum dessas vantagens.

Segundo Auty (1994), embora os recursos naturais sejam uma vantagem, os países ricos em recursos naturais desperdiçam essa vantagem porque teriam um otimismo excessivo quanto à estimação dos seus prospectos, levando ao relaxamento das políticas econômicas, à menor pressão para alcançar um rápido amadurecimento industrial, e à maior presença de grupos que manipulam o ambiente social e político em busca de benefícios próprios (rentseeking). Esses fatores aumentariam a probabilidade de um crescimento econômico ruim.

Notadamente, os primeiros estudos a sistematizar a MRN são atribuídos a Gelb (1988) e Auty (1990), os quais levantam hipóteses a partir de fatores econômicos e políticos que determinam um fraco crescimento econômico nos países ricos em recursos naturais. A partir 
de então, e dos estudos empíricos iniciados por Sachs e Warner (1995, 1999, 2001), diversas pesquisas têm procurado entender a relação entre recursos naturais e crescimento econômico.

Para compreender tal relação, Auty (2001) levanta algumas condições necessárias para o desenvolvimento econômico: 1) acesso relativamente igualitário à terra e à educação primária; 2) mercados efetivos e transparência das contas públicas; 3) políticas de livre comércio; e 4) diversificação econômica competitiva. Para o autor, uma quinta condição é necessária para ajudar a esclarecer o porquê do desempenho mais fraco dos países ricos em recursos naturais: o estado político de desenvolvimento, relacionado com a busca de políticas econômicas coerentes e o aumento do bem-estar social a longo prazo.

Nesse sentido, Auty (1994, 1997, 2001) aponta algumas características dos países ricos em recursos naturais que fariam com que o crescimento econômico fosse diferente dos demais países, como: a maior tolerância à desigualdade na distribuição das rendas decorrentes da exploração dos recursos naturais; a menor exigência pelo uso eficiente dos recursos escassos; a maior propensão a políticas comerciais protecionistas; a maior dependência do setor primário, que levaria à menor diversificação e competitividade do setor manufatureiroe tudo isso como reflexo da adoção de políticas econômicas difusas.

Assim, vários estudos observam uma tendência no comportamento dos países ricos em recursos naturais que seria prejudicial para o crescimento econômico, como a adoção de políticas econômicas restritivas, as ineficiências burocráticas, a maior pressão política sobre os rendimentos desses recursos e a maior vulnerabilidade às oscilações do mercado internacional (por exemplo, SACHS; WARNER, 1995; ROSS, 1999; TORVIK, 2002; PAPYRAKIS; GERLAGH, 2007; VAN DER PLOEG, 2011; SALA-I-MARTIN; SUBRAMANIAN, 2013).

Vale ressaltar que a MRN não é uma regra, mas uma tendência que tem sido observada (AUTY, 1994; ANSHASY, 2011). Assim, algumas exceções podem ser encontradas, de maneira especial é destacado na literatura o caso da Noruega, de Botsuana, do Chile, da Austrália, do Canadá e do Alasca (WRIGHT; CZELUSTA, 2004; LIMI, 2006; CRUZ; RIBEIRO, 2009; COUTINHO, 2011; MIDEKSA, 2013). Esses países criaram mecanismo que lhes permitiram aproveitar as vantagens proporcionadas pela exploração dos seus recursos naturais, com a criação de fundos para as futuras gerações, a distribuição de dividendos para a população, o maior controle fiscal e a liberalização de mercado.

De forma geral, os estudos empíricos sobre o crescimento econômico levantam diversos determinantes que se relacionam com o crescimento, como: capital humano, investimento, comércio exterior, qualidade das instituições, inflação, instabilidade política, 
corrupção e desigualdades sociais (BARRO, 1991; LEVINE; RENELT, 1992; SACHS; WARNER, 1997; GYLFASON; HERBERTSSON; ZOEGA, 1999).

Nos estudos que tangenciam a MRN, a abundância ou a dependência das rendas advindas da exploração dos recursos naturais é testada como um determinante direto e/ou indireto do crescimento econômico. A ideia subjacente é de que a transmissão dos efeitos da exploração dos recursos naturais não necessariamente ocorre de forma direta sobre o crescimento econômico, mas pode ocorrer indiretamente através de outros fatores que afetam o crescimento (SACHS; WARNER, 1995; PAPYRAKIS; GERLAGH, 2007).

Atualmente, o consenso entre os pesquisadores é de que os recursos naturais não são uma maldição em si, ou seja, eles não atuam de forma direta sobre o crescimento econômico, mas provocam um possível efeito negativo nas políticas de investimento, nas instituições, na composição dos gastos públicos, na distribuição de renda, na educação, na industrialização e na estabilidade econômica, que levaria ao desempenho relativamente pobre do crescimento econômico (SACHS; WARNER, 1995; GYLFASON; HERBERTSSON; ZOEGA, 1999; ROSSER, 2006; MEHLUM; MOENE; TORVIK, 2006; FRANKEL, 2010; ANSHASY, 2011; VAN DER PLOEG, 2011; SALA-I-MARTIN; SUBRAMANIAN, 2013; ROSS, 2015).

Uma das linhas de pesquisa sobre o crescimento econômico aponta como determinante a política fiscal. A ideia é de que políticas fiscais eficientes levam a um crescimento econômico sustentável. Entre estas, investiga-se a contribuição dos gastos públicos para o crescimento, sendo que, nas últimas décadas, parte dos estudos tem focado a atenção na identificação dos elementos dos gastos públicos, em vários níveis de agregação, que estariam associados com o crescimento econômico (DEVARAJAN; SWAROOP; ZOU, 1996; KNELLER; BLEANEY; GEMMELL, 1999; ROCHA; GIUBERTI, 2007; GHOSH; GREGORIOU, 2008; BAYRAKTAR E MORENO-DODSON, 2010).

Pesquisas recentes sobre crescimento econômico e gastos públicos têm seu expoente na teoria de crescimento endógeno, mais especificamente o estudo de Barro (1990). Nesses estudos, os setores público e privado são complementares, de forma que o primeiro forneceria os insumos para o segundo. Assim, os efeitos dos gastos públicos seriam avaliados pela sua contribuição à produtividade do capital privado (FERREIRA, 1994). Desse modo, o Estado é considerado um fator instrumental em prover as atividades econômicas, contribuindo para o crescimento (ALEXIOU, 2009; OGUNDIPE; OLUWATOBI, 2013).

Empiricamente, contudo, a relação entre gastos públicos e crescimento econômico é controversa, uma vez que alguns estudos apontam uma relação negativa entre os gastos e o crescimento, enquanto outros destacam uma relação positiva (ALEXIOU, 2009; 
BAYRAKTAR; MORENO-DODSON, 2010). Nesse sentido, Levine e Renelt (1992) verificaram que, possivelmente, as medidas em geral utilizadas para gastos públicos desagregados não são robustamente correlacionadas com a taxa de crescimento da economia.

Ainda assim, Moreno-Dodson (2008) afirma que, embora empiricamente a relação entre gastos e crescimento econômico possa parecer não robusta e inconclusiva, há fortes razões para acreditar que o gasto público é uma importante variável que influencia o crescimento, sendo incerto o grau real dessa influência. Por exemplo, no levantamento feito por Ferreira (1994), verificou-se que a queda no ritmo de crescimento dos EUA e de países do G7 nos 1970-80 estava ligada à redução nos gastos públicos em infraestrutura, que, por sua vez, afetou a produtividade do setor privado e o crescimento econômico.

Para Levine e Renelt (1992), aparentemente a política fiscal, na medida em que tem uma relação independente com o crescimento, está mais fortemente correlacionada com a alocação eficiente dos recursos do que com a acumulação do capital físico. Assim, o que se depreende dos estudos citados anteriormente é uma expectativa de que, em economias com políticas fiscais prudentes, os gastos públicos tendem a alavancar o crescimento econômico.

Assim, as receitas decorrentes da exploração dos recursos naturais levantam uma considerável preocupação quanto à gestão dos ativos gerados por essa exploração. Solow (1974, 1986) e Hartwick (1977) defendem a sustentabilidade na alocação dos rendimentos da exploração dos recursos naturiais (exauríveis) para que os benefícios sejam constantes para as gerações futuras. Nesse sentido, Davis et al. (2001) apontam que essas receitas impõem desafios para os formuladores de políticas fiscais, uma vez que o fluxo destas é incerto e volátil (principalmente devido a flutuações nos preços) e a oferta dos recursos naturais é esgotável. Dessa forma, diante desses desafios, eles teriam que planejar e isolar as despesas e formar uma poupança para as futuras gerações.

Segundo Atkinson e Hamilton (2003), a expectativa é que economias ricas em recursos naturais tenham uma preocupação em equilibrar conjuntamente o bem-estar futuro e o processo de liquidação da sua riqueza natural no presente, devendo buscar políticas prudentes de poupança e investimento das receitas de recursos naturais. Entretanto, estes autores afirmam que as evidências da MRN sugerem que a abundância em recursos naturais levam os países a manter políticas ruins por um período maior do que seria desejável para proporcionar um crescimento econômico sustentável.

As receitas de recursos naturais podem aumentar consideravelmente os recursos disponíveis para financiar os gastos públicos comparavelmente às economias que não contam com tais receitas. Assim, o governo de localidades ricas em recursos naturais pode ser 
incentivado a aumentar os gastos públicos (DAVIS ET AL., 2001; BLEANEY; HALLAND, 2009; ALICHI; AREZKI, 2009; DEVARAJAN ET AL., 2011), embora aparentemente isso possa não significar o mesmo efeito no crescimento econômico.

Segundo Devarajan et al. (2011), a baixa produtividade dos gastos públicos nos países ricos em recursos naturais pode ser explicada pelo fato de o governo usualmente não precisar de fundos externos - principalmente aqueles advindos da tributação da população - para financiar os gastos públicos, exceto nos períodos de queda nos preços das commodities. Dessa forma, a sociedade exerceria menor pressão pela transparência nas contas públicas, levando a uma gestão ruim dos rendimentos dos recursos naturais no médio e longo prazo.

Em Davis et al. (2001), observam-se dois efeitos das flutuações nas receitas de recursos naturais sobre os gastos: primeiro, um aumento dessas receitas - pelo aumento nos preços ou início da exploração das reservas naturais - pode levar à tentação de aumentar os gastos a níveis insustentáveis e a prestar menos atenção na qualidade dos projetos; segundo, uma redução acentuada dessas receitas - pela queda dos preços ou exaustão das reservas leva a cortes drásticos nas despesas, o que pode ser perturbador e oneroso para a população.

Dessa forma, da literatura extrai-se que embora a exploração dos recursos naturais possa representar uma vantagem econômica, as evidências indicam que nas localidades onde a exploração é mais intensa o crescimento econômico tende a ser menor comparado ao das demais localidades. Também, verifica-se que essa relação pode ser explicada indiretamente por outros fatores associados com o fraco crescimento econômico, como a inaptidão da política fiscal em lidar com o grande volume de recursos decorrentes da exploração natural. Isso poderia ser reflexo da baixa produtividade do gasto público (contribuição do gasto para o crescimento econômico) financiado com tais recursos.

No Brasil, a atual Constituição dispõe que os recursos naturais são pertencentes à União, entretanto aos estados e municípios é assegurada a participação no resultado da exploração desses recursos em seus territórios, como a compensação financeira pela exploração do petróleo, de recursos hídricos para fins de energia elétrica e de outros recursos minerais, além das receitas da produção vegetal aferidas diretamente. No caso do petróleo, alterações na legislação nas últimas duas décadas ocasionaram um aumento substancial a ser repassado aos municípios, que, juntamente com a maior liberdade na sua alocação, levanta preocupações quanto ao uso prudente dessas receitas (POSTALI, 2009).

A Tabela 1.1 mostra os valores da compensação financeira pela exploração de recursos naturais distribuídas aos municípios de 2003 a 2012. O montante repassado aos municípios foi de quase $\mathrm{R} \$ 72$ bilhões ao longo desses 10 anos, tendo dobrado o valor dos repasses ( $\mathrm{R} \$ 4,9$ 
bilhões em 2003 e R\$ 10,4 bilhões em 2012) - os royalties e participações do petróleo duplicaram e a compensão financeira de recursos minerais quadriplicou no período. Observase também, que os valores referentes a exploração petrolífera representaram a maior parcela das compensações financeiras distribuídas, $76 \%$ do total. Nesse sentido, o Brasil ficou na $14^{\mathrm{a}}$ e $13^{a}$ posição no ranking mundial de reversas e de produçãode petróleo, respectivamente, em 2012 (ANP, 2013), o que pode explicar o volume maior da compensação financeira dos recursos do petróleo repassados aos municípios.

Tabela 1.1 - Compensações financeiras de recursos naturais distribuídas aos municípios 2003-2012 valores em milhões de Reais, corrigidos para 31.12.2014

\begin{tabular}{crrrrrrrrrr|r}
\hline \hline & $\mathbf{2 0 0 3}$ & $\mathbf{2 0 0 4}$ & $\mathbf{2 0 0 5}$ & $\mathbf{2 0 0 6}$ & $\mathbf{2 0 0 7}$ & $\mathbf{2 0 0 8}$ & $\mathbf{2 0 0 9}$ & $\mathbf{2 0 1 0}$ & $\mathbf{2 0 1 1}$ & $\mathbf{2 0 1 2}$ & \multicolumn{1}{c}{ Total } \\
Minerais & 352 & 366 & 427 & 471 & 534 & 740 & 707 & 864 & 1.203 & 1.405 & $\mathbf{7 . 0 6 8}$ \\
Hídricos & 971 & 967 & 979 & 995 & 1.032 & 973 & 1.016 & 1.011 & 1.004 & 1.056 & $\mathbf{1 0 . 0 0 5}$ \\
Petróleo & 3.616 & 3.945 & 4.561 & 5.396 & 4.870 & 6.797 & 5.063 & 5.604 & 6.977 & 7.878 & $\mathbf{5 4 . 7 0 9}$ \\
\hline Total & $\mathbf{4 . 9 4 0}$ & $\mathbf{5 . 2 7 9}$ & $\mathbf{5 . 9 6 7}$ & $\mathbf{6 . 8 6 2}$ & $\mathbf{6 . 4 3 7}$ & $\mathbf{8 . 5 1 0}$ & $\mathbf{6 . 7 8 6}$ & $\mathbf{7 . 4 7 9}$ & $\mathbf{9 . 1 8 4}$ & $\mathbf{1 0 . 3 3 9}$ & $\mathbf{7 1 . 7 8 3}$ \\
\hline \hline
\end{tabular}

Minerais: CFEM; Hídricos: CFHI + royalties da usina de Itaipu; Petróleo: royalties + participações especiais.

Fonte: dados da pesquisa extraídos das base de dados do DNPM, Aneel e InfoRoyalties/ANP (detalhadas adiante).

De forma geral, a legislação brasileira não estabelece especificamente como os estados e municípios devem utilizar as receitas decorrentes da exploração dos recursos naturais. Contudo, a expectativa é que os valores recebidos devem ser aplicados, direta ou indiretamente, em projetos que beneficiem a maior capacidade científica e tecnológica dos setores relacionados com a exploração, bem como as comunidades locais na forma de melhorias em infraestrutura e qualidade ambiental (CRUZ; RIBEIRO, 2009).

Portanto, considerando-se que os municípios possuem certa autonomia para gerir as receitas recebidas como compensação pela exploração dos recursos naturais em seus territórios e que essas receitas podem representar uma vantagem para o crescimento econômico para os municípios que as recebem, a pesquisa pretende responder a seguinte pergunta: Qual a influência da abundância em rendimentos da exploração dos recursos naturais e dos gastos públicos no crescimento econômico dos municípios brasileiros?

\subsection{Objetivos da Pesquisa}

Com base na fundamentação da problemática apresentada, esta pesquisa tem o objetivo de investigar o comportamento da abundância em rendimentos obtidos pela exploração de recursos naturais e dos gastos públicos, em diferentes níveis de agregação, em relação ao crescimento econômico dos municípios brasileiros no período de 2003 a 2012. 
Para atingir o objetivo geral são delineados os seguintes objetivos específicos:

1) Verificar o efeito da abundância em recursos naturais no crescimento econômico dos municípios brasileiros;

2) Verificar o efeito do nível de abundância (alta/baixa) em recursos naturais no crescimento econômico dos municípios;

3) Verificar o comportamento dos gastos públicos em diferentes níveis de agregação no crescimento econômico dos municípios;

4) Verificar se parte do efeito da abundância em recursos naturais no crescimento é explicado pelos gastos públicos dos municípios;

5) Verificar o comportamento dos gastos públicos no crescimento econômico nos municípios abundantes em recursos naturais;

6) Verificar o comportamento dos gastos públicos no crescimento econômico nos municípios altamente abundantes (nível) em recursos naturais.

\subsection{Relevância}

Embora a maioria das pesquisas sobre a MRN aborde a situação entre países, a investigação da relação entre recursos naturais e crescimento econômico também pode ser estendida para unidades econômicas menores, intrapaís, como regiões, estados e municípios, como visto em Papyrakis e Gerlagh (2007) com estados dos EUA e em James e Aadland (2010) com municípios dos EUA. No Brasil, na maioria dos estudos que abordam a MRN, as análises têm focado nos municípios brasileiros (como em POSTALI, 2009, 2012; POSTALI; NISHIJIMA, 2011, 2013; RIBEIRO; TEIXEIRA; GUTIERREZ, 2010). A ideia é que regiões diferentes dentro de um país possuem as mesmas características econômicas fundamentais, convergindo para um mesmo estado estacionário (PAPYRAKIS; GERLAGH, 2007).

James e Aadland (2011) apontam como vantagens da pesquisa sobre a MRN ao nível municipal: o tamanho maior da amostra e da confiabilidade das estimativas econométricas em decorrência da maior quantidade de unidades de observação - por exemplo, no Brasil existem aproximadamente 5.596 municípios; a menor necessidade de controlar os efeitos da MRN pelas diferenças institucionais e políticas, uma vez que essas características tendem a ser similares entre os munícipios de um mesmo país - como o idioma, a moeda, a corrupção etc.; e a não necessidade de examinar a MRN de forma agregada, tendo em vista que a análise em nível micro permite uma compreensão mais pontual dos efeitos da MRN. 
Sobre a importância de estudos em nível municipal, James e Aadland (2011) afirmam que a análise em nível intrapaís permite ao pesquisador explorar mais detalhadamente como a MRN ocorre e entender por que os tomadores de decisões persistem na especialização da indústria de exploração de recursos naturais associada a um menor crescimento econômico. Isso seria possível, pois cada localidade teria algumas características próprias, uma vez que as políticas econômicas são estabelecidas por planejadores locais ou municipais. De fato, no caso dos municípios brasileiros, a legislação brasileira aborda, em linhas gerais, como devem ser alocadas as rendas dos recursos naturais, cabendo muitas vezes ao Executivo e ao Legislativo de cada localidade decidir sobre o uso de tais receitas.

A maioria dos estudos empíricos que tratam diretamente ou tangenciam os efeitos da MRN nos munícipios brasileiros - como Postali (2009, 2012), Postali e Nishijima (2011, 2013) e Ribeiro, Teixeira e Gutierrez (2010) - geralmente foca nas rendas advindas da exploração de petróleo e gás. A presente pesquisa expande o entendimento dos efeitos da MRN ao propor uma análise mais ampla das rendas de exploração dos recursos naturais nos munícipios brasileiros, englobando as rendas decorrentes da exploração dos recursos minerais, hídricos para fins energéticos e petrolíferos.

Ainda, esta pesquisa avança em relação aos estudos anteriores ao analisar os efeitos da MRN em relação à política fiscal, aqui representada pelo perfil dos gastos públicos em diferentes níveis de agregação, ao nível intrapaís. Em relação às pesquisas nacionais, a pesquisa também amplia a compreensão dos efeitos da MRN no Brasil ao examinar essas políticas juntamente com as múltiplas rendas pela exploração de recursos naturais com os quais um munícipio pode se beneficiar: petróleo e gás, mineração e recursos hídricos.

Segundo Atkinson e Hamilton (2003), o entendimento de como se processa um crescimento econômico sustentável em virtude dos efeitos da MRN, especificamente sobre a gestão das receitas, dos gastos e da poupança pública, possibilita o uso potencial de uma abordagem contábil na compreensão dos problemas de sustentabilidade nos países abundantes em recursos naturais. Desse modo, tal potencial é explorado na presente pesquisa, tendo em vista que a proposta é analisar os efeitos da MRN nas contas públicas municipais, a partir das informações contidas nos balanços orçamentários dos munícipios brasileiros, como os dados das despesas agregadas tanto pela categoria econômica quanto pela função dos gastos públicos.

Portanto, ao analisar como se comportam os gastos públicos dos munícipios beneficiários das rendas pela exploração de recursos naturais, a pesquisa pode contribuir com a área das finanças públicas a partir do entendimento do efeito dos gastos públicos no 
crescimento econômico e, a partir de então, contribuir como a gestão pública deve atuar para a utilização mais eficiente dos recursos públicos, mais especificamente dos recursos naturais. Segundo Brunnschweiler e Bulte (2008a), organizações internacionais tem procurado conhecer o impacto da exploração dos recursos naturais no crescimento econômico dos países para criar diretrizes que possam auxiliar na redução dos efeitos adversos que estes recursos podem trazer se não forem devidamente geridos.

\subsection{Estrutura do Trabalho}

Este estudo está organizado em cinco capítulos.

O primeiro apresenta a contextualização da problemática, os objetivos e a relevância da pesquisa.

O Capítulo 2 discorre sobre o arcabouço teórico no tocante às explicações de como ocorre a MRN e a produtividade do gasto público, sobre as pesquisas anteriores de cada um desses assuntos e, por fim, sobre o arcabouço legal e institucional referente aos recursos naturais no Brasil.

No Capítulo 3, é apresentada a estratégia da pesquisa, com os procedimentos metodológicos de seleção da amostra, dados e variáveis; a formulação e a estimação dos modelos empíricos para a investigação dos objetivos específicos; os testes e procedimentos para garantir a qualidade dos resultados; além da limitação e do escopo da pesquisa.

Aponta-se, no Capítulo 4, a análise dos resultados das estatísticas descritivas, dos testes e procedimentos de qualidade dos ajustes, dos modelos estimados para a relação entre abundância em recursos naturais e crescimento econômico dos municípios, para a produtividade do gasto público dos municípios brasileiros e para a relação entre recursos naturais, gasto público e crescimento econômico, bem como os resultados dos modelos para as variáveis de controle.

No último capítulo, são apresentadas as considerações finais do estudo. 


\section{ARCABOUÇO TEÓRICO E LEGAL/INSTITUCIONAL}

Neste capítulo, apresentam-se os arcabouços teóricos sobre as principais explicações para MRN e a produtividade do gasto público, bem como os resultados de pesquisas empíricas anteriores de cada um desses assuntos. Em seguida, discorre-se sobre o arcabouço legal e institucional da constituição, arrecadação, distribuição e aplicação dos rendimentos decorrentes do direito de exploração dos recursos naturais no Brasil.

\subsection{Arcabouço Teórico sobre a Maldição dos Recursos Naturais}

$\mathrm{Na}$ literatura, encontram-se cinco principais explicações para a MRN: a doença holandesa, os efeitos sobre a acumulação de capital, a atuação dos rent-seeking, a qualidade das instituições e as escolhas políticas sobre os rendimentos obtidos pela exploração dos recursos naturais (SACHS; WARNER, 1999; FRANKEL, 2010; TORRES; AFONSO; SOARES, 2013; ROSS, 2015). Essas explicações, entretanto, não são independentes; elas são complementares. A seguir, discorre-se detalhadamente sobre cada uma delas, abordando-se com especial ênfase as escolhas da política fiscal. Depois, são mostradas pesquisas empíricas com base nessas explicações.

Os argumentos teóricos sobre a MRN baseiam-se inicialmente no que se denomina de doença holandesa - termo que designa a experiência vivenciada pela Holanda nos anos 1960 devido ao aumento de receitas de exportação de gás e petróleo e ao processo de desindustrialização. Uma entrada maior de divisas internacionais pela exportação de recursos naturais pode levar à supervalorização da taxa de câmbio do país. Com isso, os produtos do setor manufatureiro perdem competitividade no mercado internacional, a participação desse setor na economia é reduzida e a economia do país torna-se menos diversificada. Essa menor diversificação na economia, por sua vez, deixa o país desprotegido caso haja uma queda brusca do preço das commodities, gerando um impacto negativo sobre o crescimento econômico (CORDEN; NEARY, 1982; AUTY, 1994, 1997; DAVIS, 1995; SACHS; WARNER, 1999; BRESSER-PEREIRA, 2008; STRACK; AZEVEDO, 2012).

Assim, com base num modelo de gerações sobrepostas para crescimento endógeno e doença holandesa, Sachs e Warner (1995) demonstram que, num boom nos recursos naturais seja pelo inicio da exploração ou pelo aumento nos preços -, os rendimentos pela exploração desses recursos são transferidos inicialmente para a geração mais jovem, aumentando a demanda, principalmente, por produtos do setor de não transacionáveis (non-traded goods), o 
que leva a uma transferência de força de trabalho e de capital do setor manufatureiro para o setor de não transacionáveis.

Nos momentos seguintes, com o fim do boom dos recursos naturais, a geração antes jovem, agora mais velha e ainda usufruindo dos rendimentos auferidos anteriormente, continuará a demandar mais, reduzindo ainda mais a mão de obra do setor manufatureiro e gerando efeito prolongado sobre a acumulação de capital humano. Depois disso, a mão de obra do setor manufatureiro tende a retornar gradualmente ao nível estacionário, embora a acumulação de capital humano e de capital físico e o crescimento sejam menores. Dessa forma, o setor manufatureiro é enfraquecido e torna-se incapaz de compensar os efeitos adversos de uma oscilação nos preços ou da exaustão dos recursos naturais.

Nesta mesma linha, Sachs e Warner (1999) mostram que um aumento repentino nos recursos pode levar a um desenvolvimento industrial tal que seria inalcançável de outra maneira e que esse desenvolvimento poderia, por sua vez, impulsionar consideravelmente o crescimento econômico do país. No caso da MRN, um aumento repentino nesses recursos irá aumentar temporariamente os rendimentos, mas irá frustrar o processo de industrialização. Assim, se o setor manufatureiro não tiver produção com retornos crescentes à escala, o crescimento econômico seria prejudicado. Contudo, se for o setor de não transacionáveis com esse tipo de produção, um boom nos recursos naturais transferiria mais recursos para esse setor, favorecendo o crescimento.

Gylfason, Herbertsson e Zoega (1999) demonstram como o nível de riqueza natural influencia a educação e o crescimento econômico. A excessiva concentração no setor primário pode levar à redução do investimento no capital físico e no capital humano, uma vez que esse setor não seria muito intenso em capital, principalmente em mão de obra qualificada. Assim, o crescimento econômico seria menor devido à supressão do setor secundário e aos efeitos na educação: os efeitos na taxa de câmbio provocados pela concentração de recursos no setor primário (doença holandesa) inibiria o desenvolvimento do setor secundário, reduzindo a necessidade de educação formal, e a queda de qualidade na educação também inibiria o setor secundário devido ao aumento dos custos de treinamento de profissionais emergentes.

Para Auty (2001), a MRN pode ser explicada pelo processo político. Os países ricos em recursos naturais apresentam maior propensão ao surgimento de conflitos sobre os rendimentos daí advindos, levando à formação de um Estado que utiliza esses ganhos para atender aos interesses de grupos setoriais em vez de procurar políticas econômicas coerentes e o bem-estar social a longo prazo. Tendo em vista os efeitos negativos da dependência econômica dos recursos naturais sobre o setor industrial (como visto acima) e atendendo às 
pressões destes grupos, haveria uma tendência à adoção de políticas de comércio protecionistas para forçar a industrialização. Esse tipo de política mantido por longos períodos tem efeitos econômicos distorcivos e, assim, acabaria por comprometer o crescimento a longo prazo.

Isso é observado principalmente no comportamento de grupos que buscam obter vantagens manipulando o ambiente econômico e político sem o compromisso de agregar-lhes valor (rent-seeking), gerando efeito negativo sobre o bem-estar e o crescimento econômico (TORNELL, LANE, 1999). Para Torvik (2002), quanto maior o volume de rendimentos obtidos com os recursos naturais, mais aumenta o número de empresários empenhados em obter acesso a esses rendimentos para fins próprios e reduz o número de empresários interessados em estabelecer empresas produtivas, uma vez que não seriam tão lucrativas quanto a atividade de rent-seeking. A queda na renda ocasionada pelo menor número dessas empresas teria efeito maior na economia do que o aumento da renda vinda dos recursos naturais.

De uma forma mais ampla, outra explicação para a MRN é a qualidade das instituições que iram gerir os recursos naturais, ou seja, se as instituições forem fracas, aumenta a possibilidade de as receitas obtidas por meio dos recursos naturais não serem direcionadas para o bem-estar e o crescimento econômico (SACHS; WARNER, 1995; ROSS, 1999; MEHLUM; MOENE; TORVIK, 2006; BRUNNSCHWEILER, 2008; SALA-I-MARTIN; SUBRAMANIAN, 2013). A qualidade das instituições está relacionada principalmente com o nível de burocracia governamental, a incidência da corrupção, a proteção aos direitos de propriedade, a força do estado de direito e, de forma geral, com a capacidade do estado de promover o desenvolvimento econômico (SACHS; WARNER, 1995; ROSS, 1999; VAN DER PLOEG, 2011; TORRES; AFONSO; SOARES, 2013; ROSS, 2015).

Com os rendimentos dos recursos naturais, haveria menor necessidade de tributar os cidadãos, assim a população demandaria menos prestação de contas do Estado e a pressão por melhorias na qualidade das instituições seria reduzida (ROSS, 2001). Ou, ainda, esses rendimentos poderiam ser utilizados para mitigar divergências na população e para prevenir a formação de grupos com interesses especiais que pudessem exercer pressão sobre o governo, como forma de se manter no poder (ROSS, 2001; HABER; MENALDO, 2011).

A exploração de alguns tipos de recursos naturais pode estar associada com a alta concentração de propriedades, tornando o Estado altamente dependente de um pequeno grupo. Isso permitiria que tal grupo conseguisse desonerações fiscais, subsídios e medidas protecionistas, além de polarizar a sociedade (ISHAM et al., 2005). Para Ross (1999), quando 
os direitos de propriedade são fracos, o setor manufatureiro pode encontrar dificuldades de compensar o risco de perda dos investimentos com margens de lucros normais.

A possibilidade de os recursos naturais serem controlados por pequenos grupos da sociedade aumenta a probabilidade de distribuição desigual da renda (BULTE; DAMANIA; DEACON, 2005). Dessa forma, a disputa por renda e o descontentamento da população podem levar a conflitos sociais (ROSSER, 2006; BRUNNSCHWEILER; BULTE, 2008a). Nesse sentido, o incremento de oportunidades de rent-seeking com a exploração dos recursos naturais contribui para aumentar a probabilidade de corrupção (LEITE; WEIDMANN, 1999; BUSSE; GRÖNING, 2013). Também, um maior orçamento do governo devido às receitas de recursos naturais levaria os eleitores a exercerem menor pressão por prestação de contas e punição em casos de corrupção, incentivando a continuidade de políticos corruptos (ROBINSON; TORVIK; VERDIER, 2006; BROLLO et al, 2013).

Ainda nesse contexto, as escolhas sobre as políticas macroeconômica e fiscal parecem refletir a qualidade das instituições, uma vez que essas políticas são um mecanismo de transmissão das instituições (ACEMOGLU et al., 2003; FATÁS; MIHOV, 2003, 2013; BRUNNSCHWEILER; BULTE, 2008b). Mais especificamente, vários estudos procuram explicar a MRN a partir da política fiscal, no sentido de que a exploração dos recursos naturais leva a um aumento das receitas e a aplicação dessas geraria efeito negativo sobre a economia (DAVIS et al., 2001; ATKINSON; HAMILTON, 2003; ALICHI; AREZKI, 2009; BLEANEY; HALLAND, 2009; ANSHASY, 2011; COUTINHO, 2011; POSTALI; ROCHA, 2009; DEVARAJAN et al., 2011; POSTALI 2012).

Segundo Davis et al. (2001), a dependência das receitas provenientes de recursos naturais pode trazer implicações para a política fiscal, uma vez que estas receitas são finitas devido à exaustão das reservas naturais - e estão sujeitas a grande variação em decorrência das flutuações nos preços. Isso geraria instabilidade e incertezas nas receitas fiscais que complicariam a gestão fiscal, o planejamento orçamentário e o uso eficiente dos recursos públicos. Ademais, as flutuações nessas receitas podem desencadear uma volatilidade da taxa câmbio, e seu aumento pode levar à doença holandesa.

Para Atkinson e Hamilton (2003), a MRN pode ser atribuída à inabilidade da gestão pública para gerir grandes receitas de forma sustentável. Assim, a combinação de recursos naturais com políticas ineficientes de gastos públicos levaria a uma baixa taxa de poupança pública. A proposição é que receitas volumosas advindas da exploração dos recursos naturais permitiriam aos governos seguir com gastos públicos insustentáveis por longos períodos, 
interferindo na formação da poupança pública e, consequentemente, impactando negativamente o crescimento econômico.

Conforme Alichi e Arezki (2009), os agentes privados esperam se beneficiar dos gastos correntes futuros do governo financiados pelas receitas dos recursos naturais. Isso reduziria o incentivo para a formação de poupança e investimento privados, prejudicando o crescimento do setor privado nos países ricos em recursos naturais e, logo, o crescimento econômico a longo prazo. Bleaney e Halland (2009) afirmam que o acesso aos rendimentos dos recursos naturais distorce a política fiscal, levando a uma expansão exagerada dos gastos de consumo do governo e prejudicando o crescimento econômico. Conforme observado por Frankel (2010), a receita pública com impostos e royalties tende a aumentar quando há um boom nos recursos naturais, e o governo não consegue resistir à tentação ou à pressão política para aumentar os gastos proporcionalmente, ou mais que proporcionalmente.

De acordo com Postali e Rocha (2009), acredita-se que as receitas com recursos naturais possam levar à implementação de projetos públicos com baixo retorno marginal social, à redução do esforço fiscal, à corrupção e à ineficiência. Para Postali (2012), com um fluxo maior dessas receitas, os incentivos poderiam ser reduzidos para que a administração pública maximizasse o esforço fiscal e minimizasse os gastos administrativos. Nesse sentido, Devarajan et al. (2011) afirmam que, com essas receitas, haveria um incentivo à menor tributação dos cidadãos, implicando menor transparência e compromisso com os gastos públicos, além da prestação de serviços públicos de baixa eficiência e qualidade.

Para Anshasy (2011), as decisões do governo a respeito de como serão gastos esses recursos podem desencadear a MRN, principalmente se esses recursos não forem utilizados para financiar outros setores que alavancariam o crescimento. Nesse sentido, Coutinho (2011) defende o direcionamento da política fiscal nos países ricos em recursos naturais para minimizar os efeitos da doença holandesa, principalmente por meio dos gastos públicos de capital, em infraestrutura, em capital humano e na adoção de novas tecnologias em benefício dos setores não ligados aos recursos naturais, de forma a contribuir para a diversificação da economia e a se proteger de flutuações nos preços das commodities.

Tendo em vista os efeitos adversos da dependência dos recursos naturais sobre a acumulação do capital humano, Gylfason (2001), Behbudi, Mamipour e Karami (2010) e Shao e Yang (2014) afirmam que as receitas com recursos naturais poderiam contribuir positivamente para a acumulação de capital humano por meio de gastos e investimentos em educação. Similarmente, para Acemoglu, Finkelstein e Notowidigdo (2013) e Anshasy e Katsaiti (2015), a utilização dessas receitas em gastos e investimentos em saúde também 
favorece a acumulação de capital humano, ao contribuir para o aumento da qualidade e da expectativa de vida.

\subsection{Pesquisas empíricas sobre a Maldição dos Recursos Naturais}

Dos estudos empíricos sobre os efeitos da MRN é possível identificar duas abordagens quanto aos seus determinantes: os que investigam predominantemente fatores econômicos, notadamente os realizados na segunda metade da década de 1990 e início dos anos 2000; e os que enfatizam principalmente fatores políticos e institucionais, especialmente a partir dos anos 2000. Apesar de os estudos focarem ou uma ou outra abordagem, complementam suas análises utilizando fatores da abordagem concorrente. No caso das pesquisas com munícipios brasileiros que tratam direta ou indiretamente da MRN, a abordagem predominante é a primeira, embora se concentrem na exploração dos recursos petrolíferos. O quadro 2.1 apresenta, ao final desta seção, uma síntese das pesquisas empíricas sobre a MRN.

Como estudos que investigam predominantemente fatores econômicos, apresentam-se os trabalhos de Auty (1994), Sachs e Warner (1995, 1997, 1999, 2001), Gylfason, Herbertsson e Zoega (1999), Gylfason (2001) e Manzano e Rigobon (2001) James (2015) que encontraram evidência da MRN entre países; Veríssimo e Xavier (2014), no Brasil; e Papyrakis e Gerlagh (2007) e James e Aadland (2011), nos estados e municípios dos EUA.

Auty (1994) verificou que os países com intenso processo de industrialização nos anos 1950-70 adotaram políticas de proteção ao desenvolvimento do setor industrial de metais e químicos. Nos países com mercado doméstico de menor potencial e pobres em recursos naturais, essas políticas não se sustentaram por muito tempo, sendo substituídas por políticas industriais competitivas as quais propiciaram rápido crescimento econômico. Os países com mercado maior e ricos em recursos naturais mantiveram as políticas protetivas, levando ao baixo amadurecimento do setor e afetando negativamente o crescimento.

O estudo de Sachs e Warner (1995) é reconhecido na literatura como uma das principais pesquisas empíricas sobre a MRN. Os autores analisaram o comportamento de variáveis comumente utilizadas nos estudos sobre crescimento econômico - como os investimentos, a política comercial, o nível de eficiência do governo e outras variáveis econômicas - nas evidências de MRN entre vários países. O principal resultado demonstra que, mesmo quando essas variáveis eram favoráveis ao crescimento econômico, a influência dos recursos naturais no desempenho da economia continuava adversa, ou seja, as evidências da MRN eram persistentes. 
Sachs e Warner (1997) destacam a necessidade de analisar o comportamento de variáveis representativas do capital humano, das características geográficas, da riqueza natural e das políticas econômicas no crescimento econômico. No teste empírico, os resultados confirmaram que as relações dessas variáveis são condizentes com o observado na literatura, destacando-se a relação inversa da riqueza natural com o crescimento econômico.

Sachs e Warner (1999) verificaram, ao analisarem se os efeitos de um aumento repentino (pelo aumento dos preços ou descoberta) nos recursos naturais levariam a um grande impacto no crescimento econômico, que, nos países da América Latina, os recursos naturais não se mostraram tão vantajosos assim. Em alguns países não houve aumento permanente do PIB per capita, e seguiu-se uma desaceleração do crescimento econômico. Em outros, até ocorreu um aumento do PIB, embora não tenha havido um aumento rápido do crescimento.

Nesse sentido, Sachs e Warner (2001) examinaram se as evidências da MRN entre países seriam persistentes ao serem consideradas variáveis omitidas que, potencialmente, explicariam o baixo crescimento econômico. Os autores verificaram que, embora as características geográficas e climáticas pudessem contribuir para o crescimento, as evidências da MRN eram persistentes. Eles concluíram também que os países ricos em recursos naturais tendiam a ter maior nível de preços e, como consequência parcial, as exportações do setor manufatureiro tendiam a ter menor papel no crescimento econômico.

Gylfason, Herbertsson e Zoega (1999) analisaram a relação entre o tamanho do setor primário, o nível educacional e o crescimento econômico entre países. Os autores perceberam que, quanto maior a dependência das exportações do setor primário e maior a força de trabalho desse setor, reduzida era, em dimensão e significância, a relação entre a taxa de matrículas na educação primária e secundária e o crescimento econômico.

Nesta mesma linha, Gylfason (2001) investigou como vários parâmetros educacionais são relacionados com a riqueza natural e o crescimento econômico entre países. Quando analisados os gastos públicos em educação, o nível de desenvolvimento educacional e a inclusão no sistema educacional, verificou-se que esses parâmetros eram inversamente relacionados com a intensidade da exploração dos recursos naturais. Para o autor, os países que acreditam nos recursos naturais como seu principal ativo podem desenvolver um falso sentimento de segurança e tornarem-se negligentes com a acumulação de capital humano.

Manzano e Rigobon (2001) examinaram como a dívida externa dos países foi afetada pela crise das commodities na década de 1980 e sua relação com a MRN. Os resultados mostram que, ao controlar pela dívida externa e por efeitos fixos decorrentes de variáveis não 
observáveis, a significante relação negativa dos recursos naturais com o crescimento econômico desaparecia. Para os autores, a MRN não surgia particularmente da dependência dos recursos naturais, mas sim da interação entre o mercado de créditos e a cobertura das dívidas, que levava a uma bolha, causando baixo crescimento econômico.

Apesar dos resultados encontrados por Manzano e Rigobon (2001), que, a princípio, refutariam as evidências da $\mathrm{MRN}$, pesquisas empíricas que incorporaram uma variável relacionada à dívida externa para controlar os efeitos da MRN - como visto, por exemplo, em Gylfason, Herbertson e Zoega (1999) e Papyrakis e Gerlagh (2007) -, além de utilizarem o controle por efeitos fixos - como em Anshasy (2011) -, ainda confirmam a relação negativa entre abundância de recursos naturais e crescimento econômico.

James (2015) investigou a relação entre a dependência de recursos naturais, o crescimento setorial e o crescimento econômico em 110 países. Os resultados apontam que os países mais dependentes tiveram crescimento mais lento em certos períodos, enquanto, em outros, o crescimento foi relativamente mais acelerado. Isso estaria mais relacionado com o desempenho do setor de recursos naturais e com variações nos preços do que com algum impacto nos setores não ligados aos recursos naturais.

Analisando especificamente o Brasil, Veríssimo e Xavier (2014) investigaram o efeito da exportação de tipos específicos de recursos naturais na taxa de câmbio real e no crescimento econômico brasileiro. Os resultados mostram que o choque nas exportações de commodities de alimentos, de matérias-primas, de minerais e de energia tem resposta negativa com taxa de crescimento do PIB (evidência da MRN). As commodities de alimentos, de matérias-primas e de energia tiveram resposta positiva para a taxa de câmbio ao longo do tempo (evidência da doença holandesa).

O estudo de Papyrakis e Gerlagh (2007) é um dos primeiros a estenderam a análise empírica da MRN para o nível intrapaís, tendo como objeto de estudo os estados dos EUA. Os resultados encontrados mostram que a MRN pode ser identificada considerando-se unidades diferentes pertencentes a um mesmo país, pois, nos estados com maior dependência dos recursos naturais, o crescimento era menor que nos demais. Além disso, nesses municípios, os investimentos, o nível de escolaridade, a abertura de mercado e os gastos com pesquisa e desenvolvimento eram menores, enquanto a corrupção era maior, contribuindo, assim, para um menor crescimento econômico.

James e Aadland (2011) investigaram a dependência do crescimento dos munícipios dos EUA em relação às rendas dos recursos naturais, controlando-se pela homogeneidade social, demografia populacional, capital humano e densidade populacional. A ideia é que 
localidades socialmente mais homogêneas, com maior densidade populacional, capacidade e qualificação da força de trabalho teriam custos de transações menores, facilitando o crescimento. Os resultados mostram que as evidências da MRN nos munícipios eram persistentes mesmo controlados por esses fatores, apesar da magnitude do impacto da MRN reduzir-se com o tempo.

Em relação aos estudos que focam predominantemente os fatores políticos e institucionais como determinantes dos impactos da $\mathrm{MRN}$, a ideia é que o efeito negativo das rendas dos recursos naturais no crescimento econômico se deve à estrutura que gerirá o fluxo das rendas dos recursos naturais, como a qualidade das instituições e as políticas de atuação. Dentro dessa abordagem apresentam-se os trabalhos de Papyrakis e Gerlagh (2004), Isham et al. (2005), Mehlum, Moene e Torvik (2006), Sala-i-Martin e Subramanian (2013), Busse e Gröning (2013), que analisaram a MRN sob a ótica da qualidade das instituições; e Alichi e Arezki (2009), Bleaney e Halland (2009), Atkinson e Hamilton (2003), Anshasy (2011) e Anshasy e Katsaiti (2015), cujos estudos foram feitos sob a perspectiva da política fiscal.

Papyrakis e Gerlagh (2004) ao estudarem os efeitos diretos e indiretos da exploração dos recursos naturais no crescimento econômico de 47 países, constataram que o efeito direto não era significativamente negativo quando se considerava o nível de corrupção, investimentos, abertura de mercado, termos de troca e escolaridade. Contudo, a riqueza em recursos naturais tinha efeito negativo direto sobre esses fatores, e, assim, acabava impactando negativa e indiretamente o crescimento.

Isham et al. (2005) analisaram o comportamento da dependência com os diferentes tipos de recursos naturais na qualidade das instituições e no crescimento econômico de 90 países. Os resultados mostram que a dependência de recursos de petróleo, minerais e de plantação de culturas estão associados com as piores instituições, o que reflete negativamente no crescimento, em comparação com a dependência pecuária, agrícola familiar e de café e cacau.

Mehlum, Moene e Torvik (2006) compararam os efeitos da qualidade das instituições na relação recursos naturais e crescimento econômico de 87 países. Os autores verificaram que, nos países com instituições fracas, a dependência de recursos naturais prejudicava o crescimento econômico; ao passo que, nos países com instituições mais fortes, elas próprias ajudavam a tirar o máximo de vantagem dos seus recursos naturais.

Sala-i-Martin e Subramanian (2013) investigaram a relação entre a dependência de recursos naturais, a qualidade das instituições e o crescimento econômico de 82 países. Os resultados indicam que alguns tipos de recursos naturais têm efeito negativo no crescimento 
por alterar a qualidade institucional. No caso, a dependência dos recursos minerais e do petróleo tinha maior impacto negativo no crescimento e nas instituições.

Busse e Gröning (2013), ao pesquisarem o impacto da riqueza em recursos naturais em vários indicadores de qualidade das instituições de 129 países desenvolvidos e em desenvolvimento, observaram que os recursos naturais impactavam negativamente a corrupção - sendo o impacto mais pronunciado nos países em desenvolvimento - e a qualidade da burocracia - embora a evidência não fosse robusta. Por fim, o estado de direito parecia não ser afetado pelos recursos naturais.

Atkinson e Hamilton (2003) examinaram os gastos públicos, a formação da poupança pública, a abundância em recursos naturais e o crescimento econômico entre 103 países. Os autores constataram que os gastos públicos em investimentos estavam associados positivamente com o crescimento nos países abundantes em recursos naturais. Os gastos públicos de consumo e com pessoal eram negativamente associados e, aparentemente, explicavam a MRN, uma vez que alteravam o sinal e a significância da variável de recursos naturais.

Alichi e Arezki (2009), ao investigarem o efeito dos gastos públicos no crescimento em países exportadores de petróleo, verificaram que o gasto público corrente reduziu o crescimento, enquanto o gasto de capital não provocou alterações nesse índice. Observaram, também, que, nos países com maior abertura de mercado, os efeitos negativos dos gastos correntes eram amenizados, o que corrobora a ideia de que os gastos correntes influenciam a acumulação de capital privado e de que a entrada de capital e produtos internacionais compensa essa influência.

Bleaney e Halland (2009) analisaram o efeito da qualidade da gestão fiscal e da dependência de recursos naturais no crescimento de 75 países. Os autores perceberam que a relação negativa dos gastos de consumo do governo com o crescimento era mais acentuada nos países altamente dependentes da exportação de recursos naturais, indicando que a volatilidade da política fiscal era um importante mecanismo de transmissão da MRN.

Anshasy (2011) investigou se a política fiscal explicaria a relação negativa entre a dependência de recursos naturais e o crescimento econômico em 16 países exportadores de petróleo. A autora verificou que o impacto das rendas do petróleo poderia ser uma maldição dependendo da política fiscal, principalmente da composição dos gastos públicos. Os resultados mostram que os gastos com salários retardam o crescimento de longo prazo e que os gastos de capital não apresentam relação com o crescimento. 
Anshasy e Katsaiti (2015) examinaram a relação entre a dependência de recursos naturais e os investimentos em saúde em 118 países. As autoras notaram uma associação positiva entre as exportações agrícolas e os gastos em saúde e a expectativa de vida. A mesma associação foi verificada entre a abundância de recursos minerais e os gastos em saúde. Contudo, a dependência dos recursos hidrocarbonetos estava associada negativamente com os serviços públicos de saúde, principalmente em países não democráticos.

No Brasil, a maioria das pesquisas que analisam o impacto das rendas dos recursos naturais foi realizada em nível municipal, com o foco sobre os royalties do petróleo. Os estudos de Cruz e Ribeiro (2009), Postali (2009) e Ribeiro, Teixeira e Gutierrez (2010) investigaram diretamente os efeitos da MRN nos municípios. Nos estudos que tangenciam a MRN, Postali e Nishijima (2011, 2013), Caçador e Monte (2013) e Caselli e Michaels (2013) abordam os impactos dos royalties nos indicadores de desenvolvimento; Bregman (2007), Postali e Rocha (2009) e Reis e Santana (2015) abordam como os royalties são aplicados; e Queiros e Postali (2010) e Postali (2012) tratam do efeito dos royalties no esforço fiscal.

O trabalho de Cruz e Ribeiro (2009) comparou a distribuição e alocação das compensações financeiras da atividade mineral, dos recursos hídricos e dos recursos petrolíferos no Brasil com a de outros países e com os efeitos da MRN. Os autores identificaram que a forma da previsão legal de distribuição e utilização das rendas dos recursos naturais pode levar à ocorrência da MRN no Brasil.

Postali (2009) examinou se a alteração na forma de transferência dos royalties do petróleo provocada pela promulgação da lei do petróleo impactou o crescimento econômico dos munícipios brasileiros. Os resultados encontrados confirmaram a ocorrência da MRN nos munícipios brasileiros no período entre 1996 e 2005, ou seja, os municípios que passaram a receber os royalties experimentaram um menor crescimento econômico a partir do ano 2000, em comparação com os demais municípios.

Ribeiro, Teixeira e Gutierrez (2010) examinaram como a política de distribuição dos royalties do petróleo impactou o PIB dos municípios do estado do Espírito Santo. Os autores encontraram que a política de transferência de rendas do petróleo para o setor público não teve impacto sobre o crescimento econômico dos municípios ao controlar os resultados por variáveis macroeconômicas comuns, como a taxa de câmbio, o risco Brasil e o PIB nacional.

Postali e Nishijima (2011) investigaram se os royalties do petróleo ocasionaram uma evolução nos indicadores de desenvolvimento sociais dos munícipios brasileiros. Os autores observaram que os indicadores sociais de saúde e educação dos munícipios ricos em recursos 
do petróleo não se diferenciavam dos indicadores dos demais municípios, enquanto o indicador de emprego e renda foi pior nos municípios com receitas advindas do petróleo.

De forma similar, o trabalho de Postali e Nishijima (2013) analisou se a distribuição das rendas do petróleo aos municípios brasileiros de acordo com a lei do petróleo contribuiu para uma melhoria nos indicadores sociais. Os resultados encontrados mostraram que as rendas do petróleo possibilitaram uma melhoria nos indicadores sociais ligados ao acesso à energia elétrica e à água encanada, bem como naqueles ligados à taxa de alfabetização. Ainda assim, os indicadores sociais dos municípios que receberam tais rendas eram menores do que os de outros municípios.

Caçador e Monte (2013) estudaram os impactos dos royalties do petróleo nos indicadores de desenvolvimento dos municípios do Espírito Santo. Os autores encontraram que os royalties não contribuíram significativamente para a melhoria dos indicadores de desenvolvimento total e de desenvolvimento do emprego e renda, entretanto o indicador de desenvolvimento da saúde foi um pouco melhor nos municípios que receberam os royalties.

Caselli e Michaels (2013) pesquisaram a contribuição dos royalties do petróleo para a melhoria no padrão de vida nos municípios. Os autores verificaram que os royalties aumentaram significativamente as receitas, com igual reflexo nos gastos em habitação e infraestrutura urbana, educação, saúde e transporte. Entretanto, esses aumentos não se refletiram em vários dos indicadores socioeconômicos ligados a tais gastos, como moradias, ruas pavimentadas, salas de aula, hospitais e transferências sociais.

Bregman (2007) investigou a distribuição e aplicação dos royalties do petróleo nos estados e municípios brasileiros mais dependentes dessa receita. Nessa amostra, os resultados sinalizaram que, enquanto nos estados a despesa de capital reduziu-se, nos municípios ela aumentou. No caso da despesa com overhead (despesas nas funções legislativa, judiciária, administração e planejamento), não houve alteração.

Postali e Rocha (2009) compararam o esforço fiscal entre os municípios brasileiros que recebem e não recebem receitas com exploração do petróleo. Os autores observaram que os municípios que receberam tais receitas diminuíram o esforço na arrecadação do IPTU. Os gastos públicos em investimentos aumentaram, enquanto que essas receitas não significaram uma mudança na composição dos gastos destinados à saúde, educação, energia e habitação.

Reis e Santana (2015) analisaram os efeitos da aplicação dos royalties do petróleo nos investimentos públicos dos municípios brasileiros no período de 1999 a 2011. Os autores verificaram que a despesa de capital aumentou nos municípios altamente dependentes e com 
maior volume de royalties, enquanto nos municípios que dependiam pouco desses recursos sua aplicação foi principalmente em despesa corrente.

Queiroz e Postali (2010) analisaram a relação entre a dependência dos royalties do petróleo e a eficiência tributária dos municípios brasileiros. Os resultados indicaram que os municípios mais dependentes dos royalties reduziram o esforço fiscal na arrecadação de receitas próprias, apresentando maior ineficiência técnica na coleta de impostos municipais, principalmente o IPTU.

O estudo de Postali (2012) avaliou a eficiência administrativa dos municípios brasileiros que recebem receitas pela exploração do petróleo sob a ótica da arrecadação fiscal e dos gastos públicos. Os resultados mostraram que o esforço fiscal dos municípios não foi afetado de forma positiva pelas receitas do petróleo; ao contrário, constatou-se que elas contribuíram para aumentar a ineficiência na gestão municipal.

Leite (2009) analisou a contribuição da compensação financeira de exploração de recursos minerais para o desenvolvimento dos municípios mineradores do estado de Minas Gerais. O autor encontrou que a compensação foi aplicada principalmente em gasto corrente dos municípios, além de gastos em administração, saneamento, saúde, urbanismo e assistência social, gestão ambiental e segurança pública.

Contrastando as pesquisas que observam evidências da MRN nos países, uma corrente de estudos tem apontado que os recursos naturais não seriam uma maldição ao se considerar na análise não a dependência, mas sim a abundância $^{1}$ dos recursos naturais (BRUNNSCHWEILER, 2008; BRUNNSCHWEILER; BULTE, 2008a, 2008b). Nessas pesquisas, a maldição constatada em alguns estudos seria decorrente de um erro de medida da variável de dependência de recursos naturais que levaria a problemas de endogeneidade com a variável de crescimento econômico, por isso sugerem que seja utilizada a variável de abundância em recursos naturais neste tipo de estudo (no apêndice A, isso é melhor explicado e como influenciou a variável de recursos naturais utilizada nesta pesquisa).

Brunnschweiler (2008) averiguou que a abundância de recursos naturais podia influenciar positivamente a qualidade das instituições e o crescimento econômico, embora, em algumas regiões (como a África e o Oriente Médio), o desempenho da economia possa ser pior do que em outras (Europa e Ásia Central). Brunnschweiler e Bulte (2008a) verificaram

\footnotetext{
1 A dependência representa o quanto os rendimentos dos recursos naturais fazem parte do total gerado na economia, isto é, a dependência da economia com os rendimentos de tais recursos. A medida de abundância está relacionada com o volume dos rendimentos gerados pelos recursos naturais, ou seja, com a riqueza gerada pela exploração desses recursos (BRUNNSCHWEILER, 2008; BRUNNSCHWEILER; BULTE, 2008b).
} 
que a abundância de recursos naturais tem efeito direto e significativamente positivo no crescimento econômico e indireto na redução de conflitos sociais. Brunnschweiler e Bulte (2008b) observaram que a abundância de recursos naturais estava associada positivamente com medidas de qualidade das instituições (estado de direito e a qualidade da burocracia e dos serviços públicos) e com o crescimento econômico. Também constataram que a abundância determinava a dependência e que esta não tinha associação com o crescimento.

Stijins (2005) investigou como os vários tipos de reservas de recursos naturais afetavam o crescimento econômico por meio de variados canais de transmissão, como infraestrutura política, política econômica, investimentos, educação, bem como pela doença holandesa. $\mathrm{O}$ autor verificou que a reserva de terras era negativamente associada com todos esses determinantes do crescimento econômico, na medida em que as reservas de óleo e gás, carvão e minerais estavam correlacionadas positivamente com a política econômica, os investimentos e a educação.

Seguindo os estudos de Brunnschweiler e Bulte, van der Ploeg e Poelhekke (2010), observaram também que, ao se incluírem na análise as reservas de recursos naturais, não haveria evidências da MRN, com um possível efeito positivo da dependência de recursos naturais. Contudo, constatou-se que essa dependência tinha relação positiva com a volatilidade dos canais de transmissão e, nos países com instituições fracas para se proteger da volatilidade dos preços de commodities, o efeito era negativo e indireto no crescimento.

Kennedy e Tiede (2013) constataram que a abundância de recursos petrolíferos estava relacionada positivamente com várias medidas de qualidade das instituições, como o estado de direito, a qualidade da regulação, a prestação de serviços públicos, a governança e a melhoria na qualidade de vida. Haber e Menaldo (2011) não encontraram evidências de que a abundância de recursos do petróleo estivesse relacionada com o estabelecimento de governos autoritários. Michaels (2011) observou que os municípios da região sul dos EUA abundantes nesse tipo de recurso tinham melhor crescimento econômico e educação da força de trabalho do que os demais municípios da mesma região.

O quadro 2.1 apresenta o resumo, em ordem cronológica, da amostra-período, das técnicas utilizadas e dos principais resultados encontrados nas pesquisas empirícias sobre a MRN. Das 43 pesquisas levantadas, a maioria (60\%) analisa países e 30\% municípios. Também, 44\% utilizaram a técnica de estimação por mínimos quadrados ordinários (OLS) e $19 \%$ por modelos efeitos fixos ou aleatórios e/ou de dois ou três estágios. 
Quadro 2.1 - Pesquisas empíricas sobre a MRN

\begin{tabular}{|c|c|c|c|c|}
\hline Pesquisa & Amostra & Período & Técnica & Principal Resultado \\
\hline Auty (1994) & Países & $\begin{array}{c}1950- \\
1989\end{array}$ & N.I. & $\begin{array}{l}\text { Países ricos em recursos naturais tendiam a } \\
\text { adotar políticas protecionistas }\end{array}$ \\
\hline Sachs e Warner (1995) & Países & $\begin{array}{c}1970- \\
1989\end{array}$ & OLS & $\begin{array}{l}\text { Países ricos em recursos naturais tinham } \\
\text { crescimento econômico menor }\end{array}$ \\
\hline Sachs e Warner (1997) & Países & $\begin{array}{c}1965- \\
1990\end{array}$ & OLS & $\begin{array}{l}\text { O capital humano, as características } \\
\text { geográficas e as políticas econômicas } \\
\text { favorecem o crescimento econômico, } \\
\text { diferentemente da riqueza natural }\end{array}$ \\
\hline $\begin{array}{l}\text { Gylfason, Herbertsson } \\
\text { e Zoega (1999) }\end{array}$ & Países & $\begin{array}{l}1960- \\
1992\end{array}$ & $\begin{array}{l}\text { Efeitos } \\
\text { Aleatórios }\end{array}$ & $\begin{array}{l}\text { Países dependentes das exportações do setor } \\
\text { primário tinham nível educacional e } \\
\text { crescimento econômico mais baixos }\end{array}$ \\
\hline Sachs e Warner (1999) & Países & $\begin{array}{c}1970- \\
1989\end{array}$ & OLS & $\begin{array}{l}\text { O boom nos recursos naturais (pelo aumento de } \\
\text { preços ou descoberta de jazidas) não aumentou } \\
\text { consistentemente o PIB per capita }\end{array}$ \\
\hline Gylfason (2001) & Países & $\begin{array}{l}1965- \\
1998\end{array}$ & SUR & $\begin{array}{l}\text { Países ricos em recursos naturais tinham gastos } \\
\text { públicos em educação, nível de } \\
\text { desenvolvimento educacional e inclusão no } \\
\text { sistema educacional menores }\end{array}$ \\
\hline $\begin{array}{l}\text { Manzano e Rigobon } \\
(2001)\end{array}$ & Países & $\begin{array}{c}1970- \\
1989\end{array}$ & $\begin{array}{l}\text { Efeitos } \\
\text { Fixos }\end{array}$ & $\begin{array}{l}\text { A MRN estava relacionada com o aumento das } \\
\text { dívidas externas e com a queda nos preços das } \\
\text { commodities }\end{array}$ \\
\hline Sachs e Warner (2001) & Países & $\begin{array}{c}1970- \\
1989\end{array}$ & OLS & $\begin{array}{l}\text { Países ricos em recursos naturais tendiam a ter } \\
\text { maior nível de preços e as exportações do setor } \\
\text { manufatureiro contribuíam menos para o } \\
\text { crescimento econômico }\end{array}$ \\
\hline $\begin{array}{l}\text { Atkinson e Hamilton } \\
(2003)\end{array}$ & Países & $\begin{array}{c}1980- \\
1995\end{array}$ & OLS & $\begin{array}{l}\text { Os gastos públicos em investimentos estavam } \\
\text { associados positivamente com o crescimento } \\
\text { nos países abundantes em recursos naturais, } \\
\text { diferentemente dos gastos de consumo e } \\
\text { pessoal }\end{array}$ \\
\hline $\begin{array}{l}\text { Papyrakis e Gerlagh } \\
(2004)\end{array}$ & Países & $\begin{array}{c}1975- \\
1996\end{array}$ & OLS & $\begin{array}{l}\text { A riqueza em recursos naturais tinha efeito } \\
\text { negativo direto sobre o nível de corrupção, } \\
\text { investimentos, abertura de mercado, termos de } \\
\text { troca e escolaridade; e indireto sobre o } \\
\text { crescimento econômico }\end{array}$ \\
\hline Isham et al. (2005) & Países & $\begin{array}{c}1957- \\
1997\end{array}$ & $\begin{array}{l}\text { OLS e } \\
\text { 3SLS }\end{array}$ & $\begin{array}{l}\text { Países dependentes dos recursos do petróleo, } \\
\text { dos recursos minerais e da plantação de } \\
\text { culturas estavam associados com instituições } \\
\text { de baixa qualidade }\end{array}$ \\
\hline Stijins (2005) & Países & $\begin{array}{c}1970- \\
1990\end{array}$ & OLS & $\begin{array}{l}\text { Os tipos de recursos naturais apresentavam } \\
\text { relações diferenciadas com os determinantes do } \\
\text { crescimento econômico; alguns tipos } \\
\text { contribuíram, enquanto outros não }\end{array}$ \\
\hline $\begin{array}{l}\text { Mehlum, Moene e } \\
\text { Torvik (2006) }\end{array}$ & Países & $\begin{array}{c}1965- \\
1990\end{array}$ & OLS & $\begin{array}{l}\text { Países com instituições fracas e dependentes de } \\
\text { recursos naturais tinham o crescimento } \\
\text { econômico prejudicado }\end{array}$ \\
\hline Bregman (2007) & $\begin{array}{l}\text { Estados e } \\
\text { municípios } \\
\text { brasileiros }\end{array}$ & $\begin{array}{c}1999- \\
2005\end{array}$ & OLS & $\begin{array}{l}\text { Nos estados mais dependentes dos royalties do } \\
\text { petróleo, a despesa de capital reduziu; enquanto } \\
\text { nos municípios essa despesa aumentou }\end{array}$ \\
\hline $\begin{array}{l}\text { Papyrakis e Gerlagh } \\
(2007)\end{array}$ & $\begin{array}{l}\text { Estados dos } \\
\text { EUA }\end{array}$ & $\begin{array}{c}1986- \\
2000\end{array}$ & OLS & $\begin{array}{l}\text { Nos estados com maior dependência de } \\
\text { recursos naturais, o crescimento econômico era } \\
\text { menor que nos demais }\end{array}$ \\
\hline Brunnschweiler (2008) & Países & $\begin{array}{c}1970- \\
2000\end{array}$ & $\begin{array}{l}\text { OLS e } \\
2 \mathrm{OLS}\end{array}$ & $\begin{array}{l}\text { A abundância de recursos naturais podia } \\
\text { influenciar positivamente a qualidades das } \\
\text { instituições e o crescimento econômico }\end{array}$ \\
\hline
\end{tabular}


Continuação do quadro 2.1

\begin{tabular}{|c|c|c|c|c|}
\hline $\begin{array}{l}\text { Brunnschweiler e } \\
\text { Bulte (2008a) }\end{array}$ & Países & $\begin{array}{l}1970- \\
2000\end{array}$ & $\begin{array}{l}\text { OLS e 2- } \\
\text { 3OLS }\end{array}$ & $\begin{array}{l}\text { A abundância de recursos naturais tinha efeito } \\
\text { direto e significativamente positivo no } \\
\text { crescimento econômico e indireto na redução } \\
\text { de conflitos sociais }\end{array}$ \\
\hline $\begin{array}{l}\text { Brunnschweiler e } \\
\text { Bulte (2008b) }\end{array}$ & Países & $\begin{array}{l}1970- \\
2000\end{array}$ & $\begin{array}{l}\text { OLS e 2- } \\
\text { 3OLS }\end{array}$ & $\begin{array}{l}\text { A abundância de recursos naturais estava } \\
\text { associada positivamente com medidas de } \\
\text { qualidade das instituições e com o crescimento } \\
\text { econômico }\end{array}$ \\
\hline Alichi e Arezki (2009) & $\begin{array}{c}\text { Países } \\
\text { exportadore } \\
\text { s de } \\
\text { petróleo } \\
\end{array}$ & $\begin{array}{l}1992- \\
2005\end{array}$ & $\begin{array}{l}\text { OLS e } \\
\text { GMM- } \\
\text { system }\end{array}$ & $\begin{array}{l}\text { Enquanto o gasto de capital não contribuiu para } \\
\text { o crescimento econômico, o gasto corrente } \\
\text { estava associado com o crescimento menor }\end{array}$ \\
\hline $\begin{array}{l}\text { Bleaney e Halland } \\
\text { (2009) }\end{array}$ & Países & $\begin{array}{l}1980- \\
2004\end{array}$ & OLS & $\begin{array}{l}\text { Nos países altamente dependentes de recursos } \\
\text { naturais, o gasto de consumo do governo estava } \\
\text { relacionado negativamente com o crescimento } \\
\text { econômico }\end{array}$ \\
\hline Cruz e Ribeiro (2009) & Brasil & $\begin{array}{l}2000- \\
2007\end{array}$ & N.I. & $\begin{array}{l}\text { A forma da previsão legal de distribuição e } \\
\text { utilização das rendas dos recursos naturais } \\
\text { pode levar à ocorrência da MRN no Brasil }\end{array}$ \\
\hline Leite (2009) & $\begin{array}{l}\text { Municípios } \\
\text { do estado } \\
\text { de Minas } \\
\text { Gerais }\end{array}$ & $\begin{array}{c}2000- \\
2006\end{array}$ & $\begin{array}{l}\text { Efeitos } \\
\text { Fixos }\end{array}$ & $\begin{array}{l}\text { A CFEM foi aplicada principalmente em gasto } \\
\text { corrente dos municípios, além de gastos em } \\
\text { administração, saneamento, saúde, urbanismo e } \\
\text { assistência social, gestão ambiental e segurança } \\
\text { pública }\end{array}$ \\
\hline Postali (2009) & $\begin{array}{l}\text { Municípios } \\
\text { brasileiros }\end{array}$ & $\begin{array}{c}1996- \\
2004\end{array}$ & $\begin{array}{l}\text { Differences } \\
\quad-\text { in }- \\
\text { differences }\end{array}$ & $\begin{array}{l}\text { Os municípios que passaram a receber os } \\
\text { royalties do petróleo em decorrência da } \\
\text { promulgação da Lei do Petróleo } \\
\text { experimentaram um crescimento econômico } \\
\text { menor em comparação com os demais } \\
\text { municípios }\end{array}$ \\
\hline Postali e Rocha (2009) & $\begin{array}{l}\text { Municípios } \\
\text { brasileiros }\end{array}$ & $\begin{array}{l}1999- \\
2005\end{array}$ & GMM & $\begin{array}{l}\text { Municípios com receitas da exploração do } \\
\text { petróleo reduziram o esforço na arrecadação } \\
\text { própria e aumentaram os gastos públicos em } \\
\text { investimentos, enquanto os gastos em saúde, } \\
\text { educação, energia e habitação não foram } \\
\text { alterados }\end{array}$ \\
\hline $\begin{array}{l}\text { Queiroz e Postali } \\
\text { (2010) }\end{array}$ & $\begin{array}{l}\text { Municípios } \\
\text { brasileiros }\end{array}$ & $\begin{array}{l}1999- \\
2005\end{array}$ & $\begin{array}{l}\text { Fronteiras } \\
\text { Estocásti- } \\
\text { cas }\end{array}$ & $\begin{array}{l}\text { Os municípios mais dependentes dos royalties } \\
\text { do petróleo reduziram o esforço fiscal na } \\
\text { arrecadação de receitas próprias }\end{array}$ \\
\hline $\begin{array}{l}\text { Ribeiro, Teixeira e } \\
\text { Gutierrez (2010) }\end{array}$ & $\begin{array}{l}\text { Municípios } \\
\text { do estado } \\
\text { do Espírito } \\
\text { Santo } \\
\end{array}$ & $\begin{array}{l}1999- \\
2004\end{array}$ & OLS & $\begin{array}{l}\text { A política de transferência de rendas do } \\
\text { petróleo para o setor público não teve impacto } \\
\text { sobre o crescimento econômico dos municípios }\end{array}$ \\
\hline $\begin{array}{l}\text { van der Ploeg e } \\
\text { Poelhekke (2010) }\end{array}$ & Países & $\begin{array}{l}1970- \\
2000\end{array}$ & 2-3OLS & $\begin{array}{l}\text { A dependência de recursos naturais tinha } \\
\text { relação positiva com a volatilidade dos canais } \\
\text { de transmissão da MRN e, nos países com } \\
\text { instituições fracas, o efeito era negativo e } \\
\text { indireto no crescimento }\end{array}$ \\
\hline Anshasy (2011) & Países & $\begin{array}{l}1970- \\
2000\end{array}$ & $\begin{array}{l}\text { Efeitos } \\
\text { Fixos }\end{array}$ & $\begin{array}{l}\text { A política fiscal relacionada com a composição } \\
\text { dos gastos públicos pode explicar a MRN em } \\
\text { países exportadores do petróleo }\end{array}$ \\
\hline $\begin{array}{l}\text { Haber e Menaldo } \\
\text { (2011) }\end{array}$ & Países & $\begin{array}{c}1972- \\
1999\end{array}$ & $\begin{array}{l}\text { Cointegra- } \\
\text { ção e } \\
\text { Efeitos } \\
\text { fixos } \\
\end{array}$ & $\begin{array}{l}\text { Não foram encontradas evidências de que a } \\
\text { abundância de recursos petrolíferos estivesse } \\
\text { relacionada com o estabelecimento de governos } \\
\text { autoritários }\end{array}$ \\
\hline $\begin{array}{l}\text { James e Aadland } \\
\text { (2011) }\end{array}$ & $\begin{array}{l}\text { Municípios } \\
\text { dos EUA }\end{array}$ & $\begin{array}{l}1980- \\
1995\end{array}$ & 2GLS & $\begin{array}{l}\text { A dependência de recursos naturais estava } \\
\text { relacionada com o menor crescimento dos } \\
\text { municípios }\end{array}$ \\
\hline
\end{tabular}


Continuação do quadro 2.1

\begin{tabular}{|c|c|c|c|c|}
\hline Michaels (2011) & $\begin{array}{l}\text { Municípios } \\
\text { da região } \\
\text { sul dos } \\
\text { EUA }\end{array}$ & $\begin{array}{c}1940- \\
1990\end{array}$ & $\begin{array}{l}\text { Efeitos } \\
\text { Fixos }\end{array}$ & $\begin{array}{l}\text { Os municípios abundantes em recursos } \\
\text { petrolíferos tinham melhor crescimento } \\
\text { econômico e educação da força de trabalho do } \\
\text { que os demais municípios da mesma região }\end{array}$ \\
\hline $\begin{array}{l}\text { Postali e Nishijima } \\
\text { (2011) }\end{array}$ & $\begin{array}{l}\text { Municípios } \\
\text { brasileiros }\end{array}$ & $\begin{array}{l}2000- \\
2007\end{array}$ & $\begin{array}{l}\text { Efeitos } \\
\text { Fixos }\end{array}$ & $\begin{array}{l}\text { Os indicadores sociais de saúde e educação dos } \\
\text { munícipios ricos em recursos petrolíferos não } \\
\text { se diferenciavam dos apontados pelos demais } \\
\text { municípios, embora o indicador de emprego e } \\
\text { renda tenha sido pior }\end{array}$ \\
\hline Postali (2012) & $\begin{array}{l}\text { Municípios } \\
\text { brasileiros }\end{array}$ & $\begin{array}{l}2002- \\
2009\end{array}$ & $\begin{array}{l}\text { DEA e } \\
\text { Fronteiras } \\
\text { Estocásticas }\end{array}$ & $\begin{array}{l}\text { As receitas do petróleo não afetaram o esforço } \\
\text { fiscal dos municípios, embora tenham } \\
\text { contribuído para aumentar as ineficiências na } \\
\text { gestão municipal }\end{array}$ \\
\hline $\begin{array}{l}\text { Busse e Gröning } \\
\text { (2013) }\end{array}$ & Países & $\begin{array}{l}1984- \\
2007\end{array}$ & 2GMM & $\begin{array}{l}\text { Os recursos naturais impactavam } \\
\text { negativamente a corrupção, sendo este impacto } \\
\text { mais pronunciado nos países em } \\
\text { desenvolvimento }\end{array}$ \\
\hline $\begin{array}{l}\text { Caçador e Monte } \\
(2013)\end{array}$ & $\begin{array}{l}\text { Municípios } \\
\text { do estado } \\
\text { do Espírito } \\
\text { Santo }\end{array}$ & $\begin{array}{l}2000- \\
2009\end{array}$ & GLS & $\begin{array}{l}\text { Os royalties do petróleo não contribuíram para } \\
\text { a melhoria dos indicadores de desenvolvimento } \\
\text { total e do emprego e renda, embora o indicador } \\
\text { de saúde tenha sido um pouco melhor }\end{array}$ \\
\hline $\begin{array}{l}\text { Caselli e Michaels } \\
\text { (2013) }\end{array}$ & $\begin{array}{l}\text { Municípios } \\
\text { brasileiros }\end{array}$ & $\begin{array}{l}1991- \\
2000\end{array}$ & OLS & $\begin{array}{l}\text { Os royalties do petróleo aumentaram a receita e } \\
\text { os gastos em habitação e infraestrutura urbana, } \\
\text { educação, saúde e transporte, embora os } \\
\text { indicadores socioeconômicos não tenham } \\
\text { melhorado }\end{array}$ \\
\hline $\begin{array}{l}\text { Kennedy e Tiede } \\
(2013)\end{array}$ & Países & $\begin{array}{c}\text { Vários - } \\
2008\end{array}$ & EBA & $\begin{array}{l}\text { A abundância em recursos petrolíferos estava } \\
\text { relacionada positivamente com várias medidas } \\
\text { de qualidade das instituições }\end{array}$ \\
\hline $\begin{array}{l}\text { Postali e Nishijima } \\
\text { (2013) }\end{array}$ & $\begin{array}{l}\text { Municípios } \\
\text { brasileiros }\end{array}$ & $\begin{array}{l}1991- \\
2010\end{array}$ & $\begin{array}{l}\text { Differences } \\
\quad-\text { in - } \\
\text { differences }\end{array}$ & $\begin{array}{l}\text { As rendas do petróleo contribuíram para uma } \\
\text { melhoria em alguns indicadores sociais, } \\
\text { embora os indicadores fossem menores do que } \\
\text { nos demais municípios }\end{array}$ \\
\hline $\begin{array}{l}\text { Sala-i-Martin e } \\
\text { Subramanian (2013) }\end{array}$ & Países & $\begin{array}{l}1970- \\
1998\end{array}$ & 2OLS & $\begin{array}{l}\text { O efeito negativo de alguns tipos de recursos } \\
\text { naturais no crescimento econômico estava } \\
\text { relacionado com a qualidade das instituições }\end{array}$ \\
\hline $\begin{array}{l}\text { Veríssimo e Xavier } \\
\text { (2014) }\end{array}$ & Brasil & $\begin{array}{l}1999- \\
2011\end{array}$ & VAR & $\begin{array}{l}\text { O choque nas exportações de algumas } \\
\text { commodities teve resposta negativa com a taxa } \\
\text { de crescimento do PIB brasileiro }\end{array}$ \\
\hline $\begin{array}{l}\text { Anshasy e Katsaiti } \\
(2015)\end{array}$ & Países & $\begin{array}{l}1985- \\
2008\end{array}$ & $\begin{array}{l}\text { Efeitos } \\
\text { Fixos e } \\
\text { GLS }\end{array}$ & $\begin{array}{l}\text { Países ricos em exportações agrícolas e em } \\
\text { recursos minerais tinham gastos maiores em } \\
\text { saúde, enquanto nos países dependentes de } \\
\text { recursos hidrocarbonetos e não democráticos os } \\
\text { serviços de saúde pública eram piores }\end{array}$ \\
\hline James (2015) & Países & $\begin{array}{c}1970- \\
2010\end{array}$ & OLS & $\begin{array}{l}\text { Países dependentes de recursos naturais tinham } \\
\text { crescimento econômico menor em alguns } \\
\text { períodos em decorrência, principalmente, das } \\
\text { oscilações nos preços }\end{array}$ \\
\hline Reis e Santana (2015) & $\begin{array}{l}\text { Municípios } \\
\text { brasileiros }\end{array}$ & $\begin{array}{c}1999- \\
2001\end{array}$ & $\begin{array}{c}\text { Efeitos } \\
\text { Aleatórios }\end{array}$ & $\begin{array}{l}\text { Municípios altamente dependentes e com maior } \\
\text { volume de royalties do petróleo aumentaram a } \\
\text { despesa de capital, enquanto os municípios } \\
\text { com baixa dependência aumentaram a despesa } \\
\text { corrente }\end{array}$ \\
\hline
\end{tabular}

Legenda: N.I. - Não Informado; OLS - Ordinary Least Square (Mínimos Quadrados Ordinários); 2-3OLS - OLS em 2 e/ou 3 estágios; GLS - Generalized Least Square (Mínimos Quadrados Generalizados); 2GLS - GLS em 2 estágios; SUR - Seemingly Unrelated Regression (Regressões aparentemente não relacionadas); VAR - Vetores Auto-Regressivos;

GMM - Generalized Method of Moments (Método de Momentos Generalizados); 2GMM - GMM em 2 estágios; GMMsystem - GMM-sistema; EBA - Extreme Bounds Analysis. 


\subsection{Arcabouço Teórico sobre a Produtividade do Gasto Público}

Nos estudos sobre a relação entre os gastos públicos e o crescimento econômico, analisa-se essa vinculação por meio da produtividade do gasto. As discussões sobre esse assunto alavancaram-se, notadamente, no início de 1990, com o estudo seminal de Barro (1990) sobre gastos públicos e modelos de crescimento endógeno. Embora pouco antes, em um dos primeiros trabalhos sobre a produtividade dos gastos públicos, Aschauer (1989) tenha demonstrado que, para a economia dos Estados Unidos, a acumulação de capital e os gastos públicos em bens e serviços poderiam levar a um aumento da produtividade do capital privado.

Nessa linha e observando a situação entre países, Barro (1990) considera que o crescimento econômico depende da produtividade do capital privado e que este e o gasto público são complementares. A produtividade envolveria acréscimo de retorno dos insumos privados se os insumos governamentais expandissem de forma paralela. Dessa forma, o gasto público seria um input para a produtividade privada e esta produtividade geraria uma relação positiva entre o gasto e o crescimento. O input do gasto na produtividade do capital privado ocorreria principalmente pelo fortalecimento do capital humano e pela sustentação dos direitos de propriedade, a fim de garantir o investimento privado (BARRO, 1990).

Nos estudos que seguem o modelo de Barro, os gastos públicos produtivos são definidos a priori pela sua relação teórica com a produtividade do capital. Se o gasto público entra como argumento na função de produtividade do setor privado, então este é classificado como produtivo, tendo, assim, um efeito direto na taxa de crescimento (KNELLER; BLEANEY; GEMMELL, 1999). De forma geral destacam-se como produtivos os gastos com defesa, educação, saúde, habitação transporte e comunicação, como visto em Aschauer (1989), Barro (1991), Kneller, Bleaney e Gemmell (1999), Bleaney, Gemmell e Kneller (2001) e Bayraktar e Moreno-Dodson (2010).

$\mathrm{Na}$ mesma linha destes estudos, Devarajan, Swaroop e Zou (1996) demonstram a diferença entre os gastos produtivos e improdutivos pela forma como uma mudança na composição desses dois tipos de gastos altera a taxa de crescimento de longo prazo da economia, ou seja, não é definido previamente qual gasto é produtivo ou não; a resposta é obtida pelo comportamento da composição orçamentária dos gastos no crescimento. Nesse modelo, o resultado de uma economia, y, é função do estoque de capital privado, k, e dois tipos de gastos públicos, g1 e g2, sendo o primeiro produtivo e o segundo improdutivo: $y=f(k, g 1, g 2)$. Os autores assumem que os gastos públicos são financiados a partir da 
cobrança de uma taxa fixa de impostos sobre a renda $(\tau)$ : $\tau y=g 1+g 2$. Ainda, considerando-se no modelo que o governo é obrigado a executar um orçamento equilibrado, a parcela do gasto público total vai para $\mathrm{g} 1=\varnothing \tau y$. Logo, a parcela do gasto total para $\mathrm{g} 2$ $=(1-\emptyset) \tau y$, para $(0 \leq \emptyset \leq 1)$.

Após derivações entre a taxa de crescimento da economia e a parcela do gasto destinado a g1, o gasto produtivo é definido como aquele no qual a parcela do gasto total irá aumentar a taxa de crescimento estacionário da economia. Ainda, os autores destacam que, para uma mudança na composição do gasto aumentar a taxa de crescimento, dependeria não apenas da produtividade de cada um dos dois componentes do gasto, mas também do valor inicial da parcela de cada componente. Mesmo em uma mudança favorável à composição do gasto mais produtivo, se a parcela deste no gasto total for muito elevada, poderá não haver um aumento da taxa de crescimento.

Para que um aumento na parcela do gasto produtivo leve a um aumento na taxa de crescimento, a parcela relativa entre o gasto produtivo e o gasto improdutivo deve estar abaixo da elasticidade relativa dos dois tipos de gastos: $\frac{\emptyset}{1-\varnothing}<\frac{\beta}{\gamma}$, sendo $\emptyset$ e $1-\emptyset$ a parcela do gasto produtivo e do gasto improdutivo; $\beta$ e $\gamma$ a elasticidade do gasto produtivo e do gasto improdutivo, respectivamente. Assim, mesmo que a elasticidade do gasto produtivo seja maior que a do gasto improdutivo, isso não seria condição suficiente para um aumento na taxa de crescimento se as parcelas relativas dos gastos estiverem acima da elasticidade relativa.

Também, considerando-se a elasticidade de substituição entre o gasto produtivo e o gasto não produtivo, um aumento na parcela dos gastos produtivos levaria a um aumento na taxa de crescimento quanto mais substituível fossem os dois tipos de gastos. Ao contrário, um aumento na parcela do gasto produtivo poderá não ter o mesmo efeito sobre a taxa de crescimento se a elasticidade de substituição for baixa, mesmo que a parcela inicial do gasto seja pequena.

Nesse sentido, conseguiria-se um aumento da taxa de crescimento econômico por meio do gasto produtivo sem que isso implicasse necessariamente um aumento do gasto público total. Para tanto, sendo o aumento do gasto público total financiado por impostos em igual montante, o aumento da taxa de crescimento em estado estacionário será alcançado se a produtividade do gasto exceder o peso morto da arrecadação necessária para financiá-lo.

Ampliando o estudo de Devarajan, Swaroop e Zou (1996), Ghosh e Gregoriou (2008) definiram uma composição ótima do gasto público que pudesse levar a um aumento no crescimento. Numa solução ótima, um aumento no gasto mais produtivo leva à redução da 
taxa de impostos (tamanho do governo), pois o output seria maior (na função de produção), aumentando a arrecadação e necessitando de alíquotas de impostos menores para equilibrar o orçamento do governo. Assim, uma taxa de impostos mais baixa exerceria menor pressão sobre o capital privado, levando a um aumento do crescimento.

Para Chen (2006), a composição ótima do gasto público é determinada por fatores como o tamanho do governo (político), a oferta de bens e serviços públicos e a demanda do consumo privado (econômicos). Numa solução ótima, esses fatores aumentariam a utilidade marginal do consumo privado relativa à utilidade marginal do consumo público (designado como gasto não produtivo), permitindo que o governo tenha mais dinheiro para os investimentos públicos (produtivo), conduzindo ao aumento do crescimento.

Em consonância com estes estudos, Moreno-Dodson (2008) aponta alguns fatores que levam o gasto público a exercer influência positiva no crescimento econômico. Para a autora, o contexto político deve permitir uma estabilidade macroeconômica de forma sustentável. O tamanho do orçamento do governo deve ser relativamente pequeno, de forma a evitar riscos para a estabilidade fiscal e para a eficácia do governo. Devem ser priorizados, também, o setor privado nacional e as operações estrangeiras, a fim de alavancar o capital físico e humano, e, assim, permitir que a definição da composição do gasto público seja direcionada para as atividades produtivas que mais contribuem para o crescimento.

Nesse sentido, Cândido Jr. (2001) aponta algumas medidas que afetam a produtividade dos gastos públicos: 1) os investimentos públicos devem ser alocados nos setores que geram externalidades positivas e não devem competir com os investimentos privados, mas sim complementá-los; 2) os programas de subsídios e transferências devem estar adequadamente localizados, a fim de reduzir distorções; 3) os gastos em educação primária devem ser a maior proporção dos gastos totais em educação; 4) o aumento nos gastos em saúde, em saneamento básico etc. torna a população mais saudável, fortalecendo a força de trabalho; 5) nos programas sociais, os gastos nas atividades-meio geram ineficiências, devendo ser priorizados os gastos nas atividades-fim.

\subsection{Pesquisas empíricas sobre gastos públicos e crescimento}

Em geral, os estudos empíricos entre países que relacionam políticas fiscais e crescimento econômico tendem a observar ou o comportamento do tamanho total do governo, ou a despesa pública em diferentes níveis de agregação ou a taxa de crescimento dos gastos públicos no crescimento (LEVIN; RENELT, 1992). 
Nos estudos sobre os gastos públicos, geralmente o tamanho do governo, dado pela dimensão dos gastos públicos, é apontado como fator que impede o crescimento econômico. Isso ocorreria porque um maior nível do gasto total do governo teria que ser financiado com mais impostos distorcionários ${ }^{2}$, que tendem a reduzir a acumulação de capital do setor privado e, assim, influenciam negativamente o crescimento. Entretanto, esse efeito negativo seria esperado se o tamanho do governo excedesse certo limite desejável ou ainda se a produtividade do gasto público for menor que o peso da tributação sobre o setor privado (BARRO, 1990; DEVARAJAN; SWAROOP; ZOU, 1996).

As evidências encontradas são variadas quanto ao efeito do gasto público (tamanho do governo) no crescimento. Levine e Renelt (1992) verificaram, para uma amostra mista de países desenvolvidos e em desenvolvimento, que o nível do gasto era negativamente associado com o crescimento, essa associação, porém, não era significativa. Fölster e Henrekson (2001, 2006) e Agell, Ohlsson e Thoursie (2006) observaram uma relação negativa em países ricos, entretanto para os primeiros autores essa relação foi significativa, enquanto para os segundos não. Devarajan, Swaroop e Zou (1996) e Ghosh e Gregoriou (2008) verificaram uma relação positiva em países em desenvolvimento, sendo a relação não significativa e significativa, respectivamente.

Alexiou (2009) verificou que o gasto público em formação de capital era positiva e fortemente associado com o crescimento econômico de países do sudeste europeu. OtengAbayie (2011) não encontrou relação entre os gastos públicos e o crescimento econômico de cinco países africanos. No Brasil, Rocha e Giuberti (2007), - investigando os estados -, e Divino e Silva Jr. (2012) - investigando os municípios -, identificaram relação positiva, mas significativa apenas para os municípios.

Segundo Fölster e Henrekson (2001), o comportamento do nível dos gastos públicos em países ricos está ligado com a tendência de aumento do escopo do governo quando o nível de renda é maior - conhecida como Lei de Wagner -, embora essa relação seja fraca quando a renda é maior. Além disso, os autores argumentam que a composição dos gastos públicos difere entre os países; os que, teoricamente, têm associação positiva com o crescimento compõem uma menor parcela do gasto público total nos países ricos comparativamente aos países pobres.

Assim, tendo em vista que medidas agregadas de tamanho do governo podem não capturar as implicações potenciais de como os gastos públicos são alocados (LEVIN;

\footnotetext{
2 Tradução comumente encontrada na literatura econômica nacional para distortionary taxation. Significa tributação sobre a renda, a propriedade, a folha de pagamento etc.
} 
RENELT, 1992), os estudos têm investigado como os gastos públicos em diferentes níveis de agregação se relacionam com o crescimento econômico. O quadro 2.2 apresenta, ao final desta seção, uma síntese das pesquisas empíricas a seguir dispostas sobre esse assunto.

Aschauer (1989) verificou que os gastos públicos, principalmente os gastos com bens e serviços e com pagamento de pessoal, poderiam ter efeitos compensatórios sobre a produtividade do setor privado dos EUA no período de 1949 a 1985. Entretanto, os gastos com investimentos em infraestrutura - especificamente ruas, rodovias, aeroportos, transporte de massa e outros capitais - seriam os mais produtivos, pois tinham maior poder de explicação da produtividade do setor privado daquele país.

Barro (1991) verificou que, para uma amostra de países desenvolvidos e em desenvolvimento, a despesa de consumo do governo era negativa e significativamente associada com o crescimento. Assim, ela não teria efeito direto na produtividade do capital privado, pois reduziria apenas a poupança e o crescimento através de efeitos distorcidos na tributação e nos gastos em programas de governo. Ao contrário, os gastos em educação e defesa seriam mais prováveis de contribuir para a produtividade do setor privado, pois estavam relacionados ao capital humano e à garantia dos direitos de propriedade.

Kneller, Bleaney e Gemmell (1999) e Bleaney, Gemmell e Kneller (2001) analisaram como a política fiscal relacionada à tributação e os gastos públicos se relacionavam com o crescimento econômico de 22 países desenvolvidos. Os autores verificaram que os gastos com serviços públicos gerais - defesa, educação, saúde, habitação, transporte e comunicação influenciavam positivamente o crescimento econômico. Já os gastos com previdência social, recreação e serviços econômicos não apresentavam relação com o crescimento; ao contrário: a tributação distorcionária tinha uma relação negativa com o crescimento.

Devarajan, Swaroop e Zou (1996), ao investigarem o comportamento do gasto público em países em desenvolvimento, observaram que o gasto de capital era negativa e significativamente associado com o crescimento, diferentemente do gasto corrente, que era fracamente positivo e significante. Os gastos totais com defesa, infraestrutura, educação e saúde eram negativamente relacionados com o crescimento, embora, nos dois últimos, essa relação fosse não significativa. Para os autores, fatores como o excesso de gasto em uma rubrica e a incorreta alocação dos gastos públicos podem tornar o gasto improdutivo.

Similarmente, em pesquisa realizada com países em desenvolvimento, Ghosh e Gregoriou (2008) observaram o mesmo comportamento dos gastos de capital, corrente, em saúde e em educação que Devarajan, Swaroop e Zou; entretanto os dois últimos gastos apresentaram relação significante (ao contrário do primeiro estudo). Para os autores, esses 
resultados podem estar relacionados a distorções nas estruturas de incentivos, a ineficiências burocráticas, à corrupção e a gastos em serviços públicos de baixa qualidade.

Já Bose, Haque e Osborn (2007) encontram que os gastos públicos de capital e os gastos desagregados relacionados com os gastos totais e com os investimentos em educação contribuem positivamente para o crescimento econômico em países em desenvolvimento. Os gastos correntes e os gastos desagregados em defesa e transporte e comunicação, embora tivessem associação positiva, não eram robustamente significantes no crescimento econômico.

Moreno-Dodson (2008) analisou o comportamento dos gastos públicos em sete países em desenvolvimento com os maiores crescimentos econômicos. Foi verificado efeito positivo dos gastos econômicos ${ }^{3}$ no curto e médio prazo, enquanto os gastos sociais ${ }^{4}$ não tiveram relação significativa com o crescimento. Os gastos classificados a priori como produtivos ${ }^{5}$ foram os mais relevantes para o crescimento, principalmente no médio prazo, enquanto os gastos improdutivos ${ }^{6}$ não foram significantes. Os gastos em educação e saúde também tiveram grande impacto positivo no crescimento de curto e médio prazo.

Da mesma forma, Bayraktar e Moreno-Dodson (2010) e Moreno-Dodson e Bayraktar (2011) compararam o comportamento dos gastos públicos entre dois grupos de países em desenvolvimento: um grupo de países com crescimento rápido e outro com diferentes taxas de crescimento. Os autores verificaram que o componente de gastos classificados como produtivos $^{3}$ era positivo e significante para o primeiro grupo de países, mas não para o segundo.

Ogundipe e Oluwatobi (2013), ao analisarem o comportamento dos gastos públicos na Nigéria, encontraram que os gastos com questões administrativas, com serviços econômicos e com transferências tiveram impacto negativo e não significativo no crescimento. Os gastos em saúde e educação, embora impactassem positivamente o crescimento, também não foram significativos. Para os autores, os gastos públicos não têm contribuído para o crescimento econômico devido à corrupção, a projetos sem utilidade (“elefantes brancos”) e a projetos sem continuidade.

Ferreira (1996) e Ferreira e Malliagros (1998) verificaram que nos 1970-80 a redução abrupta nos investimentos em infraestrutura e os gastos públicos com serviços precários

\footnotetext{
${ }^{3}$ Gastos públicos econômicos: combustível e energia; agricultura, silvicultura, pesca e caça; mineração, recursos minerais, fabricação e construção; transporte e comunicação; e outros assuntos e serviços econômicos.

${ }^{4}$ Gastos públicos sociais: educação; saúde; previdência e assistência social; habitação e questões comunitárias; e questões recreativas, culturais e religiosas.

${ }^{5}$ Gastos produtivos: serviços públicos gerais; defesa; educação; saúde; habitação; e transporte e comunicação.

${ }^{6}$ Gastos improdutivos: previdência social e bem-estar, lazer e outros serviços econômicos.
} 
foram um forte limitador das perspectivas de crescimento da economia brasileira. Observaram, contudo, que os gastos em infraestrutura - principalmente os gastos nos setores de energia e transporte - contribuem com o crescimento de longo prazo.

Também examinando a situação brasileira, Cândido Jr. (2001) identificou que os gastos com consumo e transferências do governo tinham efeito negativo e significativo no crescimento, ao contrário dos gastos em investimentos, que tinham efeito positivo e significativo. Observou também que o gasto público total tinha impacto positivo no curto prazo, embora esse efeito se revertesse a longo prazo. O autor sugere que a política fiscal tem efeitos distorcivos para os gastos públicos, na forma de transferências de recursos do setor mais produtivo para o menos produtivo, comprometendo, assim, o crescimento.

Rodrigues e Teixeira (2010) investigaram como os gastos públicos federais, estaduais e municipais contribuíam para o crescimento econômico brasileiro. Os autores encontraram que os gastos em investimentos tinham maior efeito positivo para o crescimento, ao contrário dos gastos com consumo, subsídios e transferências; e, ainda, que os gastos realizados pelos estados contribuíam mais para o crescimento do país do que os demais.

Rocha e Giuberti (2007) averiguaram que, nos estados brasileiros, tanto os gastos de capital quanto os gastos correntes estavam relacionados positiva e não linearmente com o crescimento econômicos, indicando, assim, um ponto ótimo, em que esses gastos contribuíam favoravelmente para este. Os gastos com defesa, educação e saúde também tinham relação positiva com o crescimento.

Em pesquisas também realizadas com estados brasileiros, Silva e Santolin (2012) verificaram que o crescimento dos gastos em custeio tinha efeito total nulo sobre o crescimento econômico. Por outro lado, o crescimento dos gastos em investimentos, infraestrutura e desenvolvimento urbano tinha efeito positivo e significativo. O mesmo efeito foi observado com os gastos de capital humano e com a manutenção administrativa, embora estes não contribuíssem significativamente para a produtividade do setor privado.

Divino e Silva Jr. (2012) observaram que o gasto corrente do governo estava associado negativamente ao crescimento dos municípios brasileiros, exceto nos municípios que se situavam abaixo da linha de pobreza, nos quais a associação era positiva. Da mesma forma, os autores encontraram relação não linear entre os gastos correntes e o crescimento, confirmando que esses gastos têm maior relevância nos municípios abaixo da linha de pobreza

Silva, Cruz e Irffi (2013) verificaram que, nos municípios do estado da Paraíba, a maior contribuição para o crescimento vinha dos gastos com a função legislativa. Os gastos em educação e cultura, saúde e saneamento e habitação e urbanismo também tinham efeito 
positivo, embora a contribuição fosse menor. Os gastos com segurança pública, administração e planejamento e assistência e previdência social não tinham efeito significativo no crescimento.

Bogoni, Hein e Beuren (2011), ao investigarem os maiores municípios da região Sul, averiguaram que os gastos em saúde, saneamento, educação, cultura, investimento, habitação, assistência e previdência social tinham relação positiva com o crescimento. Forlin e Rodrigues (2012), pesquisando os municípios do estado de São Paulo, observaram que tanto o gasto corrente quanto o gasto em investimento tinham relação positiva com o crescimento econômico.

O quadro 2.2 apresenta o resumo, em ordem cronológica, das pesquisas empirícias sobre a produtividade do gasto público. Das 21 pesquisas levantadas, $71 \%$ tem como objeto de estudo países e $24 \%$, municípios. O método de estimação mais utilizado foi o de mínimos quadrados ordinários (OLS), presente em $43 \%$ das pesquisas, seguido do método de momentos generalizados (GMM), em 29\%, e LSDV, em $19 \%$.

Quadro 2.2 - Pesquisas empíricas sobre a produtividade do gasto público

\begin{tabular}{|c|c|c|c|c|}
\hline Pesquisa & Amostra & Período & Técnica & Principal(is) resultado(s) \\
\hline $\begin{array}{l}\text { Aschauer } \\
(1989)\end{array}$ & Estados Unidos & $\begin{array}{c}1949- \\
1985\end{array}$ & OLS & $\begin{array}{l}\text { Os gastos públicos em bens e serviços e pessoal } \\
\text { influenciavam negativamente a produtividade do } \\
\text { setor privado, diferentemente dos gastos com } \\
\text { investimento em infraestrutura }\end{array}$ \\
\hline Barro (1991) & Países & $\begin{array}{c}1960- \\
1985\end{array}$ & OLS & $\begin{array}{l}\text { O gasto de consumo do governo era negativamente } \\
\text { relacionado com o crescimento econômico, } \\
\text { reduzindo a produtividade do capital privado, ao } \\
\text { contrário do gasto em educação e defesa }\end{array}$ \\
\hline $\begin{array}{l}\text { Devarajan, } \\
\text { Swaroop e Zou } \\
(1996)\end{array}$ & $\begin{array}{c}\text { Países em } \\
\text { desenvolvimento }\end{array}$ & $\begin{array}{c}1970- \\
1990\end{array}$ & $\begin{array}{l}\text { Efeitos } \\
\text { Fixos }\end{array}$ & $\begin{array}{l}\text { O gasto de capital era negativamente associado com } \\
\text { o crescimento econômico, diferentemente do gasto } \\
\text { corrente }\end{array}$ \\
\hline $\begin{array}{l}\text { Ferreira (1996) } \\
\text { e Ferreira e } \\
\text { Malliagros } \\
(1998)\end{array}$ & Brasil & $\begin{array}{c}1970- \\
1993 / \\
1950- \\
1995\end{array}$ & $\begin{array}{l}\text { VAR / } \\
\text { Co-inte- } \\
\text { gração }\end{array}$ & $\begin{array}{l}\text { Os gastos em infraestrutura contribuem com o } \\
\text { crescimento de longo prazo, principalmente os } \\
\text { gastos nos setores de energia e transporte }\end{array}$ \\
\hline $\begin{array}{l}\text { Kneller, } \\
\text { Bleaney e } \\
\text { Gemmell } \\
(1999) \text { e } \\
\text { Bleaney, } \\
\text { Gemmell e } \\
\text { Kneller (2001) }\end{array}$ & $\begin{array}{c}\text { Países } \\
\text { desenvolvidos }\end{array}$ & $\begin{array}{c}1970- \\
1995\end{array}$ & LSDV & $\begin{array}{l}\text { Os gastos com serviços públicos gerais, defesa, } \\
\text { educação, saúde, habitação, transporte e } \\
\text { comunicação tinham relação positiva com o } \\
\text { crescimento econômico }\end{array}$ \\
\hline $\begin{array}{l}\text { Cândido Jr. } \\
\text { (2001) }\end{array}$ & Brasil & $\begin{array}{c}1947- \\
1995\end{array}$ & $\begin{array}{l}\text { Modelos } \\
\text { Auto-re- } \\
\text { grecivos }\end{array}$ & $\begin{array}{l}\text { Os gastos com consumo e transferências do governo } \\
\text { tinham efeito negativo e significativo no } \\
\text { crescimento econômico, ao contrário dos gastos em } \\
\text { investimentos }\end{array}$ \\
\hline $\begin{array}{l}\text { Bose, Haque e } \\
\text { Osborn (2007) }\end{array}$ & $\begin{array}{c}\text { Países em } \\
\text { desenvolvimento }\end{array}$ & $\begin{array}{c}1970- \\
1990\end{array}$ & SUR & $\begin{array}{l}\text { Os gastos correntes e os gastos em defesa e } \\
\text { transporte e comunicação tinham associação } \\
\text { positiva com o crescimento econômico }\end{array}$ \\
\hline
\end{tabular}


Continuação do quadro 2.2

\begin{tabular}{|c|c|c|c|c|}
\hline $\begin{array}{l}\text { Rocha e } \\
\text { Giuberti (2007) }\end{array}$ & $\begin{array}{c}\text { Estados } \\
\text { brasileiros }\end{array}$ & $\begin{array}{c}1983- \\
2003\end{array}$ & LSDV & $\begin{array}{l}\text { Os gastos de capital e corrente estavam relacionado } \\
\text { positivamente com o crescimento econômico }\end{array}$ \\
\hline $\begin{array}{l}\text { Ghosh e } \\
\text { Gregoriou } \\
(2008)\end{array}$ & $\begin{array}{c}\text { Países em } \\
\text { desenvolvimento }\end{array}$ & $\begin{array}{c}1972- \\
1999\end{array}$ & $\begin{array}{l}\text { LSDV e } \\
\text { GMM }\end{array}$ & $\begin{array}{l}\text { O gasto de capital era negativamente associado com } \\
\text { o crescimento econômico, diferentemente do gasto } \\
\text { corrente }\end{array}$ \\
\hline $\begin{array}{l}\text { Moreno- } \\
\text { Dodson (2008) }\end{array}$ & $\begin{array}{c}\text { Países em } \\
\text { desenvolvimento }\end{array}$ & $\begin{array}{l}1970- \\
2006\end{array}$ & $\begin{array}{l}\text { OLS, } \\
\text { SUR e } \\
\text { GMM }\end{array}$ & $\begin{array}{l}\text { Os gastos classificados a priori como produtivos } \\
\text { apresentaram-se como os mais relevantes para o } \\
\text { crescimento econômico, principalmente no médio } \\
\text { prazo }\end{array}$ \\
\hline $\begin{array}{l}\text { Rodrigues e } \\
\text { Teixeira }(2010)\end{array}$ & $\begin{array}{l}\text { Brasil, estados e } \\
\text { municípios }\end{array}$ & $\begin{array}{c}1948- \\
1998\end{array}$ & OLS & $\begin{array}{l}\text { Os gastos em investimentos têm maior efeito } \\
\text { positivo para o crescimento, ao contrário dos gastos } \\
\text { com consumo, subsídios e transferências }\end{array}$ \\
\hline $\begin{array}{l}\text { Bayraktar e } \\
\text { Moreno- } \\
\text { Dodson (2010) } \\
\text { e Moreno- } \\
\text { Dodson e } \\
\text { Bayraktar } \\
(2011) \\
\end{array}$ & $\begin{array}{c}\text { Países em } \\
\text { desenvolvimento }\end{array}$ & $\begin{array}{l}1970- \\
2005\end{array}$ & $\begin{array}{l}\text { OLS e } \\
\text { GMM }\end{array}$ & $\begin{array}{l}\text { O componente de gastos classificados como } \\
\text { produtivos foi mais significativo nos países que } \\
\text { tiveram crescimento econômico rápido }\end{array}$ \\
\hline $\begin{array}{l}\text { Bogoni, Hein e } \\
\text { Beuren (2011) }\end{array}$ & $\begin{array}{l}\text { Municípios } \\
\text { brasileiros da } \\
\text { região Sul }\end{array}$ & $\begin{array}{l}2000- \\
2004\end{array}$ & $\begin{array}{l}\text { Modelo } \\
\text { Não- } \\
\text { linear }\end{array}$ & $\begin{array}{l}\text { Os gastos em saúde, saneamento, educação, cultura, } \\
\text { investimento, habitação, assistência e previdência } \\
\text { social tinham relação positiva com o crescimento }\end{array}$ \\
\hline $\begin{array}{l}\text { Divino e Silva } \\
\text { Jr. (2012) }\end{array}$ & $\begin{array}{l}\text { Municípios } \\
\text { brasileiros }\end{array}$ & $\begin{array}{c}1991- \\
2000\end{array}$ & OLS & $\begin{array}{l}\text { O gasto corrente do governo estava associado } \\
\text { negativamente com o crescimento dos municípios } \\
\text { brasileiros, contudo, naqueles abaixo da linha de } \\
\text { pobreza, a associação era positiva }\end{array}$ \\
\hline $\begin{array}{l}\text { Forlin e } \\
\text { Rodrigues } \\
(2012) \\
\end{array}$ & $\begin{array}{l}\text { Municípios do } \\
\text { estado de São } \\
\text { Paulo } \\
\end{array}$ & 2000 & OLS & $\begin{array}{l}\text { Tanto o gasto corrente quanto o gasto em } \\
\text { investimento tinha relação positiva com o } \\
\text { crescimento econômico }\end{array}$ \\
\hline $\begin{array}{l}\text { Silva e Santolin } \\
(2012)\end{array}$ & $\begin{array}{c}\text { Estados } \\
\text { brasileiros }\end{array}$ & $\begin{array}{l}1995- \\
2006\end{array}$ & GMM & $\begin{array}{l}\text { O crescimento dos gastos em investimentos, } \\
\text { infraestrutura e desenvolvimento urbano tinha efeito } \\
\text { positivo no crescimento econômico }\end{array}$ \\
\hline $\begin{array}{l}\text { Ogundipe e } \\
\text { Oluwatobi } \\
(2013)\end{array}$ & Nigéria & $\begin{array}{l}1970- \\
2009\end{array}$ & $\begin{array}{l}\text { Co-inte- } \\
\text { gração }\end{array}$ & $\begin{array}{l}\text { Os gastos públicos não têm contribuído para o } \\
\text { crescimento econômico devido a questões ligadas a } \\
\text { corrupção, a projetos sem utilidade e sem } \\
\text { continuidade }\end{array}$ \\
\hline $\begin{array}{l}\text { Silva, Cruz e } \\
\text { Irffi (2013) }\end{array}$ & $\begin{array}{l}\text { Municípios do } \\
\text { estado da } \\
\text { Paraíba } \\
\end{array}$ & $\begin{array}{l}2000- \\
2008\end{array}$ & $\begin{array}{l}\text { OLS e } \\
\text { GMM- } \\
\text { system }\end{array}$ & $\begin{array}{l}\text { Os gastos nas funções legislativa, educação e } \\
\text { cultura, saúde, saneamento, habitação e urbanismo } \\
\text { tinham efeito positivo no crescimento econômico }\end{array}$ \\
\hline
\end{tabular}

Legenda: OLS - Ordinary Least Square (Mínimos Quadrados Ordinários); SUR - Seemingly Unrelated Regression (Regressões aparentemente não relacionadas); VAR - Vetores Auto-Regressivos; GMM - Generalized Method of Moments (Método de Momentos Generalizados); GMM-system - GMM-sistema; LSDV - Least Square Dummy Variable (Mínimos Quadrados com Variável Dummy).

Portanto, observando-se essas pesquisas, verifica-se, em Moreno-Dodson (2008), uma síntese dos fatores que podem levar às variadas evidências ao se confrontar gastos públicos e crescimento econômico: 1) nem todo gasto público ocorre conforme sua alocação orçamentária, e esse desvio pode diminuir o impacto do gasto público e distorcer a sua relação com o crescimento; 2) a eficiência do gasto público em criar novo estoque de capital (físico e humano) influencia diretamente o crescimento; 3) a forma como um gasto público é financiado pode torná-lo improdutivo, se o financiamento comprometer o investimento privado; 4) a forma como o gasto público é classificado pode não ser suficiente para 
determinar a sua relação com o crescimento; e 5) o nível de desenvolvimento e o padrão de vida são indicativos das necessidades de cada economia; logo, influenciam diferentemente os efeitos dos tipos de gasto no crescimento.

\subsection{Arcabouço Legal e Institucional dos Recursos Naturais no Brasil}

Na Constituição Federal de 1988, a terra, o mar territorial, os recursos hídricos e minerais, inclusive os do subsolo, e os recursos naturais da plataforma continental são descrito como bens da União. Ainda assim, a Constituição garante aos estados, ao Distrito Federal e aos municípios participação nos resultados ou compensação financeira da exploração de recursos hídricos para fins energéticos, de outros recursos minerais e de petróleo e gás natural (BRASIL, 1988).

A compensação financeira para os estados, Distrito Federal e municípios pela exploração de recursos do petróleo, hídricos para fins de energia elétrica e minerais está estabelecida na Lei $n^{\circ} 7.990 / 1989$. As compensações financeiras são corrigidas e devem ser pagas pelos concessionários mensalmente, até o último dia do segundo mês após o fato gerador (BRASIL, 1989).

Os percentuais de distribuição das compensações financeiras pela exploração de recursos hídricos pra fins energéticos e de recursos minerais para a União, estados e municípios são definidos nas Leis nº 8.001/1990 e n ${ }^{\circ}$ 9.984/2000, enquanto a distribuição dos royalties e da participação especial do petróleo é disciplinada pela Lei do Petróleo (Lei $\mathrm{n}^{\circ}$ 9.478/1997). Os valores distribuídos destinados à União são direcionados especificamente para os órgãos da administração direta, em sua maioria com aplicação definida.

De forma geral, os estados, municípios e órgãos da administração direta da União têm autonomia sobre a aplicação dos recursos provenientes da compensação financeira, sendo vedada apenas sua utilização para pagamento de dívida e despesa com pessoal (BRASIL, 1989). Contudo, desde 2001, esses recursos podem ser utilizados para capitalização de fundos de previdência e, desde 2013, para o pagamento de dívidas com a União e suas entidades, bem como para despesas com manutenção e desenvolvimento do ensino, incluindo a despesa de pessoal da área de educação (BRASIL, 2001, 2013). Em alguns casos, a legislação sobre o assunto restringe a aplicação das compensações financeiras distribuídas aos órgãos da administração direta da União, como será visto a seguir. 


\subsubsection{Recursos hídricos para fins energéticos}

A fiscalização da arrecadação e da distribuição da compensação financeira da exploração de recursos hídricos para a geração de energia elétrica (CFHI) é de responsabilidade da Agência Nacional de Energia Elétrica (ANEEL), vinculada ao Mistério de Minas e Energia (MME). A CFHI é paga pelo titular da concessão ou da autorização para explorar o potencial hidroelétrico. O cálculo da CFHI é de 6,75\% do valor da energia elétrica produzida, sendo este o produto entre a quantidade de energia elétrica gerada e a tarifa atualizada de referência (TAR) (BRASIL, 1998). A TAR, fixada anualmente pela ANEEL e revisada a cada quatro anos, refere-se ao valor de venda da energia para as distribuidoras de energia elétrica, deduzido dos encargos setoriais de geração de energia, dos tributos e empréstimos compulsórios e dos custos de transmissão de energia (BRASIL, 2001).

Da CFHI, seis pontos percentuais são destinados aos estados, municípios e órgãos da administração direta da União; o restante, 0,75\%, ao Ministério do Meio Ambiente (MMA). Também entram na CFHI os royalties da usina de Itaipu. Têm direito a CFHI os estados e municípios nos quais se localizam as instalações de produção de energia elétrica ou que tenham suas áreas invadidas por águas dos reservatórios hidroelétricos (BRASIL, 1998). Cada um desses estados e municípios recebe $45 \%$ da parcela devida da CFHI; $3 \%$ para o MMA e o MME; e 4\% para o Fundo Nacional de Desenvolvimento Científico e Tecnológico (FNDCT) (BRASIL, 1990). O quadro 2.3 resume a arrecadação e distribuição da CFHI.

Quadro 2.3 - Arrecadação e distribuição dos recursos provenientes da exploração hídrica

\begin{tabular}{|c|c|c|}
\hline Tipo & Arrecadação & Distribuição \\
\hline \multirow[t]{2}{*}{$\begin{array}{l}\text { Compensação Financeira pela Exploração } \\
\text { de Recursos Hídricos para fins Energéticos }\end{array}$} & $6 \%$ & $\begin{aligned} 45 \% & \text { para os estados; } \\
45 \% & \text { para os municípios; } \\
4 \% & \text { para o FNDCT; } \\
3 \% & \text { para o MMA; } \\
3 \% & \text { para o MME. }\end{aligned}$ \\
\hline & $0.75 \%^{\mathrm{a}}$ & para o MMA. \\
\hline
\end{tabular}

${ }^{\text {a }}$ do valor da energia elétrica gerada.

Fonte: Brasil (1990, 2000)

Os recursos da CFHI repassados ao MMA são destinados especificamente para a aplicação na implementação da Política Nacional de Recursos Hídricos e do Sistema Nacional de Gerenciamento de Recursos Hídricos; enquanto pelo menos 30\% dos recursos da CFHI distribuídos para o FNDCT são dedicados a projetos de desenvolvimento por instituições de pesquisa das Regiões Norte, Nordeste e Centro-Oeste (BRASIL, 1990). 


\subsubsection{Recursos minerais}

A fiscalização da compensação financeira pela exploração de recursos minerais (CFEM) compete ao Departamento Nacional de Produção Mineral, vinculada ao MME (BRASIL, 1994). A CFEM é paga por pessoas físicas e jurídicas que extraem substâncias minerais de jazida, mina, salina ou outro depósito mineral para fins econômicos. $\mathrm{O}$ valor da CFEM corresponde a até 3\% do faturamento líquido decorrente da venda do produto mineral, dependendo do tipo de mineral (BRASIL, 1989, 1991). Para exploração de minério de alumínio, manganês, sal-gema e potássio, o percentual sobre o faturamento é de 3\%; para ferro, fertilizantes, carvão e outros, $2 \%$; para pedras preciosas e metais nobres, $0,2 \%$; e para ouro extraído por empresas mineradoras, 1\% (BRASIL, 1990).

Têm direito a CFEM os estados, o Distrito Federal e os municípios de onde foram extraídos os recursos minerais, além de órgãos da administração direta previstos em lei. Os estados e o Distrito Federal recebem 23\% da CFEM; os municípios, 65\%; o MME, 10\%, sendo $2 \%$ destinados à proteção ambiental nas regiões mineradoras; e o FNDCT, 2\%, destinados ao desenvolvimento científico e tecnológico do setor mineral (BRASIL, 1990). O quadro 2.4 resume a arrecadação e distribuição da CFEM.

\section{Quadro 2.4 - Arrecadação e distribuição dos recursos provenientes da exploração mineral}

\begin{tabular}{|c|c|cl|}
\hline \hline Tipo & Arrecadação & \multicolumn{1}{|c|}{ Distribuição } \\
\hline \multirow{3}{*}{$\begin{array}{c}\text { Compensação Financeira pela Exploração } \\
\text { de Recursos Minerais }\end{array}$} & Até 3\% do & $65 \%$ para os municípios; \\
& faturamento & $23 \%$ para os estados; \\
& líquido & $10 \%$ para o MME; \\
& $2 \%$ para o FNDCT. \\
\hline \hline
\end{tabular}

Fonte: Brasil (1990)

\subsubsection{Recursos petrolíferos}

A compensação financeira pela exploração de recursos petrolíferos é feita por meio do pagamento de royalties e participação especial pelos detentores da concessão de exploração. A arrecadação e distribuição dos royalties e participação especial são supervisionadas pela Agência Nacional do Petróleo (ANP). O valor dos royalties corresponde a $10 \%$ da produção de petróleo e gás natural (15\% para o pré-sal), podendo a ANP estabelecer no edital de licitação da concessão uma alíquota menor, de no mínimo 5\% da produção, em decorrência de riscos geológicos, das expectativas de produção e outros fatores (BRASIL, 1997).

A participação especial é devida para os casos de grande volume de produção ou grande rentabilidade. O valor corresponde a uma alíquota - que varia de 0 a $40 \%$ dependendo do volume produzido -, aplicada sobre a receita bruta, deduzida dos royalties, dos 
investimentos na exploração, dos custos operacionais, da depreciação e dos tributos (BRASIL, 1997).

As regras de distribuição dos royalties do petróleo levam em consideração o valor mínimo arrecado (referente a 5\% da produção), o valor que exceder esse percentual e o local explorado (se em terra ou na plataforma continental). A distribuição da participação especial não faz este tipo de diferencial (BRASIL, 1997). Vale ressaltar que as regras de distribuição dos royalties da exploração em plataforma continental e da participação especial sofreram alterações em 2010 e 2012, dentre as quais se destacam a criação do fundo social, em 2010, e a iniciativa de redução da cota-parte devida aos municípios produtores para o aumento da participação dos municípios afetados pelo embarque/desembarque e do fundo especial para os municípios, em 2012. O quadro 2.5 apresenta as regras de distribuição dos recursos do petróleo conforme as últimas alterações legais e, entre os parênteses, as regras precedentes, uma vez que a abrangência temporal desta pesquisa é anterior a essas alterações.

Os valores repassados para o Ministério da Ciência e Tecnologia (MCT) devem ser aplicados em programas de amparo à pesquisa científica e ao desenvolvimento tecnológico na indústria do petróleo e em programas de prevenção e recuperação de danos causados ao meio ambiente por essas indústrias. Desse total, $40 \%$ devem ser destinados ao desenvolvimento científico e tecnológico das regiões norte e nordeste (BRASIL, 1997).

Os recursos do fundo especial a serem distribuídos entre os estados, o Distrito Federal e os municípios são destinados para as áreas de educação, infraestrutura social e econômica, saúde, segurança, erradicação da miséria e da pobreza, cultura, esporte, pesquisa, ciência e tecnologia, defesa civil, meio ambiente, mitigação e adaptação às mudanças climáticas, e para o tratamento e reinserção social de dependentes químicos (BRASIL, 1997).

O fundo social, vinculado à Presidência da República, tem como função formar uma poupança pública de longo prazo e prevenir a flutuação das receitas e dos preços. Seus recursos são destinados ao desenvolvimento social e regional, na forma de programas e projetos nas áreas de desenvolvimento e de combate à pobreza, como: educação, cultura, esporte, saúde pública, ciência e tecnologia, meio ambiente e mitigação e adaptação às mudanças climáticas (BRASIL, 2010). 
Quadro 2.5 - Arrecadação e distribuição dos recursos provenientes da exploração do petróleo

\begin{tabular}{|c|c|c|}
\hline Tipo & Arrecadação & Distribuição \\
\hline \multirow{4}{*}{ Royalties } & \multirow[b]{2}{*}{$\begin{array}{l}\text { Mínimo de } 5 \% \\
\text { do valor da } \\
\text { produção }\end{array}$} & $\begin{array}{l}\text { - Lavra em terra: } \\
\qquad \begin{array}{l}70 \% \text { para os estados produtores; } \\
20 \% \text { para os municípios produtores; } \\
10 \% \text { para os municípios afetados. }\end{array}\end{array}$ \\
\hline & & $\begin{array}{rcl}\text { - Lavra em plataforma continental: } \\
\begin{array}{rcl}20 \% & (30 \%)^{1} & \text { para os estados produtores; } \\
17 \% & (30 \%)^{1} & \text { para os municípios produtores; } \\
3 \% & (10 \%)^{1} & \text { para os municípios afetados; } \\
20 \% & -1 & \text { para o Fundo Especial para os estados; } \\
20 \% & (10 \%)^{1} & \text { para o Fundo Especial para os municípios; } \\
20 \% & -1 & \text { para o Fundo Social; } \\
- & (20 \%)^{1} & \text { (para o Ministério da Marinha) }\end{array}\end{array}$ \\
\hline & \multirow[b]{2}{*}{$\begin{array}{l}\text { Excedente a } \\
5 \% \text { do valor } \\
\text { da produção }\end{array}$} & $\begin{aligned} \text { - Lavra em terra: } & \\
52.5 \% & \text { para os estados produtores; } \\
15 \% & \text { para os municípios produtores; } \\
7.5 \% & \text { para os municípios afetados; } \\
25 \% & \text { para o MCT. }\end{aligned}$ \\
\hline & & 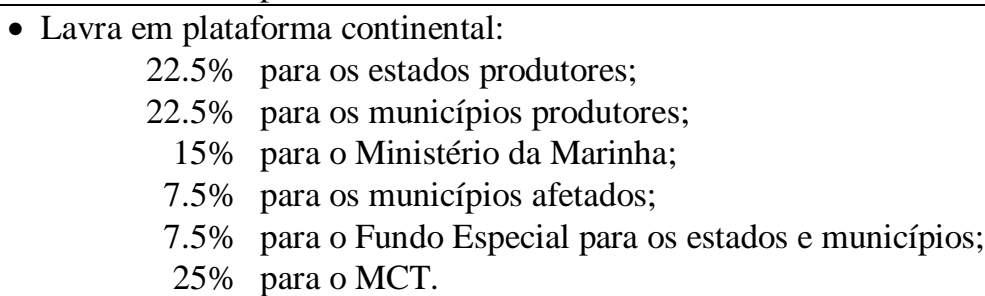 \\
\hline $\begin{array}{c}\text { Participação } \\
\text { Especial }\end{array}$ & $\begin{array}{l}0 \text { a } 40 \% \text { do } \\
\text { valor da } \\
\text { produção com } \\
\text { exclusões }\end{array}$ & $\begin{array}{rcl}42 \% & -1 & \text { para o Fundo Social; } \\
34 \% & (40 \%)^{1} & \text { para os estados produtores em terra; } \\
5 \% & (10 \%)^{1} & \text { para os municípios produtores em terra; } \\
9.5 \% & -1 & \text { para o Fundo Especial para os estados; } \\
9.5 \% & -1 & \text { para o Fundo Especial para os municípios; } \\
- & (40 \%)^{1} & \text { (para o MME) } \\
- & (10 \%)^{1} & \text { (para o MMA) }^{1}\end{array}$ \\
\hline
\end{tabular}

${ }^{1}$ Anterior as alterações de 2010 e 2012.

Fonte: Brasil (1997) 


\section{ESTRÁTEGIA DA PESQUISA}

Neste capítulo, são descritos os procedimentos adotados na pesquisa: os critérios de seleção e composição da amostra, a fundamentação dos modelos econométricos testados, a técnica utilizada para a estimação desses modelos, os dados e as variáveis comumente utilizadas; os testes e procedimentos adotados para garantir a qualidade dos ajustes e a limitação/escopo da pesquisa.

\subsection{Seleção e Composição da Amostra}

A população em estudo são os 5.596 municípios brasileiros constantes dos registros do IBGE no período de 2003 a 2012. Dentre eles foram selecionados os que tinham dados disponíveis para a formação de painéis de dados balanceados. Mais especificamente, o critério levou em consideração os municípios que apresentavam, para todos os anos do período, informações necessárias sobre o PIB, sobre a população, sobre os gastos, sobre os anos de estudo e sobre os empregos formais utilizadas nas bases de dados da pesquisa (como será detalhado adiante).

Inicialmente, identificou-se que as diferentes bases de dados divergiam quanto à nomenclatura dos municípios, seja por falta de atualização em decorrência de alteração de nome, seja por diferenças ortográficas. Dessa forma, macros e rotinas de inspeção eletrônica e visual foram criados para equalizar a nomenclatura dos municípios e possibilitar a comunicação entre as bases de dados e o seu máximo aproveitamento.

Os municípios criados no período em estudo foram descartados por não apresentarem os dados necessários, bem como aqueles que foram desmembrados para originar os primeiros, pois os dados apresentaram comportamento atípico em relação aos demais devido à divisão territorial. Além disso, não seria coerente unificar os municípios desmembrados, uma vez que cada um teria necessidades e características próprias quanto à gestão de seus recursos.

Excepcionalmente, manteve-se o município de Teresina-PI na amostra, o qual deu origem ao município de Nazária-PI em 2009, por se tratar da capital do estado e porque o município criado representa menos de $1 \%$ da população e de $0,2 \%$ do PIB do município que o originou. A informação dos municípios desmembrados foi obtida na base de dados do DataSus, compilada a partir de informações fornecidas pelo IBGE.

Assim, a amostra final do estudo passou a contemplar 4.573 municípios, os quais preenchiam os quesitos ora discorridos para formação de cinco painéis de dados, perfazendo 
um total de 22.865 observações para cinco períodos. Ainda, da amostra final foram extraídas subamostras compostas por municípios que tiveram receitas com exploração de recursos naturais em todos os anos do período analisado, conforme demostrado no quadro 3.1.

Quadro 3.1 - Amostra e subamostras da pesquisa

\begin{tabular}{|l|l|c|c|}
\hline \hline \multicolumn{1}{|c|}{ Amostra } & \multicolumn{1}{|c|}{ Descrição } & Municípios & Observações \\
\hline Completa & Todos os municípios & 4.573 & 22.865 \\
\hline Subamostra 1 & Somente municípios com recursos naturais & 1.544 & 7720 \\
\hline Subamostra 2 & Somente municípios com recursos hídricos & 519 & 2595 \\
\hline Subamostra 3 & Somente municípios com recursos minerais & 673 & 3365 \\
\hline Subamostra 4 & Somente municípios com recursos do petróleo & 576 & 2880 \\
\hline \hline
\end{tabular}

\subsection{Modelos Empíricos}

O modelo empírico dos estudos sobre a determinação do crescimento econômico representa, de forma geral, o crescimento em função de um conjunto de determinantes representativas das características estruturais da economia. Nessa linha, os estudos sobre a MRN procuram relacionar recursos naturais com crescimento econômico, destacando uma variável indicativa da riqueza gerada pela exploração dos recursos naturais (SACHS; WARNER, 1995, 1999; PAPYRAKIS; GERLAGH, 2007; JAMES; AADLAND, 2011). Dessa forma, cinco modelos empíricos foram estimados para atender aos objetivos específicos desta pesquisa.

O modelo 1, descrito a seguir, permite averiguar o efeito da riqueza em recursos naturais no crescimento econômico dos municípios. Neste trabalho, entende-se como riqueza em recursos naturais a abundância desses recursos, ou seja, os rendimentos (receitas) obtidos com a sua exploração (mais adiante, explicam-se as variáveis de recursos naturais utilizadas nas pesquisas). Assim, um município é dito abundante em recursos naturais pelos rendimentos que recebe pela exploração desses recursos, enquanto um município é não abundante quando não tem tais receitas.

$$
C_{i t}=\alpha+\beta R_{i t}+\sum_{j=1}^{J} \delta_{j}^{Z} Z_{j, i t}+\varepsilon_{i t}
$$

sendo:

$\mathrm{C}_{\mathrm{it}}-$ crescimento econômico per capita do município $i$ no período $t$;

$\mathrm{R}_{\text {it }}$ - abundância em recursos naturais do município $i$ no período $t$;

$\mathrm{Z}_{\mathrm{j}, \mathrm{it}}$ - vetor de outras variáveis explicativas $j$ do crescimento do município $i$ no período $t$;

$\varepsilon_{\text {it }}$ - termo de erro para o município $i$ no período $t$. 
A confirmação da MRN ocorre quando o coeficiente $\beta$ é negativo, indicando que, quanto maior a abundância em recursos naturais, menor foi o crescimento daquele município.

Os estudos sobre a MRN exploram, ainda, como outras variáveis influenciam a resposta direta da abundância em recursos naturais no crescimento econômico, como forma de testar se o poder explicativo de outras variáveis diminui ou anula o efeito (negativo) dos recursos naturais no crescimento econômico. Caso o comportamento do parâmetro $\beta$ se altere com a inclusão de outras variáveis, infere-se que parte do efeito da abundância em recursos naturais sobre o crescimento é explicada pelo efeito de outra variável - a proposta desta pesquisa é investigar se ela diz respeito aos gastos públicos.

Especificamente, os estudos sobre a produtividade dos gastos públicos pesquisam o impacto da composição do gasto público no crescimento econômico (DEVARAJAN; SWAROOP; ZOU, 1996; BOSE; OSBORN, 2007; ROCHA; GIUBERTI, 2007; GHOSH; GREGORIOU, 2008), como demonstrado no modelo 2. O que se pretende com este modelo é investigar inicialmente os efeitos do gasto público no crescimento econômico dos municípios.

$$
C_{i t}=\alpha+\sum_{k=1}^{K} \gamma_{k}^{G} G_{k, i t}+\sum_{j=1}^{J} \delta_{j}^{Z} Z_{j, i t}+\varepsilon_{i t}
$$

em que:

$G_{k, i t}$ - vetor de $k$ variáveis dos gastos públicos do município $i$ no período $t$;

A abordagem utilizada para analisar o efeito do gasto público no crescimento é a desenvolvida por Devarajan, Swaroop e Zou (1996), a qual não define a priori qual gasto é produtivo ou improdutivo. Dessa forma, determinado gasto público é produtivo quando está positivamente relacionado com o crescimento econômico, $\gamma_{k}^{G}>0$, indicando que aquele gasto contribui para o crescimento. De maneira análoga, determinado gasto é classificado como improdutivo quando $\gamma_{k}^{G}<0$, ou seja, o gasto público prejudica o crescimento.

Assim sendo, com a proposta de relacionar a abundância em recursos naturais e os gastos governamentais com o crescimento econômico, como visto em Atkinson e Hamilton (2003), Alichi e Arezki (2009), Bleaney e Halland (2009) e Anshasy (2011), tem-se o modelo 3. A ideia é verificar se parte do efeito da abundância em recursos naturais no crescimento econômico se deve ao comportamento dos gastos públicos e se a produtividade dos gastos públicos dos municípios que recebem rendimentos pela exploração de recursos naturais é diferente dos municípios que não são beneficiados com tais rendimentos. 


$$
C_{i t}=\alpha+\beta R_{i t}+\sum_{k=1}^{K} \gamma_{k}^{G} G_{k, i t}+\sum_{k=1}^{K} \sigma_{k}^{R G} R_{i t} . G_{k, i t}+\sum_{j=1}^{J} \delta_{j}^{Z} Z_{j, i t}+\varepsilon_{i t}
$$

Sendo:

$R_{i t} G_{k, i t}$ - variável de interação da abundância em recursos naturais com o gasto público $k$ do município $i$ no período $t$.

Como no modelo 1, a observação recai sobre as alterações no comportamento do parâmetro $\beta$, uma vez que são inseridas no modelo as variáveis de gastos públicos. Caso ocorra uma alteração no comportamento desse parâmetro, infere-se que o efeito direto da abundância em recursos naturais no crescimento depende de alguma forma da relação entre os gastos públicos e o crescimento econômico nos municípios.

A diferença na produtividade dos gastos públicos entre os municípios abundantes ou não em recursos naturais seria observada pelo comportamento das variáveis de interação entre a abundância em recursos naturais e os gastos. O efeito de interação consiste em verificar se o efeito de uma variável independente na variável dependente difere em função do valor de uma variável moderadora (JACCARD; TURRISI, 2003); no caso, se o efeito do gasto público (variável independente) no crescimento (variável dependente) difere quando condicionado à abundância em recursos naturais (variável moderadora).

Similarmente, Atkinson e Hamilton (2003) utilizaram variáveis de interação para verificar se a produtividade dos gastos públicos com investimentos, com consumo e com salários era diferente em países ricos em recursos naturais. Assim também fizeram Alichi e Arezki (2009), para analisar o comportamento do gasto corrente do governo em países exportadores de petróleo com maior restrição ao mercado internacional. E, ainda, Anshasy (2011), para avaliar se o comportamento dos gastos corrente, de capital, com salários, com aquisição de produtos e serviços e com transferências era diferente nos países altamente ricos com a exportação de petróleo.

A variável de interação pelo produto entre as variáveis (independente e de moderação) é a abordagem mais comum em modelos de regressão que analisam efeitos de interação (JACCARD; TURRISI, 2003). Nesses modelos, o coeficiente de regressão da variável independente e moderadora reflete relações condicionais para valores específicos dessas variáveis: o coeficiente da variável independente reflete sua influência na variável dependente quando o valor da variável moderadora é igual a zero, e vice-versa (idem). 
Desse modo, enquanto o parâmetro $\sigma_{k}^{R G}$ captura somente o efeito do gasto público no crescimento econômico dos municípios abundantes com a exploração de recursos naturais, o parâmetro $\gamma_{k}^{S}$ representa apenas o efeito do gasto no crescimento dos municípios não dependentes de tais recursos. O sinal positivo (negativo) de $\sigma_{k}^{R G}$ indica que, quanto maior a abundância em recursos naturais e maior o gasto público, maior (menor) foi o crescimento econômico dos municípios. Assim, a comparação dos parâmetros $\sigma_{k}^{R G}$ e $\gamma_{k}^{G}$ permite verificar se a produtividade do gasto público dos municípios abundantes em recursos naturais é diferente ou não do gasto dos municípios não abundantes nesses recursos.

Essencialmente, nos modelos anteriores, investiga-se o efeito na economia da abundância em recursos naturais tanto de municípios com receitas advindas da exploração desses recursos quanto daqueles que não as têm. Já os modelos a seguir foram desenvolvidos para uma subamostra que contenha apenas os municípios com tais receitas, a fim de verificar a relação do nível de abundância em recursos naturais no crescimento econômico, ou seja, para averiguar se o comportamento dos recursos naturais e do gasto público nos municípios com maiores receitas se diferencia dos municípios com menores receitas.

O modelo 4 investiga o efeito do nível de abundância em recursos naturais no crescimento dos municípios que recebem tais rendimentos. Este modelo é uma extensão do modelo 1 para a subamostra com apenas municípios beneficiados com a exploração de recursos naturais.

$$
C_{i t}=\alpha+\beta R_{i t}+\theta D_{i t}+\sum_{j=1}^{J} \delta_{j}^{Z} Z_{j, i t}+\varepsilon_{i t}
$$

em que:

$D_{i t}$ - variável dummy para os municípios mais abundantes em recursos naturais no período $t$.

Nesse modelo, enquanto o parâmetro $\beta$ representa o efeito da abundância em recursos naturais no crescimento nos municípios menos abundantes, o parâmetro $\theta$ indica o efeito diferencial nos municípios mais abundantes em recursos naturais no crescimento. Logo, se $\theta$ for menor do que zero, os municípios mais abundantes experimentaram crescimento menor do que os municípios menos abundantes. Vale destacar que a variável dummy pode variar temporalmente, pois um município pode ser classificado como mais abundante em recursos naturais em um período, mas não em outro.

Nessa mesma subamostra, o modelo 5 investiga se a produtividade dos gastos públicos dos municípios altamente abundantes em recursos naturais é diferente dos municípios menos 
abundantes economicamente em tais recursos. Tal como no modelo 3, utiliza-se a abordagem de efeitos de interação para a comparação da produtividade do gasto condicionada ao nível de abundância dos municípios.

$$
\begin{aligned}
C_{i t}=\alpha+\beta R_{i t}+ & \sum_{k=1}^{K} \gamma_{k}^{S} G_{k, i t}+\theta D_{i t}+\sum_{k=1}^{K} \varphi_{k}^{D G} D_{i t} G_{k, i t}+ \\
& +\sum_{j=1}^{J} \delta_{j}^{Z} Z_{j, i t}+\varepsilon_{i t}
\end{aligned}
$$

Sendo:

$D_{i t} \cdot G_{k, i t}$ - variável de interação do gasto público $k$ com a alta abundância em recursos naturais do município $i$ no período $t$.

Nesse modelo, o parâmetro $\varphi_{k}^{D G}$ representa o efeito dos gastos públicos no crescimento dos municípios com alta abundância em recursos naturais, enquanto o parâmetro $\gamma_{k}^{G}$ captura apenas o comportamento dos gastos públicos dos municípios menos abundantes em recursos naturais. Se $\varphi_{k}^{D G}<\gamma_{k}^{G}$, o gasto público nos municípios altamente abundantes em recursos naturais é menos produtivo que nos municípios menos abundantes.

Em suma, os modelos 1 a 5 estão relacionados diretamente com os objetivos específicos desta pesquisa. O quadro 3.2 mostra a ligação entre os modelos, os objetivos específicos e os comportamentos esperados dos coeficientes, conforme disposto no arcabouço teórico sobre a MRN e sobre gastos públicos e crescimento econômico.

\begin{tabular}{|c|c|c|c|c|}
\hline Modelo & $\begin{array}{c}\text { Objetivo } \\
\text { Específico }\end{array}$ & Objetivo do Modelo & Amostra & $\begin{array}{l}\text { Comportamento esperado } \\
\text { dos principais coeficientes }\end{array}$ \\
\hline 1 & 1 & $\begin{array}{l}\text { Verificar a relação entre a } \\
\text { abundância }^{1} \text { e o crescimento }\end{array}$ & \multirow{3}{*}{ Completa $^{4}$} & $\beta<0$ - evidência da MRN \\
\hline 2 & 3 & $\begin{array}{l}\text { Verificar a relação entre os } \\
\text { gastos }^{3} \text { e o crescimento }\end{array}$ & & $\begin{array}{l}\gamma_{k}^{G}>0 \text { - gasto produtivo } \\
\gamma_{k}^{G}>0 \text { - gasto não produtivo }\end{array}$ \\
\hline 3 & 4 e 5 & $\begin{array}{l}\text { Verificar a relação entre a } \\
\text { abundância }{ }^{1}, \text { os gastos }^{3} \text { e o } \\
\text { crescimento }^{2}\end{array}$ & & $\begin{array}{l}\beta \text { modelo } 3 \neq \beta \text { modelo } 1 \\
\sigma_{k}^{R G} \neq \gamma_{k}^{G}\end{array}$ \\
\hline 4 & 2 & $\begin{array}{l}\text { Verificar a relação entre o nível } \\
\text { de abundância }{ }^{1} \text { e o crescimento }\end{array}$ & \multirow{2}{*}{ Subamostra ${ }^{5}$} & $\theta<0$ \\
\hline 5 & 6 & $\begin{array}{l}\text { Verificar a relação entre o nível } \\
\text { de abundância, os gastos } 3 \text { e o } \\
\text { crescimento }^{2}\end{array}$ & & $\varphi_{k}^{D G} \neq \gamma_{k}^{G}$ \\
\hline
\end{tabular}

Quadro 3.2 - Resumo dos modelos empíricos

Onde: ${ }^{1}$ refere-se à abundância em recursos naturais; ${ }^{2}$ refere-se ao crescimento econômico; ${ }^{3}$ refere-se aos gastos públicos;

${ }^{4}$ amostra com os municípios que têm algum rendimento pela exploração dos recursos naturais e com os municípios sem tais rendimentos; ${ }^{5}$ subamostra com apenas municípios abundantes em recursos naturais. 


\subsection{Estimação dos modelos}

Para a estimação dos modelos, foi utilizada a técnica de dados em painel com o objetivo de controlar o resultado por características não observadas. Para Manzano e Rigobon (2006), a relação entre os recursos naturais e o crescimento econômico é sensível a características não observadas, não tratadas nos modelos de estimação. Nesse sentido, Van Der Ploeg (2011) e Torres, Afonso e Soares (2013) ressaltam a importância de controlar os parâmetros dos modelos para efeitos fixos não observáveis nas pesquisas sobre a MRN, embora a maioria dos estudos empíricos utilizem análises em corte transversal.

A utilização da técnica de dados em painel possibilita: 1) lidar com amplo espectro de questões e problemas mais complexos do que seria possível isoladamente, com dados em cortes transversais ou séries temporais; 2) avaliar como as variáveis e a relação entre estas mudam dinamicamente; e 3) remover o viés de variáveis omitidas nos resultados (BALTAGI, 2008; BROOKS, 2008). Logo, a utilização de dados em painel contribui para esta pesquisa ao aumentar a robustez nas análises do comportamento dos rendimentos dos recursos naturais e dos gastos públicos no crescimento econômico, pois permite controlar o resultado pelas características heterogêneas não observáveis dos municípios.

$\mathrm{Na}$ estimação de dados em painel pela abordagem de efeitos fixos, o efeito de variáveis não observadas na variável dependente é capturado variando o intercepto do modelo para cada uma das unidades transversais ou/e temporais, enquanto os demais parâmetros são constantes ao longo das unidades transversais e temporais. (BROOKS, 2008; GUJARATI, 2006). Assim, considerando-se que o intercepto captura características econômicas não observáveis, no modelo com efeitos fixos, esse varia de forma que cada município tem o seu próprio valor de intercepto, podendo ser comum ou não ao longo do tempo, representando o efeito dessas características no crescimento econômico em função dos rendimentos dos recursos naturais e dos gastos públicos.

Nos modelos de estimação com efeitos fixos, incluem-se variáveis dummy para cada unidade de observação, a fim de capturar o efeito das características não observáveis de cada município; em seguida, faz-se a estimação por mínimos quadrados ordinários, denominada de modelo de variável binária de mínimos quadrados (Least Square Dummy Variable - LSDV). Inseriram-se também nos modelos variáveis dummy para os efeitos fixos de tempo. Estimações e testes foram feitos todos no programa estatístico Stata. 


\subsection{Dados e Variáveis}

Foram utilizados na pesquisa dados disponibilizados publicamente por diversas entidades, como IBGE, IPEA, STN, ANP, DNPM, ANEEL e MTE. As variáveis dos modelos são aquelas comumente empregadas nos estudos sobre crescimento econômico, a MRN e os gastos públicos. De forma geral, a pesquisa tem uma variável dependente (crescimento econômico) e três tipos de variáveis explanatórias: variáveis de abundância de recursos naturais, variáveis do perfil dos gastos públicos e variáveis de controle.

Conforme explicado adiante, a variável dependente é a taxa de crescimento econômico entre 2004 e 2012, enquanto as variáveis explicativas compreendem o período de 2003 a 2008. Os valores referentes ao PIB, à receita com recursos naturais e aos gastos públicos foram corrigidos pelo IPCA para valores de dezembro de 2014. A descrição dos dados e variáveis comumente utilizados e daqueles adotados nesta pesquisa são apresentados a seguir.

\subsubsection{Variável Crescimento Econômico}

De forma geral, os estudos utilizam a taxa de crescimento do PIB per capita como variável dependente, conforme visto em Sachs e Warner (1995, 1997, 2001); Manzano e Rigobon (2001); Fölster e Henrekson (2001); Atkinson e Hamilton (2003); Bose, Haque e Osborn (2007); Papyrakis e Gerlagh (2007); Postali (2009); Anshasy (2011); e Divino e Silva Jr. (2012). Contudo, outras variáveis podem ser encontradas, como o valor absoluto do PIB per capita, em Ribeiro, Teixeira e Gutierrez (2010); Silva e Santolin (2012); e Ogundipe e Oluwatobi (2013); ou a renda pessoal, em James e Aadland (2010).

Para esta pesquisa, a variável dependente é expressa pela média móvel da taxa de variação do PIB per capita $\left(v p i b_{i, t}\right)$, representada por:

- $v p i b_{i, t}=\frac{1}{T} \sum_{t=1}^{T}\left[\ln \left(p i b_{i, t+5} / p_{i b_{i, t}}\right)\right]$, sendo: pib $b_{i, t+5}$ - PIB per capita do munícipio $i$ no período $t+5$; pib $b_{i, t}$ - PIB per capita do munícipio $i$ no período $t$; $\mathrm{T}$ é quantidade de períodos (igual a cinco).

A média móvel da variável dependente defasada para frente em cinco períodos foi utilizada: para aumentar o número de séries temporais no painel de dados; porque se espera que os rendimentos dos recursos naturais e os gastos públicos levem algum tempo para afetar o crescimento econômico (neste caso, entre $t+1$ e $t+5$ ); e para minimizar os problemas de endogeneidade e causalidade reversa entre os gastos públicos e o crescimento econômico, 
como explicado no apêndice A e em Devarajan, Swaroop e Zou (1996); Kneller, Bleaney e Gemmell (1999); Ghosh e Gregoriou (2008); e Rocha e Giuberti (2007).

Os dados do PIB e da população dos municípios foram coletados da base de dados do Sistema IBGE de Recuperação Automática (SIDRA) para o período de 2003 a 2012. Cabe ressaltar que o dado anual da população dos municípios é uma estimativa feita pelo IBGE para os anos em que não se realizou censo (2003-2006, 2008-2009, 2011-2012).

\subsubsection{Variáveis de Recursos Naturais}

Nos estudos que analisam a MRN, são encontradas, de forma geral, duas medidas para a riqueza em recursos naturais: uma relacionada à dependência dos recursos naturais e outra referente à abundância em recursos naturais. A primeira geralmente é expressa pela razão entre exportações do setor primário ou receitas com recursos naturais sobre o PNB, PIB, exportações totais ou receita total, como visto, por exemplo, em Sachs e Warner (1995, 1997, 2001); Manzano e Rigobon (2001); Atkinson e Hamilton (2003); Papyrakis e Gerlagh (2007); James e Aadland (2010); e Postali e Nishijima (2011).

Contudo, as variáveis de dependência de recursos naturais podem levar a problemas de endogeneidade, conforme explicação no apêndice A, razão que leva alguns pesquisadores a recomendar uma medida de abundância dos recursos naturais nos estudos sobre a MRN, ou seja, a riqueza per capita (STIJNS, 2005; BRUNNSCHWEILER, 2008; BRUNNSCHWEILER; BULTE, 2008a, 2008b; HABER; MENALDO, 2011; KENNEDY; TIEDE, 2013).

Já os estudos com munícipios brasileiros que tangenciam a discussão da MRN com os recursos do petróleo utilizam, geralmente, valores absolutos per capita recebidos a título de royalties e participações especiais do petróleo e gás, como visto em Postali (2009, 2012); Ribeiro, Teixeira e Gutierrez (2010); Postali e Nishijima (2011, 2013); Caçador e Monte (2013); e Caselli e Michaels (2013).

Assim, para esta pesquisa, a variável de recursos naturais é representada pela abundância de recursos naturais, medida pelo valor das receitas com recursos naturais per capita $\left(r n p c_{i, t}\right)$. A receita com recursos naturais é formada pela receita advinda de recursos minerais, de recursos hídricos e da exploração do petróleo.

Estudos mostram também que distintos tipos de recursos naturais podem ter diferentes impactos na economia (BULTE; DAMANIA; DEACON, 2005; ISHAM et al., 2005; SALAI-MARTIN; SUBRAMANIAN, 2013; ANSHASY; KATSAITI, 2015). Dessa forma, foi 
testado o comportamento de cada tipo de recurso natural no crescimento econômico dos municípios, com três variáveis:

- $R m p c_{i, t}$ - variável abundância de recursos minerais = receita com recursos minerais per capita;

- $R h p c_{i, t}$ - variável abundância de recursos hídricos para fins energéticos = receita com recursos hídricos per capita; e

- $R p p c_{i, t}$ - variável de abundância de recursos do petróleo - receita com exploração do petróleo per capita.

A receita com recursos minerais é constituída da compensação financeira pela exploração de recursos minerais (CFEM) distribuída entre os municípios. A informação da CFEM é disponibilizada no sítio da internet do Departamento Nacional de Produção Mineral (DNPM) e traz os valores mensais para cada município, a partir de 2004. Os valores referentes a 2003 foram obtidos de um relatório do DNPM.

A receita com recursos hídricos é constituída da compensação financeira pela utilização de recursos hídricos para fins energéticos e dos royalties da usina de Itaipu, distribuída aos municípios. Essas informações são disponibilizadas anualmente no sítio da internet da ANEEL para cada unidade da federação desde 1997.

A receita com a exploração do petróleo é formada pelos royalties e participações especiais do petróleo distribuídos aos municípios. As informações foram coletadas da base de dados InfoRoyalties compilada a partir das informações constantes na ANP. Essa base, de livre acesso, é elaborada e mantida pelo Programa de Mestrado em Planejamento Regional e Gestão de Cidades da Universidade Cândido Mendes, de Campo dos Goytacazes - RJ.

As variáveis de abundância de recursos naturais são expressas em milhares de reais. $\mathrm{O}$ quadro 3.3 resume as variáveis de recursos naturais utilizadas na pesquisa.

Quadro 3.3 - Variáveis de recursos naturais

\begin{tabular}{|c|c|c|c|}
\hline Variável & Descrição & Dado & Fonte do Dado \\
\hline$R n p c_{i, t}$ & $\begin{array}{l}\text { Abundância de recursos naturais }= \\
\qquad r m p c_{i, t}+r h p c_{i, t}+r p p c_{i, t}\end{array}$ & \multicolumn{2}{|c|}{ Vide $r m p c_{i, t}, r h p c_{i, t}, r p p c_{i, t}$} \\
\hline$R m p c_{i, t}$ & $\begin{array}{l}\text { Abundância de recursos minerais = } \\
\text { receita recursos minerais }_{i, t} / \text { populaçã }_{i, t} / 1000\end{array}$ & $\begin{array}{l}\text { Compensação } \\
\text { financeira de } \\
\text { recursos minerais }\end{array}$ & DNPM \\
\hline$R h p c_{i, t}$ & $\begin{array}{l}\text { Abundância de recursos hídricos }= \\
\text { receita recursos hídricos }{ }_{i, t} / \text { população }_{i, t} / 1000\end{array}$ & $\begin{array}{l}\text { Compensação } \\
\text { financeira de } \\
\text { recursos hídricos }\end{array}$ & ANEEL \\
\hline$R p p c_{i, t}$ & $\begin{array}{l}\text { Abundância de recursos do petróleo }= \\
\text { receita recursos petróleo }_{i, t} / \text { população }_{i, t} / 1000\end{array}$ & $\begin{array}{l}\text { Royalties e } \\
\text { participações } \\
\text { especiais do } \\
\text { petróleo }\end{array}$ & $\begin{array}{l}\text { InfoRoyalties/ } \\
\text { ANP }\end{array}$ \\
\hline
\end{tabular}




\subsubsection{Variáveis de Gastos Públicos}

Nas pesquisas que relacionam crescimento econômico e gastos públicos em diferentes níveis de agregação, alguns estudos analisam os vários níveis dos gastos como proporção do PIB, como em Kneller, Bleaney e Gemmell (2001), Bose, Haque e Osborn (2007), Anshasy (2011); enquanto outros estudos analisam a composição do gasto, ou seja, a razão entre os gastos em vários níveis e o gasto total, como em Atkinson e Hamilton (2003), Devarajan, Swaroop e Zou (1996), Rocha e Giuberti (2007), Ghosh e Gregoriou (2008).

Nesses estudos, os níveis dos gastos analisados contemplam os gastos correntes e de capital no primeiro nível; os gastos com salários e investimentos, no segundo nível; e diversos gastos desagregados relacionados com aplicações específicas do dinheiro público - como em gastos com defesa, educação, saúde, agricultura, indústria, transporte, comunicação, assistência social, habitação etc.--, no terceiro nível.

Nesta pesquisa, o gasto público foi analisado em diferentes níveis de agregação com base na classificação da despesa orçamentária: classificado pela categoria econômica (primeiro nível), pela natureza (segundo) e pela função da despesa pública (terceiro). A variável de gasto é definida pela composição do gasto público, ou seja, pela proporção do gasto em relação ao gasto total. Os dados para as variáveis de gastos foram coletados do balanço orçamentário dos municípios, disponíveis no banco de dados Finanças do Brasil FINBRA da STN.

As variáveis de gastos pela categoria da despesa pública são formadas pelas variáveis de gasto corrente $\left(\operatorname{gcor}_{i, t}\right)$ e de gasto de capital $\left(\operatorname{gcap}_{i, t}\right)$ em relação ao gasto total. Ressaltase que o somatório desses gastos compõe o gasto total; logo, é de se esperar que os gastos correntes e de capital sejam inversamente correlacionados, ou seja, se a proporção do gasto corrente no gasto total aumenta, a proporção do gasto de capital diminui, e vice-versa.

As variáveis de gastos pela natureza da despesa pública são formadas pelas variáveis de gasto com pessoal $\left(\right.$ gpes $\left._{i, t}\right)$, de outros gastos correntes $\left(\right.$ gocr $\left._{i, t}\right)$ e de investimentos $\left(\operatorname{ginv}_{i, t}\right)$, todas proporcionais ao gasto total. A variável gpes $_{i, t}$ designa os gastos com pessoal e encargos sociais. A variável gocr $_{i, t}$ representa os demais gastos correntes, ou seja, os gastos correntes menos os gastos com pessoal em encargos. A variável ginv $v_{i, t}$ representa os gastos com obras, instalações e aquisição de equipamentos permanentes.

A classificação funcional da despesa orçamentária contempla 28 categorias, das quais nove foram selecionadas para serem analisadas na pesquisa, que somadas representam em 
média aproximadamente $80 \%$ dos gastos dos municípios. Incluiu-se também uma décima variável para representar as demais despesas por função. Dessa forma, as variáveis de gastos por função são representadas pelas despesas nas funções: legislativa, administrativa, educação, bem como de assistência social, saúde, urbanismo, habitação, saneamento, gestão ambiental e demais despesas. O quadro 3.4 resume as variáveis de gastos utilizadas na pesquisa.

Quadro 3.4 - Variáveis de gastos públicos

\begin{tabular}{|c|c|c|}
\hline $\begin{array}{c}\text { Nível de } \\
\text { desagregação }\end{array}$ & $\begin{array}{c}\text { Classificação } \\
\text { do gasto }\end{array}$ & Variáveis de gastos \\
\hline 1 & $\begin{array}{l}\text { Categoria } \\
\text { econômica }\end{array}$ & $\begin{array}{l}\text { - } \text { gcor }_{\mathrm{i}, \mathrm{t}} \text { - gasto corrente do município i no período t; } \\
\text { - } \operatorname{ccap}_{i, t} \text { - gasto de capital do município i no período t; }\end{array}$ \\
\hline 2 & $\begin{array}{l}\text { Natureza da } \\
\text { despesa }\end{array}$ & $\begin{array}{l}\text { - } \text { gpes }_{\mathrm{i}, \mathrm{t}} \text { - gasto com pessoal do município i no período t; } \\
\text { - } \text { gocr }_{\mathrm{i}, \mathrm{t}}-\text { outros gastos correntes do município i no período t; } \\
\text { - } \text { ginv }_{\mathrm{i}, \mathrm{t}}-\text { gasto em investimentos do município i no período t; }\end{array}$ \\
\hline 3 & Função & 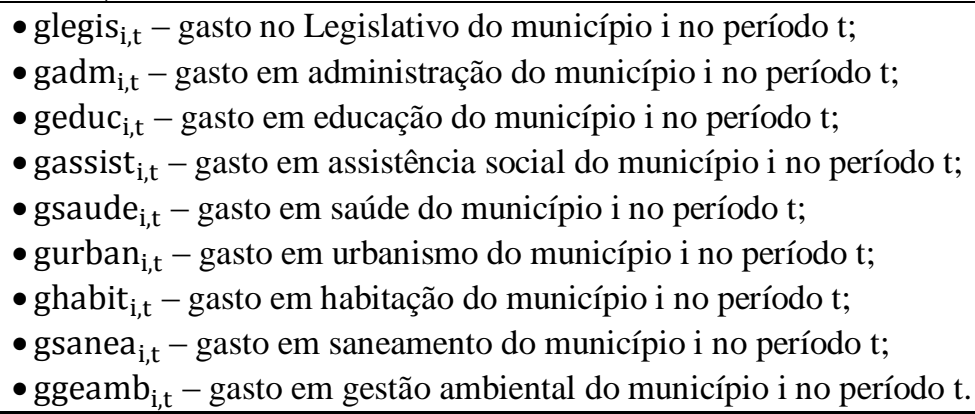 \\
\hline
\end{tabular}

O gasto corrente, com pessoal e outros gastos correntes estão relacionados com a prestação e manutenção de serviços públicos e, quando direcionados principalmente para áreas em potencial, podem contribuir para o crescimento econômico, como educação e saúde. O gasto de capital e em investimentos estão relacionados com o aumento da infraestrutura, que será explorada tanto pelo setor público quanto privado, assim servindo de suporte para o crescimento econômico.

Mediante a formulação de leis e da melhoria da gestão dos recursos públicos, os gastos com o Legislativo e com a administração podem ser relacionados à formação de um ambiente político e econômico favorável de forma a incentivar o crescimento econômico. $\mathrm{O}$ gasto em educação pode ser relacionado com o aumento do capital humano, pois a mão de obra mais qualificada teria maior capacidade de contribuir para o crescimento dos municípios.

Os gastos em assistência social, saúde, urbanismo, habitação e saneamento estão relacionados com a busca pelo bem-estar geral da população, o que pode refletir numa força de trabalho mais empenhada e motivada, contribuindo para o crescimento econômico. Os gastos em gestão ambiental podem ser também assim entendidos, e sua importância é ainda 
maior nos municípios em que ocorre a exploração de recursos naturais, tendo em vista os efeitos deletérios desta atividade no meio ambiente. Nessa linha, Serrano, Gonçalves e Gonçalves (2013) discutem como a gestão ambiental pode influenciar as políticas públicas.

\subsubsection{Variável Dummy para o Nível de Abundância}

Para as subamostras contendo apenas municípios que receberam receitas com a exploração de recursos naturais, a variável dummy representa os municípios com as maiores receitas per capita, tendo como base os municípios do último quartil do ordenamento das receitas para cada um dos anos do período em estudo. Essa variável é utilizada nos modelos 4 e 5 para verificar se a relação entre recursos naturais, gasto público e crescimento econômico entre municípios mais e menos abundantes é a mesma observada para municípios abundantes ou não (modelo 1 a 3). Dessa forma, foram calculados quatro variáveis dummy para o nível de riqueza natural, uma para cada subamostra:

- $d r n_{i, t}-d u m m y$ para os municípios com maiores receitas per capita de exploração dos recursos naturais no período t;

- $d r h_{i, t}$ - dummy para os municípios com maiores receitas per capita de exploração dos recursos hídricos no período t;

- $d r m_{i, t}-d u m m y$ para os municípios com maiores receitas per capita de exploração dos recursos minerais no período t;

- $\quad d r p_{i, t}-d u m m y$ para os municípios com maiores receitas per capita de exploração dos recursos do petróleo no período t.

\subsubsection{Variáveis de Controle}

Como variáveis de controle foram utilizadas: o capital humano, o porte, a variação do preço das commodities e o nível do gasto público. Ressalta-se que a utilização de variáveis de controle é limitada nos estudos com municípios e que envolvem séries temporais, em razão da disponibilidade limtada de dados anuais. Nos estudos com municípios brasileiros aqui levantados, utiliza-se de forma comum uma variável de controle representada pelo tamanho da população, como visto em Postali e Rocha (2009), Postali e Nishijima (2011, 2013), Postali (2012) e Caçador e Monte (2013).

A variável de capital humano (caphum) está relacionada com a especialização do corpo produtivo, assim quanto mais conhecimentos tiver a força de trabalho, maior tende a ser o crescimento econômico. Entretanto, a literatura indica que os recursos naturais podem ter 
efeitos adversos na acumulação de capital humano (SACHS; WARNER, 1995; GYLFASON; HERBERTSSON; ZOEGA, 1999).

Nesta pesquisa, a variável de capital humano é representada pelos anos médios de estudo dos registros da Relação Anual de Informações Sociais - RAIS do MTE. Como na RAIS consta a quantidade de registros para cada nível de escolaridade, foi adotada uma estimativa dos anos de estudos para cada nível, como demonstrado no quadro 3.5.

- $\operatorname{caphum}_{i t}=\sum_{k=1}^{k} A_{k} Q_{k i t} / Q_{i t}=$ anos médios de estudos ${ }_{i t}$

sendo:

$\sum_{k=1}^{k} A_{k} Q_{k i t}$ - o somatório dos produtos entre os anos estimados de estudo para o nível de escolaridade $k\left(A_{k}\right)$ e a quantidade de registrados na RAIS no nível de escolaridade $k$ no município $i$ no período $t\left(Q_{k i t}\right)$;

$Q_{i, t}$ - quantidade de registros na RAIS no município $i$ no período $t$.

\begin{tabular}{|c|c|}
\hline Escolaridade & Anos estimados \\
\hline Analfabeto & 0 \\
\hline Até o $5^{\mathrm{a}}$ ano $\left(4^{\mathrm{a}}\right.$ serie $\left.{ }^{1}\right)$ incompleto & 2,5 \\
\hline Até o $5^{\mathrm{a}}$ ano $\left(4^{\mathrm{a}}\right.$ serie $\left.^{1}\right)$ completo & 5 \\
\hline Do $6^{\mathrm{a}}$ a $9^{\mathrm{a}}$ ano $\left(5^{\mathrm{a}}\right.$ a $8^{\mathrm{a}}$ serie $\left.^{\mathrm{c}}\right)$ incompleto & 7 \\
\hline Fundamental completo (até a $8^{\mathrm{a}}$ serie $^{1}$ ) & 9 \\
\hline Médio $\left(2^{\circ} \operatorname{grau}^{1}\right)$ incompleto & 10,5 \\
\hline Médio $\left(2^{\circ}\right.$ grau $\left.^{1}\right)$ completo & 12 \\
\hline Superior incompleto & 14 \\
\hline Superior completo & 16 \\
\hline
\end{tabular}

A variável porte (porte) está relacionada com o tamanho do município. Municípios maiores possuem estruturas e necessidades diferentes de municípios menores que podem influenciar o crescimento econômico e, assim, a gestão dos recursos naturais e a composição dos gastos públicos . O porte foi medido pelo logaritmo do tamanho da população.

As variáveis de índice de commodities (vicom e vicoe) têm por objetivo controlar os efeitos dos rendimentos dos recursos naturais no crescimento pela variação nos preços. Alguns estudos atribuem parte dos efeitos da MRN às incertezas decorrentes da oscilação dos preços das commodities nas receitas de recursos naturais (AUTY, 1994, 1997; DAVIS, 1995; DAVIS et al., 2001; SACHS; WARNER, 1997). Desse modo, a variação dos Índices de Commodities Metal e Energia do Bacen foi utilizada para constituir duas variáveis: 
- vicom $_{i t}=\ln \left(\right.$ icom $_{t} /$ icom $\left._{t-1}\right)$ - variação do índice de commodities metal para os municípios com receitas da exploração de recursos minerais; e

- vicoe $_{i t}=\ln \left(\right.$ icoe $_{t} /$ icoe $\left._{t-1}\right)-$ variação do índice de commodities energia para os municípios com receitas da exploração de recursos do petróleo.

O icom é formado pelos preços das commodities de alumínio, minério de ferro, cobre, estanho, zinco, chumbo e níquel; enquanto o icoe é formado pelos preços das commodities de petróleo do tipo brent, gás natural e carvão.

A variável nível do gasto público (nig) tem a função de controlar pelo efeito do financiamento do gasto público no crescimento, que está relacionado com o nível do gasto. Devarajan, Swaroop e Zou (1996) explicam que o gasto público, para ser produtivo sem que seja necessário aumentar o gasto total (nível do gasto), deve exceder o peso morto da arrecadação necessária para financiá-lo. Logo, esta variável é designada como:

- nig $_{i t}=g^{\text {total }_{i t}} /_{\text {pib }}$, sendo: gtotal $_{i t}$ - o gasto total do município i no período t.

\subsection{Procedimentos e Testes de Qualidade dos Ajustes}

Para garantir a qualidade dos resultados empíricos de acordo com os pressupostos dos modelos de regressão, foram adotados os procedimentos a seguir:

- Para a estacionariedade das séries - foi utilizado o teste Harris e Tzavalis para identificar a presença de raiz unitária no painel de dados. Este teste é indicado para os casos em que o painel é balanceado e a quantidade de indivíduos (N) é maior que a de unidades temporais (T) (BALTAGI, 2005);

- Aderência do modelo para efeitos fixos - foram utilizados o teste F para verificar a consistência dos parâmetros de efeitos fixos individuais e para a consistência dos efeitos fixos de tempo e o teste de Hausman para a consistência dos efeitos aleatórios;

- Endogeneidade - para minimizar o nível de endogeneidade, foi utilizada a variável de abundância de recursos naturais, como sugerido por Brunnschweiler (2008) e Brunnschweiler e Bulte (2008a, 2008b); foi adotada a defasagem de cinco anos para frente da variável dependente, como em Devarajan, Swaroop e Zou (1996), Ghosh e Gregoriou (2008) e Rocha e Giuberti (2007). No apêndice A, apresenta-se uma explicação para a endogeneidade; 
- Normalidade dos resíduos - com base no Teorema Central do Limite, em amostra grandes, as médias amostrais tendem a ter distribuição normal (BROOKS, 2008; GUJARATI, 2006). Como a amostra utilizada contém 22.865 observações, assume-se a normalidade dos resíduos dos modelos;

- $\quad$ Para a colinearidade das variáveis independentes - utilizou-se o fator de inflação da variância (VIF), além da inspeção da matriz de correlação das variáveis, para verificar o risco de multicolinearidade;

- Para a heterocedasticidade - foi utilizado o teste modificado de Wald para a probabilidade de heterocedasticidade em grupo em modelos de regressão com efeitos fixos;

- Para a autocorrelação dos resíduos - foi utilizado o teste de Wooldridge para a probabilidade de correlação serial em dados em painel;

- Modelos com erros-padrão robustos - nos modelos em que as hipóteses de homocedasticidade e ausência de correlação serial tenham sido rejeitadas, foram utilizados erros-padrão robustos com agrupamento por indivíduo, também conhecido por erros-padrão de Rogers, indicado para dados em painel (HOECHLE, 2007).

\subsection{Delimitação/Escopo da pesquisa}

A abundância em recursos naturais é uma medida de riqueza dada pelo volume de recursos naturais. Nos estudos sobre a MRN, a abundância geralmente é uma medida do volume de rendimentos que uma localidade aufere pela exploração de seus recursos naturais, seja pelo volume exportado, pelo volume produzidos ou pelas receitas em geral. Falar em abundância somente faz sentido pela comparação entre as localidades que são ou não abundantes e/ou mais e menos abundantes em recursos naturais.

Nesta pesquisa, a abundância em recursos naturais é entendida como o volume de receita referente à compensação financeira advinda da concessão do direito de exploração de tais recursos. Essa receita pode representar uma vantagem arrecadadora para alguns municípios, pois nem todos a auferem e/ou o volume recebido por alguns é maior do que por outros.

Vale ressaltar que a atividade de exploração pode gerar outras receitas para os municípios, principalmente a tributária, além de trazer outras vantagens, como o desenvolvimento de programas sociais pelas empresas de exploração como parte de 
exigências dos contratos de concessão. Embora tais pontos possam representar importante vantagem para os municípios, não entram no mérito deste trabalho.

O foco da pesquisa são os recursos naturais relacionados com exploração dos recursos hídricos para geração de energia elétrica, dos recursos minerais e do petróleo. A exploração de outros recursos naturais, como o uso da terra para a produção vegetal e agropecuária e dos rios e costa marítima para pesca e aquicultura, apesar de serem igualmente ou até mais importantes para a economia de alguns municípios, não entraram no escopo deste estudo.

Os dados utilizados sobre a compensação financeira se referem ao valor efetivamente transferido aos municípios em cada período, não necessariamente condizente com o momento da exploração do recurso natural. Conforme visto anteriormente na seção 2.5 , o pagamento da compensação deve ocorrer até dois meses após o fato gerador. Contudo, Brito e Lima (2015) sugerem o registro da compensação como um direito a receber quando do fato gerador, de forma a auxiliar o ordenador de despesas a planejar as escolhas e decisões.

A MRN pode ser atribuída a características das localidades onde ocorre a exploração dos recursos naturais relacionadas a fatores econômicos e políticos na gestão das rendas decorrentes desta exploração. Nesse sentido, as escolhas da política fiscal sobre a arrecadação e a aplicação dos rendimentos desses recursos têm sido apontadas como uma característica dessas localidades que poderiam conduzir à MRN. Assim, esta pesquisa tem como foco o lado do gasto público da política fiscal como possível mecanismo de transmissão da MRN.

Por fim, ressalta-se que o gasto público em determinadas funções podem fazer parte de políticas públicas do governo estadual ou federal - como a educação e a habitação, por exemplo - as quais, apesar de poderem contribuir para o crescimento econômico dos municípios, não são apresentadas nas informações constantes no balanço municipal. Ainda assim, o foco da pesquisa são os gastos "dos" municípios e não "nos" municípios. 


\section{ANÁLISE DOS RESULTADOS}

A compreensão da relação empírica entre recursos naturais, gasto público e crescimento econômico que resultam na MRN pode ser sistematizada no modelo analítico apresentado na figura 4.1. Esse modelo tem como base o problema e os objetivos da pesquisa (páginas 20-21), o arcabouço teórico (páginas 24 e 41) e os modelos empíricos estimados (página 56). A abundância em recursos naturias representa uma vantagem para os municípios com influência direta no crescimento econômico, ou indireta pela utilização de tais recursos para financiarem o seu gasto (produtivo ou não). Quando essas relações diretas e indiretas resultam no crescimento econômico fraco, são denominadas de MRN.

Figura 4.1 - Modelo analítico

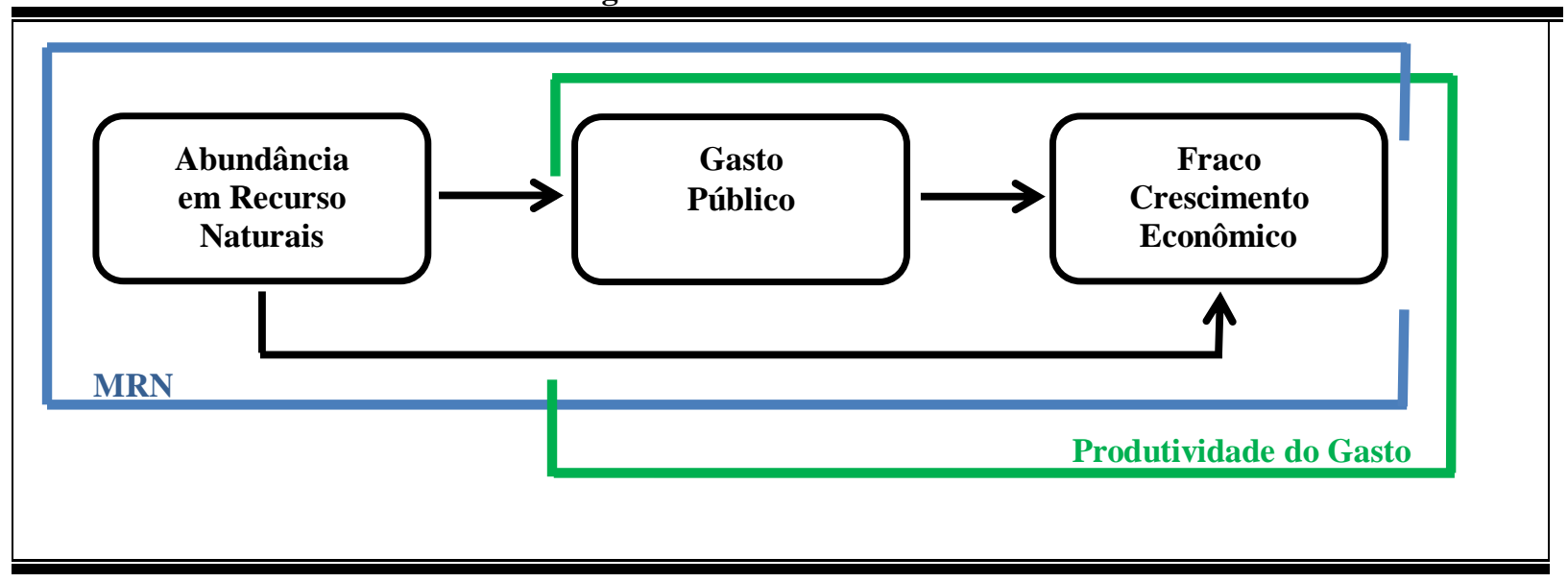

Assim, neste capítulo, são apresentados os resultados da pesquisa a partir da estimação dos modelos empíricos propostos. Inicialmente, são apresentadas as estatísticas descritivas das variáveis analisadas; em seguida, comentam-se os resultados dos testes de qualidade dos ajustes dos modelos empíricos. Na sequência, examina-se o comportamento das variáveis de recursos naturais e de gastos públicos no crescimento econômico. Por fim, analisam-se também as relações das variáveis de controle de forma geral para todos os modelos.

\subsection{Estatísticas Descritivas}

A tabela 4.1 apresenta as estatísticas descritivas das variáveis para amostra e período do estudo. Os municípios da amostra tiveram taxa de crescimento econômico per capita médio de 5,2\% para o período de 2003 a 2012, sendo que a amostra-período do estudo 
contempla desde municípios com variação negativa do PIB de 37,5\% (mínimo) até município com variação positiva de 62,5\% (máximo).

As estatísticas das variáveis de recursos naturais foram calculadas considerando-se somente os municípios que receberam receitas com recursos naturais em algum momento. Assim, a amostra contempla 10.374 observações de 2.575 municípios que receberam algum tipo de receita pela exploração de recursos naturais (Rnpc); 2.768 observações de 585 municípios com receitas pela exploração de recursos hídricos (Rhpc); 6.475 observações de 1.900 municípios com receitas pela exploração de recursos minerais (Rmpc); 3.146 observações de 683 municípios com receitas pela exploração de recursos petróleo (Rhpc).

Tabela 4.1 - Estatísticas descritivas

\begin{tabular}{lrrrrrrrr}
\hline \hline Variáveis & Obs. & \multicolumn{1}{c}{ Média } & \multicolumn{1}{c}{ D.P. } & \multicolumn{1}{l}{ Mín. } & \multicolumn{1}{c}{ Máx. } & $\mathbf{1}^{\mathbf{0}} \mathbf{Q}$ & $\mathbf{2}^{\mathbf{0}} \mathbf{Q}$ & $\mathbf{3}^{\mathbf{0}} \mathbf{Q}$ \\
\hline vpib & 22865 & 0,052 & 0,047 & $-0,375$ & 0,625 & 0,029 & 0,052 & 0,074 \\
Rnpc & 10374 & 84,52 & 405,52 & 0,01 & 10.888 & 0,19 & 2,15 & 25,40 \\
Rhpc & 2768 & 152,25 & 428,75 & 0,01 & 9.106 & 7,08 & 40,99 & 144,54 \\
Rmpc & 6745 & 10,46 & 86,37 & 0,01 & 4.374 & 0,06 & 0,25 & 1,19 \\
Rppc & 3146 & 122,31 & 592,42 & 0,01 & 10.888 & 0,52 & 3,31 & 22,08 \\
gcor & 22865 & 0,882 & 0,064 & 0,319 & 1,000 & 0,851 & 0,892 & 0,925 \\
gcap & 22865 & 0,118 & 0,064 & 0,000 & 0,681 & 0,075 & 0,108 & 0,149 \\
gpes & 22865 & 0,444 & 0,076 & 0,000 & 1,000 & 0,396 & 0,448 & 0,495 \\
gocr & 22865 & 0,435 & 0,073 & 0,000 & 1,000 & 0,386 & 0,431 & 0,481 \\
ginv & 22865 & 0,101 & 0,064 & 0,000 & 0,681 & 0,056 & 0,088 & 0,130 \\
glegis & 22865 & 0,037 & 0,018 & 0,000 & 1,000 & 0,029 & 0,039 & 0,048 \\
gadm & 22865 & 0,172 & 0,075 & 0,000 & 1,000 & 0,122 & 0,157 & 0,205 \\
gassist & 22865 & 0,039 & 0,025 & 0,000 & 0,304 & 0,021 & 0,034 & 0,051 \\
gsaude & 22865 & 0,209 & 0,052 & 0,000 & 0,538 & 0,180 & 0,207 & 0,237 \\
geduc & 22865 & 0,286 & 0,075 & 0,000 & 0,633 & 0,234 & 0,276 & 0,332 \\
gurban & 22865 & 0,084 & 0,056 & 0,000 & 0,522 & 0,041 & 0,080 & 0,117 \\
ghabit & 22865 & 0,005 & 0,016 & 0,000 & 0,380 & 0,000 & 0,000 & 0,004 \\
gsanea & 22865 & 0,017 & 0,030 & 0,000 & 0,457 & 0,000 & 0,004 & 0,022 \\
ggeamb & 22865 & 0,003 & 0,010 & 0,000 & 0,427 & 0,000 & 0,000 & 0,002 \\
caphum & 22865 & 9,300 & 1,267 & 2,222 & 16,000 & 8,541 & 9,381 & 10,133 \\
porte & 22865 & 35.382 & 212.991 & 863 & 11.016 .703 & 5.037 & 10.635 & 22.880 \\
nig & 22865 & 0,178 & 0,106 & 0,000 & 0,865 & 0,096 & 0,153 & 0,238 \\
vicom & 22865 & 0,064 & 0,192 & $-0,214$ & 0,362 & $-0,038$ & 0,058 & 0,154 \\
vicoe & 22865 & 0,029 & 0,174 & $-0,288$ & 0,220 & $-0,005$ & 0,086 & 0,131 \\
\hline \hline & & & & & & & & \\
\hline
\end{tabular}

A receita per capita média com recursos naturais foi de $\mathrm{R} \$ 84,52$ para os municípios da amostra, sendo que a receita média foi maior para exploração de recursos minerais ( $R$ \$ 152,25 per capita). O desvio-padrão (D.P.) indica grande dispersão das observações referentes às receitas com recursos naturais. $\mathrm{Na}$ amostra, estão presentes desde municípios 
que tiveram um centavo de real de receita per capita com exploração de algum tipo de recurso natural até município com receita média anual de $\mathrm{R} \$ 10.888$ per capita com recursos do petróleo.

Das variáveis de gasto público, o gasto corrente representou $88 \%$ e o gasto de capital, $12 \%$ em média dos gastos dos municípios da amostra-período estudada. Dos quartis verificase que o gasto corrente dos municípios foi muito próximo; enquanto para $25 \%$ da amostra o gasto corrente foi de até $85 \%$ dos gastos totais, para $50 \%$ da amostra foi de até $89 \%$ e para $75 \%$ da amostra foi de até $93 \%$ dos gastos totais. O gasto de capital teve maior dispersão entre os municípios, uma vez que, no segundo quartil, o gasto de capital foi $44 \%$ maior do que o valor do primeiro quartil; e, no terceiro quartil, foi quase o dobro do primeiro quartil.

O gasto com pessoal (gpes) e os outros gastos correntes (gocr) correspondam ao gasto corrente e apresentam médias próximas a $44 \%$ dos gastos totais e baixa dispersão (baixa variação entre os quartis), indicando que a composição destes gastos é muito próxima entre os municípios e os períodos. O gasto em investimentos (ginv) representa a maior parte do gasto de capital e, aproximadamente, $10 \%$ do gasto total em média, sendo que a dispersão na amostra é alta; o segundo quartil é $57 \%$ e o terceiro, $232 \%$ maior que o primeiro.

Dos gastos por função, os gastos médios em saúde (gsaude) e educação (geduc) correspondem a maior composição dos gastos dos municípios, $21 \%$ e $29 \%$ respectivamente. Dos gastos analisados, os gastos médios em habitação (ghabit), gestão ambiental (ggeamb) e saneamento (gsanea) foram os gastos com menor proporção nos gastos totais $(0,5 \%, 0,3 \%$ e $1,7 \%$, respectivamente), sendo que, para pelo menos metade dos municípios, não constavam gastos em habitação e gestão ambiental no período analisado (segundo quartil). Isso pode ocorrer porque a habitação geralmente faz parte de programas sociais do governo federal.

Pelas estatísticas descritivas da variável capital humano (caphum), observa-se que o tempo médio de estudos dos empregados formais dos municípios é de 9,3 anos, o que equivaleria ao ensino fundamental (vide quadro 3.5). Pela variável porte, verifica-se que os municípios da amostra têm em média 35.382 habitantes, contemplando desde municípios com 863 habitantes até com mais de 11 milhões de habitantes, embora pelo menos $75 \%$ das observações (terceiro quartil) correspondam a municípios pequenos (menores que 50 mil habitantes).

O nível do gasto público (nig) foi de 17,8\% em média na amostra, incluídos municípios com $0,01 \%$ a $86,5 \%$ do PIB equivalente ao gasto público, sendo que, em pelo menos $75 \%$ da amostra, o gasto público representou até $24 \%$ do PIB dos municípios. A 
variação dos índices de commodities metal (vicom) e energia (vicoe) foi de 6,4\% e 2,9\% em média, respectivamente, para o período do estudo.

A correlação entre as variáveis é apresentada na matriz de correlação no apêndice B. De forma geral, as variáveis de recursos naturais e de gasto têm correlação muito fraca com o crescimento econômico (vpib). O gasto corrente e de capital tem correlação perfeita e negativa, o que já era esperado, tendo em vista que estes gastos formam os gastos totais. Por essa razão, essas variáveis foram testadas em modelos separados para reduzir o risco de colinearidade entre as variáveis dos modelos. De maneira análoga, o gasto em investimentos, que compõe o gasto de capital, e o gasto corrente têm correlação quase perfeita e negativa.

\subsection{Comentários aos Testes de Qualidade dos Ajustes e Estimação dos Modelos}

Os resultados do teste de Harris-Tazavalis (HT) para estacionariedade das séries das variáveis estão no apêndice C. Para as variáveis de abundância em recursos hídricos (Rhpc) e abundância em recursos minerais (Rmpc), a estatística do teste HT foi menor do que a estatística $z(p$-value $=1,0)$, sugerindo a não rejeição da hipótese nula de presença de raiz unitária nas séries destas variáveis. Para as demais variáveis, a hipótese nula foi rejeitada, ou seja, as séries destas variáveis são estacionárias. Portanto, na estimação dos modelos empíricos, foi utilizada a primeira diferença das variáveis de recursos naturais.

Os resultados do teste para o risco de colinearidade das variáveis independentes encontram-se no apêndice D. No modelo para a produtividade dos gastos por grupo da natureza (2.3), com as variáveis de gasto com pessoal, outros gastos correntes e investimentos, o fator de inflação da variância (VIF) foi maior do que 10, indicando o risco de multicolinearidade, embora a correlação entre essas variáveis tenha sido fraca ou moderada. Assim, elas foram testadas separadamente (modelos 2.4 e 2.5).

Também, nos modelos 3 e 5, o VIF foi maior do que 10 para as variáveis de interação e de recursos naturais. Embora possa parecer um problema, a multicolinearidade é uma característica dos modelos de regressão com variáveis de interação e, aparentemente, não interfere na qualidade das estimações, conforme explicado no apêndice E. Para os demais modelos estimados, não foi identificado risco de multicolinearidade entre as variáveis.

Os resultados dos testes de qualidade dos ajustes dos modelos estão no apêndice F. Tendo em vista que, na estimação por LSDV, são inseridas variáveis dummies para os efeitos fixos individuais, foi realizado o teste $\mathrm{F}$ para verificar a aderência dos modelos de efeitos fixos nos modelos. Esse teste é uma versão simples do teste de Chow, conforme sugerido por 
Baltagi (2005) para verificar a significância dos efeitos fixos. Em todos os modelos, foi rejeitada a hipótese nula de que as dummies eram iguais a zero, dando suporte à estimação por LSDV.

Outrossim, o teste $\mathrm{F}$ foi executado para verificar a aderência dos efeitos fixos de tempo nos modelos, sendo igualmente rejeitada a hipótese nula de que as variáveis de tempo fossem iguais a zero em todos os modelos. O teste de Hausman para aderência dos modelos aos efeitos aleatórios indicou a rejeição da hipótese de diferença não sistemática nos coeficientes, sugerindo que a estimação dos modelos por efeitos fixos seria mais adequada.

No teste modificado de Wald para a probabilidade de heterocedasticidade em grupo em modelos de regressão com efeitos fixos, a hipótese nula de homocedasticidade dos resíduos foi rejeitada em todos os modelos. Da mesma forma, a hipótese nula de autocorrelação de primeira ordem nos resíduos do teste de Wooldridge foi rejeitada.

Portanto, em razão da aderência dos modelos aos efeitos fixos individuais e de tempo e dos riscos de heterocedasticidade e autocorrelação dos resíduos, todos os modelos apresentados a seguir foram estimados por Least Square Dummy Variable (LSDV) com efeitos específicos de tempo e erros-padrão robustos a heterocedasticidade e a correlação serial, agrupados por municípios (conhecido como erros-padrão de Rogers).

\subsection{Recursos Naturais e o Crescimento Econômico dos Municípios}

Os estudos que investigam a contribuição da exploração de recursos naturais e o crescimento econômico têm demonstrado que, embora o recurso natural possa ser uma vantagem econômica, a relação entre eles é negativa, sugerindo que, nas localidades onde ocorre a exploração, o crescimento econômico é menor do que nas demais localidades, o que se convencionou denominar como maldição dos recursos naturais.

Nesse sentido, a estimação do modelo 1 (página 56), apresentada na tabela 4.2, com municípios brasileiros que recebem ou não receitas (compensações financeiras) pela exploração de recursos naturais - seja hídrico, mineral e/ou petróleo -, mostra que a abundância em recursos naturais teve relação negativa e significativa a $1 \%$ com o crescimento econômico per capita. Esse modelo com a variável de recursos naturais total (Rnpc) (modelo 1a) explica $18,2 \%$ da variação do crescimento econômico dos municípios e é estatisticamente significativo a $1 \%$.

Por esse resultado, a cada mil reais de receita per capita com recursos naturais recebidos pelos municípios, a variação do PIB per capita foi menor em 5,7 pontos percentuais 
em média. Ou, ainda, tal resultado pode indicar que o crescimento econômico, no período de 2004 a 2012, dos municípios abundantes em recursos naturais foi em média menor do que nos municípios não abundantes, o que sugere que a ocorrência da maldição dos recursos naturais pode ser observada nos municípios brasileiros para o período estudado.

Tabela 4.2 - Abundância em recursos naturais e crescimento econômico

\begin{tabular}{crr}
\hline \hline & 1a & $\mathbf{1 b}$ \\
\hline Rnpc & $-0,0568$ *** & \\
& $(-2,62)$ & $-0,0301$ \\
Rhpc & & $(-1,21)$ \\
Rmpc & & $-0,132 \quad * * *$ \\
& & $(-15,79)$ \\
Rppc & & $-0,034 * * *$ \\
& & $(-4,04)$ \\
Munic. & 4573 & 4573 \\
Obs. & 18292 & 18292 \\
R2 Aj. & 0,1819 & 0,1888 \\
F & 396,47 & 351,02 \\
Prob>F & 0,00 & 0,00 \\
Controles & Sim & Sim \\
Efeitos tempo & Sim & Sim \\
\hline \hline
\end{tabular}

Resultados das estimações do modelo 1 (pág. 56): $C_{i t}=\alpha+\beta R_{i t}+\sum_{j=1}^{j} \delta_{j}^{Z} Z_{j, i t}+\varepsilon_{i t}$. Variável dependente é o crescimento econômico. Modelos estimados por LSDV com efeitos fixos de tempo e erros-padrão robustos agrupados por municípios. ***, ** e * referem-se à significância dos coeficientes a 1\%,5\% e 10\%, respectivamente. Entre parênteses, a estatística t dos coeficientes. Resultados das variáveis de controle, efeitos fixos de tempo e testes de qualidade dos ajustes estão nos apêndices F e G. Legenda das variáveis: Rnpc - abundância em recursos naturais em milhares de reais; Rhpc - abundância em recursos hídricos em milhares de reais; Rmpc - abundância em recursos minerais em milhares de reais; Rppc - abundância em recursos do petróleo em milhares de reais.

$\mathrm{Na}$ estimação do modelo $1 \mathrm{~b}$ (tabela 4.2), a variável de abundância em recursos naturais total foi desmembrada nos três tipos de recursos naturais que a compõem - recursos hídrico, mineral e do petróleo -, para verificar a contribuição de cada um deles no crescimento econômico dos municípios. Os resultados mostram que a abundância em recursos hídricos, embora tivesse relação negativa com a variação do PIB, não foi estatisticamente significativa - não sendo possível inferir que a receita pela exploração de recursos hídricos para fins energéticos tenha contribuído para o crescimento dos municípios com tais receitas.

Ainda no modelo $1 b$, verifica-se que a relação da abundância em recursos minerais e da abundância em recursos do petróleo com o crescimento foi negativa e estatisticamente significante a $1 \%$, insinuando que as receitas com recursos minerais e do petróleo impactaram negativamente o crescimento econômico dos munícipios que receberam tais receitas. 
O maior impacto é observado nos municípios abundantes em recursos minerais, onde a cada mil reais per capita recebidos a título de compensação financeira, o crescimento foi menor, em média, 13,2 pontos percentuais em comparação com os municípios que não receberam essa compensação. Nos municípios abundantes em recursos do petróleo, a cada mil reais per capita recebidos a título de royalties e participação especial, o crescimento econômico foi, em média, 3,4 pontos percentuais menor do que nos municípios não abundantes.

Para verificar se o nível de abundância em recursos naturais teria alguma influência no crescimento econômico dos municípios que receberam algum tipo de receita com recursos naturais, o modelo 4 (página 59) foi estimado com municípios que obtiveram tal receita em todos os anos do período de 2003 a 2007, como apresentado na tabela 4.3. A variável dummy foi incluída para designar o efeito dos recursos naturais no crescimento para os municípios com maior volume de receita per capita com recursos naturais em cada um dos anos.

De forma geral, no modelo $4 \mathrm{a}$, verifica-se a persistência da relação negativa entre recursos naturais totais e crescimento econômico quando se observa somente os municípios que tiveram receita com algum tipo de recurso natural em todos os anos do período estudado (1.544). A variável dummy para os municípios com maior volume de receita per capita foi igualmente negativa e significativa, indicando que, nos municípios mais abundantes em recursos naturais o crescimento econômico foi menor em média 1,8 pontos percentuais em comparação com os municípios com menor volume de receita.

No modelo 4b, estimado para 519 municípios que tiveram receitas com recursos hídricos em todos os anos, a variável de abundância em recursos hídricos continuou negativa e não significativa, tal como no modelo 1 b. Contudo, a variável dummy para os municípios com maiores receitas com recursos hídricos foi negativa e estatisticamente significativa a $1 \%$, sugerindo que nos municípios mais abundantes em recursos hídricos, o crescimento econômico foi menor do que nos municípios menos abundantes.

No modelo 4c, que contém apenas municípios com receitas com recursos minerais, a variável de abundância em recursos minerais (Rmpc) foi negativa, como no modelo $1 \mathrm{~b}$, embora não estatisticamente significante. Igualmente, a variável binária para os municípios mais abundantes foi negativa e não significativa. Esses resultados sugerem que o crescimento econômico dos municípios abundantes em recursos minerais se comporta de maneira semelhante; contudo, comparados com os municípios que não receberam nenhum tipo de receita com recursos naturais (modelo $1 \mathrm{~b}$ ), o crescimento foi em média menor. 
Tabela 4.3 - Nível de abundância em recursos naturais e crescimento econômico

\begin{tabular}{|c|c|c|c|c|}
\hline & $\bar{A}$ & B & $\bar{C}$ & D \\
\hline & $4 a$ & $4 \mathrm{~b}$ & $4 c$ & $4 d$ \\
\hline & $\mathrm{D}=\mathrm{drn}$ & $\mathrm{D}=\mathrm{drh}$ & $\mathrm{D}=\mathrm{drm}$ & $\mathrm{D}=\operatorname{drp}$ \\
\hline Rnpc & $\begin{array}{rl}-0.0296 & * * * \\
(-4.29) & \end{array}$ & & & \\
\hline Rhpc & & $\begin{array}{r}-0.0133 \\
(-0.78)\end{array}$ & & \\
\hline Rmpc & & & $\begin{array}{l}-0.031 \\
(-0.50)\end{array}$ & \\
\hline Rppc & & & & $\begin{array}{r}-0.0306 * * * \\
(-4.44)\end{array}$ \\
\hline D & $\begin{array}{l}-0.018 * * * \\
(-3.23)\end{array}$ & $\begin{array}{r}-0.0213 \quad * * * \\
(-3.06)\end{array}$ & $\begin{array}{r}-0.000923 \\
(-0.21)\end{array}$ & $\begin{array}{r}-0.00528 \\
(-0.90)\end{array}$ \\
\hline Munic. & 1544 & 519 & 673 & 576 \\
\hline Obs. & 6176 & 2076 & 2692 & 2304 \\
\hline R2 Aj. & 0.2024 & 0.2319 & 0.1992 & 0.1649 \\
\hline $\mathbf{F}$ & 148.38 & 77.92 & 85.54 & 55.46 \\
\hline Prob $>$ F & 0.00 & 0.00 & 0.00 & 0.00 \\
\hline Controles & Sim & Sim & Sim & Sim \\
\hline Efeitos tempo & Sim & Sim & Sim & Sim \\
\hline \multicolumn{5}{|c|}{$\begin{array}{l}\text { Resultados das estimações do modelo } 4 \text { (pág. 59): } C_{i t}=\alpha+\beta R_{i t}+\theta D_{i t}+\sum_{j=1}^{j} \delta_{j}^{Z} Z_{j, i t}+\varepsilon_{i t} \text {. Variável } \\
\text { dependente é o crescimento econômico. Modelos estimados por LSDV com efeitos fixos de tempo e erros- } \\
\text { padrão robustos agrupados por municípios. } * * *, * * \mathrm{e} * \text { referem-se à significância dos coeficientes a } 1 \%, 5 \% \mathrm{e} \\
10 \% \text {, respectivamente. Entre parênteses, a estatística t dos coeficientes. Resultados das variáveis de controle, } \\
\text { efeitos fixos de tempo e testes de qualidade dos ajustes estão nos apêndices } \mathrm{F} \text { e G. Legenda das variáveis: } \mathbf{D}- \\
\text { dummy para os municípios mais abundantes em recursos naturais; drn }-d u m m y \text { para os municípios mais } \\
\text { abundantes em recursos naturais totais; drh - para os municípios mais abundantes em recursos hídricos; drm - } \\
\text { dummy para os municípios mais abundantes em recursos minerais; drn - dummy para os municípios mais } \\
\text { abundantes em recursos do petróleo; Rnpc - abundância em recursos naturais total em milhares de reais; Rhpc } \\
\text { - abundância em recursos hídricos em milhares de reais; Rmpc - abundância em recursos minerais em milhares } \\
\text { de reais; Rppc - abundância em recursos do petróleo em milhares de reais. }\end{array}$} \\
\hline
\end{tabular}

No modelo 4d, estimado com 576 municípios com receitas advindas dos recursos do petróleo em todos os anos, observa-se que a variável de abundância em recursos do petróleo foi negativa e significativa, como no modelo $1 \mathrm{~b}$. A variável binária para os municípios com maior volume de receitas com recursos do petróleo também foi negativa, porém não estatisticamente significativa, indicando que não existe diferença no impacto destas receitas no crescimento econômico dos municípios mais/menos abundantes em recursos do petróleo.

\subsection{Produtividade do Gasto Público dos Municípios}

Os resultados das estimações do modelo empírico 2 (página 57) são apresentados na tabela 4.4 para o teste da contribuição dos gastos por categoria econômica e pela natureza da despesa para o crescimento econômico dos municípios. Enquanto, no modelo estimado 2.1, o gasto corrente aparenta ser produtivo para o crescimento dos municípios (gcor $>0$ ), não se verifica o mesmo para o gasto de capital (gcap < 0) na estimação 2.2, o que indica que os municípios com maior composição do gasto total referente a gasto de capital tiveram 
crescimento econômico menor no período de 2003 a 2012. Ambos os gastos tiveram relação estatisticamente significativa a $1 \%$ com o crescimento dos municípios.

Tabela 4.4 - Gastos públicos e crescimento econômico

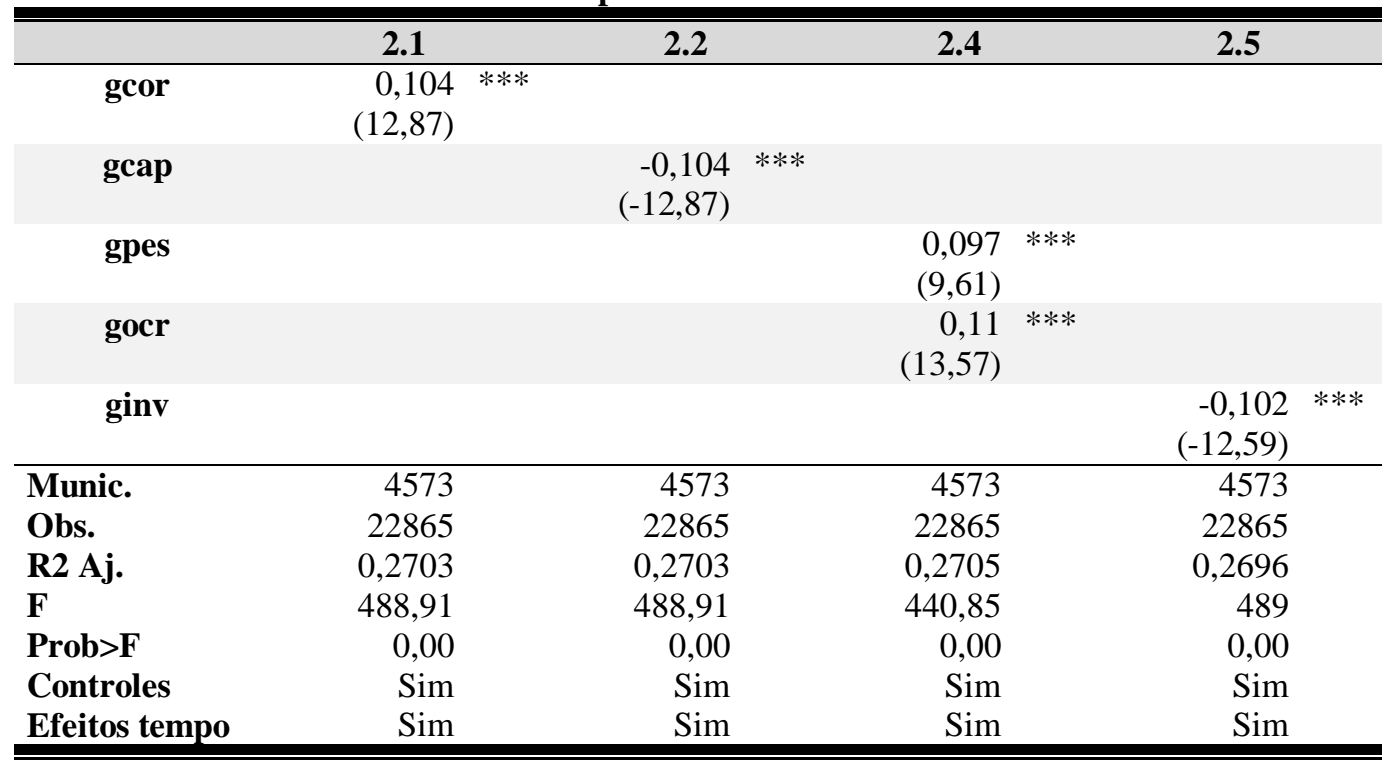

Resultados das estimações do modelo 2 (pág. 57) para o gasto público por categoria econômica e pela natureza da despesa: $C_{i t}=\alpha+\sum_{k=1}^{k} \gamma_{k}^{G} G_{k, i t}+\sum_{j=1}^{j} \delta_{j}^{Z} Z_{j, i t}+\varepsilon_{i t}$. Variável dependente é o crescimento econômico. Modelos estimados por LSDV com efeitos fixos de tempo e erros-padrão robustos agrupados por municípios. $* * *, * * \mathrm{e} *$ referem-se à significância dos coeficientes a $1 \%, 5 \%$ e $10 \%$, respectivamente. Entre parênteses, a estatística t dos coeficientes. Resultados das variáveis de controle, efeitos fixos de tempo e testes de qualidade dos ajustes estão nos apêndices F e G. Legenda das variáveis: gcor - gasto corrente; gcap - gasto de capital; gpes - gasto com pessoal; gocr - outros gastos correntes; ginv - gasto em investimentos. Modelo 2.3 não apresentado devido ao risco de multicolinearidade.

Segundo Devarajan, Swaroop e Zou (1996), o fato de o gasto de capital não ser produtivo pode estar relacionado com distorções que fazem com que o nível desejado dos bens públicos seja menor; logo, gastos adicionais referentes a esses bens públicos podem, de fato, ser improdutivos. Os autores apontam que esse resultado pode ser condizente com os interesses dos governantes na escolha do nível e da composição do gasto, por exemplo: os governantes podem estar empenhados com gasto de capital em obras públicas sem utilidade ("elefantes brancos"), o que tornaria o gasto improdutivo.

Nesse sentido, Bayraktar e Moreno-Dodson (2010) e Moreno-Dodson e Bayraktar (2011) verificaram que a produtividade do gasto público era diferente entre países em desenvolvimento com maiores e menores taxa de crescimento. Assim, quando analisados em conjunto, o comportamento do gasto público e seus componentes tendiam a diminuir. Para os autores, essa discrepância poderia estar associada às diferenças na eficácia do governo e na qualidade da governança, relacionada principalmente à burocracia. 
Nos modelos 2.4 e 2.5, foram estimadas a contribuição dos gastos por grupo de natureza da despesa no crescimento econômico. Os gastos com pessoal e os outros gastos correntes apresentaram comportamento positivo e estatisticamente significante a $1 \%$, sugerindo que estes gastos contribuíram para o crescimento econômico dos municípios no período. Ao contrário, o comportamento do gasto em investimentos foi negativo e significativo, indicando a não produtividade desse gasto, tal como observado para o gasto de capital.

Diante disso, deve-se considerar que o efeito do gasto em investimentos no crescimento econômico pode levar algum tempo para ocorrer, tendo em vista a necessidade de tempo para a execução e disponibilização da obra para o público, que pode ainda prolongar-se por conta de atrasos devidos a aditivos de contrato ou disputas judiciais. Dessa forma, municípios que priorizaram o gasto em investimentos em detrimento aos demais gastos tiveram crescimento, em média, menor do que aqueles no período compreendido no estudo.

A administração pública pode ser considerada uma importante fonte de renda para os municípios, fazendo com que o gasto público tenha peso maior na promoção do crescimento econômico, principalmente nas localidades mais pobres, pelo pagamento de salários aos servidores públicos e pela demanda por bens e serviços produzidos pelo setor privado (DIVINO; SILVA Jr, 2012), o que poderia explicar a maior produtividade do gasto corrente e seus componentes no primeiro momento

O resultado da estimação do modelo 2 (página 57) para a produtividade dos gastos por função (estimação 2.6) mostram, na tabela 4.5, que o gasto com o Legislativo teve relação negativa e significativa com a taxa de variação do PIB dos municípios no período, ou seja, os municípios que mais gastaram na função legislativa tiveram crescimento econômico menor. $\mathrm{O}$ gasto na função administração esteve associado positiva e significativamente com o crescimento dos municípios, indicando que o gasto com a administração foi produtivo no período.

Os gastos em assistência social e em saúde também apresentaram relação positiva com a variação do PIB, entretanto essa relação foi significativa a $10 \%$ para o primeiro gasto e a $1 \%$ para o segundo. Isso mostra que os gastos em assistência social e em saúde foram produtivos para os municípios com maior proporção desses na composição do gasto total. $\mathrm{O}$ gasto em gestão ambiental, embora se relacionasse positivamente com o crescimento per capita dos municípios, não foi estatisticamente significativo. 
Tabela 4.5 - Gastos por função e crescimento econômico

\begin{tabular}{|c|c|c|}
\hline \multicolumn{3}{|c|}{2.6} \\
\hline glegis & $\begin{array}{r}-0,0697 \\
(-3,27)\end{array}$ & $* * *$ \\
\hline gadm & $\begin{array}{r}0,0335 \\
(4,07)\end{array}$ & $* * *$ \\
\hline gassist & $\begin{array}{r}0,0365 \\
(1,80)\end{array}$ & $*$ \\
\hline gsaude & $\begin{array}{r}0,0304 \\
(2,95)\end{array}$ & $* * *$ \\
\hline geduc & $\begin{array}{r}0,0805 \\
(6,92)\end{array}$ & $* * *$ \\
\hline gurban & $\begin{array}{r}-0,0442 \\
(-4,20)\end{array}$ & $* * *$ \\
\hline ghabit & $\begin{array}{r}-0,0796 \\
(-3,61)\end{array}$ & $* * *$ \\
\hline gsanea & $\begin{array}{r}-0,0486 \\
(-3,23)\end{array}$ & $* * *$ \\
\hline ggeamb & $\begin{array}{r}0,0521 \\
(1,14)\end{array}$ & \\
\hline Munic. & 4573 & \\
\hline Obs. & 22865 & \\
\hline R2 Aj. & 0,2648 & \\
\hline $\mathbf{F}$ & 249,93 & \\
\hline Prob $>$ F & 0,00 & \\
\hline Controles & Sim & \\
\hline Efeitos tempo & Sim & \\
\hline
\end{tabular}

Resultados da estimação do modelo 2 (pág. 57) para o gasto público por função. Variável dependente é o crescimento econômico. Modelos estimados por LSDV com efeitos fixos de tempo e erros-padrão robustos agrupados por municípios. $* * *, * * \mathrm{e} *$ referem-se à significância dos coeficientes a $1 \%, 5 \%$ e $10 \%$, respectivamente. Entre parênteses, a estatística t dos coeficientes. Resultados das variáveis de controle, efeitos fixos de tempo e testes de qualidade dos ajustes estão nos apêndices F e G. Legenda das variáveis: glegis - gasto com o Legislativo; gadm - gasto com a administração; geduc gasto em educação; gassist - gasto em assistência social; gsaude - gasto em saúde; gurban - gasto em urbanismo; ghabit - gasto em habitação; gsanea gasto em saneamento; ggeamb - gasto em gestão ambiental.

O gasto em educação também se associou positivamente com a variação do PIB, ou seja, nos municípios onde esse gasto representava maior porção na composição dos gastos públicos, o crescimento econômico foi maior. Ainda, o gasto em educação foi o que mais contribuiu para o crescimento dentre os tipos de gastos analisados, indicando que, para cada $1 \%$ de aumento na composição dos gastos direcionados para a função educação, o crescimento econômico era 8 pontos percentuais em média maior nos municípios.

Os gastos em urbanismo, em habitação e em saneamento foram negativos e estatisticamente significantes a $1 \%$ associados com a variação do PIB per capita dos munícipios no período analisado, o que sugere que, nos municípios com maiores gastos nessas funções, o crescimento econômico foi menor do que nos demais municípios. 


\subsection{Recursos Naturais e a Produtividade do Gasto Público dos Municípios}

A MRN corresponde à relação inversa entre a abundância em recursos naturais e o crescimento econômico. Existe um consenso na literatura de que essa associação pode estar relacionada com os efeitos indiretos de outras características das localidades abundantes em recursos naturais que levariam a um baixo crescimento. A seguir, são apresentados os resultados dos modelos empíricos 3 e 5, que relacionam a abundância em recursos naturais, o gasto público e o crescimento econômico dos municípios.

\subsubsection{Recursos Naturais e Gastos pela Categoria Econômica}

Na coluna A da tabela 4.6, são apresentados os resultados da estimação do modelo 3 (página 58), utilizado nos municípios que receberam ou não receita pela exploração de algum tipo de recurso natural. Verifica-se que, ao considerar os gastos por categoria econômica, a variável de abundância em recursos naturais total (Rnpc) continua com o sinal negativo, tal como no modelo 1a da tabela 4.2, embora não estatisticamente significativa no modelo $3.1 \mathrm{a}$ com a variável de gasto corrente. Esse resultado sugere que o efeito da abundância em recursos naturais no crescimento foi sensível à inclusão da variável desse gasto no modelo, ou seja, parte da variação da MRN pode ser explicada pela produtividade do gasto corrente dos municípios abundantes em recursos naturais.

As variáveis de interação mostram a produtividade dos gastos públicos condicionada à abundância em recursos naturais. Observa-se que o gasto corrente nos municípios abundantes em recursos naturais teve associação negativa - enquanto o gasto de capital, positiva - com o crescimento econômico desses municípios, embora não fossem estatisticamente significativos. Logo, não é possível inferir que a receita com a exploração de recursos naturais tenha contribuído de alguma forma para a produtividade desses gastos dos municípios.

O efeito da abundância em recursos hídricos no crescimento também se mostrou sensível à inclusão da variável de gasto no modelo, assumindo valor estatisticamente significativo e positivo no modelo com o gasto corrente (3.1b) e negativo no modelo com o gasto de capital 3.2b, coluna B da tabela 4.6, quando comparado com a tabela 4.2. O sinal positivo da variável de interação $R h p c^{*}$ gcap indica que a produtividade do gasto de capital condicionada à abundância em recursos hídricos foi maior nos municípios que utilizaram as receitas com recursos hídricos para financiar uma maior composição do gasto público em favor do gasto de capital no período estudado. 
Tabela 4.6 - Abundância em recursos naturais, gastos por categoria e crescimento econômico

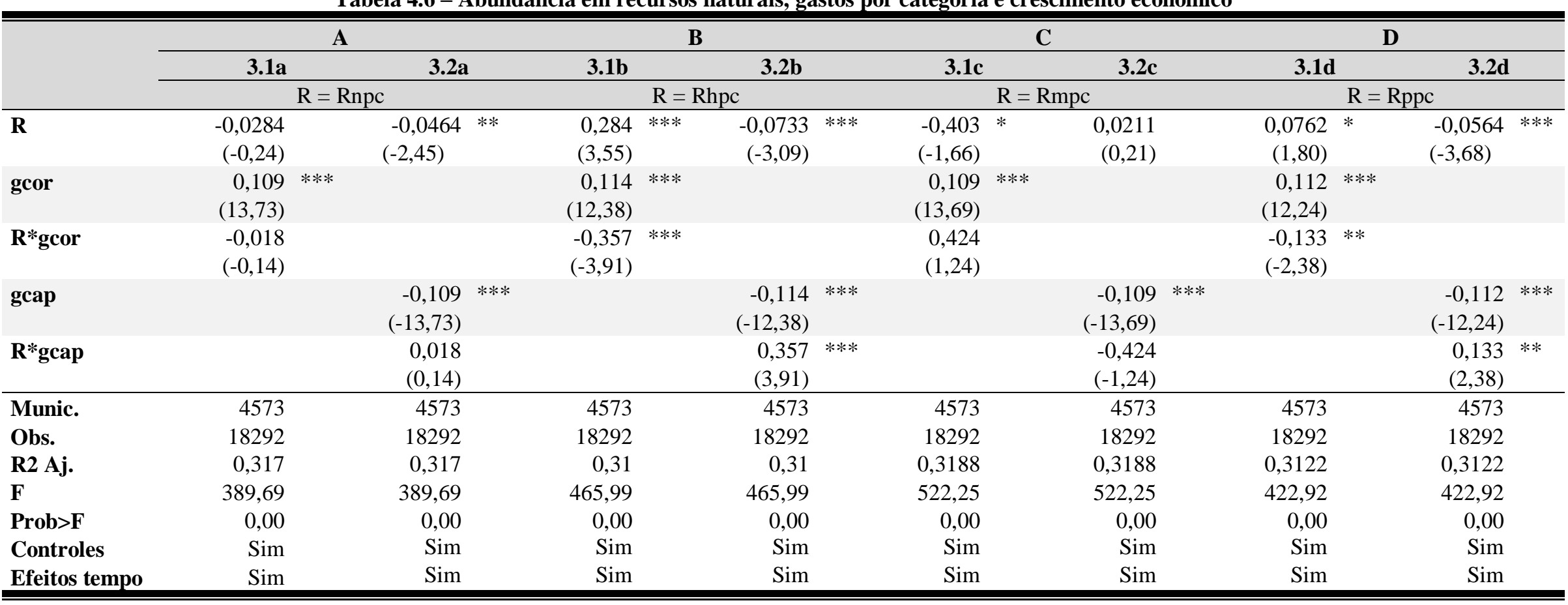

Resultados das estimações do modelo 3 (pág. 58) para os gastos públicos pela categoria econômica: $C_{i t}=\alpha+\beta R_{i t}+\sum_{k=1}^{k} \gamma_{k}^{G} G_{k, i t}+\sum_{k=1}^{k} \sigma_{k}^{R G} R_{i t} . G_{k, i t}+\sum_{j=1}^{j} \delta_{j}^{Z} Z_{j, i t}+\varepsilon_{i t}$. Variável dependente é o crescimento econômico. Modelos estimados por LSDV com efeitos fixos de tempo e erros-padrão robustos agrupados por municípios. ***, ** e * referem-se à significância dos coeficientes a $1 \%, 5 \%$ e $10 \%$, respectivamente. Entre parênteses, a estatística t dos coeficientes. Resultados das variáveis de controle, efeitos fixos de tempo e testes de qualidade dos ajustes estão nos apêndices F e G. Legenda das variáveis: $\mathbf{R}$ - variável de recursos naturais; Rnpc - abundância em recursos naturais total em milhares de reais; Rhpc - abundância em recursos hídricos em milhares de reais; Rmpc - abundância em recursos minerais em milhares de reais; Rppc - abundância em recursos do petróleo em milhares de reais; gcor - gasto corrente; gcap - gasto de capital; $\mathbf{R}^{*}$ - variável de interação entre recursos naturais e gastos públicos. 
Nos modelos estimados com municípios abundantes em recursos minerais, na coluna C da tabela 4.6, observa-se que o gasto corrente e o de capital explicam parte do efeito das receitas com recursos minerais no crescimento. Comparando-se com a variável Rmpc no modelo 1 b da tabela 4.2, no modelo 3.1c (tabela 4.6), essa variável continuou com o sinal negativo, mas a significância reduziu de 1 para 10\%; e no modelo 3.2c, a variável passou a ser positiva, porém não significativa. Isso pode indicar que parte do efeito negativo da abundância em recursos minerais no crescimento é explicada pela escolha da composição do gasto público em gasto corrente e gasto de capital nos municípios abundantes.

A produtividade dos gastos corrente e de capital condicionada à abundância em recursos minerais não foi estatisticamente significativa, infere-se, portanto, que, nos municípios abundantes em recursos minerais, a produtividade desses gastos não foi diferente dos demais municípios pelo fato de aqueles terem uma fonte de receita que estes não possuíam.

Nos modelos 3.1d e 3.2d, coluna D, da tabela 4.6, para abundância em recursos do petróleo, verifica-se que o comportamento da variável Rppc mudou no modelo com o gasto corrente quando comparado com o modelo $1 \mathrm{~b}$ (tabela 4.2). O sinal dessa variável foi positivo, embora significativo a $10 \%$, indicando que parte do efeito negativo da receita com recursos petrolíferos no crescimento econômico dos municípios pode ser explicada pela escolha de uma composição do gasto público que privilegie o gasto corrente.

Quanto à produtividade do gasto condicionada à abundância em recursos do petróleo, verifica-se que o gasto de capital foi mais produtivo nos municípios com receitas daí advindas, sugerindo que a utilização dessas receitas para financiar uma composição do gasto público que privilegiasse o gasto de capital contribuiu para o crescimento econômico dos municípios abundantes no período.

Os resultados apresentados anteriormente comparam a produtividade do gasto entre municípios que recebem ou não receitas pela exploração de recursos naturais. Na tabela 4.7, são apresentados os resultados da estimação do modelo 5 (página 60), considerando-se somente os municípios que tiveram receitas com recursos naturais em todo o período estudado.

A coluna A da tabela 4.7 mostra os resultados dos modelos para os municípios que tiveram receitas com algum tipo de recurso natural em todos os anos. A variável dummy para os municípios mais abundantes em recursos naturais foi sensível à inclusão da variável de gasto corrente quando comparada com o sinal dessa variável na coluna A da tabela 4.3, pois aqui a variável não foi significativa. Esse resultado sugere que parte do efeito negativo do 
recurso natural no crescimento nos municípios com maiores receitas pode ser explicada pela maior composição do gasto público formada por gasto corrente.

A variável de interação para produtividade do gasto condicionada ao nível de abundância em recursos naturais não foi significativa para nenhum dos tipos de gasto corrente e de capital. Isso indica que, nos municípios com maiores receitas com recursos naturais, estas não contribuíram para que os gastos fossem mais produtivos.

Nos modelos com somente municípios abundantes em recursos hídricos, coluna B da tabela 4.7, a variável dummy para os municípios mais abundantes foi mais sensível para a composição do gasto de capital (quando comparado com o comportamento da variável na coluna B da tabela 4.3), ou seja, parte do crescimento econômico menor nos municípios mais abundantes pode ter como causa a produtividade do gasto de capital. A variável de recursos hídricos $(R h p c)$, embora tenha mudado o comportamento, continuou não significativa.

Pela variável de interação para a produtividade do gasto condicionada ao nível de abundância em recursos hídricos, verifica-se que, nos municípios mais abundantes, o comportamento do gasto foi similar aos menos abundantes (mesmo sinal na variável de interação e na variável de gasto). Contudo, nos municípios mais abundantes, o efeito dos gastos foi maior no crescimento econômico: a composição do gasto público para um maior volume de gasto corrente contribuiu mais para os municípios mais abundantes em recursos hídricos, pois a variável de interação foi igualmente significativa.

Nos modelos com apenas municípios abundantes em recursos minerais (coluna $\mathrm{C}$ da tabela 4.7), a variável de recursos minerais e a variável dummy continuaram não estatisticamente significantes, embora no modelo com o gasto de capital (5.2b) essas variáveis tenham relação com o crescimento alterado de negativa (coluna $\mathrm{C}$ da tabela 4.3) para positiva. Verifica-se que, em tais municípios, o gasto corrente foi produtivo em detrimento do gasto de capital e que não houve diferença na produtividade desses gastos entre os municípios mais e menos abundantes, pois as variáveis de interação não foram, apesar de apresentar o mesmo sinal das variáveis de gasto, estatisticamente significativas.

Similarmente, nos modelos com apenas municípios abundantes em recursos do petróleo (coluna D da tabela 4.7), a respectiva variável teve o mesmo comportamento observado na coluna $\mathrm{D}$ da tabela 4.3, sugerindo que o efeito das receitas daí advindas no crescimento econômico não está relacionado com um possível efeito indireto dos gastos corrente e de capital. $\mathrm{O}$ crescimento também não foi diferente entre os municípios mais e 
Tabela 4.7 - Nível de abundância em recursos naturais, gastos por categoria e crescimento econômico

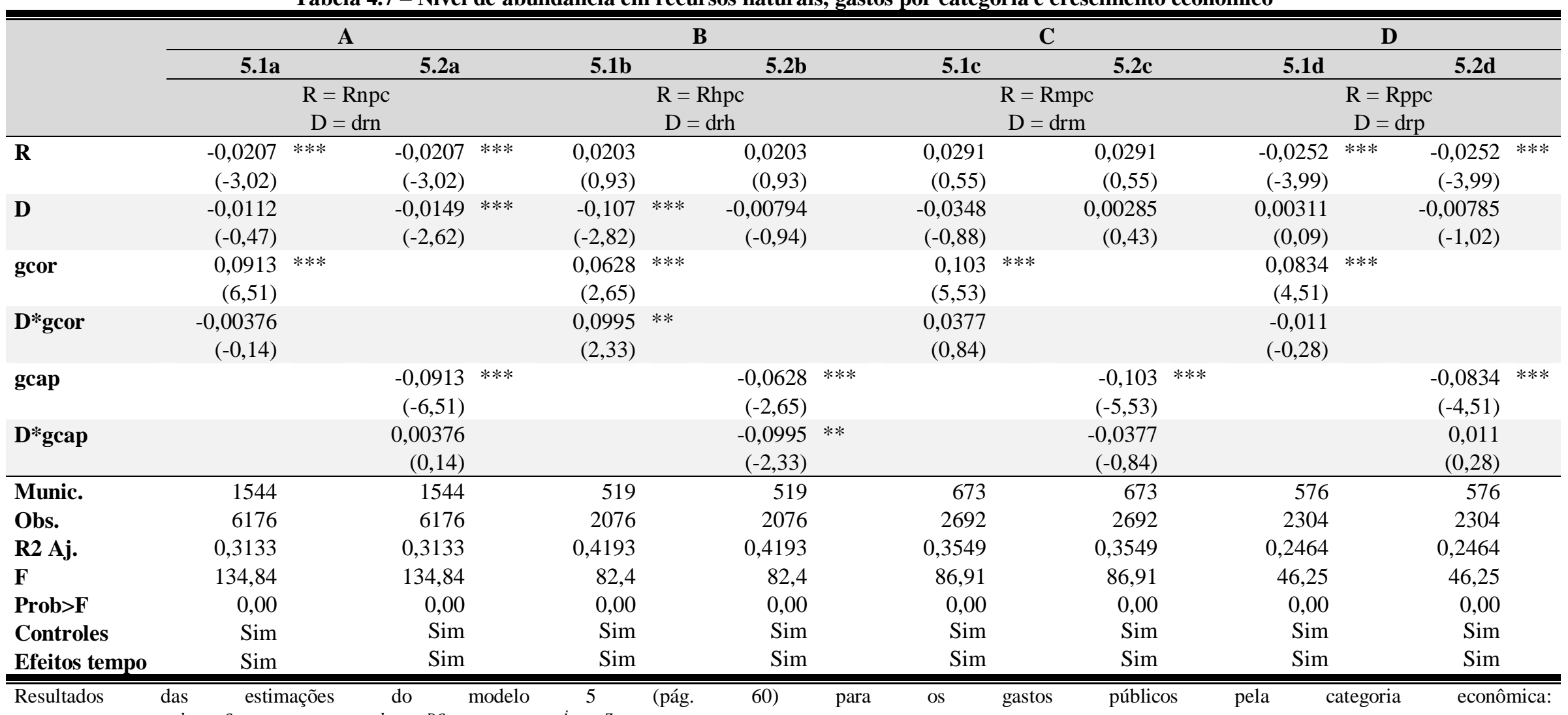

$C_{i t}=\alpha+\beta R_{i t}+\sum_{k=1}^{k} \gamma_{k}^{S} G_{k, i t}+\theta D_{i t}+\sum_{k=1}^{k} \varphi_{k}^{D G} D_{i t} G_{k, i t}+\sum_{j=1}^{j} \delta_{j}^{Z} Z_{j, i t}+\varepsilon_{i t}$. Variável dependente é o crescimento econômico. Modelos estimados por LSDV com efeitos fixos de tempo e erros-padrão robustos agrupados por municípios. ***, ** e * referem-se à significância dos coeficientes a $1 \%, 5 \%$ e $10 \%$, respectivamente. Entre parênteses, a estatística t dos coeficientes. Resultados das variáveis de controle, efeitos fixos de tempo e testes de qualidade dos ajustes estão nos apêndices F e G. Legenda das variáveis: D - dummy para os municípios mais abundantes em recursos naturais; drn - dummy para os municípios mais abundantes em recursos naturais total; drh - dummy para os municípios mais abundantes em recursos hídricos; drm - dummy para os municípios mais abundantes em recursos minerais; drp - para os municípios mais abundantes em recursos do petróleo; $\mathbf{R}$ - variável de recursos naturais; Rnpc - abundância em recursos naturais total em milhares de reais; Rhpc - abundância em recursos hídricos em milhares de reais; Rmpc - abundância em recursos minerais em milhares de reais; Rppc - abundância em recursos do petróleo em milhares de reais; gcor - gasto corrente; gcap - gasto de capital; $\mathbf{D}^{*}$ - variável de interação entre a dummy para municípios mais abundantes em recursos naturais e gastos públicos. 
menos abundantes (variável dummy não foi significativa). Da mesma forma, observou-se que a produtividade do gasto corrente e de capital não foi diferente entre os municípios mais e menos abundantes (variável de interação não foi significativa).

\subsubsection{Recursos Naturais e Gastos pela Natureza da Despesa}

$\mathrm{Na}$ tabela 4.8, são apresentados os resultados da estimação do modelo empírico 3 (página 58) para a relação entre abundância em recursos naturais, gastos por natureza da despesa pública e crescimento econômico dos municípios.

De forma geral, na coluna A desta tabela, verifica-se que o comportamento da abundância em recursos naturais $(R n p c)$ no crescimento econômico foi novamente sensível à inclusão das variáveis de gastos, principalmente quando se considera o gasto com pessoal e os outros gastos correntes ( modelo 3.3a). Ou seja, a produtividade desses gastos explica parte da relação negativa entre recursos naturais e o crescimento dos municípios abundantes em recursos naturais.

A variável de interação entre a abundância em recursos naturais e o gasto público foi significativa apenas para outros gastos correntes, mas ao nível de $10 \%$. Considerando-se certo grau de robustez (significância a 10\%), nos municípios abundantes em rendimentos com recursos naturais, em que esses eram utilizados para financiar uma maior proporção de outros gastos correntes, o crescimento econômico foi menor do que nos municípios não abundantes. Para o gasto com pessoal e em investimentos, as receitas com recursos naturais não contribuíram para uma maior produtividade desses gastos, comparada aos demais municípios.

Igualmente, na coluna B da tabela 4.8, observa-se que o efeito negativo da abundância em recursos hídricos no crescimento econômico pode ser explicado em parte pela produtividade do gasto com pessoal e outros gastos correntes, uma vez que, no modelo $3.3 \mathrm{~b}$, o sinal da variável $R h p c$ foi positivo e significativo (na tabela 4.2, o sinal foi negativo).

A variável de interação para a produtividade do gasto com pessoal e dos outros gastos correntes condicionada à abundância em recursos hídricos foi negativa, enquanto a do gasto em investimentos foi positiva. Esse resultado sugere que a receita com recursos hídricos contribuiu para que a produtividade do gasto em investimentos fosse maior nos municípios que utilizaram tal receita para financiar uma maior parcela do gasto em investimentos, comparativamente aos municípios não abundantes em recursos hídricos. Ao contrário, os municípios que direcionaram a receita com recursos hídricos para financiar gasto com pessoal e outros gastos correntes tiveram crescimento menor que os demais municípios. 
Tabela 4.8 - Abundância em recursos naturais, gastos por natureza e crescimento econômico

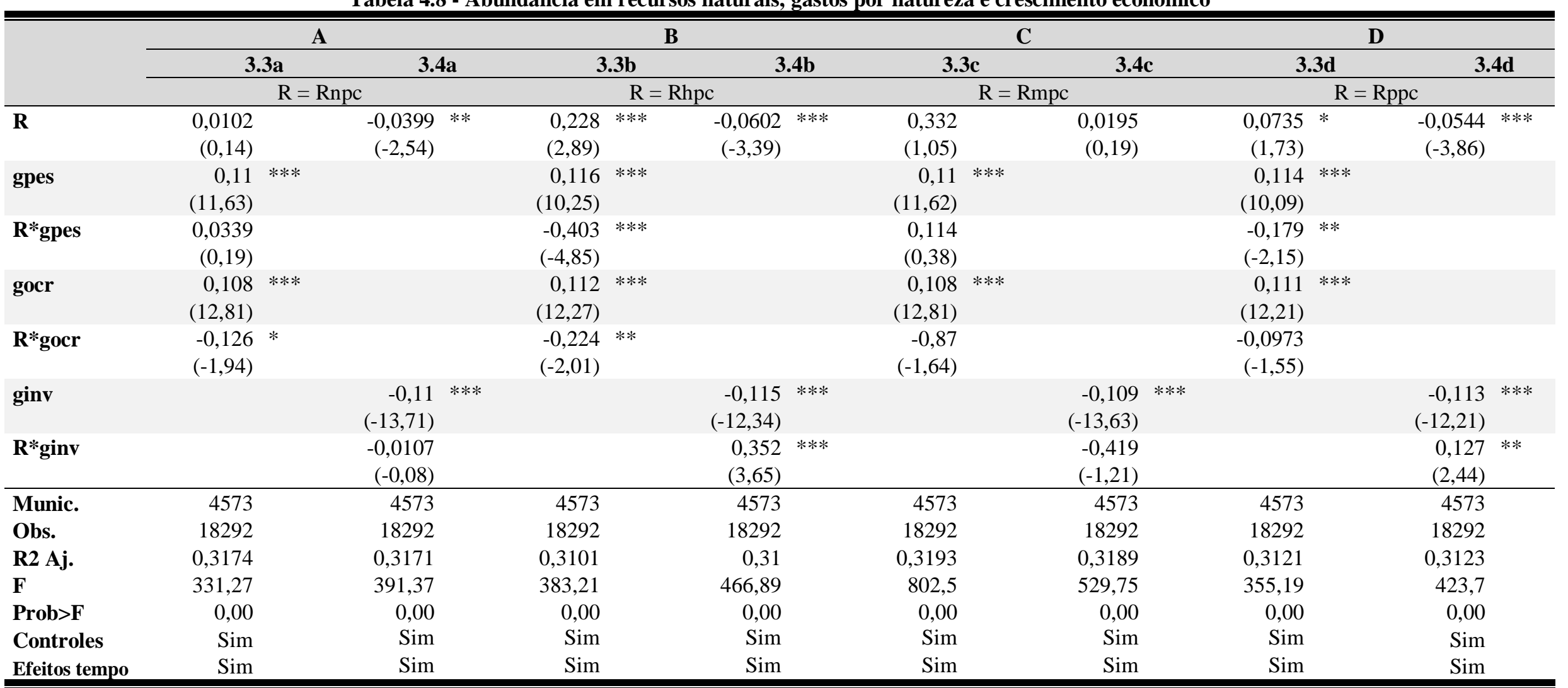

Resultados das estimações do modelo 3 (pág. 58) para os gastos públicos pela natureza da despesa: $C_{i t}=\alpha+\beta R_{i t}+\sum_{k=1}^{k} \gamma_{k}^{G} G_{k, i t}+\sum_{k=1}^{k} \sigma_{k}^{R G} R_{i t} \cdot G_{k, i t}+\sum_{j=1}^{j} \delta_{j}^{Z} Z_{j, i t}+\varepsilon_{i t}$. Variável dependente é o crescimento econômico. Modelos estimados por LSDV com efeitos fixos de tempo e erros-padrões robustos agrupados por municípios. ***, ** e * referem-se à significância dos coeficientes a $1 \%, 5 \%$ e 10\%, respectivamente. Entre parênteses, a estatística t dos coeficientes. Resultados das variáveis de controle, efeitos fixos de tempo e testes de qualidade dos ajustes estão nos apêndices F e G. Legenda das variáveis: $\mathbf{R}$ - variável de recursos naturais; Rnpc - abundância em recursos naturais total em milhares de reais; Rhpc - abundância em recursos hídricos em milhares de reais; Rmpc - abundância em recursos minerais em milhares de reais; Rppc - abundância em recursos do petróleo em milhares de reais; gpes - gastos com pessoal; gocr - outros gastos correntes; ginv - gastos em investimentos; $\mathbf{R}^{*}$ - variável de interação entre recursos naturais e gastos públicos. 
Na coluna $\mathrm{C}$ da tabela 4.8, a variável de abundância em recursos minerais foi positiva e não significativa (na tabela 4.6, foi negativa e significativa e positiva e não significativa; na tabela 4.2, foi negativa e significativa), indicando que o efeito negativo dessa variável pode ser explicado pela produtividade da composição do gasto público, no caso, pela produtividade do gasto com pessoal, outros gastos correntes e gasto em investimentos.

As variáveis de interação para a produtividade dos gastos condicionada à abundância em recursos minerais não foram estatisticamente significativas. Ou seja, nos municípios abundantes em recursos minerais as receitas daí advindas não contribuíram para a que a produtividade dos gastos com pessoal, outros custeios e em investimentos fosse diferente dos municípios não abundantes nesses recursos .

Comparando municípios abundantes em recursos do petróleo com os demais municípios (coluna D da tabela 4.8), observa-se que o gasto com pessoal e os outros gastos correntes explicam, com certo nível de robustez, parte do efeito negativo no crescimento econômico associado à receita com recursos do petróleo, pois a variável Rppc teve sinal positivo e significativo a $10 \%$ (na tabela 4.2 , o sinal foi negativo e significativo a $1 \%$ ).

O comportamento da variável de interação da produtividade do gasto com pessoal condicionada à abundância em recursos do petróleo foi negativa e significativa a 5\%, sugerindo que os municípios que utilizaram a receita com recursos do petróleo para financiar esse tipo de gasto teve crescimento econômico menor que nos demais municípios. Ao contrário, os municípios que utilizaram tal receita para financiar o gasto em investimentos tiveram maior crescimento (a variável de interação foi positiva e significativa a 5\%).

Na tabela 4.9, são apresentados os resultados da estimação do modelo 5 (página 60) para a relação entre o nível de abundância em recursos naturais, os gastos por natureza da despesa e o crescimento econômico das subamostras com municípios que receberam receitas pela exploração de recursos naturais em todo o período analisado.

Na coluna A desta tabela, a variável dummy para os municípios mais abundantes em recursos naturais não foi significativa no modelo 5.3a (na tabela 4.3, essa variável foi negativa e significativa), o que indica que, nesses municípios, parte do efeito negativo da receita com recursos naturais pode ser explicada pela produtividade do gasto com pessoal e dos outros gastos correntes. As variáveis de interação para a produtividade do gasto nos municípios mais abundantes em recursos naturais não foram estatisticamente significativas, sugerindo que a produtividade do gasto com pessoal, outros gastos correntes e gasto em investimentos não foi diferente entre os municípios mais e menos abundantes. 
Tabela 4.9 - Nível de abundância em recursos naturais, gastos por natureza e crescimento econômico

\begin{tabular}{|c|c|c|c|c|c|c|c|c|c|c|c|c|c|c|c|c|}
\hline \multirow[b]{4}{*}{$\mathbf{R}$} & \multicolumn{4}{|c|}{$\overline{\mathbf{A}}$} & \multicolumn{4}{|c|}{$\overline{\mathbf{B}}$} & \multicolumn{4}{|c|}{$\overline{\mathrm{C}}$} & \multicolumn{4}{|c|}{$\overline{\mathrm{D}}$} \\
\hline & \multicolumn{2}{|l|}{$5.3 \mathrm{a}$} & \multicolumn{2}{|l|}{$5.4 a$} & \multirow[t]{2}{*}{$5.3 \mathrm{~b}$} & & \multicolumn{2}{|l|}{$5.4 \mathrm{~b}$} & \multirow[t]{2}{*}{$5.3 \mathrm{c}$} & & \multicolumn{2}{|l|}{$5.4 \mathrm{c}$} & \multirow[t]{2}{*}{$5.3 \mathrm{c}$} & \multirow{2}{*}{\multicolumn{3}{|c|}{$\begin{array}{c}\mathrm{R}=\mathrm{Rppc} \\
\mathrm{D}=\mathrm{drp}\end{array}$}} \\
\hline & \multicolumn{4}{|c|}{$\begin{array}{c}\mathrm{R}=\mathrm{Rnpc} \\
\mathrm{D}=\mathrm{drn}\end{array}$} & & \multicolumn{3}{|c|}{$\begin{array}{c}\mathrm{R}=\mathrm{Rhpc} \\
\mathrm{D}=\mathrm{drh}\end{array}$} & & \multicolumn{3}{|c|}{$\begin{array}{l}\mathrm{R}=\mathrm{Rmpc} \\
\mathrm{D}=\mathrm{drm}\end{array}$} & & & & \\
\hline & $\begin{array}{r}-0,0199 \\
(-3,01)\end{array}$ & $* * *$ & $\begin{array}{r}-0,0206 \\
(-3,00)\end{array}$ & $* * *$ & $\begin{array}{r}0,0227 \\
(1,08)\end{array}$ & & $\begin{array}{r}0,0216 \\
(0,96)\end{array}$ & & $\begin{array}{r}0,027 \\
(0,52)\end{array}$ & & $\begin{array}{r}0,0292 \\
(0,55)\end{array}$ & & $\begin{array}{r}-0,0241 \\
(-4,09)\end{array}$ & $* * *$ & $\begin{array}{r}-0,0252 \\
(-3,96)\end{array}$ & $* * *$ \\
\hline D & $\begin{array}{r}-0,0127 \\
(-0,52)\end{array}$ & & $\begin{array}{r}-0,0145 \\
(-2,68)\end{array}$ & $* * *$ & $\begin{array}{l}-0,114 \\
(-2,96)\end{array}$ & $* * *$ & $\begin{array}{r}-0,00844 \\
(-1,05)\end{array}$ & & $\begin{array}{r}-0,0321 \\
(-0,81)\end{array}$ & & $\begin{array}{r}0,00241 \\
(0,42)\end{array}$ & & $\begin{array}{r}-0,000946 \\
(-0,03)\end{array}$ & & $\begin{array}{r}-0,00765 \\
(-1,07)\end{array}$ & \\
\hline gpes & $\begin{array}{r}0,0959 \\
(5,86)\end{array}$ & $* * *$ & & & $\begin{array}{r}0,0709 \\
(2,38)\end{array}$ & $* *$ & & & $\begin{array}{l}0,105 \\
(4,54)\end{array}$ & $* * *$ & & & $\begin{array}{r}0,103 \\
(4,20)\end{array}$ & $* * *$ & & \\
\hline D*gpes & $\begin{array}{l}0,025 \\
(0,74)\end{array}$ & & & & $\begin{array}{l}0,178 \\
(3,15)\end{array}$ & $* * *$ & & & $\begin{array}{r}0,0164 \\
(0,33)\end{array}$ & & & & $\begin{array}{r}0,0226 \\
(0,47)\end{array}$ & & & \\
\hline gocr & $\begin{array}{r}0,0906 \\
(6,16)\end{array}$ & $* * *$ & & & $\begin{array}{r}0,0587 \\
(2,42)\end{array}$ & $* *$ & & & $\begin{array}{l}0,104 \\
(4,98)\end{array}$ & $* * *$ & & & $\begin{array}{r}0,074 \\
(3,85)\end{array}$ & $* * *$ & & \\
\hline D*gocr & $\begin{array}{r}-0,0295 \\
(-0,99)\end{array}$ & & & & $\begin{array}{r}0,0403 \\
(0,75)\end{array}$ & & & & $\begin{array}{r}0,0549 \\
(1,15)\end{array}$ & & & & $\begin{array}{r}-0,0351 \\
(-0,85)\end{array}$ & & & \\
\hline ginv & & & $\begin{array}{r}-0,0907 \\
(-6,55)\end{array}$ & $* * *$ & & & $\begin{array}{l}-0,065 \\
(-2,79)\end{array}$ & $* * *$ & & & $\begin{array}{l}-0,096 \\
(-4,94)\end{array}$ & & & & $\begin{array}{r}-0,0867 \\
(-4,48)\end{array}$ & $* * *$ \\
\hline D*ginv & & & $\begin{array}{r}0,00142 \\
(0,05)\end{array}$ & & & & $\begin{array}{l}-0,111 \\
(-2,58)\end{array}$ & $* *$ & & & $\begin{array}{r}-0,0391 \\
(-0,92)\end{array}$ & & & & $\begin{array}{r}0,0127 \\
(0,33)\end{array}$ & \\
\hline Munic. & 1544 & & 1544 & & 519 & & 519 & & 673 & & 673 & & 576 & & 576 & \\
\hline Obs. & 6176 & & 6176 & & 2076 & & 2076 & & 2692 & & 2692 & & 2304 & & 2304 & \\
\hline R2 Aj. & 0,3142 & & 0,3133 & & 0,4238 & & 0,4216 & & 0,3549 & & 0,353 & & 0,2512 & & 0,2469 & \\
\hline $\mathbf{F}$ & 116,45 & & 134,83 & & 70,84 & & 82,93 & & 73,04 & & 86,31 & & 39,78 & & 45,78 & \\
\hline Prob $>$ F & 0,00 & & 0,00 & & 0,00 & & 0,00 & & 0,00 & & 0,00 & & 0,00 & & 0,00 & \\
\hline Controles & Sim & & Sim & & Sim & & Sim & & Sim & & Sim & & Sim & & Sim & \\
\hline Efeitos tempo & Sim & & Sim & & Sim & & Sim & & Sim & & Sim & & Sim & & Sim & \\
\hline
\end{tabular}

$C_{i t}=\alpha+\beta R_{i t}+\sum_{k=1}^{k} \gamma_{k}^{S} G_{k, i t}+\theta D_{i t}+\sum_{k=1}^{k} \varphi_{k}^{D G} D_{i t} G_{k, i t}+\sum_{j=1}^{j} \delta_{j}^{Z} Z_{j, i t}+\varepsilon_{i t}$. Variável dependente é o crescimento econômico. Modelos estimados por LSDV com efeitos fixos de tempo e erros-padrões robustos agrupados por municípios. ***, ** e * referem-se à significância dos coeficientes a 1\%, 5\% e 10\%, respectivamente. Entre parênteses, a estatística dos coeficientes. Resultados das variáveis de controle, efeitos fixos de tempo e testes de qualidade dos ajustes estão nos apêndices F e G. Legenda das variáveis: D - dummy para os municípios mais abundantes em recursos naturais; drn - dummy para os municípios mais abundantes em recursos naturais total; drh - dummy para os municípios mais abundantes em recursos hídricos; drm - dummy para os municípios mais abundantes em recursos minerais; drp - dummy para os municípios mais abundantes em recursos do petróleo; $\mathbf{R}$ - variável de recursos naturais; Rnpc - abundância em recursos naturais total em milhares de reais; Rhpc - abundância em recursos hídricos em milhares de reais; Rmpc - abundância em recursos minerais em milhares de reais; Rppc - abundância em recursos do petróleo em milhares de reais; gpes - gastos com pessoal; gocr - outros gastos correntes; ginv - gastos em investimentos; D* - variável de interação entre a dummy para municípios mais abundantes em recursos naturais e gastos públicos. 
Na coluna B da tabela 4.9, são apresentados os resultados dos modelos estimados para os municípios abundantes em recursos hídricos. A variável para os municípios que mais receberam receitas com exploração de recursos hídricos foi sensível ao gasto em investimentos (no modelo 5.4b, a variável foi não significativa, diferentemente da tabela 4.3), indicando que esse gasto pode explicar parte do efeito negativo do crescimento econômico dos municípios mais abundantes em recursos hídricos.

O comportamento das variáveis de interação mostra que a produtividade do gasto com pessoal foi maior nos municípios mais abundantes em recurso hídricos (a variável foi positiva e significativa), enquanto a produtividade do gasto em investimentos foi menor nesses municípios (a variável foi negativa e significativa). A produtividade dos outros gastos correntes não foi diferente entre municípios mais ou menos abundantes em recursos hídricos.

Na coluna C e D da tabela 4.9, nos modelos estimados com somente municípios abundantes em recurso minerais e recursos do petróleo, respectivamente, as variáveis dummies para os municípios mais abundantes não foram significativas, tal como visto nas colunas $\mathrm{C}$ e $\mathrm{D}$ da tabela 4.3. Isso sugere que a composição do gasto por natureza não influenciou a relação entre a abundância em recursos minerais e do petróleo e o crescimento.

Também, verifica-se que as variáveis de interação não foram estatisticamente significativas, o que indica que a produtividade do gasto com pessoal, dos outros gastos correntes e do gasto em investimentos não foi diferente entre os municípios mais e menos abundantes em recursos minerais e do petróleo.

\subsubsection{Recursos Naturais e Gastos por Função}

Na tabela 4.10, são apresentados os resultados da estimação do modelo 3 (página 58) para a relação entre a abundância em recursos naturais, os gastos públicos por função e o crescimento econômico dos municípios. De forma geral, para municípios abundantes em qualquer tipo de recurso natural, o modelo 3.5a (na coluna A) mostra que a variável de abundância total (Rnpc) foi sensível à inclusão das variáveis de gastos por função - agora positiva e não significativa, anteriormente negativa e significativa, modelo 1a (tabela 4.2).

A produtividade dos gastos com o Legislativo e em assistência social condicionada à abundância em recursos naturais foi menor nos municípios abundantes: a variável de interação com esses gastos foi negativa com certo nível de robustez (significativa a 10\%). Isso sugere que os municípios que utilizaram as receitas com recursos naturais para financiar uma maior composição dos gastos com o Legislativo e em assistência social tiveram crescimento econômico menor do que nos municípios não abundantes em recursos naturais. 
Tabela 4.10 - Abundância em recursos naturais, gastos por função e crescimento econômico

\begin{tabular}{|c|c|c|c|c|c|c|c|c|}
\hline & \multicolumn{2}{|l|}{$\mathbf{A}$} & \multicolumn{2}{|l|}{ B } & \multicolumn{2}{|l|}{$\mathbf{C}$} & \multicolumn{2}{|l|}{ D } \\
\hline & \multicolumn{2}{|l|}{$3.5 a$} & \multicolumn{2}{|l|}{ 3.5b } & \multicolumn{2}{|l|}{$3.5 \mathrm{c}$} & \multicolumn{2}{|l|}{ 3.5d } \\
\hline & $\mathrm{R}=\mathrm{Rnpc}$ & & $\mathrm{R}=\mathrm{Rhpc}$ & & $\mathrm{R}=\mathrm{Rmpc}$ & & $\mathrm{R}=\mathrm{Rppc}$ & \\
\hline \multirow[t]{2}{*}{$\mathbf{R}$} & 0,0772 & & 0,185 & & $-0,956$ & & $-0,0413$ & \\
\hline & $(0,74)$ & & $(1,29)$ & & $(-1,32)$ & & $(-0,31)$ & \\
\hline \multirow[t]{2}{*}{ glegis } & $-0,0575$ & $* *$ & $-0,0495$ & $*$ & $-0,0596$ & $* *$ & $-0,0532$ & $* *$ \\
\hline & $(-2,21)$ & & $(-1,84)$ & & $(-2,28)$ & & $(-1,99)$ & \\
\hline \multirow[t]{2}{*}{$\mathbf{R}^{*}$ glegis } & $-1,305$ & $*$ & $-2,868$ & $* *$ & 8,806 & & $-0,626$ & \\
\hline & $(-1,84)$ & & $(-2,52)$ & & $(1,34)$ & & $(-0,60)$ & \\
\hline \multirow[t]{2}{*}{ gadm } & 0,0419 & $* * *$ & 0,0453 & $* * *$ & 0,0443 & $* * *$ & 0,0437 & $* * *$ \\
\hline & $(4,72)$ & & $(4,94)$ & & $(4,97)$ & & $(4,88)$ & \\
\hline \multirow[t]{2}{*}{$\mathbf{R}^{*}$ gadm } & $-0,0861$ & & 0,196 & & 0,858 & & $-0,0655$ & \\
\hline & $(-0,65)$ & & $(1,03)$ & & $(1,09)$ & & $(-0,37)$ & \\
\hline \multirow[t]{2}{*}{ gassist } & 0,0581 & $* *$ & 0,0568 & $* *$ & 0,058 & $* *$ & 0,0568 & $* *$ \\
\hline & $(2,42)$ & & $(2,36)$ & & $(2,42)$ & & $(2,37)$ & \\
\hline \multirow[t]{2}{*}{$\mathbf{R}$ *gassist } & $-0,717$ & $*$ & $-0,324$ & & 2,206 & & 0,104 & \\
\hline & $(-1,96)$ & & $(-0,42)$ & & $(1,30)$ & & $(0,17)$ & \\
\hline \multirow[t]{2}{*}{ gsaude } & 0,0399 & $* * *$ & 0,0468 & $* * *$ & 0,043 & $* * *$ & 0,0447 & $* * *$ \\
\hline & $(3,66)$ & & $(4,03)$ & & $(3,92)$ & & $(3,88)$ & \\
\hline \multirow[t]{2}{*}{$\mathbf{R} *$ gsaude } & 0,238 & & $-0,664$ & & $-0,789$ & & 0,574 & $*$ \\
\hline & $(1,09)$ & & $(-1,01)$ & & $(-0,61)$ & & $(1,91)$ & \\
\hline \multirow[t]{2}{*}{ geduc } & 0,0862 & $* * *$ & 0,0912 & $* * *$ & 0,0862 & $* * *$ & 0,0918 & $* * *$ \\
\hline & $(7,19)$ & & $(6,82)$ & & $(7,16)$ & & $(6,84)$ & \\
\hline \multirow[t]{2}{*}{$\mathbf{R} *$ geduc } & $-0,304$ & & $-0,236$ & & 0,947 & & $-0,502$ & $* *$ \\
\hline & $(-1,56)$ & & $(-0,65)$ & & $(0,74)$ & & $(-2,20)$ & \\
\hline \multirow[t]{2}{*}{ gurban } & $-0,0424$ & $* * *$ & $-0,0492$ & $* * *$ & $-0,0437$ & $* * *$ & $-0,0471$ & $* * *$ \\
\hline & $(-3,88)$ & & $(-4,14)$ & & $(-4,03)$ & & $(-3,96)$ & \\
\hline $\mathbf{R} *$ gurban & $-0,149$ & & 0,0705 & & 0,986 & & 0,0277 & \\
\hline & $(-1,17)$ & & $(0,21)$ & & $(0,75)$ & & $(0,20)$ & \\
\hline ghabit & $-0,0883$ & $* * *$ & $-0,0822$ & $* * *$ & $-0,0872$ & $* * *$ & $-0,08$ & $* * *$ \\
\hline & $(-3,96)$ & & $(-3,45)$ & & $(-3,88)$ & & $(-3,31)$ & \\
\hline $\mathbf{R} *$ ghabit & 0,946 & & 0,331 & & 5,115 & & 2,082 & \\
\hline & $(0,81)$ & & $(0,32)$ & & $(1,27)$ & & $(0,98)$ & \\
\hline gsanea & $-0,0514$ & $* * *$ & $-0,0514$ & $* * *$ & $-0,0489$ & $* * *$ & $-0,0508$ & $* * *$ \\
\hline & $(-3,13)$ & & $(-3,10)$ & & $(-2,97)$ & & $(-3,06)$ & \\
\hline $\mathbf{R} *$ gsanea & 0,271 & & 1,316 & & 4,434 & $* * *$ & 0,148 & \\
\hline & $(1,21)$ & & $(1,28)$ & & $(3,21)$ & & $(0,79)$ & \\
\hline ggeamb & 0,0672 & & 0,064 & & 0,0724 & & 0,0646 & \\
\hline & $(1,21)$ & & $(1,15)$ & & $(1,29)$ & & $(1,16)$ & \\
\hline $\mathbf{R} *$ ggeamb & $-0,291$ & & $-0,346$ & & $-5,602$ & & 0,189 & \\
\hline & $(-1,17)$ & & $(-0,16)$ & & $(-0,98)$ & & $-0,55$ & \\
\hline Munic. & 4573 & & 4573 & & 4573 & & 4573 & \\
\hline Obs. & 18292 & & 18292 & & 18292 & & 18292 & \\
\hline R2 Aj. & 0,3186 & & 0,3058 & & 0,3156 & & 0,3083 & \\
\hline $\mathbf{F}$ & 211,95 & & 168,15 & & 645,64 & & 378,52 & \\
\hline Prob $>F$ & 0,00 & & 0,00 & & 0,00 & & 0,00 & \\
\hline Controles & Sim & & Sim & & Sim & & Sim & \\
\hline Efeitos tempo & Sim & & Sim & & Sim & & Sim & \\
\hline
\end{tabular}

Resultados das estimações do modelo 3 (pág. 58) para os gastos públicos função: $C_{i t}=\alpha+\beta R_{i t}+\sum_{k=1}^{k} \gamma_{k}^{G} G_{k, i t}+$ $\sum_{k=1}^{k} \sigma_{k}^{R G} R_{i t} . G_{k, i t}+\sum_{j=1}^{j} \delta_{j}^{Z} Z_{j, i t}+\varepsilon_{i t}$. Variável dependente é o crescimento econômico. Modelos estimados por LSDV com efeitos fixos de tempo e erros-padrão robustos agrupados por municípios. ***, ** e $*$ referem-se à significância dos coeficientes a 1\%,5\% e 10\%, respectivamente. Entre parênteses, a estatística t dos coeficientes. Resultados das variáveis de controle, efeitos fixos de tempo e testes de qualidade dos ajustes estão nos apêndices $F$ e $G$. Legenda das variáveis: $\mathbf{R}$ - variável de recursos naturais; Rnpc - abundância em recursos naturais total em milhares de reais; Rhpc - abundância em recursos hídricos em milhares de reais; Rmpc - abundância em recursos minerais em milhares de reais; Rppc - abundância em recursos do petróleo em milhares de reais; glegis - gasto com o Legislativo; gadm - gasto com a administração; geduc - gasto em educação; gassist - gasto em assistência social; gsaude - gasto em saúde; gurban - gasto em urbanismo; ghabit - gasto em habitação; gsanea - gasto em saneamento; ggeamb - gasto em gestão ambiental; $\mathbf{R}^{*}$ - variável de interação entre recursos naturais e gastos públicos. 
$\mathrm{Na}$ coluna $\mathrm{B}$ da tabela 4.10, a abundância em recursos hídricos não foi sensível à composição dos gastos por função. Embora o sinal do parâmetro se tenha alterado (agora positivo, antes negativo no modelo $1 b$ ), ele continuou estatisticamente não significativo. Ainda assim, observa-se que a produtividade do gasto com o Legislativo dos municípios abundantes em recursos hídricos foi menor nos municípios que financiaram maior parcela desse gasto com as receitas com recursos hídricos.

Na coluna C da tabela 4.10, a composição do gasto por função explica parte da relação negativa da abundância em recursos minerais e crescimento econômico, pois a variável não foi estatisticamente significativa (no modelo $1 \mathrm{~b}$, tabela 4.2, a variável foi negativa e significava). A variável de interação para produtividade do gasto por função condicionada à abundância em recursos minerais foi menor para o gasto com o legislativo, sugerindo que nos municípios abundantes que utilizaram as receitas com tais recursos para custear esse gasto, o crescimento foi menor do que nos municípios não abundantes.

Na coluna $\mathrm{D}$, a variável de recursos do petróleo também foi sensível à composição do gasto por função (comparando-se com o modelo $1 \mathrm{~b}$ ). A produtividade dos gastos em saúde e educação foi diferente nos municípios abundantes nesse tipo de recurso: aqueles que utilizaram a receita com recursos do petróleo para financiar maior parcela do gasto em saúde tiveram crescimento maior que os municípios não abundantes, considerando-se certo nível de robustez (variável de interação foi significativa a 10\%); ao contrário, para aqueles que utilizaram tais receitas para custear o gasto em educação, o crescimento foi menor.

Na tabela 4.11, são apresentados os resultados da estimação do modelo 5 (página 60) para os gastos públicos por função para os municípios que receberam receitas com a exploração de recursos naturais em todo o período do estudo. No modelo da coluna A, com somente municípios abundantes em recursos naturais, a variável de recursos naturais e a dummy para os municípios mais abundantes tiveram o mesmo comportamento observado no modelo 4a (tabela 4.3), sugerindo que a composição funcional do gasto público não influenciou a relação entre recursos naturais e crescimento no período estudado.

A produtividade dos gastos com administração, educação e urbanismo para a subamostra que continha apenas municípios abundantes em recursos naturais foi similar à observada para a amostra com todos os municípios (tabela 4.5). Os demais gastos não foram produtivos no período. Contudo, o gasto em saúde foi mais produtivo nos municípios mais abundantes em recursos naturais, considerando certo grau de robustez (10\% de significância). 
Tabela 4.11 - Nível de abundância em recursos naturais, gastos por função e crescimento econômico

\begin{tabular}{|c|c|c|c|c|c|c|c|c|}
\hline & $\mathbf{A}$ & & B & & $\mathbf{C}$ & & D & \\
\hline & $5.5 a$ & & $5.5 b$ & & $5.5 \mathrm{c}$ & & $5.5 d$ & \\
\hline & $\begin{array}{c}\mathrm{R}=\mathrm{Rnpc} \\
\mathrm{D}=\mathrm{drn}\end{array}$ & & $\begin{array}{c}\mathrm{R}=\mathrm{Rhpc} \\
\mathrm{D}=\mathrm{drh}\end{array}$ & & $\begin{array}{c}\mathrm{R}=\mathrm{Rmpc} \\
\mathrm{D}=\mathrm{drm}\end{array}$ & & $\begin{array}{c}\mathrm{R}=\mathrm{Rppc} \\
\mathrm{D}=\mathrm{drp}\end{array}$ & \\
\hline $\mathbf{R}$ & $\begin{array}{r}-0,0201 \\
(-2,87)\end{array}$ & $* * *$ & $\begin{array}{r}0,0225 \\
(1,11)\end{array}$ & & $\begin{array}{r}0,0209 \\
(0,39)\end{array}$ & & $\begin{array}{r}-0,0251 \\
(-3,93)\end{array}$ & $* * *$ \\
\hline D & $\begin{array}{r}-0,0482 \\
(-1,66)\end{array}$ & $*$ & $\begin{array}{r}-0,0855 \\
(-1,72)\end{array}$ & * & $\begin{array}{r}0,0186 \\
(0,65)\end{array}$ & & $\begin{array}{r}-0,0696 \\
(-1,51)\end{array}$ & \\
\hline glegis & $\begin{array}{r}0,015 \\
(0,32)\end{array}$ & & $\begin{array}{r}-0,0209 \\
(-0,28)\end{array}$ & & $\begin{array}{r}0,0207 \\
(0,25)\end{array}$ & & $\begin{array}{r}-0,0285 \\
(-0,53)\end{array}$ & \\
\hline D*glegis & $\begin{array}{l}-0,125 \\
(-1,36)\end{array}$ & & $\begin{array}{l}-0,263 \\
(-1,62)\end{array}$ & & $\begin{array}{l}0,074 \\
(0,41)\end{array}$ & & $\begin{array}{r}0,335 \\
(2,46)\end{array}$ & $* *$ \\
\hline gadm & $\begin{array}{l}0,033 \\
(2,39)\end{array}$ & $* *$ & $\begin{array}{r}0,055 \\
(2,22)\end{array}$ & $* *$ & $\begin{array}{r}0,0268 \\
(1,12)\end{array}$ & & $\begin{array}{r}0,0269 \\
(1,47)\end{array}$ & \\
\hline$D *$ gadm & $\begin{array}{r}0,0352 \\
(0,86)\end{array}$ & & $\begin{array}{r}0,0181 \\
(0,31)\end{array}$ & & $\begin{array}{r}-0,0324 \\
(-0,78)\end{array}$ & & $\begin{array}{r}0,0601 \\
(0,97)\end{array}$ & \\
\hline gassist & $\begin{array}{r}0,0399 \\
(1,13)\end{array}$ & & $\begin{array}{r}0,0252 \\
(0,30)\end{array}$ & & $\begin{array}{l}0,045 \\
(0,72)\end{array}$ & & $\begin{array}{r}-0,0215 \\
(-0,48)\end{array}$ & \\
\hline D*gassist & $\begin{array}{r}-0,0805 \\
(-0,95)\end{array}$ & & $\begin{array}{l}0,097 \\
(0,58)\end{array}$ & & $\begin{array}{r}0,0619 \\
(0,55)\end{array}$ & & $\begin{array}{r}-0,0612 \\
(-0,61)\end{array}$ & \\
\hline gsaude & $\begin{array}{r}0,0154 \\
(0,92)\end{array}$ & & $\begin{array}{r}0,0696 \\
(2,60)\end{array}$ & $* * *$ & $\begin{array}{r}0,0394 \\
(1,61)\end{array}$ & & $\begin{array}{r}0,00259 \\
(0,12)\end{array}$ & \\
\hline D*gsaude & $\begin{array}{r}0,0729 \\
(1,69)\end{array}$ & $*$ & $\begin{array}{r}0,147 \\
(1,54)\end{array}$ & & $\begin{array}{r}-0,0338 \\
(-0,68)\end{array}$ & & $\begin{array}{r}0,0381 \\
(0,73)\end{array}$ & \\
\hline geduc & $\begin{array}{r}0,0736 \\
(4,20)\end{array}$ & $* * *$ & $\begin{array}{r}0,0408 \\
(0,88)\end{array}$ & & $\begin{array}{r}0,0569 \\
(2,37)\end{array}$ & $* *$ & $\begin{array}{r}0,0728 \\
(3,04)\end{array}$ & $* * *$ \\
\hline D*geduc & $\begin{array}{r}0,0556 \\
(1,16)\end{array}$ & & $\begin{array}{r}0,177 \\
(1,80)\end{array}$ & * & $\begin{array}{r}-0,0151 \\
(-0,32)\end{array}$ & & $\begin{array}{r}0,0852 \\
(1,29)\end{array}$ & \\
\hline gurban & $\begin{array}{r}-0,0534 \\
(-2,58)\end{array}$ & $* * *$ & $\begin{array}{r}-0,00631 \\
(-0,22)\end{array}$ & & $\begin{array}{r}-0,0655 \\
(-2,18)\end{array}$ & $* *$ & $\begin{array}{r}-0,0422 \\
(-1,79)\end{array}$ & $*$ \\
\hline D*gurban & $\begin{array}{r}0,0433 \\
(1,15)\end{array}$ & & $\begin{array}{r}-0,0789 \\
(-1,21)\end{array}$ & & $\begin{array}{r}-0,0413 \\
(-0,76)\end{array}$ & & $\begin{array}{r}0,0974 \\
(1,68)\end{array}$ & $*$ \\
\hline ghabit & $\begin{array}{r}0,0215 \\
(0,55)\end{array}$ & & $\begin{array}{r}0,0106 \\
(0,15)\end{array}$ & & $\begin{array}{r}0,105 \\
(1,26)\end{array}$ & & $\begin{array}{r}0,00204 \\
(0,05)\end{array}$ & \\
\hline D*ghabit & $\begin{array}{r}-0,0932 \\
(-0,95)\end{array}$ & & $\begin{array}{r}0,0755 \\
(0,44)\end{array}$ & & $\begin{array}{r}-0,4 \\
(-2,30)\end{array}$ & $* *$ & $\begin{array}{r}-0,00218 \\
(-0,02)\end{array}$ & \\
\hline gsanea & $\begin{array}{r}-0,0265 \\
(-1,00)\end{array}$ & & $\begin{array}{r}-0,0409 \\
(-1,02)\end{array}$ & & $\begin{array}{r}-0,0219 \\
(-0,54)\end{array}$ & & $\begin{array}{r}-0,0291 \\
(-0,76)\end{array}$ & \\
\hline D*gsanea & $\begin{array}{r}-0,0296 \\
(-0,46)\end{array}$ & & $\begin{array}{r}-0,0683 \\
(-0,81)\end{array}$ & & $\begin{array}{r}-0,0304 \\
(-0,45)\end{array}$ & & $\begin{array}{l}-0,118 \\
(-0,95)\end{array}$ & \\
\hline ggeamb & $\begin{array}{r}0,0395 \\
(0,66)\end{array}$ & & $\begin{array}{r}0,1 \\
(0,71)\end{array}$ & & $\begin{array}{r}0,0947 \\
(0,83)\end{array}$ & & $\begin{array}{l}-0,029 \\
(-0,51)\end{array}$ & \\
\hline$D^{*}$ ggeamb & $\begin{array}{r}0,154 \\
(1,05)\end{array}$ & & $\begin{array}{l}1,339 \\
(2,28)\end{array}$ & $* *$ & $\begin{array}{l}-0,133 \\
(-0,80)\end{array}$ & & $\begin{array}{r}0,0749 \\
(0,49)\end{array}$ & \\
\hline Munic. & 1544 & & 519 & & 673 & & 576 & \\
\hline Obs. & 6176 & & 2076 & & 2692 & & 2304 & \\
\hline $\mathbf{R 2} \mathbf{A j}$. & 0,3135 & & 0,428 & & 0,3448 & & 0,2542 & \\
\hline $\mathbf{F}$ & 60,35 & & 31,45 & & 36,03 & & 25,24 & \\
\hline Prob $>$ F & 0,00 & & 0,00 & & 0,00 & & 0,00 & \\
\hline Controles & Sim & & Sim & & Sim & & Sim & \\
\hline Efeitos tempo & Sim & & Sim & & Sim & & Sim & \\
\hline
\end{tabular}

Resultados das estimações do modelo 5 (pág. 60) $C_{i t}=\alpha+\beta R_{i t}+\sum_{k=1}^{k} \gamma_{k}^{S} G_{k, i t}+\theta D_{i t}+\sum_{k=1}^{k} \varphi_{k}^{D G} D_{i t} G_{k, i t}+\sum_{j=1}^{j} \delta_{j}^{Z} Z_{j, i t}+\varepsilon_{i t}$. Variável dependente é o crescimento econômico. Modelos estimados por LSDV com efeitos fixos de tempo e erros-padrão robustos agrupados por municípios. ***, ** e * referem-se à significância dos coeficientes a 1\%, 5\% e 10\%, respectivamente. Entre parênteses, a estatística t dos coeficientes. Resultados das variáveis de controle, efeitos fixos de tempo e testes de qualidade dos ajustes estão nos apêndices F e G. Legenda das variáveis: D - dummy para os municípios mais abundantes em recursos naturais; drn dummy para os municípios mais abundantes em recursos naturais total; drh - dummy para os municípios mais abundantes em recursos hídricos; drm - dummy para os municípios mais abundantes em recursos minerais; drp - dummy para os municípios mais abundantes em recursos do petróleo; $\mathbf{D}^{*}$ - variável de interação entre a dummy e gastos públicos. 
No modelo estimado na coluna B da tabela 4.11, com somente municípios abundantes em recursos hídricos, a composição dos gastos por função não influenciou na relação entre recursos hídricos e o crescimento. Isso é verificado pelo comportamento da variável de abundância em recursos hídricos e da dummy para os municípios mais abundantes, que foi similar ao observado no modelo 4b (tabela 4.3): a primeira, embora o sinal tenha mudado para positivo, continuou não estatisticamente significativa; na segunda, o sinal foi o mesmo, apesar de a significância ter reduzido para $10 \%$.

Apenas as variáveis de gastos com administração e saúde foram significativas para a subamostra com municípios abundantes em recursos hídricos no período. As variáveis de interação foram positivas e significativas para os gastos em educação e gestão ambiental, sugerindo que, nos municípios em que houve mais receita com recursos hídricos, a produtividade desses gastos foi maior do que nos municípios menos abundantes.

$\mathrm{Na}$ coluna $\mathrm{C}$ da tabela 4.11, para a subamostra de municípios abundantes em recursos minerais, as variáveis de recursos minerais e a dummy para os municípios mais abundantes continuaram não estatisticamente significativas, embora o sinal tenha sido positivo (no modelo 4c, tabela 4.3, essas variáveis foram negativas e não significativas). Esse resultado indica que a composição funcional dos gastos não influenciou a relação entre abundância de recursos minerais e o crescimento econômico dos municípios mais e menos abundantes.

Ainda para o modelo com esses municípios, o gasto em saúde foi produtivo e o gasto em urbanismo foi improdutivo no período do estudo - a variável desses gastos foi, respectivamente, positiva e negativa e significativa. A variável de interação com os gasto em habitação foi negativa e significativa a 5\%, sugerindo que nos municípios mais abundantes, a produtividade do gasto em habitação foi menor do que nos municípios menos abundantes em recursos minerais.

No modelo estimado com os municípios abundantes em recursos do petróleo, a composição funcional do gasto também não influenciou a relação entre esses recursos e o crescimento econômico: a variável de recursos do petróleo e a dummy para os municípios mais abundantes teve o mesmo comportamento negativo do modelo $4 \mathrm{~d}$ (tabela 4.3), sendo que apenas a primeira variável foi igualmente significante. Ou seja, não se observa comportamento diferenciado no crescimento entre municípios mais e menos abundantes em recursos do petróleo.

Somente o gasto em educação foi produtivo (variável com sinal positivo e significativo), diferentemente do gasto em urbanismo (negativo e significativo), enquanto os demais gastos não contribuíram para o crescimento econômico dos municípios abundantes em 
recursos do petróleo. As variáveis de interação do gasto com o Legislativo e do gasto em urbanismo com o nível de abundância em recursos do petróleo foram positivas e significativas, indicando que, nos municípios mais abundantes em tais recursos, esses gastos foram mais produtivos do que nos municípios menos abundantes.

\subsection{Variáveis de controle}

Os resultados para as variáveis de controle dos modelos estimados anteriormente são apresentados no apêndice G. De forma geral, o comportamento esperado da variável de capital humano era uma relação positiva com o crescimento econômico; a evidência, contudo, não foi robusta. Essa variável não foi estatisticamente significativa na maioria dos modelos, e o valor do parâmetro foi quase nulo, apesar de, nos modelos $1 \mathrm{a}$ e $1 \mathrm{~b}$, o sinal dessa variável ter sido positivo, considerando-se certo grau de robustez (significante a 10\%).

Esse resultado pode ser explicado pelo fato de a variável de capital humano da pesquisa representar os anos médios de estudo dos trabalhadores formais registrados na RAIS, restringindo a consideração dessa variável a uma parte da população dos municípios. Nesse sentido, os trabalhadores formais podem representar uma pequena parte da população, principalmente nos municípios menores (pelo menos $75 \%$ da amostra são municípios de pequeno porte), onde a Justiça do trabalho pode não ter atuação tão marcante, o que limitaria o efeito dos anos médios de estudo dos trabalhadores formais no crescimento dos municípios.

A variável porte foi positiva e estatisticamente significativa a $1 \%$ em todos os modelos, sugerindo que, nos municípios maiores, o crescimento econômico foi maior. Essa variável representa o tamanho dos municípios pela estimativa da população local, o que também pode ser um indício da força de trabalho, ou seja, nos municípios mais populosos a oferta de mão de obra é maior, o que contribuiria para o crescimento econômico.

As variáveis para a variação do índice de commodities metal e energia foram incluídas nos modelos em que as variáveis de abundância em recursos minerais e do petróleo, respectivamente, estivessem presentes (modelos com Rnpc, Rmpc, Rppc). Nos modelos com subamostra de apenas municípios abundantes em recursos minerais ou em recursos do petróleo, a variável de commodities relacionada foi omitida devido ao risco de colinearidade. Isso ocorreu porque, nesses modelos, todas as observações tinham o mesmo valor para as variáveis de commodities em cada ano; por isso, elas não variaram.

O comportamento da variação do índice de commodities energia foi positivo e significativo a $1 \%$ em todos os modelos nos quais estava presente, sugerindo que a variação 
dos preços das commodities de produtos da exploração do petróleo contribuiu, de alguma forma, para o crescimento econômico dos municípios abundantes em tais recursos.

Diferentemente, o sinal da variação do índice de commodities metal foi negativo, embora essa evidência tenha sido robusta (significância a 5\%) apenas nos modelos com a variável de recursos minerais. Ou seja, nos municípios abundantes em recursos minerais, o crescimento econômico foi influenciado negativamente pela variação do preço das commodities de produtos da exploração de recursos metálicos.

A variável para o nível do gasto público teve relação positiva e significativa com o crescimento em todos os modelos com variáveis de gasto, indicando que o financiamento da despesa pública subiu com o crescimento econômico, ou seja, a partir da maior arrecadação de impostos. No modelo de produtividade da composição do gasto público de Devarajan, Swaroop e Zou (1996), esse resultado sugeriria que, para financiar um nível mais elevado da despesa pública, seriam necessários mais impostos distorcidos. Indicaria, ainda, que a produtividade dos gastos teria compensado o peso morto associado da tributação sobre o crescimento.

Outrossim, o comportamento do nível do gasto poderia indicar que o setor público tem papel fundamental no crescimento econômico dos municípios brasileiros, especialmente se se considerar que, em muitas localidades, os gastos governamentais representa uma importante fonte de renda da população, responsável por movimentar a economia local. 


\section{CONSIDERAÇÕES FINAIS}

A exploração de recursos naturais pode constituir-se numa importante vantagem econômica para os municípios onde eles abundam porque gera um volume de rendimentos financeiros que poderiam contribuir para o crescimento econômico da região se forem devidamente utilizados. Contudo, a literatura mostra que, em localidades abundantes em recursos naturais, o crescimento tende a ser menor do que nas localidades não abundantes.

Fatores ligados ao modo como as localidades ricas em recursos naturais lidam com os rendimentos resultantes da exploração desses recursos explicam o porquê da relação negativa entre recursos naturais e crescimento econômico - tais como a maneira de se utilizar os rendimentos para financiar o gasto público. Dessa forma, a maldição dos recursos naturais poderia ser um efeito indireto da produtividade do gasto público.

Assim, esta pesquisa analisou como a abundância em rendimentos decorrentes da exploração de recursos naturais e a produtividade do gasto público condicionada a esses rendimentos se relacionavam com o crescimento econômico dos municípios brasileiros abundantes/não abundantes ou mais/menos abundantes.

Os resultados da pesquisa mostram, de forma geral, uma relação negativa entre as receitas municipais decorrentes da compensação financeira pela exploração dos recursos naturais em seus territórios e o crescimento econômico, o que é um indício da ocorrência da maldição dos recursos naturais nos municípios brasileiros. Foi verificado, também, que o gasto público em diferentes tipos de agregação apresenta comportamento variado com o crescimento econômico, indicando que a composição do gasto pode ser importante para os municípios.

A comparação entre municípios abundantes e não abundantes em recursos naturais mostrou que, nos primeiros, o crescimento econômico era menor do que nos segundos, principalmente nos municípios abundantes em recursos minerais e do petróleo. Quando verificado pelo nível de abundância, nos municípios com maior volume de receitas de recursos naturais o crescimento foi menor do que nos municípios onde a receita foi inferior, especialmente nos municípios com maiores receitas advindas da exploração de recursos hídricos.

Quando analisado o comportamento do gasto público, nos municípios onde a composição do gasto privilegiou o gasto corrente e seus componentes (gasto com pessoal e outros gastos correntes), o crescimento econômico foi maior que do nos municípios onde o 
gasto de capital e em investimentos foram maiores. Esses resultados apontam para a produtividade do gasto corrente ante ao gasto de capital.

Nessa linha, os gastos com administração, assistência social, saúde e educação foram os que contribuíram para o crescimento econômico dos municípios entre 2003 e 2012, destacando-se a maior produtividade do último. Enquanto os gastos com o Legislativo, com urbanismo, habitação e saneamento influenciaram negativamente o crescimento dos municípios no citado período; o gasto com gestão ambiental não se mostrou um gasto importante para o crescimento.

$\mathrm{Na}$ análise da sensibilidade dos efeitos dos recursos naturais no crescimento econômico em função do gasto público, o gasto corrente e seus componentes (gasto com pessoal e outros custeios) e os gastos nas funções estudadas foram os que mais interferiram na relação, o que sugere que parte da maldição dos recursos naturais nos municípios brasileiros pode ser explicada pela produtividade do gasto público.

Similarmente, quando analisado o nível de abundância, a produtividade do gasto corrente e seus componentes explicam, de forma geral, parte da relação negativa dos recursos naturais no crescimento dos municípios com maiores receitas de exploração. Nos municípios mais abundantes em recursos hídricos, a relação foi influenciada pela produtividade do gasto de capital e em investimentos. Já a produtividade dos gastos por função não foi significativa na explicação da relação entre municípios mais abundantes e crescimento econômico.

$\mathrm{Na}$ análise da produtividade do gasto público condicionada às receitas com recursos naturais, verificou-se que, nos municípios abundantes em recursos hídricos e do petróleo, a produtividade do gasto de capital e em investimentos foi maior (e a do gasto corrente e seus componentes foi menor) do que nos municípios não abundantes. Quanto aos gastos por função, não se verificou diferença na produtividade dos gastos, apenas o gasto em saneamento nos municípios abundantes em recursos minerais e o gasto em saúde nos municípios abundantes em recursos do petróleo foram maiores do que nos municípios não abundantes.

Igualmente, observou-se que a produtividade do gasto nos municípios mais abundantes em recursos naturais não foi diferente da dos municípios menos abundantes. Apenas nos municípios mais abundantes em recursos hídricos o gasto corrente e com pessoal teve maior produtividade do que nos municípios menos abundantes. Quanto aos gastos por função, as evidências mais robustas indicaram maior produtividade do gasto em gestão ambiental e com o Legislativo nos municípios mais abundantes em recursos hídricos e do petróleo, respectivamente, em comparação com os menos abundantes. 
Portanto, esses resultados sugerem evidências da maldição dos recursos naturais nos municípios brasileiros e indicam que ela pode ser explicada em parte pela produtividade do gasto público. Ainda, há poucos indícios de que os gastos condicionados às receitas com a exploração dos recursos naturais foram mais produtivos, ou seja, nos municípios abundantes em recursos naturais, as receitas de exploração pouco contribuíram para a produtividade do gasto público.

As limitações da pesquisa estão relacionadas principalmente com a disponibilidade dos dados, que restringiram o período analisado, e com as variáveis utilizadas. Os dados sobre a CFEM distribuída aos municípios limitaram o período inicial da análise, uma vez que estão publicamente disponibilizados no sítio da internet do DNPM somente a partir de 2004, embora tenha sido possível encontrar um relatório com esses dados referentes a 2003.

Até o encerramento da coleta dos dados, o IBGE não havia disponibilizado o PIB dos municípios a partir de 2013; e, devido à defasagem para frente da variável dependente, limitou-se o período da análise até 2012. Portanto, a pesquisa analisou o efeito dos recursos naturais e do gasto público de 2003 a 2007 no crescimento econômico médio dos municípios entre de 2004 a 2012.

O gasto público analisado é aquele empenhado pelo município, tendo em vista a disponibilidade dos dados do balanço orçamentário pela FINBRA para o período do estudo. Ainda, a forma de classificação da despesa no balanço orçamentário pode distorcer a informação dos gastos efetivos em determinada função, por exemplo, dentro da despesa em educação estão incluídos desde os gastos da secretaria municipal de educação (ou similar) até os gastos efetivos para melhoria do sistema escolar.

Ainda, a despesa pública é apresentada no balanço orçamentário como se fosse uma situação pontual no fim do exercício financeiro-orçamentário, embora o repasse das receitas e a execução das despesas ocorressem em períodos variados, podendo ultrapassar o exercício financeiro. Ainda assim, apesar dessas limitações, acredita-se que os resultados da pesquisa sejam robustos, tendo em vista a coerência dos procedimentos aqui adotados com o de outros estudos, bem como a adequação dos resultados com o arcabouço teórico e com trabalhos anteriores.

Para futuras pesquisas sugere-se a investigação de outros períodos - principalmente, para capturar os efeitos da crise de 2007/2008 -, a utilização da variável dependente com maior defasagem para frente, de outras variáveis de controle - como o IDH, índice Firjan, as tranferências do Fundo de Participação dos Municípios etc. -, a análise de outros recursos naturais - como o uso da terra para a agricultura, pecuária etc. -, de outros tipos de gastos 
públicos (da classificação funcional), dos efeitos da receita com a exploração dos recursos naturais na arrecadação própria dos municípios, além de outras técnicas de estimação para minimizar os problemas de endogeneidade nos modelos com variáveis econômicas - como a técnica de painéis dinâmicos, sistemas de equações em dois estágios, modelos de momentos generalizados etc. 


\section{REFERÊNCIAS}

ACEMOGLU, Daron; FINKELSTEIN, Amy; NOTOWIDIGDO, Matthew J. Income and health spending: evidence from oil price shocks. The Review of Economics and Statistics, v. 95, n. 4, p. 1079-1095, 2013.

ACEMOGLU, Daron; JOHNSON, Simon; ROBINSON, James; THAICHAROEN, Yunyong. Institutional causes, macroeconomic symptoms: volatility, crises and growth. Journal of Monetary Economics, v. 50, n. 1, p. 49-123, 2003.

AGELL, Jonas; OHLSSON, Henry; THOURSIE, Peter S. Growth effects of government expenditure and taxation in rich countries: a comment. European Economic Review, v. 50, n. 1, p. 211-218, 2006.

AIKEN, Leona S.; WEST, Stephen G. Multiple regression: testing and interpreting interactions. Thousand Oaks, CA: Sage Publications, 1991.

ALEXIOU, Constantinos. Government spending and economic growth: econometric evidence from the South Eastern Europe (SEE). Journal of Economic and Social Research, v. 11, n. 1, p. 1-16, 2009.

ALICHI, Ali; AREZKI, Rabah. An alternative explanation for the resource curse: the income effect channel. Washington D.C.: International Monetary Fund, 2009. (IMF Working Paper, n. 112).

ANP - Agência Nacional do Petróleo, Gás Natural e Biocombustíveis. Anuário estatístico brasileiro do petróleo, gás natural e biocombustíveis: 2013. Rio de Janeiro: ANP, 2013.

ANSHASY, Amany A. Oil windfall shocks, government spending, and the resource curse. Journal of Applied Business and Economics, v. 12, n. 4, p. 44-63, 2011.

ANSHASY, Amany A.; KATSAITI, Marina-Selini. Are natural resources bad for health? Health \& Place, v. 32, p. 29-42, 2015.

ASCHAUER, David A. Is public expenditure productive? Journal of Monetary Economics, v. 23, n. 2, p. 177-200, 1989.

ATKINSON, Giles; HAMILTON, Kirk. Savings, growth and the resource curse hypothesis. World Development, v. 31, n. 11, p. 1793-1807, 2003. 
AUTY, Richard M. Industrial policy reform in six large newly industrializing countries: the resource curse thesis. World Development, v. 22, n. 1, p. 11-26, 1994.

AUTY, Richard M. Natural resource endowment, the state and development strategy. Journal of International Development, v. 9, n. 4, p. 651-663, 1997.

AUTY, Richard M. Resource-based industrialization: sowing the oil in eight developing countries. New York: Oxford University Press, 1990.

AUTY, Richard M. The political economy of resource-driven growth. European Economic Review, v. 45, n. 4-6, p. 839-846, 2001.

BALTAGI, Badi H. Econometric analysis of panel data. 3 ed. Chichester: John Wiley \& Sons, 2005.

BALTAGI, Badi H. Econometrics. 4 ed. Berlin: Springer, 2008.

BARRO, Robert J. Economic Growth in a Cross Section of Countries. The Quarterly Journal of Economics, v. 106, n. 2, p. 407-443, 1991.

BARRO, Robert J. Government spending in a sample model of endogenous growth. The Journal of Political Economy, v. 98, n. 5, p. s103-s125, 1990.

BAYRAKTAR, Nihal; MORENO-DODSON, Blanca. How can public spending help you grow? An empirical analysis for developing countries. Washington, DC: The World Bank, 2010. (Policy Research Working Paper, n. 5367).

BEHBUDI, DAVOOD; MAMIPOUR, SIAB; KARAMI, AZHDAR. Natural resource abundance, human capital and economic growth in the petroleum Exporting countries. Journal of Economic Development, v. 35, n. 3, p. 81-102, 2010.

BLEANEY, Michael; GEMMELL, Norman; KNELLER, Richard. Testing the endogenous growth model: public expenditure, taxation and growth over the long run. The Canadian Journal of Economics, v. 34, n. 1, p. 36-57, 2001.

BLEANEY, Michael; HALLAND, Havard. The resource curse and fiscal policy volatility. Nottingham: University of Nottingham, 2009. (CREDIT Research Paper, n. 9).

BOGONI, Nadia M; HEIN, Nelson; BEUREN, Ilse M. Análise da relação entre crescimento econômico e gastos públicos nas maiores cidades da região Sul do Brasil. Revista de Administração Pública, v. 45, n. 1, p. 159-79, 2011. 
BOSE, Niloy; HAQUE, M. Emranul; OSBORN, Denise R. Public expenditure and economic growth: a disaggregated analysis for developing countries. The Manchester School, v. 75, n. 5, p. 533-556, 2007.

BRASIL. Constituição da República Federativa do Brasil de 1988. Disponível em: < http://www.planalto.gov.br/ccivil_03/Constituicao/Constituicao.htm> Acesso em: 5 de out. de 2015.

BRASIL. Decreto n. 1, de 11 de janeiro de 1991. Regulamenta o pagamento da compensação financeira instituída pela Lei no 7.990, de 28 de dezembro de 1989, e dá outras providências. Disponível em: < http://www.planalto.gov.br/ccivil_03/decreto/19901994/D0001 compilado.htm> Acesso em: 5 de out. de 2015.

BRASIL. Decreto n. 3.739, de 31 de janeiro de 2001. Dispõe sobre o cálculo da tarifa atualizada de referência para compensação financeira pela utilização de recursos hídricos [...].Disponível em: < http:// http://www.planalto.gov.br/ccivil_03/decreto/2001/D3739.htm> Acesso em: 5 de out. de 2015.

BRASIL. Lei n. 10.195, DE 14 DE FEVEREIRO DE 2001. Institui medidas adicionais de estímulo e apoio à reestruturação e ao ajuste fiscal dos Estados e dá outras providências. Disponível em: < http://www.planalto.gov.br/ ccivil_03/leis/LEIS_2001/L10195.htm > Acesso em: 5 de out. de 2015.

BRASIL. Lei n. 12.351, de 22 de dezembro de 2010. Dispõe sobre a exploração e a produção de petróleo, de gás natural e de outros hidrocarbonetos fluidos [...].Disponível em: < http://www.planalto.gov.br/ccivil_03/_Ato2007-2010/2010/Lei/L12351.htm > Acesso em: 5 de out. de 2015.

BRASIL. Lei n. 12.858, DE 9 DE SETEMBRO DE 2013. Dispõe sobre a destinação para as áreas de educação e saúde de parcela da participação no resultado ou da compensação financeira pela exploração de petróleo e gás natural [...]. Disponível em: < http://www.planalto.gov.br/ccivil_03/_Ato2011-2014/2013/Lei/L12858.htm > Acesso em: 5 de out. de 2015.

BRASIL. Lei n. 7.990, de 28 de dezembro de 1989. Institui, para os Estados, Distrito Federal e Municípios, compensação financeira pelo resultado da exploração de petróleo ou gás natural, de recursos hídricos para fins de geração de energia elétrica, de recursos minerais [...].Disponível em: < http://www.planalto.gov.br/ccivil_03/leis/L7990.htm > Acesso em: 5 de out. de 2015.

BRASIL. Lei n. 8.001, de 13 de março de 1990. Define os percentuais da distribuição da compensação financeira de que trata a Lei $\mathrm{n}^{\circ} 7.990$, de 28 de dezembro de 1989, e dá outras providências. Disponível em: < http://www.planalto.gov.br/ccivil_03/leis/L8001.htm > Acesso em: 5 de out. de 2015. 
BRASIL. Lei n. 8.876, de 2 de maio de 1994. Autoriza o Poder Executivo a instituir como Autarquia o Departamento Nacional de Produção Mineral (DNPM), e dá outras providências. Disponível em: < http://www.planalto.gov.br/ccivil_03/LEIS/L8876.htm > Acesso em: 5 de out. de 2015.

BRASIL. Lei n. 9.478, de 6 de agosto de 1997. Dispõe sobre a política energética nacional, as atividades relativas ao monopólio do petróleo, institui o Conselho Nacional de Política Energética e a Agência Nacional do Petróleo e dá outras providências. Disponível em: < http://www.planalto.gov.br/ccivil_03/leis/19478.htm >. Acesso em: 5 de out. de 2015.

BRASIL. Lei n. 9.648, de 27 de maio de 1998. Altera dispositivos das Leis no 3.890-A, de 25 de abril de 1961 [...]. Disponível em: < http://www.planalto.gov.br/ccivil_03/Leis/L9648cons. htm > Acesso em: 5 de out. de 2015.

BRASIL. Lei n. 9.984, DE 17 DE JULHO DE 2000. Dispõe sobre a criação da Agência Nacional de Águas - ANA, entidade federal de implementação da Política Nacional de Recursos Hídricos e de coordenação do Sistema Nacional de Gerenciamento de Recursos Hídricos, e dá outras providências. Disponível em: < http://www.planalto.gov.br/ccivil_03/ LEIS/L9984.htm> Acesso em: 5 de out. de 2015.

BREGMAN, D. Formação, distribuição e aplicação de royalties de recursos naturais: o caso do petróleo no Brasil. 2007. 150 p. Dissertação (Mestrado em Economia) - Instituto de Economia, Universidade Federal do Rio de Janeiro, Rio de Janeiro, 2007.

BRESSER-PEREIRA, Luiz C. The dutch disease and its neutralization: a ricardian approach. Revista de Economia Política, v. 28, n.1, p. 48-71, Jan/Mar 2008.

BRITO, Geverson D. LIMA, Diana V. Uma discussão sobre o tratamento contábil das compensações financeiras decorrentes da exploração de petróleo e gás natural no setor público brasileiro. Revista Catarinense da Ciência Contábil, v. 14, n. 43, p.74-87, 2015.

BROLLO, Fernanda; NANNICINI, Tommaso; PEROTTI, Roberto; TABELLINI, Guido. The political resource curse. American Economic Review, v. 103, n. 5, p. 1759-1796, 2013.

BROOKS, Chris. Introductory econometrics for finance. 2 ed. Cambrige: Cambrige University Press, 2008.

BRUNNSCHWEILER, Crista N. Cursing the blessings? Natural resource abundance, institutions, and economic growth. World Development, v. 36, n. 3, p. 399-419, 2008.

BRUNNSCHWEILER, Crista N.; BULTE, Erwin, H. Linking natural resources to slow growth and more conflict. Science, v. 320, p. 616-617, 2008a. 
BRUNNSCHWEILER, Crista N.; BULTE, Erwin, H. The resource curse revisited and revised: a tale of paradoxes and red herrings. Journal of Environmental Economics and Management, v. 55, n. 3, p. 248-264, 2008b.

BULTE, Erwin; DAMANIA, Richard; DEACON, Robert T. Resource intensity, institutions, and development. World Development, v. 33, n. 7, p. 1029-1044, 2005.

BUSSE, Matthias; GRÖNING, Steffen. The resource curse revisited: governance and natural resources. Public Choice, v. 154, n. 1-2, p. 1-20, 2013.

CAÇADOR, Sávio B. MONTE, Edson Z. Impactos dos royalties do petróleo nos indicadores de desenvolvimento dos municípios do Espírito Santo. Interações, v. 14, n. 2, p. 267-278, 2013.

CÂNDIDO JR., José O. Os gastos públicos no Brasil são produtivos? Brasília: IPEA, 2001. (Texto para Discussão, n. 781).

CASELLI, Francesco; MICHAELS, Guy. Do oil windfalls improve living standards? Evidence from Brazil. American Economic Journal, v. 5, n. 1, p. 208-238, 2013.

CHEN, Been-Lon. Economic growth with an optimal public spending composition. Oxford Economic Papers, n. 58, p. 123-136, 2006.

CLARIDA, Richard; NOGUER, Marta. Learning from economic data. In.: GELMAN, Andrew; CORTINA, Jeronimo. A quantitative tour of the social sciences. New York: Cambridge University Press, 2009. p. 99-110.

CORDEN, Max W.; NEARY, Peter J. Booming sector and de-industrialization in a small open economy. The Economic Journal, v. 92, n. 368, p. 825-848, 1982.

COUTINHO, Leonor. The resource curse and fiscal policy. Cyprus Economic Policy Review, v. 5, n. 1, p. 43-70, 2011.

CRUZ, Bruno O.; RIBEIRO, Márcio B. Sobre maldições e bênçãos: é possível gerir recursos naturais de forma sustentável? Uma análise sobre os royalties e as compensações financeiras no brasil. IPEA: Brasília, 2009. (Texto para discussão, n. 1412).

DAVIS, Graham A. Learning to love the Dutch disease: evidence from the mineral economies. World Development, v. 23, n. 10, p. 1765-1779, 1995. 
DAVIS, Jeffrey; OSSOWSKI, Rolando; DANIEL, James; BARNETT, STEVEN.

Stabilization and savings funds for non-renewable resources: experience and fiscal policy implications. Washington D.C.: International Monetary Fund, 2001. (Occasional Paper, n. 205).

DEVARAJAN, Shantayanan; EHRHART, Hélène; LE, Tuan M.; RABALLAND, Gaël. Direct redistribution, taxation, and accountability in oil-rich economies: a proposal.

Washington, DC: Center for Global Development, 2011. (CGD Working Papers, n. 281).

DEVARAJAN, Shantayanan; SWARROP, Vinaya; ZOU, Heng-fu. The composition of public expenditure and economic growth. Journal of Monetary Economics, v. 37, n. 2, p. 313-344, 1996.

DIVINO, José A.; SILVA Jr, Rogério L. S. Composição dos Gastos Públicos e Crescimento Econômico dos Municípios Brasileiros. EconomiA, v. 13, n. 3a, p. 507-528, 2012.

EASTERLY, William; REBELO, Sergio. Fiscal policy and economic growth: an empirical investigation. Journal of Monetary Economics, v. 32, n. 3, p. 417-458, 1993.

ECHAMBADI, Raj; HESS James D. Mean-centering does not alleviate collinearity problems in moderated multiple regression models. Marketing Science, v. 26, n. 3, p. 438-445, 2007.

FATÁS, Antonio; MIHOV, Ilian. Policy volatility, institutions and economic growth. The Review of Economics and Statistics, v. 95, n. 2, p. 362-376, 2013.

FATÁS, Antonio; MIHOV, Ilian. The case for restricting fiscal policy discretion. Quarterly Journal of Economics, v. 118, n. 4, p. 1419-1447, 2003.

FERREIRA, Pedro C. Infraestrutura pública, produtividade e crescimento. Pesquisa e Planejamento Econômico, v. 24, n. 2, p. 187-202, 1994.

FERREIRA, Pedro C. Investimento em infra-estrutura no Brasil: fatos estilizados e relações de longo prazo. Pesquisa e Planejamento Econômico, v. 26, n. 2, p. 231-252, 1996.

FERREIRA, Pedro C.; MALLIAGROS, Thomas G. Impactos produtivos da infra-estrutura no Brasil - 1950/95. Pesquisa e Planejamento Econômico, v. 28 n. 2, p. 315-338, 1998.

FÖLSTER, Stefan; HENREKSON, Magnus. Growth effects of government expenditure and taxation in rich countries. European Economic Review, v. 45, n. 8, p. 1501-1520, 2001. 
FÖLSTER, Stefan; HENREKSON, Magnus. Growth effects of government expenditure and taxation in rich countries: a reply. European Economic Review, v. 50, n. 1, p. 219-221, 2006.

FORLIN, Juliana A.; RODRIGUES, Rodrigo V. Finanças públicas e crescimento econômico nos municípios paulistas. Revista Economia e Desenvolvimento, v. 24, n. 2, 2012.

FRANKEL, Jeffrey A. The natural resource curse: a survey. Massachusetts: NBER, 2010. (NBER Working Paper Series, n. 15836).

GELB, Alan H. Windfall gains: blessing or curse? New York: Oxford University Press, 1988.

GHOSH, Sugata; GREGORIOU, Andros. The composition of government spending and growth: Is current or capital spending better? Oxford Economic Papers, n. 60, p. 484-516, 2008.

GUJARATI, Damodar. Econometria básica. Rio de Janeiro: Elsevier, 2006.

GYLFASON, Thorvaldur. Natural resources, education, and economic development. European Economic Review, v. 45, n. 4-6, p. 847-859, 2001.

GYLFASON, Thorvaldur; HERBERTSSON, Tryggvi T.; ZOEGA, Gylfi. A mixed blessing: natural resources and economic growth. Macroeconomic Dynamics, v. 3, n. 2, p. 204-225, 1999.

HABER, Stephen; MENALDO, Victor. Do natural resources fuel authoritarianism? A reappraisal of the resource curse. American Political Science Review, v. 105, n. 1, p. 1-26, 2011.

HARTWICK, John M. Intergenerational equity and the investing of rents from exhaustible resources. The American Economic Review, v. 67, n. 5, p. 972-974, 1977.

HOECHLE, Daniel. Robust standard erros for panel regressions with cross-sectional dependence. The Stata Journal, v. 7, n. 3, p. 281-312, 2007.

ISHAM, Jonathan; WOODCOCK, Michael; PRITCHETT, Lant; BUSBY, Gwen. The varieties of resource experience: natural resource export structures and the political economy of economic growth. World Bank Economic Review, v. 19, n. 2, p. 141-174, 2005. 
JACCARD, James R.; TURRISI, Robert. Interaction Effects in Multiple Regression. 2 ed. Thousand Oaks, CA: Sage Publications, 2003.

JAMES, Alex; AADLAND, David. The Curse of Natural Resources: an empirical investigation of U.S. counties. Resource and Energy Economics, v. 33, n.2, p. 440-453, 2011.

JAMES, Alexander. The resource curse: a statistical mirage? Journal of Development Economics, v. 114, p. 55-63, 2015.

KENNEDY, Ryan; TIEDE, Tiede. Economic development assumptions and the elusive curse of oil. International Studies Quarterly, v. 57, n. 4, p. 760-771, 2013.

KNELLER, Richard; BLEANEY, Michael F.; GEMMELL, Norman. Fiscal policy and growth: evidence from OECD countries. Journal of Public Economics, v. 74, n. 2. p. 171190, 1999.

LEITE, Carlos; WEIDMANN, Jens. Does mother nature corrupt? Natural resources, corruption, and economic growth. Washington D.C.: International Monetary Fund, 1999. (IMF Working Paper, n. 85).

LEITE, Eduardo T. Compensação financeira pela exploração de recursos minerais CFEM: uma análise de sua contribuição para o desenvolvimentos dos principais municípios mineradores de Minas Gerais. 2009. 339p. Dissertação (Mestrado em Administração) Universidade Federal de Lavras, 2009.

LEVINE, Ross; RENELT, David. A sensitivity analysis of cross-country growth regressions. American Economic Review, v. 82, n. 4, p. 942-63, 1992.

MANZANO, Osmel; RIGOBON, Roberto. Resource curse or debt overhang? Massachusetts: NBER, 2001. (NBER Working Paper Series, n. 8390).

MELHUM, Halvor; MOENE, Karl; TORVIK, Ragnar. Institutions and the resource curse. The Economic Journal, v. 116, n. 1, p. 1-20, 2006.

MICHAELS, Guy. The Long Term Consequences of Resource-Based Specialization. Economic Journal, v. 121, n. 551, p. 31-57, 2011.

MORENO-DODSON, Blanca. Assessing the impact of public spending on growth: an empirical analysis for seven fast growing countries. Washington, DC: The World Bank, 2008. (Policy Research Working Paper, n. 4663). 
MORENO-DODSON, Blanca; BAYRAKTAR, Nihal. How public spending can help you grow: an empirical analysis for developing countries. Washington, DC: The World Bank, 2011. (Economic Premise, n. 48).

OGUNDIPE, Adeyemi A.; OLUWATOBI, Stephen. Government spending and economic growth in Nigeria: evidence from disaggregated analysis. Journal of Business Management and Applied Economics, v.2, n. 4, 2013.

OTENG-ABAYIE, E. F. Government expenditure and economic growth in five ECOWAS countries: a panel econometric estimation. Journal of Economic Theory, v. 5, n.1, p 11-14, 2011.

PAPYRAKIS, Elissaios. GERLAGH, Reyer. Resource abundance and economic growth in the United States. European Economic Review, v. 51, n. 4, p. 1011-1039, 2007.

PAPYRAKIS, Elissaios; GERLAGH, Reyer. The resource curse hypothesis and its transmission channels. Journal of Comparative Economics, v. 32, n. 1, p. 181-193, 2004.

POSTALI, Fernando A. S. Petroleum royalties and regional development in Brazil: the economic growth of recipient towns. Resources Policy, v. 34, n. 4, p. 205-213, 2009.

POSTALI, Fernando A. S. Rendas do petróleo e ineficiências administrativas nos munícipios brasileiros. 2012. 122 p. Tese (Livre-Docência em Economia) - Universidade de São Paulo, São Paulo, 2012.

POSTALI, Fernando A. S.; NISHIJIMA, Marislei. Distribuição das Rendas do Petróleo e Indicadores de Desenvolvimento Municipal no Brasil nos Anos 2000. Estudos Econômicos, v. 41, n. 2, p. 463-485, abril-junho/2011.

POSTALI, Fernando A. S.; NISHIJIMA, Marislei. Oil windfalls in Brazil and their long-run social impacts. Resources Policy, v. 38, n. 1, p. 94-101, 2013.

POSTALI, Fernando A. S.; ROCHA, Fabiana. Resource windfalls, fiscal effort and public spending: evidence from Brazilian municipalities. New York: SSRN, 2009. (SSRN Working Paper, n. 1458085).

QUEIROZ, Carlos R. A.; POSTALI, Fernando A. S. Rendas do petróleo e eficiência tributária dos municípios brasileiros. Economia \& Tecnologia, v. 22, n. 3, p. 147-156, 2010.

REIS, Diego A.; SANTANA, José Ricardo. Os efeitos da aplicação dos royalties petrolíferos sobre os investimentos públicos nos municípios brasileiros. Revista de Administra Pública, v. 49, n. 1, p. 91-117, 2015. 
RIBEIRO, Edivan G.; TEIXEIRA, Arilton; GUTIERREZ, Carlos H. C. Impacto dos royalties do petróleo no PIB per capita dos municípios do estado do Espírito Santo, Brasil. Revista Brasileira de Gestão de Negócios, v. 12, n. 34, p. 25-41, jan/mar 2010.

ROBINSON, James A.; TORVIK, Ragnar; VERDIER, Thierry. Political foundations of the resource curse. Journal of Development Economics, v. 79, n. 2, p. 447-468, 2006.

ROCHA, Fabiana; GIUBERTI, Ana C. Composição do gasto público e crescimento econômico: uma avaliação macroeconômica da qualidade dos gastos dos estados brasileiros. Economia Aplicada, v. 11, n. 4, p. 463-485, 2007.

RODRIGUES, Rodrigo V.; TEIXEIRA, Erly C. Gasto público e crescimento econômico no Brasil: uma análise comparativa dos gastos das esferas de governo. Revista Brasileira de Economia, v. 64, n. 4, p. 423-438, 2010.

ROSS, Michael L. Does oil hinder democracy? World Politics, v. 53, n. 3, p. 325-361, 2001.

ROSS, Michael L. The Political Economy of the Resource Curse. World Politics, v. 51, n. 2, p. 297-322, 1999.

ROSS, Michael L. What have we learned about the resource curse? Annual Review of Political Science, v. 18, n. 1, p. 239-259, 2015.

ROSSER, Andrew. The political economy of the resource curse: a literature survey. Brighton: University of Sussex, 2006. (IDS Working Paper, n. 268).

SACHS, Jeffrey D.; WARNER, Andrew M. The big push, natural resource booms and growth. Journal of Development Economics, v. 59, n. 1, p. 43-76, 1999.

SACHS, Jeffrey D.; WARNER, Andrew M. Fundamental sources of long-run growth. The American Economic Review, v. 87, n. 2, p. 184-188, may/1997.

SACHS, Jeffrey D.; WARNER, Andrew M. Natural resource abundance and economic growth. Massachusetts: NBER, 1995. (NBER Working Paper Series, n. 5398).

SACHS, Jeffrey D.; WARNER, Andrew M. Natural resources and economic development: the curse of natural resources. European Economic Review, v. 45, n. 4-6, p. 827-838, 2001.

SALA-I MARTIN, Xavier; SUBRAMANIAN, Arvind. Addressing the natural resource curse an illustration from Nigeria. Journal of African Economies, v. 22, n. 4, p. 570-615, 2013. 
SERRANO, André L. M.; GONÇALVES, Rodrigo S.; GONÇALVES, Andréa O. Avaliação do impacto de políticas públicas federais no processo de desmatamento na Amazônia. Revista de Administração e Negócios da Amazônia, v.5, n.1, p. 1-19, 2013.

SHAO, Shuai; YANG, Lili. Natural resource dependence, human capital accumulation, and economic growth: a combined explanation for the resource curse and the resource blessing. Energy Policy, v. 74, n. 1, p. 632-642, 2014.

SILVA, Guilherme J.C.; SANTOLIN, Roberto S. Gastos públicos e crescimento econômico recente dos estados brasileiros. Revista Economia \& Tecnologia, v. 8, n. 3, p. 19-38, 2012.

SILVA, Laércio D. C.; CRUZ, Mércia S.; IRFFI, Guilherme. Gastos públicos e crescimento econômico: uma análise para os municípios paraibanos. Revista Econômica do Nordeste, v. 44, n. 3, p. 741-760, 2013. 2013.

SOLOW, Robert M. Intergenerational equity and exhaustible resources. The Review of Economic Studies, v. 41, n. 5, p. 29-45, 1974.

SOLOW, Robert M. On the intergenerational allocation of natural resources. The Scandinavian Journal of Economics, v. 88, n. 1, p. 141-149, 1986.

STIJINS, Jean-Philippe C. Natural resource abundance and economic growth revisited. Resources Policy, v. 30, n. 2, p. 107-30, 2005.

STRACK, Diego; AZEVEDO, André F. Z. A doença holandesa no Brasil: sintomas e efeitos. Revista Economia e Desenvolvimento, v. 24, n. 2, p. 68-91, 2012.

TORNELL, Aaron; LANE, Philip R. The Voracity Effect. American Economic Review, v. 89, n. 1, p. 22-46, 1999.

TORRES, Nuno; AFONSO, Óscar; SOARES, Isabel. A survey of literature on the resource curse: critical analysis of the main explanations, empirical tests and resource proxies. Porto/Portugal: Centro de Economia e Finanças da Universidade do Porto, 2013. (CEF.UP Working Paper, n. 2013-02).

TORVIK, Ragnar. Natural resource rent seeking and welfare. Journal of Development Economics, v. 67, n. 2, p. 455-70, 2002.

VAN DER PLOEG, Frederick. Natural resources: curse or blessing? Journal of Economic Literature, v. 49, n. 2, p. 366-420, 2011. 
VAN DER PLOEG, Frederick; POELHEKKE, Steven. The pungent smell of 'red herrings': subsoil assets, rents, volatility and the resource curse. Journal of Environmental Economics and Management, v. 60, n. 1, p. 44-55, 2010.

VERÍSSIMO, Michele P.; XAVIER, Clésio L. Tipos de commodities, taxa de câmbio e crescimento econômico: evidências da maldição dos recursos naturais para o BRASIL. Revista de Economia Contemporânea, v. 18, n. 2, p. 267-295, 2014.

WOOLDRIDGE, Jeffrey M. Econometric analysis of cross section and panel data. Massachusetts: MIT Press, 2002. 


\section{APÊNDICES}

APÊNDICE A - Endogeneidade ............................................................................. 116

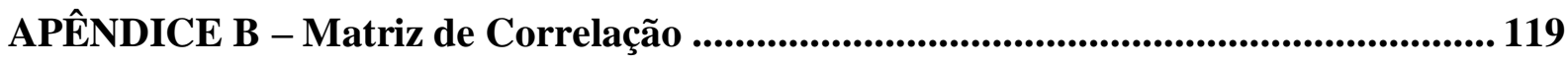

APÊNDICE C - Teste de Raiz Unitária das Variáveis............................................ 121

APÊNDICE D - Teste de Multicolinearidade .................................................................. 123

APÊNDICE E - Multicolinearidade em Modelos com Variável de Interação ............... 128

APÊNDICE F - Resultados dos Testes de Qualidade dos Ajustes .................................. 130

APÊNDICE G - Resultados Complementares dos Modelos Empíricos ......................... 134 


\section{APÊNDICE A - Endogeneidade}

Nesta seção é apresentada uma explicação para a endogeneidade das variáveis de crescimento econômico, recursos naturais e gastos públicos. Incialmente, discorre-se sobre o conceito e tipos de endogeneidade; em seguida, sobre os argumentos e alternativas apontados na literatura sobre a endogeneidade de tais variáveis; por fim, apresentam-se os procedimentos adotados para minimizar os problemas de endogeneidade.

Segundo Wooldridge (2002), uma variável é endógena se for determinada dentro do contexto do modelo, assim na econometria endógeno refere-se a alguma situação em que uma variável explanatória é correlacionada com o termo de erro do modelo. Para o autor, a endogeneidade aparece, usualmente, de três formas:

1) Variáveis omitidas - ocorre quando se deseja controlar uma ou mais variáveis adicionais, mas não é possível incluí-las no modelo, tendo em vista a indisponibilidade dos dados. Assim, o efeito das variáveis omitidas seria colocado no termo de erro;

2) Erro de medida - a disponibilidade dos dados permite apenas que se observe uma medida imperfeita da variável, fazendo com que o termo de erro do modelo capture esse erro de medida;

3) Simultaneidade - ocorre quando pelo menos uma variável explicativa é determinada simultaneamente com a variável dependente; logo, como a variável explicativa é determinada parcialmente com uma função da variável dependente, aquela variável tende a ser correlacionada com o termo de erro.

No caso de variáveis econômicas, muitas vezes é difícil determinar teoricamente quando uma variável é endógena ou exógena ou, ainda, qual o tipo de endogeneidade apresenta as variáveis. De forma geral, Clarida e Noguer (2009) afirmam que, nas aplicações econométricas, isso é um problema, porque seria difícil encontrar alguma variável que fosse essencialmente exógena. Para os autores, quando se trabalha com dados econômicos, tudo é endógeno em algum nível, principalmente nos trabalhos estatísticos que envolvem séries temporais econômicas.

Manzano e Rigobon (2006), Van Der Ploeg (2011) e Torres, Afonso e Soares (2013) apontam que os resultados da MRN podem ser influenciados por variáveis omitidas. Também, alguns estudos indicam a possibilidade de erro de medida na variável de recursos naturais quando representada pelo índice de dependência - razão entre a exportação de recursos 
naturais (ou o valor produzido) e o produto interno bruto. Conforme Brunnschweiler e Bulte (2008b), como esta variável tem como denominador o tamanho da economia (PIB), parece razoável supor que ela é endógena em relação a várias outras variáveis que determinam o desempenho econômico.

Nesse sentido, algumas pesquisas têm utilizado como variável de recursos naturais uma medida que expressa a abundância de recursos naturais para reduzir o nível de endogeneidade, como os rendimentos com recursos naturais per capita ou o tamanhos das reserva de recursos naturais per capita (STIJNS, 2005; BRUNNSCHWEILER, 2008; BRUNNSCHWEILER; BULTE, 2008a, 2008b; HABER; MENALDO, 2011; KENNEDY; TIEDE, 2013).

Nos modelos com crescimento econômico e variáveis de política fiscal, a simultaneidade é o tipo de endogeneidade mais comum. Nesse caso, a literatura aponta duas fontes de simultaneidade nos modelos de regressão: os efeitos do ciclo do econômico de curto prazo, nos quais a expansão/retração da economia pode ser acompanhada da expansão/retração dos gastos, e a lei de Wagner, que é a tendência de os gastos do governo serem maiores quanto maior for o nível do PIB per capita (EASTERLY; REBELO, 1993; KNELLER; BLEANEY; GEMMELL, 1999).

As principais formas utilizadas nas pesquisas sobre crescimento e política fiscal para lidar com a endogeneidade são a utilização da variável dependente defasada para frente, geralmente cinco anos à frente das variáveis independentes, para minimizar os efeitos do ciclo do negócio, pois espera-se que os gastos influenciem o crescimento entre $t+1$ e $t+5$ (DEVARAJAN et al, 1996; GHOSH; GREGORIOU, 2008; ROCHA; GIUBERTI, 2007); e a utilização de variáveis instrumentais (KNELLER; BLEANEY; GEMMELL, 1999; BLEANEY; GEMMELL; KNELLER, 2001; GHOSH; GREGORIOU, 2008).

Portanto, nesta pesquisa, foram adotados os seguintes procedimentos para minimizar os problemas de endogeneidade nos modelos com variáveis de crescimento econômico, de recursos naturais e de gastos públicos:

1) Utilização da compensação financeira pela exploração de recursos naturais per capita recebida pelo município como variável de abundância de recursos naturais;

2) Utilização da variável dependente (crescimento econômico) defasada em cinco períodos à frente $(\mathrm{t}+1 \mathrm{a} \mathrm{t}+5)$ em relação às variáveis independentes $(\mathrm{t})$;

3) A utilização de modelos de efeitos fixos foi considerada uma forma de lidar com os problemas de endogeneidade, uma vez que estes podem ser atribuídos a efeitos fixos não observáveis (variáveis omitidas). 
Tendo em vista o exposto acima, considera-se que esses procedimentos são suficientes para reduzir os problemas com endogeneidade. Uma alternativa seria a utilização de variáveis instrumentais, embora a seleção dos instrumentos seja crítica e os instrumentos possam ser enviesados na presença dos efeitos fixos (KNELLER; BLEANEY; GEMMELL, 1999; FÖLSTER; HENREKSON, 2006). Observa-se, também, que os resultados com variáveis instrumentais não se alteram significativamente em relação aos resultados aferidos com efeitos fixos (KNELLER; BLEANEY; GEMMELL, 1999; BLEANEY; GEMMELL; KNELLER，2001; FÖLSTER; HENREKSON，2001; GHOSH; GREGORIOU，2008; MORENO-DODSON, 2008). 


\section{APÊNDICE B - Matriz de Correlação}

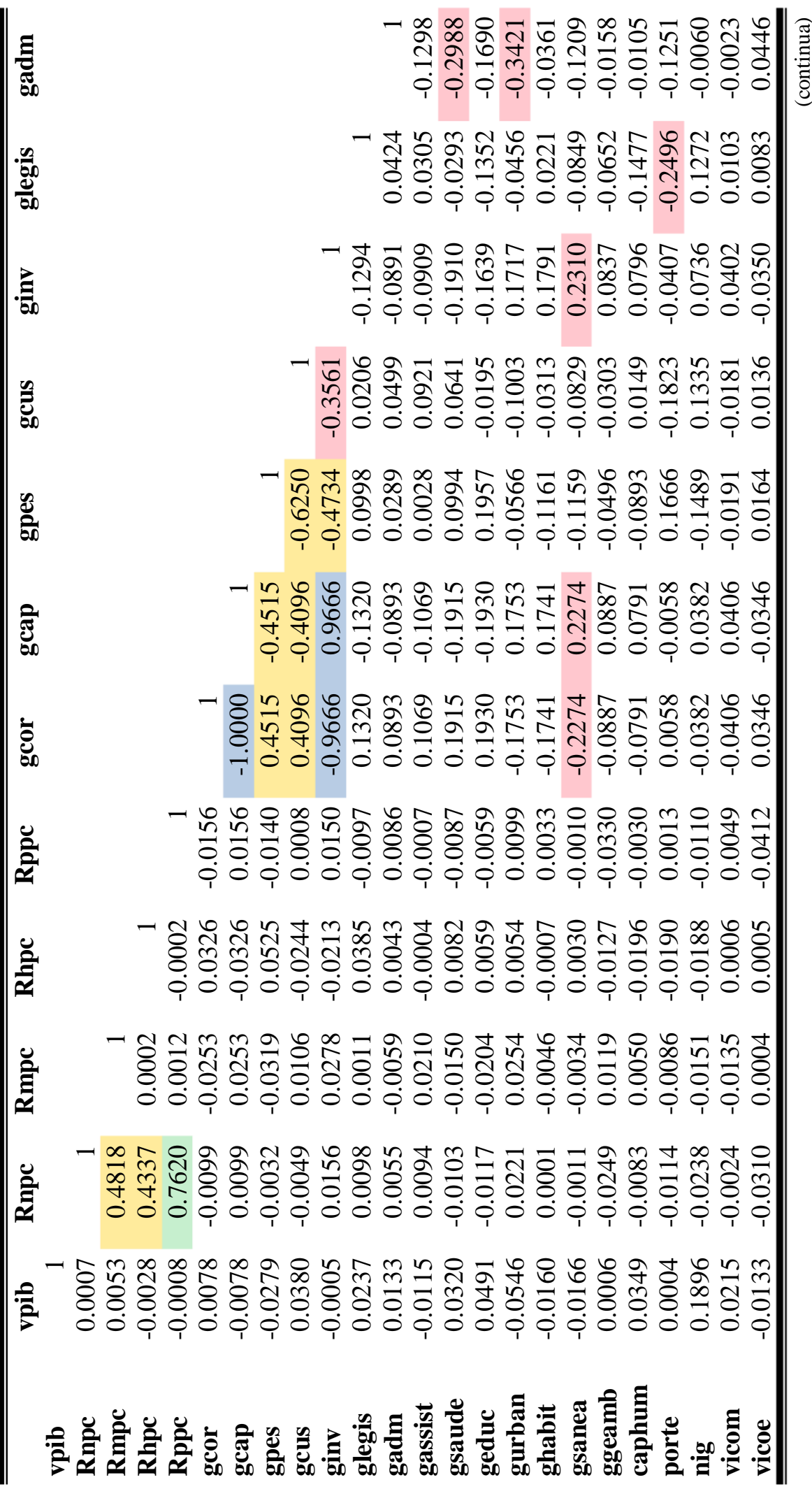




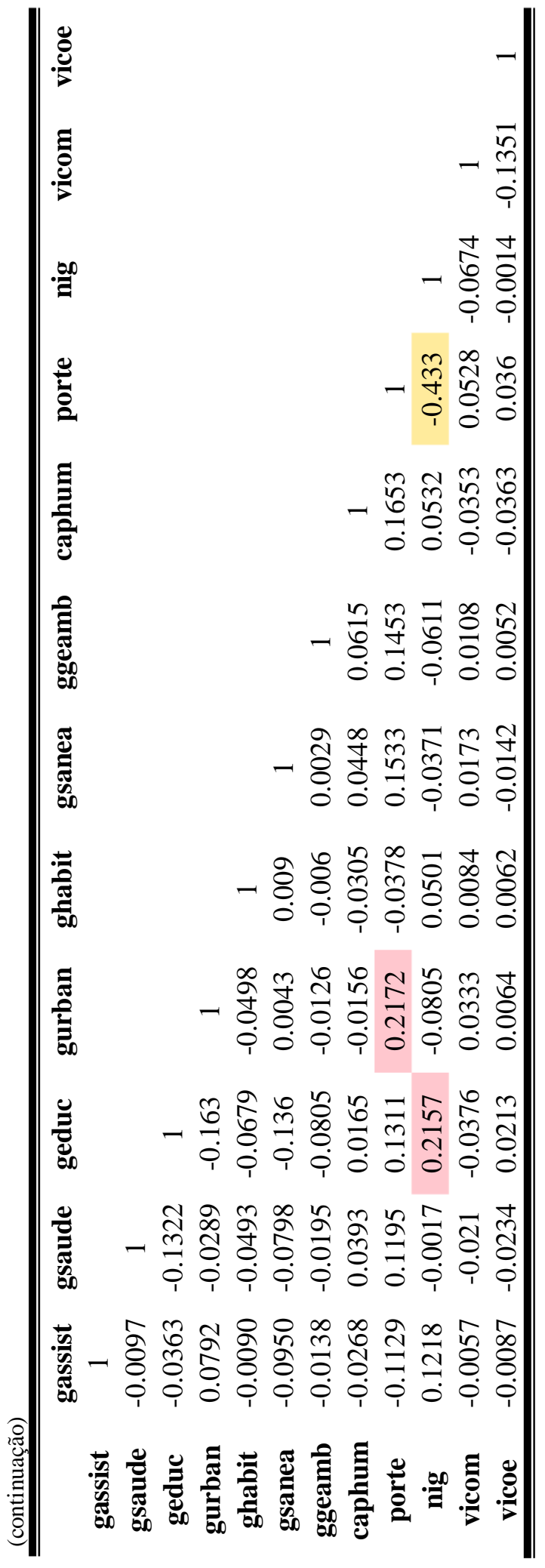




\section{APÊNDICE C - Teste de Raiz Unitária das Variáveis}

A seguir, são apresentados os resultados do teste de Harris-Tazavalis para presença de raiz unitária nas variáveis em dados em painel balanceado:

- H0: O painel contém raiz unitária.

Quadro C.1 - Resultado do teste de raiz unitária

\begin{tabular}{|c|c|c|c|c|c|c|c|c|c|}
\hline & Variável & Statistic & $\mathbf{z}$ & p-value & & Variável & Statistic & $\mathbf{z}$ & p-value \\
\hline 1 & vpib & 0.184 & -43.847 & 0.000 & 36 & Rnpc*gassist & -0.189 & -68.915 & 0.000 \\
\hline 2 & Rnpc & 0.478 & -3.042 & 0.001 & 37 & Rnpc*gsaude & -0.279 & -79.388 & 0.000 \\
\hline 3 & Rhpc & 0.619 & 16.522 & 1.000 & 38 & Rnpc*geduc & -0.404 & -94.009 & 0.000 \\
\hline 4 & $\mathrm{Rmpc}$ & 0.853 & 49.043 & 1.000 & 39 & Rnpc*gurban & -0.643 & -120.000 & 0.000 \\
\hline 5 & Rppc & 0.274 & -31.426 & 0.000 & 40 & Rnpc*ghabit & -0.637 & -120.000 & 0.000 \\
\hline 6 & Rnpc[d1] & -0.401 & -93.654 & 0.000 & 41 & Rnpc*gsanea & -1.392 & -210.000 & 0.000 \\
\hline 7 & $\operatorname{Rhpc}[\mathrm{d} 1]$ & -0.160 & -65.442 & 0.000 & 42 & Rnpc*ggeamb & -3.663 & -480.000 & 0.000 \\
\hline 8 & $\mathrm{Rmpc}[\mathrm{d} 1]$ & -0.443 & -98.570 & 0.000 & 43 & Rhpc*gcor & -0.328 & -85.130 & 0.000 \\
\hline 9 & $\operatorname{Rppc}[\mathrm{d} 1]$ & -0.468 & -100.000 & 0.000 & 44 & Rhpc*gcap & 0.318 & -9.651 & 0.000 \\
\hline 10 & gcor & -0.017 & -71.782 & 0.000 & 45 & Rhpc*gpes & -0.571 & -110.000 & 0.000 \\
\hline 11 & gcap & -0.017 & -71.782 & 0.000 & 46 & Rhpc*gpesl & -0.645 & -120.000 & 0.000 \\
\hline 12 & gpes & 0.145 & -49.329 & 0.000 & 47 & Rhpc*gocr & -0.167 & -66.323 & 0.000 \\
\hline 13 & gocr & 0.102 & -55.204 & 0.000 & 48 & Rhpc*ginv & 0.284 & -13.577 & 0.000 \\
\hline 14 & ginv & -0.020 & -72.155 & 0.000 & 49 & Rhpc*glegis & -0.329 & -85.269 & 0.000 \\
\hline 15 & glegis & 0.051 & -62.319 & 0.000 & 50 & Rhpc*gadm & -0.172 & -66.858 & 0.000 \\
\hline 16 & gadm & 0.005 & -68.642 & 0.000 & 51 & Rhpc*gassist & -0.365 & -89.466 & 0.000 \\
\hline 17 & gassist & 0.067 & -60.090 & 0.000 & 52 & Rhpc*gsaude & -0.206 & -70.898 & 0.000 \\
\hline 18 & gsaude & 0.002 & -69.156 & 0.000 & 53 & Rhpc*geduc & -0.275 & -78.938 & 0.000 \\
\hline 19 & geduc & -0.002 & -69.692 & 0.000 & 54 & Rhpc*gurban & -0.249 & -75.938 & 0.000 \\
\hline 20 & gurban & 0.014 & -67.412 & 0.000 & 55 & Rhpc*ghabit & -0.654 & -120.000 & 0.000 \\
\hline 21 & ghabit & -0.091 & -81.966 & 0.000 & 56 & Rhpc*gsanea & -0.185 & -68.418 & 0.000 \\
\hline 22 & gsanea & -0.049 & -76.141 & 0.000 & 57 & Rhpc*ggeamb & -0.500 & -110.000 & 0.000 \\
\hline 23 & ggeamb & -0.017 & -71.665 & 0.000 & 58 & Rmpc*gcor & -0.440 & -98.193 & 0.000 \\
\hline 24 & nig & 0.250 & -34.652 & 0.000 & 59 & Rmpc*gcap & -0.319 & -84.072 & 0.000 \\
\hline 25 & caphum & 0.386 & -15.823 & 0.000 & 60 & Rmpc*gpes & -0.415 & -95.263 & 0.000 \\
\hline 26 & porte & -0.166 & -92.412 & 0.000 & 61 & Rmpc*gocr & -0.468 & -100.000 & 0.000 \\
\hline 27 & vicom & -1.156 & -230.000 & 0.000 & 62 & Rmpc*ginv & -0.304 & -82.358 & 0.000 \\
\hline 28 & vicoe & -0.254 & -100.000 & 0.000 & 63 & Rmpc*glegis & -0.373 & -90.391 & 0.000 \\
\hline 29 & Rnpc*gcor & -0.350 & -87.694 & 0.000 & 64 & Rmpc*gadm & -0.471 & -100.000 & 0.000 \\
\hline 30 & Rnpc*gcap & -0.517 & -110.000 & 0.000 & 65 & Rmpc*gassist & -0.339 & -86.417 & 0.000 \\
\hline 31 & Rnpc*gpes & -0.408 & -94.479 & 0.000 & 66 & Rmpc*gsaude & -0.411 & -94.871 & 0.000 \\
\hline 32 & Rnpc*gocr & -0.298 & -81.626 & 0.000 & 67 & Rmpc*geduc & -0.451 & -99.464 & 0.000 \\
\hline 33 & Rnpc*ginv & -0.580 & -110.000 & 0.000 & 68 & Rmpc*gurban & -0.391 & -92.490 & 0.000 \\
\hline 34 & Rnpc*glegis & -0.315 & -83.604 & 0.000 & 69 & Rmpc*ghabit & -0.445 & -98.792 & 0.000 \\
\hline 35 & Rnpc*gadm & -0.363 & -89.238 & 0.000 & 70 & Rmpc*gsanea & -0.243 & -75.152 & 0.000 \\
\hline
\end{tabular}




\begin{tabular}{|c|c|c|c|c|c|c|c|c|c|}
\hline & Variável & Statistic & $\mathbf{z}$ & p-value & & Variável & Statistic & $\mathbf{z}$ & p-value \\
\hline 71 & Rmpc*ggeamb & -0.479 & -100.000 & 0.000 & 109 & drh*gassist & -0.004 & -23.573 & 0.000 \\
\hline 72 & Rppc*gcor & -0.348 & -87.443 & 0.000 & 110 & drh*gsaude & -0.042 & -25.336 & 0.000 \\
\hline 73 & Rppc*gcap & -0.780 & -140.000 & 0.000 & 111 & drh*geduc & -0.028 & -24.674 & 0.000 \\
\hline 74 & Rppc*gpes & -0.364 & -89.299 & 0.000 & 112 & drh*gurban & -0.035 & -25.014 & 0.000 \\
\hline 75 & Rppc*gocr & -0.343 & -86.826 & 0.000 & 113 & drh*ghabit & 0.142 & -16.726 & 0.000 \\
\hline 76 & Rppc*ginv & -0.798 & -140.000 & 0.000 & 114 & drh*gsanea & 0.012 & -22.805 & 0.000 \\
\hline 77 & Rppc*glegis & -0.304 & -82.301 & 0.000 & 115 & drh* ggeamb $^{*}$ & 0.016 & -22.642 & 0.000 \\
\hline 78 & Rppc*gadm & -0.420 & -95.938 & 0.000 & 116 & drm & 0.071 & -22.841 & 0.000 \\
\hline 79 & Rppc*gassist & -0.116 & -60.343 & 0.000 & 117 & drm*gcor & 0.074 & -22.670 & 0.000 \\
\hline 80 & Rppc*gsaude & -0.289 & -80.581 & 0.000 & 118 & drm*gcap & 0.075 & -22.648 & 0.000 \\
\hline 81 & Rppc*geduc & -0.444 & -98.689 & 0.000 & 119 & drm*gpes & 0.093 & -21.675 & 0.000 \\
\hline 82 & Rppc*gurban & -0.661 & -120.000 & 0.000 & 120 & drm*gocr & 0.048 & -24.039 & 0.000 \\
\hline 83 & Rppc*ghabit & -0.637 & -120.000 & 0.000 & 121 & drm*ginv & 0.085 & -22.112 & 0.000 \\
\hline 84 & Rppc*gsanea & -1.521 & -220.000 & 0.000 & 122 & drm*glegis & 0.065 & -23.174 & 0.000 \\
\hline 85 & Rppc*ggeamb & -3.964 & -510.000 & 0.000 & 123 & drm*gadm & 0.022 & -25.466 & 0.000 \\
\hline 86 & drn & 0.005 & -39.915 & 0.000 & 124 & drm* gassist & 0.018 & -25.658 & 0.000 \\
\hline 87 & drn*gcor & 0.000 & -40.295 & 0.000 & 125 & drm*gsaude & 0.047 & -24.092 & 0.000 \\
\hline 88 & drn*gcap & 0.105 & -31.861 & 0.000 & 126 & drm*geduc & 0.069 & -22.923 & 0.000 \\
\hline 89 & drn*gpes & 0.004 & -39.981 & 0.000 & 127 & drm*gurban & 0.065 & -23.167 & 0.000 \\
\hline 90 & drn*gocr & 0.029 & -37.976 & 0.000 & 128 & drm*ghabit & -0.062 & -29.906 & 0.000 \\
\hline 91 & drn*ginv & 0.097 & -32.503 & 0.000 & 129 & drm*gsanea & 0.080 & -22.370 & 0.000 \\
\hline 92 & drn*glegis & 0.069 & -34.793 & 0.000 & 130 & drm* ggeamb & 0.036 & -24.677 & 0.000 \\
\hline 93 & drn*gadm & -0.049 & -44.266 & 0.000 & 131 & $\operatorname{drp}$ & 0.202 & -14.688 & 0.000 \\
\hline 94 & drn*gassist & -0.058 & -44.970 & 0.000 & 132 & drp*gcor & 0.186 & -15.472 & 0.000 \\
\hline 95 & drn*gsaude & 0.008 & -39.689 & 0.000 & 133 & drp*gcap & 0.062 & -21.595 & 0.000 \\
\hline 96 & drn*geduc & -0.010 & -41.077 & 0.000 & 134 & drp*gpes & 0.187 & -15.418 & 0.000 \\
\hline 97 & drn*gurban & 0.023 & -38.484 & 0.000 & 135 & drp*gocr & 0.170 & -16.262 & 0.000 \\
\hline 98 & drn*ghabit & -0.135 & -51.202 & 0.000 & 136 & drp*ginv & 0.058 & -21.790 & 0.000 \\
\hline 99 & drn*gsanea & 0.008 & -39.654 & 0.000 & 137 & drp*glegis & 0.070 & -21.175 & 0.000 \\
\hline 100 & drn*ggeamb & -0.005 & -40.744 & 0.000 & 138 & drp*gadm & -0.031 & -26.162 & 0.000 \\
\hline 101 & drh & -0.043 & -25.363 & 0.000 & 139 & drp*gassist & 0.162 & -16.650 & 0.000 \\
\hline 102 & drh*gcor & -0.021 & -24.347 & 0.000 & 140 & drp*gsaude & 0.081 & -20.621 & 0.000 \\
\hline 103 & drh*gcap & 0.066 & -20.283 & 0.000 & 141 & drp*geduc & 0.138 & -17.841 & 0.000 \\
\hline 104 & drh*gpes & 0.009 & -22.939 & 0.000 & 142 & drp*gurban & 0.118 & -18.806 & 0.000 \\
\hline 105 & drh*gocr & -0.029 & -24.724 & 0.000 & 143 & drp*ghabit & -0.433 & -45.960 & 0.000 \\
\hline 106 & drh*ginv & 0.075 & -19.884 & 0.000 & 144 & drp*gsanea & 0.108 & -19.327 & 0.000 \\
\hline 107 & drh*glegis & 0.175 & -15.195 & 0.000 & 145 & drp* ggeamb & 0.072 & -21.082 & 0.000 \\
\hline 108 & drh*gadm & 0.084 & -19.444 & 0.000 & & & & & \\
\hline
\end{tabular}




\section{APÊNDICE D - Teste de Multicolinearidade}

\section{Quadro D.1 - Fator de Inflação da Variância dos Modelos}

\begin{tabular}{|c|c|c|c|c|c|c|c|}
\hline \multicolumn{2}{|l|}{$\underline{1 \mathbf{a}}$} & \multicolumn{2}{|l|}{$\underline{1 b}$} & \multicolumn{2}{|c|}{$\underline{2.1}$} & \multicolumn{2}{|l|}{$\underline{2.2}$} \\
\hline Variável & $V I F$ & Variável & $V I F$ & Variável & $V I F$ & Variável & $V I F$ \\
\hline porte & 1.03 & porte & 1.03 & porte & 1.27 & porte & 1.27 \\
\hline caphum & 1.03 & caphum & 1.03 & nig & 1.24 & nig & 1.24 \\
\hline vicom & 1.02 & vicom & 1.02 & caphum & 1.05 & caphum & 1.05 \\
\hline vicoe & 1.02 & vicoe & 1.02 & gcor & 1.01 & gcap & 1.01 \\
\hline Rnpc & 1.00 & Rppc & 1.00 & Mean VIF & 1.14 & Mean VIF & 1.14 \\
\hline \multirow[t]{3}{*}{ Mean VIF } & 1.02 & Rhpc & 1.00 & & & & \\
\hline & & $\mathrm{Rmpc}$ & 1.00 & & & & \\
\hline & & Mean VIF & 1.02 & & & & \\
\hline \multicolumn{2}{|c|}{$\underline{2.3}$} & \multicolumn{2}{|l|}{$\underline{2.4}$} & \multicolumn{2}{|c|}{$\underline{2.5}$} & \multicolumn{2}{|l|}{$\underline{2.6}$} \\
\hline Variável & $V I F$ & Variável & $V I F$ & Variável & $V I F$ & Variável & $V I F$ \\
\hline gpes & 17.83 & gpes & 1.70 & porte & 1.27 & porte & 1.71 \\
\hline gocr & 15.88 & gocr & 1.69 & nig & 1.25 & geduc & 1.58 \\
\hline $\operatorname{gin} v$ & 12.26 & porte & 1.30 & caphum & 1.05 & gadm & 1.53 \\
\hline porte & 1.31 & nig & 1.25 & ginv & 1.01 & nig & 1.48 \\
\hline nig & 1.27 & caphum & 1.06 & Mean VIF & 1.15 & gurban & 1.43 \\
\hline caphum & 1.06 & Mean VIF & 1.40 & & & gsaude & 1.34 \\
\hline \multirow[t]{7}{*}{ Mean VIF } & 8.27 & & & & & gsanea & 1.19 \\
\hline & & & & & & glegis & 1.11 \\
\hline & & & & & & caphum & 1.08 \\
\hline & & & & & & gassist & 1.07 \\
\hline & & & & & & ggeamb & 1.06 \\
\hline & & & & & & ghabit & 1.04 \\
\hline & & & & & & Mean VIF & 1.30 \\
\hline \multicolumn{2}{|c|}{ 3.1a } & \multicolumn{2}{|c|}{$\underline{3.2 \mathrm{a}}$} & \multicolumn{2}{|c|}{$\underline{3.1 b}$} & \multicolumn{2}{|c|}{$\underline{3.2 \mathrm{~b}}$} \\
\hline Variável & $V I F$ & Variável & $V I F$ & Variável & $V I F$ & Variável & $V I F$ \\
\hline Rnpc & 75.04 & Rnpc*gcap & 7.29 & Rhpc & 56.38 & Rhpc*gcap & 4.67 \\
\hline Rnpc*gcor & 75.03 & Rnpc & 7.29 & Rhpc*gcor & 56.37 & Rhpc & 4.67 \\
\hline porte & 1.29 & porte & 1.29 & porte & 1.29 & porte & 1.29 \\
\hline nig & 1.26 & nig & 1.26 & nig & 1.26 & nig & 1.26 \\
\hline caphum & 1.06 & caphum & 1.06 & caphum & 1.06 & caphum & 1.06 \\
\hline vicom & 1.03 & vicom & 1.03 & gcor & 1.01 & gcap & 1.01 \\
\hline vicoe & 1.02 & vicoe & 1.02 & Mean VIF & 19.56 & Mean VIF & 2.32 \\
\hline gcor & 1.01 & gcap & 1.01 & & & & \\
\hline Mean VIF & 19.59 & Mean VIF & 2.66 & & & & \\
\hline
\end{tabular}


(continuação)

\begin{tabular}{|c|c|c|c|c|c|c|c|}
\hline \multicolumn{2}{|c|}{$\underline{3.1 c}$} & \multicolumn{2}{|c|}{$\underline{3.2 \mathrm{c}}$} & \multicolumn{2}{|c|}{$\underline{3.1 d}$} & \multicolumn{2}{|c|}{ 3.2d } \\
\hline Variável & $V I F$ & Variável & $V I F$ & Variável & $V I F$ & Variável & $V I F$ \\
\hline Rmpc*gcor & 346.19 & Rmpc & 55.13 & Rppc & 80.30 & Rppc*gcap & 6.58 \\
\hline Rmpc & 346.18 & Rmpc*gcap & 55.13 & Rppc*gcor & 80.29 & Rppc & 6.58 \\
\hline porte & 1.29 & porte & 1.29 & porte & 1.29 & porte & 1.29 \\
\hline nig & 1.26 & nig & 1.26 & nig & 1.26 & nig & 1.26 \\
\hline caphum & 1.06 & caphum & 1.06 & caphum & 1.06 & caphum & 1.06 \\
\hline gcor & 1.01 & gcap & 1.01 & gcor & 1.01 & gcap & 1.01 \\
\hline vicom & 1.01 & vicom & 1.01 & vicoe & 1.01 & vicoe & 1.01 \\
\hline Mean VIF & 99.71 & Mean VIF & 16.56 & Mean VIF & 23.75 & Mean VIF & 2.68 \\
\hline \multicolumn{2}{|c|}{$\underline{3.3 a}$} & \multicolumn{2}{|c|}{$\underline{3.4 a}$} & \multicolumn{2}{|c|}{$\underline{3.3 b}$} & \multicolumn{2}{|c|}{$\underline{3.4 \mathrm{~b}}$} \\
\hline Variável & $V I F$ & Variável & $V I F$ & Variável & $V I F$ & Variável & $V I F$ \\
\hline Rnpc & 90.27 & Rnpc*ginv & 6.31 & Rhpc & 94.08 & Rhpc*ginv & 4.01 \\
\hline Rnpc*gocr & 57.04 & Rnpc & 6.30 & Rhpc*gocr & 66.78 & Rhpc & 4.01 \\
\hline Rnpc*gpes & 11.66 & porte & 1.29 & Rhpc*gpes & 6.85 & porte & 1.29 \\
\hline gpes & 1.68 & nig & 1.26 & gpes & 1.68 & nig & 1.26 \\
\hline gocr & 1.67 & caphum & 1.06 & gocr & 1.66 & caphum & 1.06 \\
\hline porte & 1.33 & vicom & 1.03 & porte & 1.32 & ginv & 1.01 \\
\hline nig & 1.27 & vicoe & 1.02 & nig & 1.26 & Mean VIF & 2.11 \\
\hline caphum & 1.07 & $\operatorname{ginv}$ & 1.02 & caphum & 1.06 & & \\
\hline vicom & 1.03 & Mean VIF & 2.41 & Mean VIF & 21.84 & & \\
\hline vicoe & 1.03 & & & & & & \\
\hline Mean VIF & 16.80 & & & & & & \\
\hline \multicolumn{2}{|c|}{$3.3 \mathrm{c}$} & \multicolumn{2}{|c|}{$\underline{3.4 c}$} & \multicolumn{2}{|c|}{$\underline{3.3 \mathrm{~d}}$} & \multicolumn{2}{|l|}{$\underline{3.4 d}$} \\
\hline Variável & $V I F$ & Variável & $V I F$ & Variável & $V I F$ & Variável & $V I F$ \\
\hline Rmpc & 1191.09 & Rmpc & 49.62 & Rppc & 80.77 & Rppc*ginv & 5.81 \\
\hline Rmpc*gocr & 876.04 & Rmpc*ginv & 49.62 & Rppc*gocr & 42.28 & Rppc & 5.81 \\
\hline Rmpc*gpes & 37.07 & porte & 1.29 & Rppc*gpes & 23.01 & porte & 1.29 \\
\hline gpes & 1.68 & nig & 1.26 & gpes & 1.68 & nig & 1.26 \\
\hline gocr & 1.66 & caphum & 1.06 & gocr & 1.66 & caphum & 1.06 \\
\hline porte & 1.32 & ginv & 1.02 & porte & 1.32 & $\operatorname{gin} v$ & 1.01 \\
\hline nig & 1.27 & vicom & 1.01 & nig & 1.26 & vicoe & 1.01 \\
\hline caphum & 1.07 & Mean VIF & 14.98 & caphum & 1.06 & Mean VIF & 2.46 \\
\hline vicom & 1.01 & & & vicoe & 1.01 & & \\
\hline Mean VIF & 234.69 & & & Mean VIF & 17.12 & & \\
\hline
\end{tabular}




\begin{tabular}{|c|c|c|c|c|c|c|c|}
\hline \multicolumn{2}{|l|}{$\underline{3.5 \mathrm{a}}$} & \multicolumn{2}{|l|}{$\underline{3.5 \mathrm{~b}}$} & \multicolumn{2}{|l|}{$\underline{3.5 \mathrm{c}}$} & \multicolumn{2}{|l|}{$\underline{3.5 \mathrm{~d}}$} \\
\hline Variável & $V I F$ & Variável & $V I F$ & Variável & $V I F$ & Variável & $V I F$ \\
\hline Rnpc & 171.48 & Rhpc & 99.18 & Rmpc & 4347.16 & Rppc & 477.16 \\
\hline Rnpc*gsaude & 34.78 & Rhpc*gsaude & 38.53 & Rmpc*gurban & 836.57 & Rppc*gsaude & 60.52 \\
\hline Rnpc*geduc & 29.49 & Rhpc*geduc & 22.78 & Rmpc*gassist & 234.10 & Rppc*geduc & 46.42 \\
\hline Rnpc*gadm & 14.65 & Rhpc*gadm & 12.22 & Rmpc*geduc & 200.51 & Rppc*gadm & 36.07 \\
\hline Rnpc*gurban & 13.27 & Rhpc*gassist & 6.26 & Rmpc*gsaude & 171.04 & Rppc*gurban & 23.76 \\
\hline Rnpc*gassist & 11.19 & Rhpc*gurban & 4.43 & Rmpc*glegis & 160.74 & Rppc*gassist & 10.15 \\
\hline Rnpc*glegis & 7.44 & Rhpc*glegis & 3.68 & Rmpc*gadm & 84.23 & Rppc*ggeamb & 9.45 \\
\hline Rnpc*ggeamb & 6.05 & Rhpc*gsanea & 2.43 & Rmpc*ggeamb & 38.33 & Rppc*gsanea & 8.72 \\
\hline Rnpc*gsanea & 5.11 & Rhpc*ggeamb & 2.29 & Rmpc*gsanea & 2.68 & Rppc*glegis & 7.86 \\
\hline porte & 1.74 & porte & 1.73 & porte & 1.73 & Rppc*ghabit & 2.12 \\
\hline geduc & 1.61 & Rhpc*ghabit & 1.70 & geduc & 1.61 & porte & 1.73 \\
\hline Rnpc*ghabit & 1.60 & geduc & 1.62 & gadm & 1.59 & geduc & 1.61 \\
\hline gadm & 1.59 & gadm & 1.59 & nig & 1.50 & gadm & 1.59 \\
\hline nig & 1.50 & nig & 1.51 & gurban & 1.45 & nig & 1.50 \\
\hline gurban & 1.46 & gurban & 1.46 & gsaude & 1.36 & gurban & 1.45 \\
\hline gsaude & 1.37 & gsaude & 1.37 & Rmpc*ghabit & 1.28 & gsaude & 1.36 \\
\hline gsanea & 1.20 & gsanea & 1.20 & gsanea & 1.20 & gsanea & 1.20 \\
\hline glegis & 1.12 & glegis & 1.12 & glegis & 1.11 & glegis & 1.12 \\
\hline caphum & 1.08 & caphum & 1.08 & caphum & 1.08 & caphum & 1.08 \\
\hline gassist & 1.07 & gassist & 1.07 & gassist & 1.07 & gassist & 1.07 \\
\hline ggeamb & 1.06 & ggeamb & 1.06 & ggeamb & 1.06 & ggeamb & 1.07 \\
\hline ghabit & 1.04 & ghabit & 1.04 & ghabit & 1.04 & ghabit & 1.04 \\
\hline vicoe & 1.03 & Mean VIF & 9.52 & vicom & 1.01 & vicoe & 1.01 \\
\hline vicom & 1.03 & & & Mean VIF & 264.93 & Mean VIF & 30.39 \\
\hline Mean VIF & 13.04 & & & & & & \\
\hline \multicolumn{2}{|l|}{$\underline{4 a}$} & \multicolumn{2}{|l|}{$4 \mathrm{bb}$} & \multicolumn{2}{|l|}{$\underline{4 c}$} & \multicolumn{2}{|l|}{$\underline{4 d}$} \\
\hline Variável & $V I F$ & Variável & $V I F$ & Variável & $V I F$ & Variável & $V I F$ \\
\hline porte & 1.13 & porte & 1.21 & porte & 1.32 & caphum & 1.07 \\
\hline caphum & 1.11 & drh & 1.12 & caphum & 1.27 & porte & 1.06 \\
\hline vicoe & 1.04 & caphum & 1.09 & drm & 1.07 & vicoe & 1.01 \\
\hline vicom & 1.04 & Rhpc & 1.00 & vicom & 1.01 & drp & 1.01 \\
\hline drn & 1.03 & Mean VIF & 1.10 & Rmpc & 1.01 & Rppc & 1.00 \\
\hline Rnpc & 1.00 & & & Mean VIF & 1.14 & Mean VIF & 1.03 \\
\hline Mean VIF & 1.06 & & & & & & \\
\hline
\end{tabular}




\begin{tabular}{|c|c|c|c|c|c|c|c|}
\hline \multicolumn{2}{|c|}{$\underline{5.1 \mathrm{a}}$} & \multicolumn{2}{|c|}{$\underline{5.2 \mathrm{a}}$} & \multicolumn{2}{|c|}{ 5.1b } & \multicolumn{2}{|c|}{$\underline{5.2 \mathrm{~b}}$} \\
\hline & $V I F$ & Variável & $V I F$ & Variável & $V I F$ & Variável & $V I F$ \\
\hline drn*gcor & 174.64 & drn*gcap & 4.78 & drh & 209.85 & drh*gcap & 5.17 \\
\hline drn & 174.53 & drn & 4.34 & drh*gcor & 209.07 & drh & 4.68 \\
\hline porte & 1.46 & porte & 1.46 & porte & 1.55 & porte & 1.55 \\
\hline gcor & 1.46 & gcap & 1.46 & gcor & 1.46 & gcap & 1.46 \\
\hline nig & 1.30 & nig & 1.30 & nig & 1.43 & nig & 1.43 \\
\hline caphum & 1.12 & caphum & 1.12 & caphum & 1.12 & caphum & 1.12 \\
\hline vicom & 1.05 & vicom & 1.05 & Rhpc & 1.05 & Rhpc & 1.05 \\
\hline vicoe & 1.04 & vicoe & 1.04 & Mean VIF & 60.79 & Mean VIF & 2.35 \\
\hline Rnpc & 1.00 & Rnpc & 1.00 & & & & \\
\hline Mean VIF & 39.73 & Mean VIF & 1.95 & & & & \\
\hline \multicolumn{2}{|c|}{$\underline{5.1 \mathrm{c}}$} & \multicolumn{2}{|c|}{$\underline{5.2 \mathrm{c}}$} & \multicolumn{2}{|c|}{$\underline{5.1 d}$} & \multicolumn{2}{|c|}{$\underline{5.2 \mathrm{~d}}$} \\
\hline Variável & $V I F$ & Variável & $V I F$ & Variável & $V I F$ & Variável & $V I F$ \\
\hline drm*gcor & 185.02 & drm*gcap & 5.24 & drp & 148.97 & drp*gcap & 4.47 \\
\hline drm & 184.64 & drm & 4.85 & drp*gcor & 148.01 & drp & 3.85 \\
\hline porte & 1.58 & porte & 1.58 & porte & 1.90 & porte & 1.90 \\
\hline gcor & 1.47 & gcap & 1.47 & nig & 1.82 & nig & 1.82 \\
\hline caphum & 1.29 & caphum & 1.29 & gcor & 1.50 & gcap & 1.50 \\
\hline nig & 1.26 & nig & 1.26 & caphum & 1.09 & caphum & 1.09 \\
\hline vicom & 1.02 & vicom & 1.02 & vicoe & 1.02 & vicoe & 1.02 \\
\hline Rmpc & 1.02 & Rmpc & 1.02 & Rppc & 1.01 & Rppc & 1.01 \\
\hline Mean VIF & 47.16 & Mean VIF & 2.21 & Mean VIF & 38.16 & Mean VIF & 2.08 \\
\hline \multicolumn{2}{|c|}{$\underline{5.3 \mathrm{a}}$} & \multicolumn{2}{|c|}{$\underline{5.4 a}$} & \multicolumn{2}{|c|}{$\underline{5.3 b}$} & \multicolumn{2}{|c|}{$\underline{5.4 \mathrm{~b}}$} \\
\hline Variável & $V I F$ & Variável & $V I F$ & Variável & $V I F$ & Variável & $V I F$ \\
\hline drn & 171.90 & drn*ginv & 3.90 & drh & 207.94 & drh*ginv & 4.20 \\
\hline drn*gocr & 58.85 & drn & 3.43 & drh*gocr & 76.02 & drh & 3.69 \\
\hline drn*gpes & 51.96 & ginv & 1.46 & drh*gpes & 56.67 & porte & 1.54 \\
\hline gpes & 2.41 & porte & 1.46 & gpes & 2.68 & ginv & 1.46 \\
\hline gocr & 2.36 & nig & 1.31 & gocr & 2.43 & nig & 1.43 \\
\hline porte & 1.48 & caphum & 1.12 & porte & 1.55 & caphum & 1.12 \\
\hline nig & 1.32 & vicom & 1.05 & nig & 1.51 & Rhpc & 1.03 \\
\hline caphum & 1.14 & vicoe & 1.04 & caphum & 1.15 & Mean VIF & 2.07 \\
\hline vicom & 1.05 & Rnpc & 1.00 & Rhpc & 1.11 & & \\
\hline vicoe & 1.05 & Mean VIF & 1.75 & Mean VIF & 39.01 & & \\
\hline Rnpc & 1.01 & & & & & & \\
\hline Mean VIF & 26.78 & & & & & & \\
\hline
\end{tabular}




\begin{tabular}{|c|c|c|c|c|c|c|c|}
\hline \multicolumn{2}{|c|}{$\underline{5.3 \mathrm{c}}$} & \multicolumn{2}{|c|}{$\underline{5.4 \mathrm{c}}$} & \multicolumn{2}{|c|}{$\underline{5.3 \mathrm{~d}}$} & \multicolumn{2}{|c|}{$\underline{5.4 \mathrm{~d}}$} \\
\hline Variável & $V I F$ & Variável & $V I F$ & Variável & $V I F$ & Variável & $V I F$ \\
\hline drm & 178.72 & drm*ginv & 4.19 & $\mathrm{drp}$ & 148.42 & drp*ginv & 3.76 \\
\hline drm*gpes & 61.17 & drm & 3.77 & drp*gocr & 48.03 & drp & 3.12 \\
\hline drm*gocr & 55.49 & porte & 1.58 & drp*gpes & 47.33 & porte & 1.89 \\
\hline gpes & 2.32 & ginv & 1.47 & gpes & 2.39 & nig & 1.83 \\
\hline gocr & 2.28 & caphum & 1.29 & gocr & 2.36 & ginv & 1.51 \\
\hline porte & 1.62 & nig & 1.26 & porte & 1.91 & caphum & 1.09 \\
\hline caphum & 1.30 & Rmpc & 1.02 & nig & 1.86 & vicoe & 1.02 \\
\hline nig & 1.27 & vicom & 1.02 & caphum & 1.10 & Rppc & 1.01 \\
\hline Rmpc & 1.02 & Mean VIF & 1.95 & vicoe & 1.02 & Mean VIF & 1.90 \\
\hline vicom & 1.02 & & & Rppc & 1.01 & & \\
\hline Mean VIF & 30.62 & & & Mean VIF & 25.54 & & \\
\hline \multicolumn{2}{|c|}{$\underline{5.5 \mathrm{a}}$} & \multicolumn{2}{|c|}{$\underline{5.5 b}$} & \multicolumn{2}{|c|}{$5.5 \mathrm{c}$} & \multicolumn{2}{|c|}{$\underline{5.5 d}$} \\
\hline Variável & $V I F$ & Variável & $V I F$ & Variável & $V I F$ & Variável & $V I F$ \\
\hline drn & 123.74 & drh & 113.97 & drm & 135.48 & drp & 212.74 \\
\hline drn*geduc & 22.94 & drh*geduc & 26.59 & drm*gsaude & 25.59 & drp*geduc & 28.42 \\
\hline drn*gsaude & 19.87 & drh*gsaude & 23.88 & drm*geduc & 23.62 & drp*gsaude & 20.79 \\
\hline drn*gadm & 10.31 & drh*gadm & 11.18 & drm*gadm & 10.72 & drp*gadm & 14.97 \\
\hline drn*glegis & 5.95 & drh*glegis & 6.05 & drm*glegis & 8.78 & drp*gurban & 10.40 \\
\hline drn*gurban & 5.72 & drh*gassist & 5.50 & drm*gurban & 5.22 & drp*glegis & 6.07 \\
\hline drn*gassist & 4.59 & drh*gurban & 5.13 & drm*gassist & 4.46 & drp*gassist & 4.25 \\
\hline gadm & 2.24 & gadm & 2.03 & gadm & 2.24 & gadm & 3.39 \\
\hline gurban & 2.01 & porte & 1.91 & porte & 2.00 & gurban & 2.75 \\
\hline geduc & 2.00 & gurban & 1.84 & geduc & 2.00 & geduc & 2.59 \\
\hline gsaude & 1.83 & geduc & 1.78 & gurban & 1.86 & drp*gsanea & 2.58 \\
\hline porte & 1.77 & gsaude & 1.77 & drm*gsanea & 1.85 & drp*ggeamb & 2.39 \\
\hline drn*gsanea & 1.75 & gassist & 1.58 & gsaude & 1.79 & gsaude & 2.23 \\
\hline drn*ggeamb & 1.71 & gsanea & 1.58 & gsanea & 1.68 & porte & 2.20 \\
\hline drn*ghabit & 1.66 & glegis & 1.56 & glegis & 1.48 & nig & 1.98 \\
\hline ggeamb & 1.59 & drh*ghabit & 1.54 & gassist & 1.48 & ggeamb & 1.93 \\
\hline gsanea & 1.58 & nig & 1.53 & drm*ghabit & 1.40 & gsanea & 1.93 \\
\hline gassist & 1.56 & drh*gsanea & 1.44 & nig & 1.39 & gassist & 1.80 \\
\hline glegis & 1.56 & drh*ggeamb & 1.42 & drm*ggeamb & 1.36 & drp*ghabit & 1.77 \\
\hline nig & 1.53 & ghabit & 1.38 & caphum & 1.32 & ghabit & 1.65 \\
\hline ghabit & 1.53 & ggeamb & 1.37 & ggeamb & 1.28 & glegis & 1.56 \\
\hline caphum & 1.14 & caphum & 1.17 & ghabit & 1.24 & caphum & 1.12 \\
\hline vicoe & 1.05 & Rhpc & 1.07 & Rmpc & 1.02 & Rppc & 1.04 \\
\hline vicom & 1.05 & Mean VIF & 9.45 & vicom & 1.02 & vicoe & 1.03 \\
\hline Rnpc & 1.02 & & & Mean VIF & 10.01 & Mean VIF & 13.82 \\
\hline Mean VIF & 8.87 & & & & & & \\
\hline
\end{tabular}




\section{APÊNDICE E - Multicolinearidade em Modelos com Variável de Interação}

A multicolinearidade foi rejeitada nos modelos de teste da MRN e da produtividade dos gastos. Entretanto, para os modelos com variáveis de interação entre as variáveis de recursos naturais e os gastos, foram observados valores altos do fator de inflação da variância, indicando a presença de problemas de multicolinearidade.

Entre as soluções para contornar esse tipo de problema incluem-se a ampliação da amostra, as transformações de variáveis, o uso de regressões polinomiais, da combinação de dados em corte transversal e séries temporais, além da análise fatorial e de componentes principais e a exclusão das variáveis que são altamente correlacionadas (GUJARATI, 2006; BROOKS, 2008). Enquanto alguns desses procedimentos já estão presentes na pesquisa como amostra grande, dados em painel e o fato de as variáveis de interação serem transformação de variáveis no modelo -, a exclusão de variáveis não se mostra como alternativa, dado o interesse em analisar o comportamento dos gastos entre os municípios que recebem rendas pela exploração de recursos naturais e os que não recebem.

De fato, a multicolinearidade é uma situação previsível no caso das variáveis de interação, pois estas são formadas a partir de variáveis presentes no modelo. Dessa forma, há uma recomendação geral de se trabalhar com as variáveis que compõem a interação centralizada à média para corrigir a alta colinearidade (AIKEN; WEST, 1991). Entretanto, existem críticas a esse procedimento, uma vez que ele traz certa complexidade à análise dos resultados, pois os parâmetros passam a informar o comportamento do desvio à média das observações em relação à variável dependente. A recomendação é que a centralização à média deve ser utilizada quando houver argumentos (teóricos ou práticos) que levem à sua utilização, e não exclusivamente quando se quer contornar a multicolinearidade (ECHAMBADI; HESS, 2007).

Segundo Jaccard e Turrisi (2003), quando se trabalha com variáveis de interação, altos níveis de colinearidade entre os termos multiplicativos e os termos que os compõem não são um problema, a não ser que a colinearidade seja tão alta que esbarre na limitação computacional dos algoritmos do pacote estatístico em isolar os erros-padrão (indicado por mensagem de erro ao rodar os dados). Nesse caso, os autores sugerem o procedimento de centralização à média. Outro problema, também apontado pelos autores, seria o caso de ocorrer alta colinearidade entre as variáveis componentes da interação. De fato, nesta pesquisa, o pacote estatístico se mostrou eficiente ao lidar com os erros-padrão, além de as 
variáveis de recursos naturais e de gastos (que compõem a variável de interação) não serem fortemente correlacionadas (vide matriz de correlação no apêndice B).

No mais, mesmo na presença de multicolinearidade muito alta, os estimadores obtidos por mínimos quadrados ordinários ainda serão melhores estimadores lineares não tendenciosos (BLUE) e tenderão a não reduzir à estatística t das variáveis, sendo que o problema seria a dificuldade em obter erros-padrão pequenos para os coeficientes (GUJARATI, 2006; BROOKS, 2008). Nesse sentido, Jaccard e Turrisi (2003) afirmam que, mesmo se utilizando o procedimento de centralização à média para contornar a multicolinearidade (resolvendo o problema), os parâmetros da variável de interação seriam idênticos caso não se fizesse nenhuma transformação com as variáveis que a compõem. 


\section{APÊNDICE F - Resultados dos Testes de Qualidade dos Ajustes}

Apresentam-se a seguir os resultados dos testes de qualidade dos ajustes dos modelos empíricos:

- O teste F para aderência dos efeitos fixos individuais;

- H0: Os termos de efeitos fixos individuais são iguais a zero;

- O teste F para aderência dos efeitos fixos de tempo;

- H0: Os termos de efeitos fixos de tempo são iguais a zero;

- O teste de Hausman de aderência dos efeitos aleatórios;

- H0: Diferença dos coeficientes é não sistemática (efeitos aleatórios);

- O teste de Wald para heterocedasticidade;

- H0: Os resíduos são homocedásticos;

- O teste de Wooldridge para autocorrelação dos resíduos.

- H0: Não há autocorrelação de primeira ordem nos resíduos.

Tabela F.1 - Resultados dos testes de qualidade dos ajustes dos modelos empíricos

\begin{tabular}{|c|c|c|c|c|c|}
\hline & $1 \mathbf{1 a}$ & $1 \mathrm{1b}$ & & & \\
\hline Teste $F$ efeitos fixos & 5.76 & 5.84 & & & \\
\hline Prob $>$ F & 0.00 & 0.00 & & & \\
\hline Teste $F$ ef. fixos tempo & 572.14 & 572.79 & & & \\
\hline Prob $>$ F & 0.00 & 0.00 & & & \\
\hline Teste de Hausman & 3022.46 & 3110.18 & & & \\
\hline Prob>chi2 & 0.00 & 0.00 & & & \\
\hline Teste de Wald & $2.50 \mathrm{E}+07$ & $2.60 \mathrm{E}+07$ & & & \\
\hline Prob>chi2 & 0.00 & 0.00 & & & \\
\hline Teste de Wooldridge & 413.926 & 423.222 & & & \\
\hline \multirow[t]{2}{*}{ Prob $>$ F } & 0.00 & 0.00 & & & \\
\hline & 2.1 & 2.2 & 2.4 & 2.5 & 2.6 \\
\hline Teste $F$ efeitos fixos & 6.95 & 6.95 & 6.95 & 6.94 & 6.81 \\
\hline Prob $>$ F & 0.00 & 0.00 & 0.00 & 0.00 & 0.00 \\
\hline Teste $F$ ef. fixos tempo & 383.33 & 383.33 & 378.31 & 382.75 & 393.06 \\
\hline Prob $>$ F & 0.00 & 0.00 & 0.00 & 0.00 & 0.00 \\
\hline Teste de Hausman & 2943.48 & 2943.48 & 2932.59 & 2936.85 & 2837.30 \\
\hline Prob>chi2 & 0.00 & 0.00 & 0.00 & 0.00 & 0.00 \\
\hline Teste de Wald & $5.70 \mathrm{E}+06$ & $5.70 \mathrm{E}+06$ & $3.40 \mathrm{E}+06$ & $6.30 \mathrm{E}+06$ & $5.30 \mathrm{E}+06$ \\
\hline Prob>chi2 & 0.00 & 0.00 & 0.00 & 0.00 & 0.00 \\
\hline Teste de Wooldridge & 536.82 & 536.82 & 533.21 & 539.05 & 524.76 \\
\hline Prob $>$ F & 0.00 & 0.00 & 0.00 & 0.00 & 0.00 \\
\hline
\end{tabular}


(continuação)

\begin{tabular}{|c|c|c|c|c|c|c|}
\hline & $3.1 \mathrm{a}$ & $3.2 \mathrm{a}$ & $3.1 b$ & $3.2 \mathrm{~b}$ & $3.1 c$ & $3.2 \mathrm{c}$ \\
\hline Teste F efeitos fixos & 7.06 & 7.06 & 6.96 & 6.96 & 7.08 & 7.08 \\
\hline Prob $>$ F & 0.00 & 0.00 & 0.00 & 0.00 & 0.00 & 0.00 \\
\hline Teste $F$ ef. fixos tempo & 550.63 & 550.63 & 557.27 & 557.27 & 545.19 & 545.19 \\
\hline Prob $>$ F & 0.00 & 0.00 & 0.00 & 0.00 & 0.00 & 0.00 \\
\hline Teste de Hausman & 2677.56 & 2677.56 & 2946.45 & 2946.45 & 2737.43 & 2737.43 \\
\hline Prob>chi2 & 0.00 & 0.00 & 0.00 & 0.00 & 0.00 & 0.00 \\
\hline Teste de Wald & $2.50 \mathrm{E}+07$ & $2.50 \mathrm{E}+07$ & $2.30 \mathrm{E}+07$ & $2.30 \mathrm{E}+07$ & $1.80 \mathrm{E}+07$ & $1.80 \mathrm{E}+07$ \\
\hline Prob>chi2 & 0.00 & 0.00 & 0.00 & 0.00 & 0.00 & 0.00 \\
\hline Teste de Wooldridge & 380.431 & 380.431 & 366.151 & 366.151 & 384.515 & 384.515 \\
\hline \multirow[t]{2}{*}{ Prob $>$ F } & 0.00 & 0.00 & 0.00 & 0.00 & 0.00 & 0.00 \\
\hline & 3.1d & $3.2 \mathrm{~d}$ & & & & \\
\hline Teste $F$ efeitos fixos & 6.99 & 6.99 & & & & \\
\hline Prob $>$ F & 0.00 & 0.00 & & & & \\
\hline Teste $F$ ef. fixos tempo & 566.54 & 566.54 & & & & \\
\hline Prob $>$ F & 0.00 & 0.00 & & & & \\
\hline Teste de Hausman & 2882.4 & 2882.4 & & & & \\
\hline Prob>chi2 & 0.00 & 0.00 & & & & \\
\hline Teste de Wald & $3.40 \mathrm{E}+07$ & $3.40 \mathrm{E}+07$ & & & & \\
\hline Prob>chi2 & 0.00 & 0.00 & & & & \\
\hline Teste de Wooldridge & 366.354 & 366.354 & & & & \\
\hline \multirow[t]{2}{*}{ Prob $>$ F } & 0.00 & 0.00 & & & & \\
\hline & $3.3 \mathrm{a}$ & $3.4 a$ & $3.3 \mathrm{~b}$ & $3.4 \mathrm{~b}$ & $3.3 \mathrm{c}$ & $3.4 c$ \\
\hline Teste $\mathrm{F}$ efeitos fixos & 7.06 & 7.06 & 6.95 & 6.96 & 7.05 & 7.08 \\
\hline Prob $>$ F & 0.00 & 0.00 & 0.00 & 0.00 & 0.00 & 0.00 \\
\hline Teste $F$ ef. fixos tempo & 546.5 & 549.94 & 556.22 & 556.67 & 542.17 & 544.54 \\
\hline Prob $>$ F & 0.00 & 0.00 & 0.00 & 0.00 & 0.00 & 0.00 \\
\hline Teste de Hausman & 2597.03 & 2684.5 & 2889.98 & 2966.89 & 2659.8 & 2745.67 \\
\hline Prob>chi2 & 0.00 & 0.00 & 0.00 & 0.00 & 0.00 & 0.00 \\
\hline Teste de Wald & $3.40 \mathrm{E}+07$ & $2.10 \mathrm{E}+07$ & $2.30 \mathrm{E}+07$ & $7.20 \mathrm{E}+07$ & $2.90 \mathrm{E}+07$ & $1.30 \mathrm{E}+08$ \\
\hline Prob>chi2 & 0.00 & 0.00 & 0.00 & 0.00 & 0.00 & 0.00 \\
\hline Teste de Wooldridge & 381.621 & 379.911 & 363.465 & 364.932 & 378.7 & 383.79 \\
\hline \multirow[t]{2}{*}{ Prob $>$ F } & 0.00 & 0.00 & 0.00 & 0.00 & 0.00 & 0.00 \\
\hline & 3.3d & 3.4d & & & & \\
\hline Teste $\mathrm{F}$ efeitos fixos & 6.98 & 6.99 & & & & \\
\hline Prob $>$ F & 0.00 & 0.00 & & & & \\
\hline Teste $F$ ef. fixos tempo & 564.45 & 566.47 & & & & \\
\hline Prob $>$ F & 0.00 & 0.00 & & & & \\
\hline Teste de Hausman & 2873.38 & 2891.78 & & & & \\
\hline Prob>chi2 & 0.00 & 0.00 & & & & \\
\hline Teste de Wald & $7.60 \mathrm{E}+07$ & $2.80 \mathrm{E}+07$ & & & & \\
\hline Prob>chi2 & 0.00 & 0.00 & & & & \\
\hline Teste de Wooldridge & 363.436 & 365.704 & & & & \\
\hline Prob $>$ F & 0.00 & 0.00 & & & & \\
\hline
\end{tabular}


(continuação)

\begin{tabular}{|c|c|c|c|c|c|c|}
\hline & $3.5 \mathrm{a}$ & $3.5 b$ & $3.5 \mathrm{c}$ & 3.5d & & \\
\hline Teste $F$ efeitos fixos & 7.00 & 6.82 & 6.9 & 6.85 & & \\
\hline Prob $>$ F & 0.00 & 0.00 & 0.00 & 0.00 & & \\
\hline Teste $F$ ef. fixos tempo & 568.53 & 566.79 & 556.89 & 575.54 & & \\
\hline Prob $>$ F & 0.00 & 0.00 & 0.00 & 0.00 & & \\
\hline Teste de Hausman & 2911.66 & 2815.28 & 3117.47 & 2662.46 & & \\
\hline Prob>chi2 & 0.00 & 0.00 & 0.00 & 0.00 & & \\
\hline Teste de Wald & $2.20 \mathrm{E}+08$ & $9.50 \mathrm{E}+07$ & $3.40 \mathrm{E}+07$ & $2.60 \mathrm{E}+07$ & & \\
\hline Prob>chi2 & 0.00 & 0.00 & 0.00 & 0.00 & & \\
\hline Teste de Wooldridge & 388.175 & 368.662 & 379.529 & 368.752 & & \\
\hline \multirow[t]{2}{*}{ Prob $>$ F } & 0.00 & 0.00 & 0.00 & 0.00 & & \\
\hline & $4 \mathbf{a}$ & $4 \mathbf{b}$ & $4 c$ & 4d & & \\
\hline Teste $\mathrm{F}$ efeitos fixos & 7.85 & 7.56 & 6.95 & 8.92 & & \\
\hline Prob $>$ F & 0.00 & 0.00 & 0.00 & 0.00 & & \\
\hline Teste $F$ ef. fixos tempo & 214.41 & 97.92 & 93.52 & 45.41 & & \\
\hline Prob $>$ F & 0.00 & 0.00 & 0.00 & 0.00 & & \\
\hline Teste de Hausman & 46.75 & 126.69 & 309.04 & 92.32 & & \\
\hline Prob>chi2 & 0.00 & 0.00 & 0.00 & 0.00 & & \\
\hline Teste de Wald & $6.80 \mathrm{E}+06$ & $1.30 \mathrm{E}+06$ & $1.10 \mathrm{E}+07$ & $1.00 \mathrm{E}+07$ & & \\
\hline Prob>chi2 & 0.00 & 0.00 & 0.00 & 0.00 & & \\
\hline Teste de Wooldridge & 483.018 & 214.85 & 245.19 & 119.366 & & \\
\hline \multirow[t]{2}{*}{ Prob $>$ F } & 0.00 & 0.00 & 0.00 & 0.00 & & \\
\hline & $5.1 \mathrm{a}$ & $5.2 \mathrm{a}$ & $5.1 \mathrm{~b}$ & $5.2 \mathrm{~b}$ & 5.1c & $5.2 \mathrm{c}$ \\
\hline Teste $\mathrm{F}$ efeitos fixos & 9.07 & 9.07 & 10.04 & 10.04 & 8.4 & 8.4 \\
\hline Prob $>$ F & 0.00 & 0.00 & 0.00 & 0.00 & 0.00 & 0.00 \\
\hline Teste $F$ ef. fixos tempo & 189.86 & 189.86 & 89.54 & 89.54 & 111.17 & 111.17 \\
\hline Prob $>$ F & 0.00 & 0.00 & 0.00 & 0.00 & 0.00 & 0.00 \\
\hline Teste de Hausman & 760.17 & 760.17 & 361.63 & 361.63 & 234.19 & 234.19 \\
\hline Prob>chi2 & 0.00 & 0.00 & 0.00 & 0.00 & 0.00 & 0.00 \\
\hline Teste de Wald & $7.90 \mathrm{E}+06$ & $7.90 \mathrm{E}+06$ & $1.10 \mathrm{E}+06$ & $1.10 \mathrm{E}+06$ & $4.60 \mathrm{E}+06$ & $4.60 \mathrm{E}+06$ \\
\hline Prob>chi2 & 0.00 & 0.00 & 0.00 & 0.00 & 0.00 & 0.00 \\
\hline Teste de Wooldridge & 280.157 & 280.157 & 152.914 & 152.914 & 177.426 & 177.426 \\
\hline \multirow[t]{2}{*}{ Prob $>$ F } & 0.00 & 0.00 & 0.00 & 0.00 & 0.00 & 0.00 \\
\hline & 5.1d & $5.2 \mathrm{~d}$ & & & & \\
\hline Teste $F$ efeitos fixos & 9.79 & 9.79 & & & & \\
\hline Prob $>$ F & 0.00 & 0.00 & & & & \\
\hline Teste $F$ ef. fixos tempo & 45.05 & 45.05 & & & & \\
\hline Prob $>$ F & 0.00 & 0.00 & & & & \\
\hline Teste de Hausman & 240.66 & 240.66 & & & & \\
\hline Prob>chi2 & 0.00 & 0.00 & & & & \\
\hline Teste de Wald & $2.50 \mathrm{E}+06$ & $2.50 \mathrm{E}+06$ & & & & \\
\hline Prob>chi2 & 0.00 & 0.00 & & & & \\
\hline Teste de Wooldridge & 91.132 & 91.132 & & & & \\
\hline Prob $>$ F & 0.00 & 0.00 & & & & \\
\hline
\end{tabular}


(continuação)

\begin{tabular}{|c|c|c|c|c|c|c|}
\hline & $5.3 a$ & $5.4 a$ & $5.3 b$ & $5.4 b$ & $5.3 \mathrm{c}$ & $5.4 \mathrm{c}$ \\
\hline Teste $\mathrm{F}$ efeitos fixos & 9.06 & 9.06 & 10.03 & 10.1 & 8.38 & 8.36 \\
\hline Prob $>$ F & 0.00 & 0.00 & 0.00 & 0.00 & 0.00 & 0.00 \\
\hline Teste $F$ ef. fixos tempo & 191.48 & 190.69 & 91.54 & 89.04 & 111.16 & 111.23 \\
\hline Prob $>$ F & 0.00 & 0.00 & 0.00 & 0.00 & 0.00 & 0.00 \\
\hline Teste de Hausman & 794.36 & 773.05 & 397.36 & 375.65 & 237.09 & 235.57 \\
\hline Prob>chi2 & 0.00 & 0.00 & 0.00 & 0.00 & 0.00 & 0.00 \\
\hline Teste de Wald & $1.30 \mathrm{E}+07$ & $5.40 \mathrm{E}+06$ & $1.60 \mathrm{E}+06$ & $5.90 \mathrm{E}+05$ & $3.30 \mathrm{E}+06$ & $2.10 \mathrm{E}+06$ \\
\hline Prob>chi2 & 0.00 & 0.00 & 0.00 & 0.00 & 0.00 & 0.00 \\
\hline Teste de Wooldridge & 284.411 & 275.114 & 147.639 & 150.478 & 185.843 & 176.029 \\
\hline \multirow[t]{2}{*}{ Prob $>$ F } & 0.00 & 0.00 & 0.00 & 0.00 & 0.00 & 0.00 \\
\hline & 5.3d & 5.4d & & & & \\
\hline Teste $F$ efeitos fixos & 9.79 & 9.8 & & & & \\
\hline Prob $>$ F & 0.00 & 0.00 & & & & \\
\hline Teste $F$ ef. fixos tempo & 48.47 & 46.16 & & & & \\
\hline Prob $>$ F & 0.00 & 0.00 & & & & \\
\hline Teste de Hausman & 715.84 & 257.47 & & & & \\
\hline Prob>chi2 & 0.00 & 0.00 & & & & \\
\hline Teste de Wald & $1.50 \mathrm{E}+06$ & $3.20 \mathrm{E}+06$ & & & & \\
\hline Prob>chi2 & 0.00 & 0.00 & & & & \\
\hline Teste de Wooldridge & 91.064 & 90.784 & & & & \\
\hline \multirow[t]{2}{*}{ Prob $>$ F } & 0.00 & 0.00 & & & & \\
\hline & $5.5 a$ & $5.5 b$ & $5.5 \mathrm{c}$ & $5.5 d$ & & \\
\hline Teste $F$ efeitos fixos & 9.00 & 10.16 & 8.08 & 9.33 & & \\
\hline Prob $>$ F & 0.00 & 0.00 & 0.00 & 0.00 & & \\
\hline Teste $F$ ef. fixos tempo & 190.29 & 86.38 & 111.66 & 42.41 & & \\
\hline Prob $>$ F & 0.00 & 0.00 & 0.00 & 0.00 & & \\
\hline Teste de Hausman & $8.00 \mathrm{E}+06$ & $1.10 \mathrm{E}+06$ & $5.70 \mathrm{E}+06$ & $9.80 \mathrm{E}+06$ & & \\
\hline Prob>chi2 & 0.00 & 0.00 & 0.00 & 0.00 & & \\
\hline Teste de Wald & 785.3 & 319.69 & 90.48 & 244.23 & & \\
\hline Prob>chi2 & 0.00 & 0.00 & 0.00 & 0.00 & & \\
\hline Teste de Wooldridge & 316.752 & 174.251 & 214.781 & 105.425 & & \\
\hline Prob $>$ F & 0.00 & 0.00 & 0.00 & 0.00 & & \\
\hline
\end{tabular}




\section{APÊNDICE G - Resultados Complementares dos Modelos Empíricos}

Tabela G.1 - Resultados complementares modelos empíricos 1a e 1b

\begin{tabular}{|c|c|c|c|c|}
\hline & $1 \mathrm{a}$ & & $1 \mathrm{~b}$ & \\
\hline vicom & $\begin{array}{r}-0,00364 \\
(-1.84)\end{array}$ & $*$ & $\begin{array}{r}-0,0039 \\
(-1.98)\end{array}$ & $* *$ \\
\hline vicoe & $\begin{array}{r}0,0159 \\
(4,89)\end{array}$ & $* * *$ & $\begin{array}{r}0,0168 \\
(5,23)\end{array}$ & $* * *$ \\
\hline caphum & $\begin{array}{r}0,00142 \\
(1,77)\end{array}$ & $*$ & $\begin{array}{r}0,00149 \\
(1,85)\end{array}$ & $*$ \\
\hline porte & $\begin{array}{r}0,149 \\
(24,84)\end{array}$ & $* * *$ & $\begin{array}{r}0,151 \\
(26,49)\end{array}$ & $* * *$ \\
\hline 2004 & . & & . & \\
\hline 2005 & $\begin{array}{r}0,0215 \\
(34,26)\end{array}$ & $* * *$ & $\begin{array}{r}. \\
0,0214 \\
(34,39)\end{array}$ & $* * *$ \\
\hline 2006 & $\begin{array}{r}0,0159 \\
(18,5)\end{array}$ & $* * *$ & $\begin{array}{r}0,0159 \\
(18,36)\end{array}$ & $* * *$ \\
\hline 2007 & $\begin{array}{r}-0,00111 \\
(-1.07)\end{array}$ & & $\begin{array}{r}-0,00114 \\
(-1.11)\end{array}$ & \\
\hline _cons & $\begin{array}{r}-1,372 \\
(-24.18)\end{array}$ & $* * *$ & $\begin{array}{r}-1,392 \\
(-25.95)\end{array}$ & $* * *$ \\
\hline
\end{tabular}

***, ** e * referem-se à significância dos coeficientes a 1\%,5\% e 10\%, respectivamente. Entre parênteses, a estatística t dos coeficientes. Legenda variáveis: vicom - variação do índice de commodities metal; vicoe - variação do índice de commodities energia; caphum capital humano; porte - porte do município; _cons - constante; 2004-2007 - efeitos fixos de tempo.

Tabela G.2 - Resultados complementares modelos empíricos 2.1 - 2.6

\begin{tabular}{|c|c|c|c|c|c|c|c|c|c|c|}
\hline & 2.1 & & 2.2 & & 2.4 & & 2.5 & & 2.6 & \\
\hline nig & $\begin{array}{r}0,556 \\
(21,19)\end{array}$ & $* * *$ & $\begin{array}{r}0,556 \\
(21,19)\end{array}$ & $* * *$ & $\begin{array}{l}0,554 \\
(20,8)\end{array}$ & $* * *$ & $\begin{array}{r}0,557 \\
(21,09)\end{array}$ & $* * *$ & $\begin{array}{r}0,522 \\
(20,71)\end{array}$ & $* * *$ \\
\hline caphum & $\begin{array}{r}-0,000152 \\
(-0.22)\end{array}$ & & $\begin{array}{r}-0,000152 \\
(-0.22)\end{array}$ & & $\begin{array}{r}-0,000091 \\
(-0.13)\end{array}$ & & $\begin{array}{r}-0,000192 \\
(-0.28)\end{array}$ & & $\begin{array}{r}-0,000146 \\
(-0.21)\end{array}$ & \\
\hline porte & $\begin{array}{l}0,162 \\
(30,4)\end{array}$ & $* * *$ & $\begin{array}{l}0,162 \\
(30,4)\end{array}$ & $* * *$ & $\begin{array}{r}0,162 \\
(30,41)\end{array}$ & $* * *$ & $\begin{array}{l}0,162 \\
(30,3)\end{array}$ & $* * *$ & $\begin{array}{r}0,161 \\
(29,66)\end{array}$ & $* * *$ \\
\hline 2003 & $\cdot$ & & $\cdot$ & & . & & . & & $\cdot$ & \\
\hline 2004 & $\begin{array}{r}-0,00535 \\
(-9.86)\end{array}$ & $* * *$ & $\begin{array}{r}-0,00535 \\
(-9.86)\end{array}$ & $* * *$ & $\begin{array}{r}-0,00536 \\
(-9.87)\end{array}$ & $* * *$ & $\begin{array}{r}-0,00524 \\
(-9.68)\end{array}$ & $* * *$ & $\begin{array}{r}-0,00571 \\
(-10.25)\end{array}$ & $* * *$ \\
\hline 2005 & $\begin{array}{r}0,00716 \\
(7,55)\end{array}$ & $* * *$ & $\begin{array}{r}0,00716 \\
(7,55)\end{array}$ & $* * *$ & $\begin{array}{r}0,00716 \\
(7,55)\end{array}$ & $* * *$ & $\begin{array}{r}0,00729 \\
(7,70)\end{array}$ & $* * *$ & $\begin{array}{r}0,00761 \\
(8,18)\end{array}$ & $* * *$ \\
\hline 2006 & $\begin{array}{r}-0,00327 \\
(-2.77)\end{array}$ & $* * *$ & $\begin{array}{r}-0,00327 \\
(-2.77)\end{array}$ & $* * *$ & $\begin{array}{r}-0,00325 \\
(-2.74)\end{array}$ & $* * *$ & $\begin{array}{r}-0,00309 \\
(-2.62)\end{array}$ & $* * *$ & $\begin{array}{r}-0,00368 \\
(-3.11)\end{array}$ & $* * *$ \\
\hline 2007 & $\begin{array}{l}-0,0183 \\
(-13.68)\end{array}$ & $* * *$ & $\begin{array}{l}-0,0183 \\
(-13.68)\end{array}$ & $* * *$ & $\begin{array}{l}-0,0182 \\
(-13.39)\end{array}$ & $* * *$ & $\begin{array}{l}-0,0182 \\
(-13.60)\end{array}$ & $* * *$ & $\begin{array}{l}-0,0185 \\
(-13.98)\end{array}$ & $* * *$ \\
\hline _cons & $\begin{array}{r}-1,659 \\
(-31.69)\end{array}$ & $* * *$ & $\begin{array}{r}-1,554 \\
(-30.31)\end{array}$ & $* * *$ & $\begin{array}{r}-1,658 \\
(-31.68)\end{array}$ & $* * *$ & $\begin{array}{r}-1,553 \\
(-30.23)\end{array}$ & $* * *$ & $\begin{array}{r}-1,576 \\
(-30.21)\end{array}$ & $* * *$ \\
\hline
\end{tabular}

***, ** e * referem-se à significância dos coeficientes a 1\%, 5\% e 10\%, respectivamente. Entre parênteses, a estatística $\mathrm{t}$ dos coeficientes. Legenda variáveis: nig - nível do gasto; caphum - capital humano; porte - porte do município; _cons constante; 2003-2007 - efeitos fixos de tempo. Modelo 2.3 não apresentado devido ao risco de multicolinearidade. 
Tabela G.3 - Resultados complementares modelos empíricos 3.1a - 3.2d

\begin{tabular}{|c|c|c|c|c|c|c|c|c|c|c|c|c|c|c|c|c|}
\hline & \multicolumn{4}{|c|}{$\mathbf{A}$} & \multicolumn{4}{|c|}{ B } & \multicolumn{4}{|c|}{$\mathrm{C}$} & \multicolumn{4}{|c|}{ D } \\
\hline & $3.1 \mathrm{a}$ & & $3.2 \mathrm{a}$ & & 3.1b & & $3.2 \mathrm{~b}$ & & $3.1 \mathrm{c}$ & & $3.2 \mathrm{c}$ & & 3.1d & & $3.2 \mathrm{~d}$ & \\
\hline vicom & $\begin{array}{r}-0,00321 \\
(-1.81)\end{array}$ & $*$ & $\begin{array}{r}-0,00321 \\
(-1.81)\end{array}$ & $*$ & & & & & $\begin{array}{r}-0,00362 \\
(-2.01)\end{array}$ & $* *$ & $\begin{array}{r}-0,00362 \\
(-2.01)\end{array}$ & $* *$ & & & & \\
\hline vicoe & $\begin{array}{r}0,0111 \\
(3,71)\end{array}$ & $* * *$ & $\begin{array}{r}0,0111 \\
(3,71)\end{array}$ & $* * *$ & & & & & & & & & $\begin{array}{r}0,0118 \\
(3,96)\end{array}$ & $* * *$ & $\begin{array}{r}0,0118 \\
(3,96)\end{array}$ & $* * *$ \\
\hline nig & $\begin{array}{r}0,541 \\
(20,48)\end{array}$ & $* * *$ & $\begin{array}{r}0,541 \\
(20,48)\end{array}$ & $* * *$ & $\begin{array}{r}0,554 \\
(19,25)\end{array}$ & $* * *$ & $\begin{array}{r}0,554 \\
(19,25)\end{array}$ & $* * *$ & $\begin{array}{r}0,54 \\
(20,4)\end{array}$ & $* * *$ & $\begin{array}{r}0,54 \\
(20,4)\end{array}$ & $* * *$ & $\begin{array}{r}0,549 \\
(19,05)\end{array}$ & $* * *$ & $\begin{array}{r}0,549 \\
(19,05)\end{array}$ & $* * *$ \\
\hline caphum & $\begin{array}{r}0,000505 \\
(0,72)\end{array}$ & & $\begin{array}{r}0,000505 \\
(0,72)\end{array}$ & & $\begin{array}{r}0,00049 \\
(0,69)\end{array}$ & & $\begin{array}{r}0,00049 \\
(0,69)\end{array}$ & & $\begin{array}{r}0,000576 \\
(0,81)\end{array}$ & & $\begin{array}{r}0,000576 \\
(0,81)\end{array}$ & & $\begin{array}{r}0,000462 \\
(0,65)\end{array}$ & & $\begin{array}{r}0,000462 \\
(0,65)\end{array}$ & \\
\hline porte & $\begin{array}{r}0,182 \\
(34,54)\end{array}$ & $* * *$ & $\begin{array}{r}0,182 \\
(34,54)\end{array}$ & $* * *$ & $\begin{array}{r}0,184 \\
(35,72)\end{array}$ & $* * *$ & $\begin{array}{r}0,184 \\
(35,72)\end{array}$ & $* * *$ & $\begin{array}{r}0,185 \\
(36,12)\end{array}$ & $* * *$ & $\begin{array}{r}0,185 \\
(36,12)\end{array}$ & $* * *$ & $\begin{array}{r}0,184 \\
(35,71)\end{array}$ & $* * *$ & $\begin{array}{r}0,184 \\
(35,71)\end{array}$ & $* * *$ \\
\hline 2004 & . & & ( & & & & . & & . & & . & & 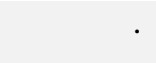 & & . & \\
\hline 2005 & $\begin{array}{r}0,0124 \\
(17,37)\end{array}$ & $* * *$ & $\begin{array}{r}0,0124 \\
(17,37)\end{array}$ & $* * *$ & $\begin{array}{r}0,0121 \\
(16,60)\end{array}$ & $* * *$ & $\begin{array}{c}0,0121 \\
(16,60)\end{array}$ & $* * *$ & $\begin{array}{r}0,0122 \\
(16,92)\end{array}$ & $* * *$ & $\begin{array}{r}0,0122 \\
(16,92)\end{array}$ & $* * *$ & $\begin{array}{r}0,0124 \\
(16,75)\end{array}$ & $* * *$ & $\begin{array}{r}0,0124 \\
(16,75)\end{array}$ & $* * *$ \\
\hline 2006 & $\begin{array}{r}0,00298 \\
(2,93)\end{array}$ & $* * *$ & $\begin{array}{r}0,00298 \\
(2,93)\end{array}$ & $* * *$ & $\begin{array}{r}0,00164 \\
(1,63)\end{array}$ & & $\begin{array}{r}0,00164 \\
(1,63)\end{array}$ & & $\begin{array}{r}0,00215 \\
(2,16)\end{array}$ & $* *$ & $\begin{array}{r}0,00215 \\
(2,16)\end{array}$ & $* *$ & $\begin{array}{r}0,00264 \\
(2,50)\end{array}$ & $* *$ & $\begin{array}{r}0,00264 \\
(2,50)\end{array}$ & $* *$ \\
\hline 2007 & $\begin{array}{l}-0,0133 \\
(-11.37)\end{array}$ & $* * *$ & $\begin{array}{l}-0,0133 \\
(-11.37)\end{array}$ & $* * *$ & $\begin{array}{l}-0,0136 \\
(-11.58)\end{array}$ & $* * *$ & $\begin{array}{r}-0,0136 \\
(-11.58)\end{array}$ & $* * *$ & $\begin{array}{l}-0,0136 \\
(-11.51)\end{array}$ & $* * *$ & $\begin{array}{l}-0,0136 \\
(-11.51)\end{array}$ & $* * *$ & $\begin{array}{l}-0,0133 \\
(-11.12)\end{array}$ & $* * *$ & $\begin{array}{l}-0,0133 \\
(-11.12)\end{array}$ & $* * *$ \\
\hline _cons & $\begin{array}{r}-1,86 \\
(-35.70)\end{array}$ & $* * *$ & $\begin{array}{r}-1,75 \\
(-34.35)\end{array}$ & $* * *$ & $\begin{array}{r}-1,881 \\
(-36.88)\end{array}$ & $* * *$ & $\begin{array}{r}-1,767 \\
(-35.62)\end{array}$ & $* * *$ & $\begin{array}{r}-1,886 \\
(-37.00)\end{array}$ & $* * *$ & $\begin{array}{r}-1,777 \\
(-35.82)\end{array}$ & $* * *$ & $\begin{array}{r}-1,879 \\
(-36.65)\end{array}$ & $* * *$ & $\begin{array}{r}-1,766 \\
(-35.44)\end{array}$ & $* * *$ \\
\hline
\end{tabular}
2004-2007 - efeitos fixos de tempo. 
Tabela G.4 - Resultados complementares modelos empíricos 3.3a - 3.4d

\begin{tabular}{|c|c|c|c|c|c|c|c|c|c|c|c|c|c|c|c|c|}
\hline & \multicolumn{4}{|c|}{$\bar{A}$} & \multicolumn{4}{|c|}{$\bar{B}$} & \multicolumn{4}{|c|}{$\bar{C}$} & \multicolumn{4}{|c|}{ D } \\
\hline & $3.3 \mathrm{a}$ & & $3.4 a$ & & $3.3 \mathrm{~b}$ & & $3.4 \mathrm{~b}$ & & $3.3 \mathrm{c}$ & & $3.4 \mathrm{c}$ & & 3.3d & & 3.4d & \\
\hline vicom & $\begin{array}{r}-0,00318 \\
(-1.79)\end{array}$ & $*$ & $\begin{array}{r}-0,00325 \\
(-1.84)\end{array}$ & $*$ & & & & & $\begin{array}{r}-0,00358 \\
(-1.99)\end{array}$ & $* *$ & $\begin{array}{r}-0,00364 \\
(-2.02)\end{array}$ & $* *$ & & & & \\
\hline vicoe & $\begin{array}{r}0,0115 \\
(3,91)\end{array}$ & $* * *$ & $\begin{array}{r}0,0115 \\
(3,85)\end{array}$ & $* * *$ & & & & & & & & & $\begin{array}{r}0,0116 \\
(3,92)\end{array}$ & $* * *$ & $\begin{array}{r}0,0121 \\
(4,09)\end{array}$ & $* * *$ \\
\hline nig & $\begin{array}{r}0,54 \\
(20,32)\end{array}$ & $* * *$ & $\begin{array}{r}0,543 \\
(20,44)\end{array}$ & $* * *$ & $\begin{array}{r}0,554 \\
(18,95)\end{array}$ & $* * *$ & $\begin{array}{r}0,556 \\
(19,25)\end{array}$ & $* * *$ & $\begin{array}{r}0,54 \\
(20,19)\end{array}$ & $* * *$ & $\begin{array}{r}0,542 \\
(20,39)\end{array}$ & $* * *$ & $\begin{array}{r}0,55 \\
(18,76)\end{array}$ & $* * *$ & $\begin{array}{r}0,551 \\
(19,03)\end{array}$ & $* * *$ \\
\hline caphum & $\begin{array}{r}0,000508 \\
(0,72)\end{array}$ & & $\begin{array}{r}0,000468 \\
(0,66)\end{array}$ & & $\begin{array}{r}0,000495 \\
(0,70)\end{array}$ & & $\begin{array}{r}0,000443 \\
(0,62)\end{array}$ & & $\begin{array}{r}0,000565 \\
(0,80)\end{array}$ & & $\begin{array}{r}0,000536 \\
(0,75)\end{array}$ & & $\begin{array}{r}0,000456 \\
(0,64)\end{array}$ & & $\begin{array}{r}0,00042 \\
(0,59)\end{array}$ & \\
\hline porte & $\begin{array}{r}0,183 \\
(35,17)\end{array}$ & $* * *$ & $\begin{array}{l}0,182 \\
(34,5)\end{array}$ & $* * *$ & $\begin{array}{r}0,184 \\
(35,66)\end{array}$ & $* * *$ & $\begin{array}{r}0,184 \\
(35,68)\end{array}$ & $* * *$ & $\begin{array}{l}0,185 \\
(36,1)\end{array}$ & $* * *$ & $\begin{array}{r}0,185 \\
(36,05)\end{array}$ & $* * *$ & $\begin{array}{r}0,184 \\
(35,77)\end{array}$ & $* * *$ & $\begin{array}{r}0,184 \\
(35,66)\end{array}$ & $* * *$ \\
\hline 2004 & & & - & & . & & $\cdot$ & & . & & . & & . & & . & \\
\hline 2005 & $\begin{array}{r}0,0124 \\
(17,33)\end{array}$ & $* * *$ & $\begin{array}{c}0,0124 \\
(17,25)\end{array}$ & $* * *$ & $\begin{array}{c}0,0121 \\
(16,61)\end{array}$ & $* * *$ & $\begin{array}{r}0,012 \\
(16,47)\end{array}$ & $* * *$ & $\begin{array}{c}0,0122 \\
(16,93)\end{array}$ & $* * *$ & $\begin{array}{c}0,0121 \\
(16,81)\end{array}$ & $* * *$ & $\begin{array}{c}0,0124 \\
(16,76)\end{array}$ & $* * *$ & $\begin{array}{c}0,0123 \\
(16,63)\end{array}$ & $* * *$ \\
\hline 2006 & $\begin{array}{r}0,00298 \\
(2,92)\end{array}$ & $* * *$ & $\begin{array}{r}0,00307 \\
(3,01)\end{array}$ & $* * *$ & $\begin{array}{r}0,00161 \\
(1,59)\end{array}$ & & $\begin{array}{r}0,0017 \\
(1,69)\end{array}$ & $*$ & $\begin{array}{r}0,00209 \\
(2,10)\end{array}$ & $* *$ & $\begin{array}{r}0,0022 \\
(2,22)\end{array}$ & $* *$ & $\begin{array}{r}0,00262 \\
(2,47)\end{array}$ & $* *$ & $\begin{array}{r}0,00272 \\
(2,59)\end{array}$ & $* * *$ \\
\hline _cons & $\begin{array}{r}-1,863 \\
(-36.21)\end{array}$ & $* * *$ & $\begin{array}{r}-1,752 \\
(-34.35)\end{array}$ & $* * *$ & $\begin{array}{r}-1,877 \\
(-36.82)\end{array}$ & $* * *$ & $\begin{array}{r}-1,769 \\
(-35.60)\end{array}$ & $* * *$ & $\begin{array}{r}-1,887 \\
(-36.98)\end{array}$ & $* * *$ & $\begin{array}{r}-1,778 \\
(-35.78)\end{array}$ & $* * *$ & $\begin{array}{r}-1,878 \\
(-36.71)\end{array}$ & $* * *$ & $\begin{array}{r}-1,768 \\
(-35.42)\end{array}$ & $* * *$ \\
\hline
\end{tabular}

***, ** e * referem-se à significância dos coeficientes a 1\%,5\% e 10\%, respectivamente. Entre parênteses, a estatística t dos coeficientes. Entre parênteses, a estatística t do coeficientes. Legenda variáveis: vicom - variação do índice de commodities metal; vicoe - variação do índice de commodities energia; nig - nível do gasto; caphum - capital humano; porte - porte do município; _cons - constante; 2004-2007 - efeitos fixos de tempo. 
Tabela G.5 - Resultados complementares modelos empíricos 3.5a - 3.5d

\begin{tabular}{|c|c|c|c|c|c|c|c|c|}
\hline & $3.5 \mathrm{a}$ & & $3.5 b$ & & $3.5 \mathrm{c}$ & & $3.5 d$ & \\
\hline vicom & $\begin{array}{r}-0,00359 \\
(-1.98)\end{array}$ & $* *$ & & & $\begin{array}{r}-0,00382 \\
(-2.08)\end{array}$ & $* *$ & & \\
\hline vicoe & $\begin{array}{l}0,012 \\
(3,98)\end{array}$ & $* * *$ & & & & & $\begin{array}{r}0,0119 \\
(4,03)\end{array}$ & $* * *$ \\
\hline nig & $\begin{array}{r}0,502 \\
(20,05)\end{array}$ & $* * *$ & $\begin{array}{r}0,518 \\
(18,88)\end{array}$ & $* * *$ & $\begin{array}{l}0,505 \\
(19,9)\end{array}$ & $* * *$ & $\begin{array}{l}0,515 \\
(18,7)\end{array}$ & $* * *$ \\
\hline caphum & $\begin{array}{r}0,000582 \\
(0,82)\end{array}$ & & $\begin{array}{r}0,000496 \\
(0,72)\end{array}$ & & $\begin{array}{r}0,00062 \\
(0,86)\end{array}$ & & $\begin{array}{r}0,000498 \\
(0,68)\end{array}$ & \\
\hline porte & $\begin{array}{r}0,182 \\
(34,51)\end{array}$ & $* * *$ & $\begin{array}{r}0,183 \\
(34,51)\end{array}$ & $* * *$ & $\begin{array}{r}0,183 \\
(34,85)\end{array}$ & $* * *$ & $\begin{array}{r}0,182 \\
(34,79)\end{array}$ & $* * *$ \\
\hline 2004 & (1) & & s & & . & & & \\
\hline 2005 & $\begin{array}{c}0,0132 \\
(19,45)\end{array}$ & $* * *$ & $\begin{array}{r}0,0129 \\
(19,02)\end{array}$ & $* * *$ & $\begin{array}{r}0,0129 \\
(18,7)\end{array}$ & $* * *$ & $\begin{array}{r}0,0132 \\
(18,66)\end{array}$ & $* * *$ \\
\hline 2006 & $\begin{array}{r}0,00302 \\
(2,98)\end{array}$ & $* * *$ & $\begin{array}{r}0,00163 \\
(1,64)\end{array}$ & & $\begin{array}{r}0,00199 \\
(2,0)\end{array}$ & $* *$ & $\begin{array}{r}0,00258 \\
(2,46)\end{array}$ & $* *$ \\
\hline 2007 & $\begin{array}{l}-0,0131 \\
(-11.35)\end{array}$ & $* * *$ & $\begin{array}{l}-0,0134 \\
(-11.74)\end{array}$ & $* * *$ & $\begin{array}{r}-0,0134 \\
(-11.44)\end{array}$ & $* * *$ & $\begin{array}{l}-0,0131 \\
(-11.13)\end{array}$ & $* * *$ \\
\hline _cons & $\begin{array}{r}-1,79 \\
(-35.05)\end{array}$ & $* * *$ & $\begin{array}{r}-1,8 \\
(-35.26)\end{array}$ & $* * *$ & $\begin{array}{r}-1,804 \\
(-35.29)\end{array}$ & $* * *$ & $\begin{array}{r}-1,797 \\
(-35.22)\end{array}$ & $* * *$ \\
\hline
\end{tabular}

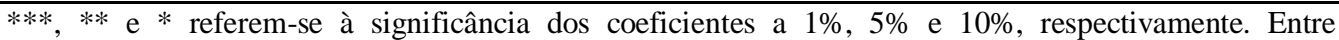
parênteses, a estatística $\mathrm{t}$ dos coeficientes. Entre parênteses, a estatística t dos coeficientes. Legenda variáveis: vicom - variação do índice de commodities metal; vicoe - variação do índice de commodities energia; nig - nível do gasto; caphum - capital humano; porte - porte do município; _cons - constante; 2004-2007 - efeitos fixos de tempo.

Tabela G.6 - Resultados complementares modelos empíricos 4a - 4d

\begin{tabular}{|c|c|c|c|c|c|c|c|c|}
\hline & $\overline{4 a}$ & & $4 \mathrm{~b}$ & & $4 \mathrm{c}$ & & $\overline{4 d}$ & \\
\hline vicom & $\begin{array}{r}-0,00569 \\
(-1.78)\end{array}$ & $*$ & & & . & & & \\
\hline vicoe & $\begin{array}{r}0,0268 \\
(6,33)\end{array}$ & $* * *$ & & & & & . & \\
\hline caphum & $\begin{array}{r}0,000913 \\
(0,65)\end{array}$ & & $\begin{array}{r}0,00238 \\
(0,72)\end{array}$ & & $\begin{array}{r}0,00277 \\
(0,85)\end{array}$ & & $\begin{array}{r}0,000305 \\
(0,20)\end{array}$ & \\
\hline porte & $\begin{array}{r}0,16 \\
(17,21)\end{array}$ & $* * *$ & $\begin{array}{r}0,16 \\
(9,49)\end{array}$ & $* * *$ & $\begin{array}{r}0,206 \\
(10,53)\end{array}$ & $* * *$ & $\begin{array}{r}0,137 \\
(12,02)\end{array}$ & $* * *$ \\
\hline 2004 & . & & . & & 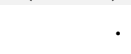 & & . & \\
\hline 2005 & $\begin{array}{l}0,0233 \\
(22,29)\end{array}$ & $* * *$ & $\begin{array}{c}0,0298 \\
(15,66)\end{array}$ & $* * *$ & $\begin{array}{c}0,0246 \\
(15,03)\end{array}$ & $* * *$ & $\begin{array}{r}0,0132 \\
(9,54)\end{array}$ & $* * *$ \\
\hline 2006 & $\begin{array}{r}0,0218 \\
(12,39)\end{array}$ & $* * *$ & $\begin{array}{r}0,0256 \\
(9,98)\end{array}$ & $* * *$ & $\begin{array}{r}0,0152 \\
(6,15)\end{array}$ & $* * *$ & $\begin{array}{r}0,00535 \\
(2,69)\end{array}$ & $* * *$ \\
\hline 2007 & $\begin{array}{r}0,00214 \\
(1,17)\end{array}$ & & $\begin{array}{r}0,00901 \\
(2,74)\end{array}$ & $* * *$ & $\begin{array}{r}0,00115 \\
(0,37)\end{array}$ & & $\begin{array}{r}-0,00551 \\
(-2.28)\end{array}$ & $* *$ \\
\hline _cons & $\begin{array}{r}-1,534 \\
(-16.53)\end{array}$ & $* * *$ & $\begin{array}{l}-1,499 \\
(-9.09)\end{array}$ & $* * *$ & $\begin{array}{r}-2,057 \\
(-10.08)\end{array}$ & $* * *$ & $\begin{array}{r}-1,321 \\
(-11.42)\end{array}$ & $* * *$ \\
\hline
\end{tabular}

***, ** e $*$ referem-se a significância dos coeficientes a $1 \%, 5 \%$ e $10 \%$, respectivamente. Entre parênteses, a estatística t dos coeficientes. Entre parênteses, a estatística t dos coeficientes. Legenda variáveis: vicom - variação do índice de commodities metal; vicoe - variação do índice de commodities energia; caphum - capital humano; porte - porte do município; _cons - constante; 2004-2007 - efeitos fixos de tempo. 
Tabela G.7 - Resultados complementares modelos empíricos 5.1a - 5.2d

\begin{tabular}{|c|c|c|c|c|c|c|c|c|c|c|c|c|c|c|c|c|}
\hline & \multicolumn{4}{|c|}{$\overline{\mathbf{A}}$} & \multicolumn{4}{|c|}{ B } & \multicolumn{4}{|c|}{$\bar{C}$} & \multicolumn{4}{|c|}{ D } \\
\hline & $5.1 \mathrm{a}$ & & $5.2 \mathrm{a}$ & & $5.1 b$ & & $5.2 \mathrm{~b}$ & & 5.1c & & $5.2 \mathrm{c}$ & & 5.1d & & $5.2 \mathrm{~d}$ & \\
\hline vicom & $\begin{array}{r}-0,00376 \\
(-1.29)\end{array}$ & & $\begin{array}{r}-0,00376 \\
(-1.29)\end{array}$ & & & & & & & & & & & & & \\
\hline vicoe & $\begin{array}{r}0,0257 \\
(6,62)\end{array}$ & $* * *$ & $\begin{array}{r}0,0257 \\
(6,62)\end{array}$ & $* * *$ & & & & & & & & & & & & \\
\hline nig & $\begin{array}{l}0,521 \\
(9,46)\end{array}$ & $* * *$ & $\begin{array}{l}0,521 \\
(9,46)\end{array}$ & $* * *$ & $\begin{array}{r}0,71 \\
(9,75)\end{array}$ & $* * *$ & $\begin{array}{r}0,71 \\
(9,75)\end{array}$ & $* * *$ & $\begin{array}{c}0,858 \\
(12,6)\end{array}$ & $* * *$ & $\begin{array}{c}0,858 \\
(12,6)\end{array}$ & $* * *$ & $\begin{array}{r}0,346 \\
(5,02)\end{array}$ & $* * *$ & $\begin{array}{l}0,346 \\
(5,02)\end{array}$ & $* * *$ \\
\hline caphum & $\begin{array}{r}0,0000149 \\
(0,01)\end{array}$ & & $\begin{array}{r}0,0000149 \\
(0,01)\end{array}$ & & $\begin{array}{r}0,00115 \\
(0,40)\end{array}$ & & $\begin{array}{r}0,00115 \\
(0,40)\end{array}$ & & $\begin{array}{r}0,00096 \\
(0,37)\end{array}$ & & $\begin{array}{r}0,00096 \\
(0,37)\end{array}$ & & $\begin{array}{r}-0,00058 \\
(-0.42)\end{array}$ & & $\begin{array}{r}-0,00058 \\
(-0.42)\end{array}$ & \\
\hline porte & $\begin{array}{r}0,188 \\
(21,81)\end{array}$ & $* * *$ & $\begin{array}{r}0,188 \\
(21,81)\end{array}$ & $* * *$ & $\begin{array}{r}0,201 \\
(12,49)\end{array}$ & $* * *$ & $\begin{array}{r}0,201 \\
(12,49)\end{array}$ & $* * *$ & $\begin{array}{l}0,212 \\
(11,0)\end{array}$ & $* * *$ & $\begin{array}{l}0,212 \\
(11,0)\end{array}$ & $* * *$ & $\begin{array}{r}0,162 \\
(14,85)\end{array}$ & $* * *$ & $\begin{array}{r}0,162 \\
(14,85)\end{array}$ & $* * *$ \\
\hline 2004 & $\cdot$ & & (1) & & . & & & & - & & 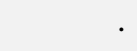 & & 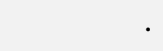 & & . & \\
\hline 2005 & $\begin{array}{r}0,017 \\
(15,52)\end{array}$ & $* * *$ & $\begin{array}{r}0,017 \\
(15,52)\end{array}$ & $* * *$ & $\begin{array}{r}0,0212 \\
(11,14)\end{array}$ & $* * *$ & $\begin{array}{r}0,0212 \\
(11,14)\end{array}$ & $* * *$ & $\begin{array}{r}0,017 \\
(10,16)\end{array}$ & $* * *$ & $\begin{array}{r}0,017 \\
(10,16)\end{array}$ & $* * *$ & $\begin{array}{r}0,00842 \\
(5,61)\end{array}$ & $* * *$ & $\begin{array}{r}0,00842 \\
(5,61)\end{array}$ & $* * *$ \\
\hline 2006 & $\begin{array}{l}0,012 \\
(6,38)\end{array}$ & $* * *$ & $\begin{array}{l}0,012 \\
(6,38)\end{array}$ & $* * *$ & $\begin{array}{r}0,0107 \\
(4,05)\end{array}$ & $* * *$ & $\begin{array}{r}0,0107 \\
(4,05)\end{array}$ & $* * *$ & $\begin{array}{r}0,0024 \\
(0,98)\end{array}$ & & $\begin{array}{r}0,0024 \\
(0,98)\end{array}$ & & $\begin{array}{r}-0,000649 \\
(-0.29)\end{array}$ & & $\begin{array}{r}-0,000649 \\
(-0.29)\end{array}$ & \\
\hline 2007 & $\begin{array}{r}-0,00674 \\
(-3.44)\end{array}$ & $* * *$ & $\begin{array}{r}-0,00674 \\
(-3.44)\end{array}$ & $* * *$ & $\begin{array}{r}-0,00487 \\
(-1.53)\end{array}$ & & $\begin{array}{r}-0,00487 \\
(-1.53)\end{array}$ & & $\begin{array}{r}-0,0131 \\
(-4.30)\end{array}$ & $* * *$ & $\begin{array}{r}-0,0131 \\
(-4.30)\end{array}$ & $* * *$ & $\begin{array}{l}-0,011 \\
(-4.28)\end{array}$ & $* * *$ & $\begin{array}{l}-0,011 \\
(-4.28)\end{array}$ & $* * *$ \\
\hline _cons & $\begin{array}{r}-1,957 \\
(-21.50)\end{array}$ & $* * *$ & $\begin{array}{r}-1,866 \\
(-21.16)\end{array}$ & $* * *$ & $\begin{array}{r}-2,025 \\
(-12.37)\end{array}$ & $* * *$ & $\begin{array}{r}-1,962 \\
(-12.39)\end{array}$ & $* * *$ & $\begin{array}{r}-2,283 \\
(-11.41)\end{array}$ & $* * *$ & $\begin{array}{r}-2,179 \\
(-10.89)\end{array}$ & $* * *$ & $\begin{array}{r}-1,699 \\
(-14.15)\end{array}$ & $* * *$ & $\begin{array}{r}-1,616 \\
(-14.06)\end{array}$ & $* * *$ \\
\hline
\end{tabular}

( Legenda variáveis: vicom - variação do índice de commodities metal; vicoe - variação do índice de commodities energia; nig - nível do gasto; caphum - capital humano, porte - porte
do município; _cons - constante; 2004-2007 - efeitos fixos de tempo. 
Tabela G.8 - Resultados complementares modelos empíricos 5.3a - 5.4d

\begin{tabular}{|c|c|c|c|c|c|c|c|c|c|c|c|c|c|c|c|c|}
\hline & \multicolumn{4}{|c|}{$\overline{\mathbf{A}}$} & \multicolumn{4}{|c|}{$\overline{\mathbf{B}}$} & \multicolumn{4}{|c|}{$\bar{C}$} & \multicolumn{4}{|c|}{ D } \\
\hline & $5.3 a$ & & $5.4 a$ & & $5.3 \mathrm{~b}$ & & $5.4 \mathrm{~b}$ & & $5.3 \mathrm{c}$ & & $5.4 \mathrm{c}$ & & 5.3d & & $5.4 d$ & \\
\hline vicom & $\begin{array}{l}-0,004 \\
(-1.37)\end{array}$ & & $\begin{array}{r}-0,00406 \\
(-1.39)\end{array}$ & & & & & & . & & . & & & & & \\
\hline vicoe & $\begin{array}{r}0,0258 \\
(6,65)\end{array}$ & $* * *$ & $\begin{array}{r}0,0261 \\
(6,74)\end{array}$ & $* * *$ & & & & & & & & & & & & \\
\hline nig & $\begin{array}{l}0,528 \\
(9,48)\end{array}$ & $* * *$ & $\begin{array}{l}0,523 \\
(9,42)\end{array}$ & $* * *$ & $\begin{array}{r}0,73 \\
(10,56)\end{array}$ & $* * *$ & $\begin{array}{l}0,717 \\
(9,71)\end{array}$ & $* * *$ & $\begin{array}{r}0,855 \\
(12,53)\end{array}$ & $* * *$ & $\begin{array}{r}0,854 \\
(12,49)\end{array}$ & $* * *$ & $\begin{array}{l}0,359 \\
(5,06)\end{array}$ & $* * *$ & $\begin{array}{r}0,35 \\
(4,99)\end{array}$ & $* * *$ \\
\hline caphum & $\begin{array}{r}-0,00008 \\
(-0.07)\end{array}$ & & $\begin{array}{r}-0,000008 \\
(-0.01)\end{array}$ & & $\begin{array}{c}0,001 \\
(0,35)\end{array}$ & & $\begin{array}{r}0,0012 \\
(0,42)\end{array}$ & & $\begin{array}{r}0,0011 \\
(0,41)\end{array}$ & & $\begin{array}{r}0,00093 \\
(0,35)\end{array}$ & & $\begin{array}{r}-0,00063 \\
(-0.46)\end{array}$ & & $\begin{array}{r}-0,00061 \\
(-0.44)\end{array}$ & \\
\hline porte & $\begin{array}{r}0,189 \\
(21,92)\end{array}$ & $* * *$ & $\begin{array}{r}0,188 \\
(21,84)\end{array}$ & $* * *$ & $\begin{array}{r}0,203 \\
(12,83)\end{array}$ & $* * *$ & $\begin{array}{r}0,2 \\
(12,47)\end{array}$ & $* * *$ & $\begin{array}{r}0,211 \\
(10,96)\end{array}$ & $* * *$ & $\begin{array}{r}0,212 \\
(11,0)\end{array}$ & $* * *$ & $\begin{array}{r}0,164 \\
(14,93)\end{array}$ & $* * *$ & $\begin{array}{r}0,162 \\
(14,83)\end{array}$ & $* * *$ \\
\hline 2004 & & & . & & & & . & & . & & . & & & & . & \\
\hline 2005 & $\begin{array}{c}0,0171 \\
(15,54)\end{array}$ & $* * *$ & $\begin{array}{r}0,0169 \\
(15,3)\end{array}$ & $* * *$ & $\begin{array}{c}0,0212 \\
(11,25)\end{array}$ & $* * *$ & $\begin{array}{r}0,021 \\
(10,94)\end{array}$ & $* * *$ & $\begin{array}{r}0,017 \\
(10,22)\end{array}$ & $* * *$ & $\begin{array}{c}0,0171 \\
(10,21)\end{array}$ & $* * *$ & $\begin{array}{r}0,00833 \\
(5,45)\end{array}$ & $* * *$ & $\begin{array}{r}0,00823 \\
(5,35)\end{array}$ & $* * *$ \\
\hline 2006 & $\begin{array}{r}0,0119 \\
(6,38)\end{array}$ & $* * *$ & $\begin{array}{l}0,012 \\
(6,42)\end{array}$ & $* * *$ & $\begin{array}{r}0,0102 \\
(3,90)\end{array}$ & $* * *$ & $\begin{array}{r}0,0107 \\
(4,03)\end{array}$ & $* * *$ & $\begin{array}{r}0,00244 \\
(1,0)\end{array}$ & & $\begin{array}{r}0,00242 \\
(0,98)\end{array}$ & & $\begin{array}{r}-0,00117 \\
(-0.50)\end{array}$ & & $\begin{array}{r}-0,000854 \\
(-0.38)\end{array}$ & \\
\hline 2007 & $\begin{array}{l}-0,007 \\
(-3.52)\end{array}$ & $* * *$ & $\begin{array}{r}-0,00691 \\
(-3.51)\end{array}$ & $* * *$ & $\begin{array}{r}-0,00543 \\
(-1.72)\end{array}$ & $*$ & $\begin{array}{l}-0,005 \\
(-1.57)\end{array}$ & & $\begin{array}{r}-0,0131 \\
(-4.32)\end{array}$ & $* * *$ & $\begin{array}{r}-0,0131 \\
(-4.28)\end{array}$ & $* * *$ & $\begin{array}{r}-0,0122 \\
(-4.45)\end{array}$ & $* * *$ & $\begin{array}{r}-0,0114 \\
(-4.36)\end{array}$ & $* * *$ \\
\hline _cons & $\begin{array}{r}-1,965 \\
(-21.58)\end{array}$ & $* * *$ & $\begin{array}{r}-1,867 \\
(-21.20)\end{array}$ & $* * *$ & $\begin{array}{r}-2,039 \\
(-12.75)\end{array}$ & $* * *$ & $\begin{array}{r}-1,955 \\
(-12.38)\end{array}$ & $* * *$ & $\begin{array}{r}-2,278 \\
(-11.39)\end{array}$ & $* * *$ & $\begin{array}{r}-2,184 \\
(-10.91)\end{array}$ & $* * *$ & $\begin{array}{r}-1,73 \\
(-14.14)\end{array}$ & $* * *$ & $\begin{array}{r}-1,622 \\
(-14.03)\end{array}$ & $* * *$ \\
\hline
\end{tabular}
respectivamente. Entre páteses, a estat́stica t dos coeficientes. Ente parenteses, a estatistica t dos porte - porte do município; _cons - constante; 2004-2007 - efeitos fixos de tempo. 
Tabela G.9 - Resultados complementares modelos empíricos 5.5a - 5.5d

\begin{tabular}{|c|c|c|c|c|c|c|c|c|}
\hline & $5.5 a$ & & $5.5 b$ & & $\overline{5.5 c}$ & & $\overline{5.5 d}$ & \\
\hline vicom & $\begin{array}{r}-0,00343 \\
(-1.16)\end{array}$ & & & & . & & & \\
\hline vicoe & $\begin{array}{r}0,0255 \\
(6,52)\end{array}$ & $* * *$ & & & & & . & \\
\hline nig & $\begin{array}{l}0,495 \\
(9,63)\end{array}$ & $* * *$ & $\begin{array}{r}0,705 \\
(10,34)\end{array}$ & $* * *$ & $\begin{array}{r}0,783 \\
(11,79)\end{array}$ & $* * *$ & $\begin{array}{r}0,322 \\
(5,17)\end{array}$ & $* * *$ \\
\hline caphum & $\begin{array}{r}0,0000483 \\
(0,04)\end{array}$ & & $\begin{array}{r}0,00069 \\
(0,25)\end{array}$ & & $\begin{array}{r}0,00155 \\
(0,58)\end{array}$ & & $\begin{array}{r}-0,000825 \\
(-0.61)\end{array}$ & \\
\hline porte & $\begin{array}{r}0,189 \\
(21,49)\end{array}$ & $* * *$ & $\begin{array}{r}0,211 \\
(11,53)\end{array}$ & $* * *$ & $\begin{array}{r}0,214 \\
(11,3)\end{array}$ & $* * *$ & $\begin{array}{r}0,161 \\
(15,49)\end{array}$ & $* * *$ \\
\hline 2004 & & & 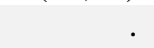 & & & & & \\
\hline 2005 & $\begin{array}{c}0,0174 \\
(16,53)\end{array}$ & $* * *$ & $\begin{array}{r}0,0204 \\
(11,59)\end{array}$ & $* * *$ & $\begin{array}{r}0,0179 \\
(10,51)\end{array}$ & $* * *$ & $\begin{array}{r}0,00923 \\
(6,54)\end{array}$ & $* * *$ \\
\hline 2006 & $\begin{array}{r}0,0117 \\
(6,31)\end{array}$ & $* * *$ & $\begin{array}{r}0,00863 \\
(3,41)\end{array}$ & $* * *$ & $\begin{array}{r}0,00273 \\
(1,08)\end{array}$ & & $\begin{array}{r}-0,000136 \\
(-0.06)\end{array}$ & \\
\hline 2007 & $\begin{array}{r}-0,00643 \\
(-3.35)\end{array}$ & $* * *$ & $\begin{array}{r}-0,00621 \\
(-2.00)\end{array}$ & $* *$ & $\begin{array}{r}-0,0124 \\
(-3.94)\end{array}$ & $* * *$ & $\begin{array}{r}-0,0098 \\
(-3.85)\end{array}$ & $* * *$ \\
\hline _cons & $\begin{array}{r}-1,908 \\
(-21.15)\end{array}$ & $* * *$ & $\begin{array}{r}-2,084 \\
(-11.55)\end{array}$ & $* * *$ & $\begin{array}{r}-2,239 \\
(-11.39)\end{array}$ & $* * *$ & $\begin{array}{r}-1,634 \\
(-14.83)\end{array}$ & $* * *$ \\
\hline
\end{tabular}

***, ** e * referem-se à significância dos coeficientes a 1\%,5\% e 10\%, respectivamente. Entre parênteses, a estatística $t$ dos coeficientes. Entre parênteses, a estatística t dos coeficientes. Legenda variáveis: vicom - variação do índice de commodities metal; vicoe - variação do índice de commodities energia; nig - nível do gasto; caphum - capital humano; porte - porte do município; _cons - constante; 2004-2007 - efeitos fixos de tempo. 